\title{
MARYS LAKE 69/115-kV TRANSMISSION LINE UPGRADE AND SUBSTATION EXPANSION PROJECTS
}

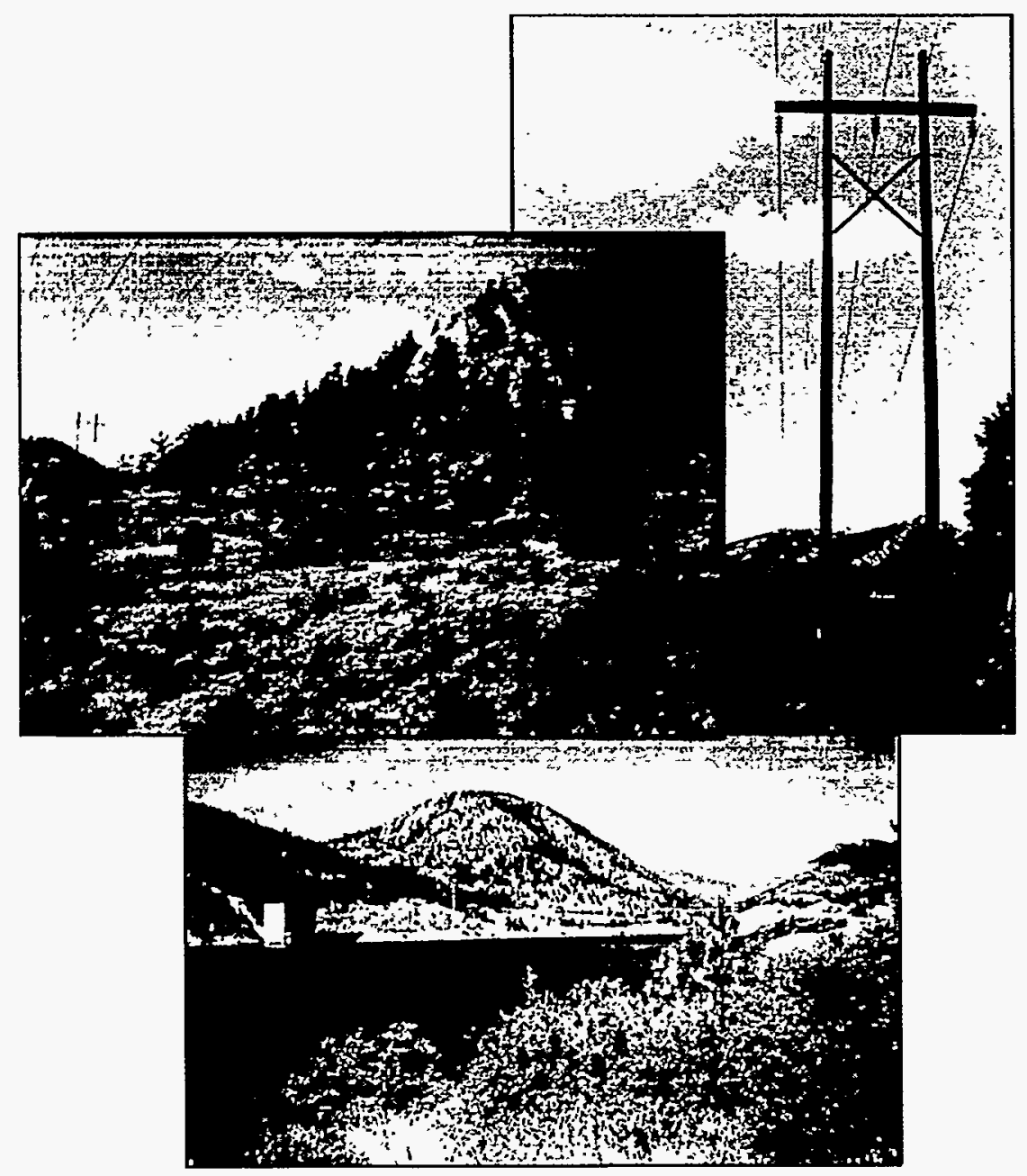

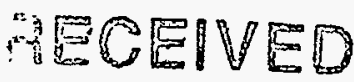

OCT 17 1989

OSTI

Estes Park, Larimer County, Colorado

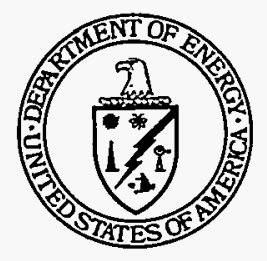

U.S. Department of Energy

Western Area Power Administration Rocky Mountain Customer Service Region

Loveland, Colorado

and

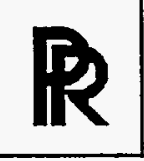

Platte River Power Authority Fort Collins, Colorado

DISTRIBUTION OF THIS DOCUMENT IS UNLIMITED 


\section{DISCLAIMER}

Portions of this document may be illegible in electronic image products. Images are produced from the best available original document. 


\section{DFPARTMENT OF ENERGY}

Western Area Powcr Administration

Marys Lake 69/115-kV Transmission Line Upgrade and Substation Expansion Projects, Estes Park, Larimer County, Colorado

AGENCY: Westem Area Power Administration, DOE.

ACIION: Finding of no significant impact

SUMMARY: Westem Area Power Administration (Westem) and the Platte River Power Authnrity (Platte River) propose to upgrade portions of the existing electric transmission and substation system that serves the Town of Estes Park, Colorado. The existing transmission lines between the Estes Power Plant Switchyard and the Marys Lake Substation include a 115,000 volt $(115-\mathrm{kV})$ line and 69,000 volt (69-kV) line. Approximately one mile is a double-circuit 115/69-kV line on steel lattice structures, and approximalely two miles consists of separate single-circuit $115-\mathrm{kV}$ and $\mathrm{a} 69-\mathrm{kV}$ lines, constructed on wood H-Frame structures. Both lines were constructed in 1951 by the U.S. Bureau of Reclamation. Upgrading the existing 69-kV Lransmission line between the Marys Lake Substation and the Estes Power Plant Switchyard to 115-kV and expanding the Marys Lake Substation was identified as the most effective way in which to improve electric service to Estes Park.

Western prepared an environmental assessment (EA) titled "Environmental Assessment for the Marys Lake 69/115-kV Transmission Line Upgrade and Substation Expansion Projects" (DOEREA-1074). The EA contains an analysis of the proposed construction, operation, and maintenance of the transmission line. Information and analysis contained in the $E A$ is summarized in this Finding of No Significant Impact (FONSI) unde "SUPPLEMENTARY INFORMATION".

1

DISTRIBUTION OF THIS DOCUMENT IS UNLMITED,

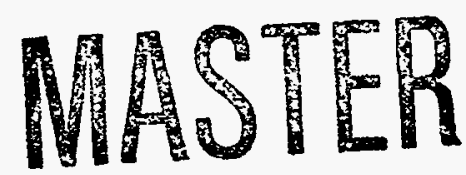




\section{FOR FURTHER INFORMATION CONTACT:}

Mr. Stephen A. Fausett

Regional Manager

Rocky Mountain Customer Service Region

Western Area Puwer Administration

P.O. Box 3700

Loveland, CO 80539 (970) 490-7201

Additional infurmation and copies of the EA and FONSI are available to all interested persons and the general public from the person named above. For general information on DOE National Environmental Policy Act (NEPA) activities contact:

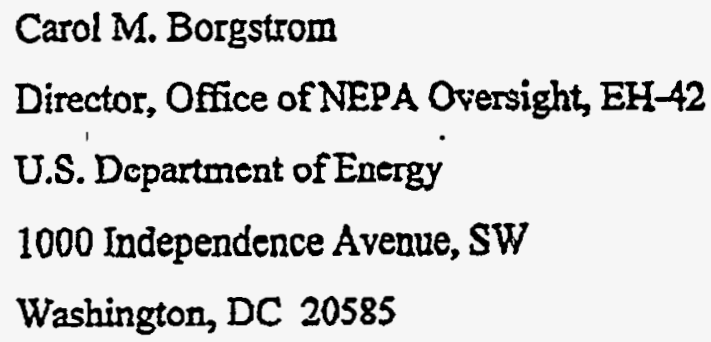

SUPPLEMENTARY INFORMATION: Western and the Platte River propose to upgrade portions of the existing electric transmission and substation system that serves the Town of Estes Park, Colorado. The existing transmission lines between the Estes Power Plant Switchyard and the Marys Lake Substation includc a 115,000 volt (115-kV) line and 69,000 volt (69-kV) line. Approximatcly one mile is a double-circuit $115 / 69-\mathrm{kV}$ line on steel lattice structures, and approximately two miles consists of separate single-circuit $115-\mathrm{kV}$ and a $69-\mathrm{kV}$ lines, constructed on wood H-Frame structures. Both lines were constructed in I95I by the U.S. Buredu of Reclamation. The existing transmission lines are on rights-of-way (ROW) that vary from 75 feet to 120 feet and are owned by Western. Therc are 48 landowners adjacent to the existing ROW. All of the houses were built adjacent to the existing ROW after the transmission lines were constructed.

Upgrading the existing $69-k V$ transmission line between the Marys Lake Substation and the 
Estes Power Plant Switchyard to 115-kV and expanding the Marys Lake Substation was identified as the most effective way in which to improve electric service to Estes Park. The proposed project involves:

- Removing a $115-\mathrm{kV}$ to $69-\mathrm{kV}$ transformer at the Estes Power Plant Switchyard and pertorming other associated work as required to allow upgrading the three-milc transmission line from $69-\mathrm{kV}$ to $115-\mathrm{kV}$;

- Begin operating ar $115-\mathrm{kV}$ the one-mile section of the existing $69-\mathrm{kV}$ portion of the double-circuit transmission line between the Estes Power Plant Switchyard and the East Portal of the Adams Tunnel. This existing transmission line section has been in place since 1951 on steel-lattice towers, and is already insulated for operation at $115-\mathrm{kV}$;

- Removing two miles of existing 69-kV transmission line on wood H-frame structures between the Estes Power Plant Switchyard (beginning after the one-mile section of - double-circuit, steel-lattice towers) and the Marys Lake Substation, and rebuilding this section to operate at $115-\mathrm{kV}$ utilizing wood $\mathrm{H}$-frame construction and connecting this line at Marys Lake Substation; and

- Installing a 115-kV to 69-kV transformer at the Marys Lake Substation and performing other associated work to maintain a 69-kV connection between the Marys Lake Substation and the East Poral of the Adams Tunnel.

The primary purpose and need of the proposed project is to improve the reliability of electric service to the Town of Estes Park. Lack of reliability has been a historical concern, and reliability will always be less than desired until physical improvements are made to the electrical facilities serving Estes Park.

Westem and Platte River conducted public workshop/scoping meetings in Estes Park to discuss the project on June 14, 1995, October 4, 1995, and February 15, 1996. An agency workshop/ scoping meeting was also conducted between 1:00 p.m. and 4:00 p.m. on June 14, 1995. Tho purpose of the workshop/scoping meeting was to describe the project, initiate a project mailing 
list, share information with the public and agencies, and to receive input and comments to identify issues, concerns, and prioritize considerations for the cnvironmental assessment.

As part of its marketing policies, Westem encourages energy conservation through the promotion of efficient and economic uses of energy, and through the use of renewable resources; such as, hydro, wind, solar, and geothermal energy sources. However, the purpose and need for the Marys Lake transmission line and substation upgrade project can not be met by energy conservation. The purpose of this project is to improve the reliability of electric service to the Town of Estes Park by providing a second transmission source to the Marys Lake Substation and modifying the configuration at the Estes Power Plant Switchyard. Therefore, energy conservation is not considercd as a reasonable altemanive for this project.

Several actions were considered as alternatives to the Proposed Action including the "no action" alternative, altemative clectrical systems, altemative structure designs, altemative methods of construction, and altemative routes.

Under the No Action Alternative, Western and Platte River would not upgrade the existing 69-kV transmission line to $115-\mathrm{kV}$ and the associated work at the Estes Power Plant Switchyard and the Marys Lake Substation would not be performed. Structures and hardware would be repaired and/or replaced as réquired during regular maintenance operations and in response to emergency outages on the transmission lines and at the substations. These repairs would bave to be made with increasing frequency in the future as the facilities increase in age. The No Action Altcrnative would not provide the required reliability to Estes Park and therefore is not considered as a reasonable alternative for this project.

Elcetric system planning sudies for the project area were conducted and 32 system alternatives were identified and evaluated. Of these alternatives, 28 would not provide the required loop service to the Marys Lake Substation and therefore, would not address the purpose and need for the project. Four of these alternatives, including the Proposed Action, would provide the 
required loop service to the Marys Lake Substation. Electric System Alternative I, the Proposed Action, was selected. This alternative would provide loop service to Marys Lake Substation by upgrading the existing 69-kV transmission line between the Marys Lake Substation and the Estes Power Plant. This would result in two direct 115-kV connections between Marys Lake Substarion and Estes Power Plant.

Scycral potential alteruative routes were identified based on the review of aerial photography and field reconnaissance. The altemative routes included utilizing the existing ROW, Prospect Mountain-West, Highway 7-North, Highway 7-South, Fish Creek-North, and Fish Creek-South. All of these alternatives, except the existing ROW had impacts which resulted in them not being carried forward for full analysis in the EA. Utilizing the existing 69-kV ROW is Western and Platte River's proposed route. This alternative has mure advantages and fewer constraints than the other alteriative routes, and was carried forward for full evaluation as the Proposed Action in the EA. The Proposed Action alternative consists of upgrading the existing single-circuit $69-k \mathrm{kV}$ transmission line to $115-\mathrm{kV}$ on wood H-frarae structures.

Conventional overbead and underground construction alterantives wcre considered. The primary disadvantages of underground transmission line construction would include cost; the time and expense required to locate and repair problems if outages occur; and the recurring environmental impacts associated with searching for and repairing problcms. Rather than limiting construction disturbances to relatively small areas around each suructure location for an overhead line, a continuous linear disturbance would result from underground construction. This may result in increased impacts to the soil, water quality, cultural resources, and biological resources that could be avoided by spanning with overhead construction. The impacts to vegetation would likely be significant due to the sensitive nature of the ares due to the altitude, short growing season, and reclamation difficulties associated with the south-facing slopes. Specific underground route altematives were not considcred and conventional overhead construction was selected for the proposed project. 
Although existing land uses in the study area are generally sensitive to the construction and operation of transmission lines, the proposed project would result in reduced impacts to these land uses ovcr the long-tern because fewer new landowners would be impacted. Currently, the existing ROW crosses or is adjacent to 89 existing residential parecls. An additional 7 new residential parcels and 5 commercial parcels are adjacent to or would be crossed by the proposed project, and no new ROW would be required. This.results in a total impact to 101 parcels. The altemative routes would impact $126,266,318,216$, and 268 parcels, respectively.

The Proposed Action would result in no long-term effects on the existing or planned land uses hecause the existing ROWs that have been in-place for over 40 years would be used. Local land use planning has considered the existing use of the transmission line corridor. This would be no significant impacts to existing or planned land uses. The project would have minor short-term effects on existing residents due to noisc, air quality, area traflic, and vegetation disturbances related to construction of the line. These effects would be limited primarily to short-term emissions from construction vehicles and fugitive dust generated by construction activities. Construction is scheduled to begin in the Spring and proceed through October in a sequential manner. The peak number of workers in the area at any one time would be 12-16. Cross-country travel along the ROW would only be necessary between three to four spans in the area that parallels Peak View Drive. All disturbed areas would be reseeded to minimize erosion and restored, as nearly as feasible, to their original condition. Except where clearing is requircd at the structure locations, vegetation would be protected from damage.

The operation of the transmission line would not present a safety or electrical hazard to the general public. Western and Platte River are committed to programs and policies that ensure a safe and healthy environment. Safety and health are essential elements of the working environment and are demonstrated daily in everyday work practices. By far, the greatest hazard from transmission lines is direct contact with the conductors. Power lines, as with electrical wiring in homes and businesses, can cause serious electric shocks if precautions are not taken to minimize shock hazard. All of Western's transmission lines are designed and constructed in 
accordance with the National Electrical Safety Code (NESC) standards.

Impacts to the visual resources that could result from the construction, operation and subsequent reclamation of the proposed project would include any visibility of the modified landform, color and texture, potential glare from new conductors, and any dust resulting from construction. Visual resources were identified as an important issuc by the Rocky Mountain National Park and sevcral citizens through the public/agency scoping meetings. The primary visual concerns identified focused on physical disturbances on the existing ROW, the guy wires associated with the three-pole angle structures, the disturbance at Marys Lake Substation, and the existing distribution line that parallels portions of the transmission line adjacent to the residential area. As a result of these concerns, the environmental studies assessed the visual impacts of the proposed action. The results indicated that the overall visual contrast of the project would be moderate to weak, and the project would be located in an area characterized as a Class B variety class. When companing the visual contrast and the landscape variety class, the overall scenic quality was assessed to be weak. There would be no significant impacts to visual resources.

The proposed project would result in a small short-term increase in population in Estes Park due to employment of contract construction workers. As the Estes valley experiences a nearly four-fold increase during the summer months, this construction force represents an insignificant increase. Based on housing data available from the U.S. Census, the rental vacancy rate of 6.3 percent and 4.48 housing unit vacancies for seasonal, recreational, or occasional use should be more than adequate for the temporary population increase associated with construction.

It is unlikely that the proposed project would have a perceptible impact on the area economy as it will not affect tourist visitation to the Rocky Mountain National Park and Estes Park. The short-term nature of project construction and the limited number of workers employed would result in limited positive economic impacts to Estes Park in the form of increased spending on lodging. meals, and other consumer goods and services. 
Construction, operation, and maintenance of the proposed project would not increase or decrease the need for police, fire; medical, or othor community resources in the project area. Although construction of the project could temporarily increase the local population, the incresse for seivices by those associated with construction would be insignificant as the local population increases significandy on an annual basis during tourist seasons. There would be no significant impacts.

This EA was prepared with DOE's environmental justice guidelines in mind. The proposed project is located within an area characterized by a uniform population. The largest scgment of the population in Estes Park, or nearly 99 percent, was described by the 1990 census as White, including those of Hispanic origin; other races made up a little less than one percent of the population. The project area is represented by a range of upper-middle income levels and fairly uniform backgrounds. Therefore, this project will not disproporionately impact minority and low-income populations.

The project would have no cffect on soils as long as disturbances are revegetated to prevent crosion. Westem's Standard Construction Practices include procedures to prevent soil erosion. The project would have no effect on geology and there are no geologic hazards present which would have an effect on the project.

The Proposed Action would not physically affect any identified sufface water resources. The Proposed Action would only span Marys Lake at the existing location and any new disturbance to the banks or channels for pole placement would not result in significant impacts. Access to the transmission lizes would occur on existing roeds. Western and Platte River employ best management practices for sediment control. Western's Standard Construction Practices include procedures to prevent soil erosion into surface water bodies. These practices also include procedures to prevent spills into surface water bodies.

The Proposed Action would not affect any ground water resources. The water table along the 
existing transmission ROW is approximately 42 feet below the ground surface. The placement of the proposed wood H-frame poles would be a maximum of only 8-10 feet into the ground. There are no wells located within the existing transmission line ROW.

No feature of the proposed project is located within a designated floadplain. There would be no flond-reiated impacts associated with the proposed project.

Impacts to the existing wildlife resource is expected to be minimal. This consideration is based on both the nature of the project and the existing condition of the habicals in the area. Since there would be minimal new disturbance for the Proposed Action, no wildilife habitats would be permanently impacted. Some species such as elk and deer may be temporarily displaced during construction. However, this displacement would be temporary and all habitats would be available immediately after construction. In addition, construction disturbances are not expected to be greater than human disturbances already occurring within the project area. There would be no significant impacts.

Scveral threatened, endangered, candidate or sensitive species are known to occur or potentially occur in the study area, based on information provided by the U.S. Fish and Wildlife Service (USFWS), the Colorado Division of Wildlife (CDOW), and the Colorado Natural Heritage Program (CNHP). These species include the peregrinc falcon, bald eagle, and greenback cutthroat troul. Since none of these species are known to occur in the project area, none are expected to be affected by the Proposed Action and no mitigation is recommended.

The exisling $69-\mathrm{kV}$ transmission line currenty spans a wetlands area. The EA recommends that the new $115-\mathrm{kV}$ structures be located so that this wetland will be spanned, and the installation of a temporary fence to restrict any access across the wetland during construction. These recommendations would be implemented and there would be no impact to wetlands by the Proposed Action. There are no important habitats that would be impacted by the Proposed Action. 
Construction of the Proposed Action would not impact any significant archaeological or historic sites as no significant resources were encountered during an archaeological survey of the existing ROW. For compliance with the National Historic Preservation Act, Section 106, Western and Platte River consulted with the Colorado State Historic Prescrvation Officer (SHPO). On November 2, 1995, the SHPO concurred with the determination that no historic properties will be affected by the project.

The project would have very minor, local, short-term effects on air quality, limited primarily to short-term emissions from construction vehicles and fugitive dust generatcd by construction activities. The upgrade of the $69-\mathrm{kV}$ linc to $115-\mathrm{kV}$ would have no measurable effects on ozone levels. The project would have no effect on climate. There would be no significant impacts.

Potentially important fossil bearing locales are not present along the route of the Proposed Action. Therefore, the project is not expected to affect paleontological resources.

DETERMINATION: The analyses contained in the EA indlcate that the proposed action is not a major Federal action significantly affecting the quality of the human environment, within the meaning of NEPA. Western has determined that preparation of an EIS is not required and is, therefore, issuing this FONSI.

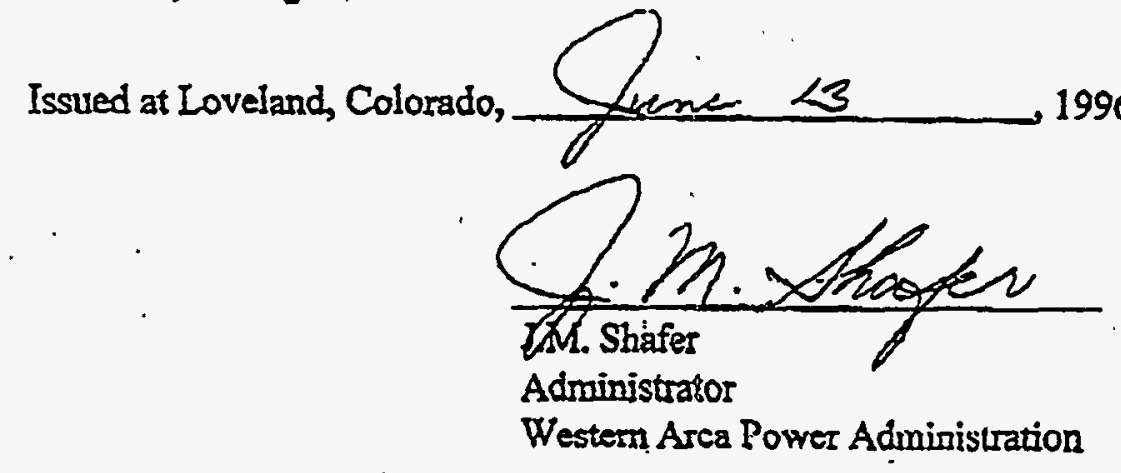


FINAL ENVIRONMENTAL ASSESSMENT

\title{
MARYS LAKE 69/115-kV TRANSMISSION LINE UPGRADE AND SUBSTATION EXPANSION PROJECTS
}

Estes Park, Larimer County, Colorado

\author{
U.S. Department of Energy \\ Western Area Power Administration \\ Rocky Mountain Customer Service Region \\ Loveland, Colorado \\ and \\ Platte River Power Authority \\ Fort Collins, Colorado
}




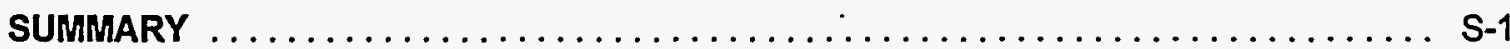

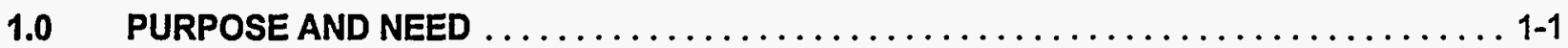

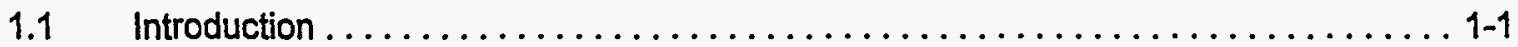

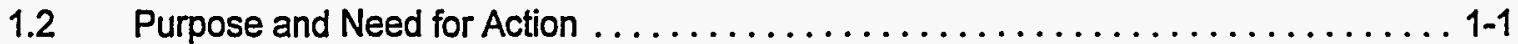

1.3 Public Involvement and Scoping . . . . . . . . . . . . . .

1.3.1 June 14, 1995 Public Workshop/Scoping Meetings .............. 1-2

1.3.2 October 4, 1995 Public Workshop ..................... 1-9

1.3.3 February 15, 1996 Public Meeting ................... 1-9

2.0 DESCRIPTION OF ALTERNATIVES INCLUDING THE PROPOSED ACTION $\ldots \ldots \ldots \ldots 2-1$

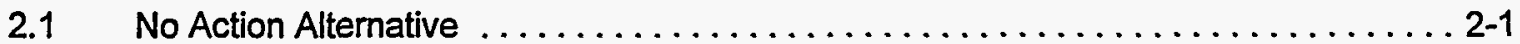

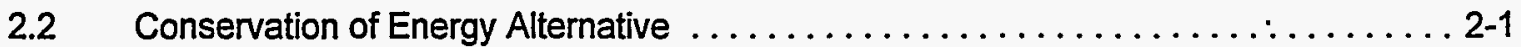

2.3 Electric System Alternatives . . . . . . . . . . . . . . . . . . . . .

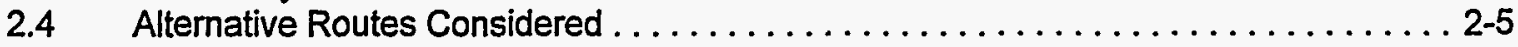

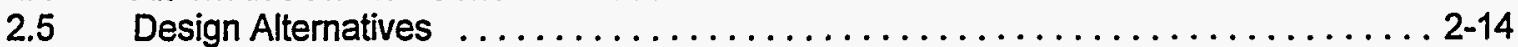

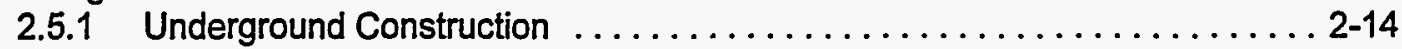

2.5 .2 Overhead Construction ............................ 2-17

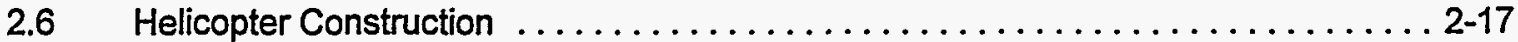

2.7 Proposed Action ................................ 2-18

2.7.1 Alternative A - The Proposed Action ................. 2-18

2.7.2 Structure Alternatives to the Proposed Action $\ldots \ldots \ldots \ldots \ldots \ldots \ldots .2-21$

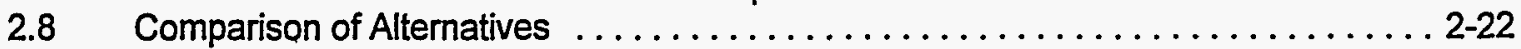

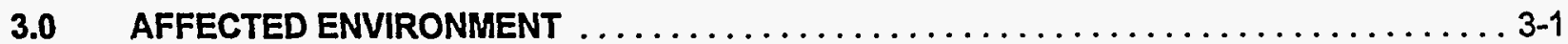

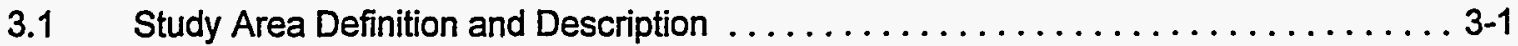

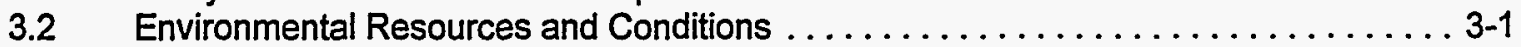

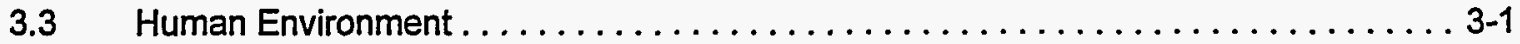

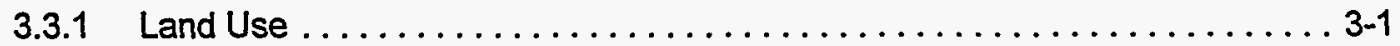

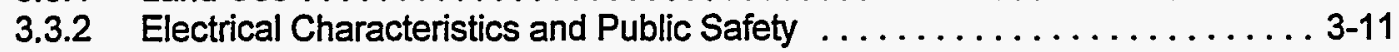

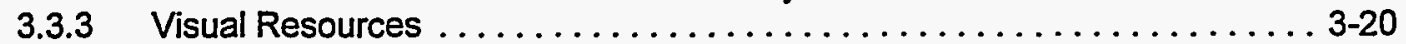

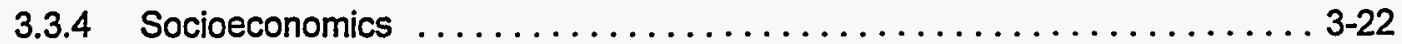

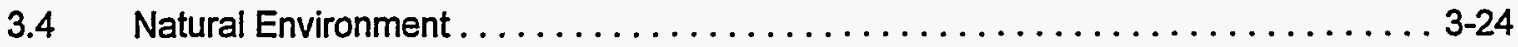

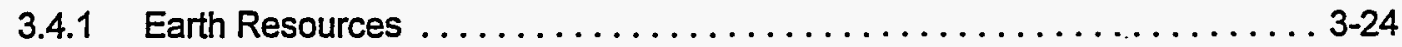

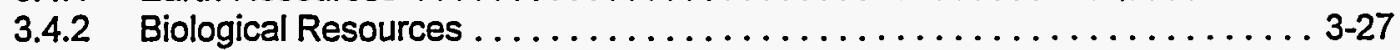

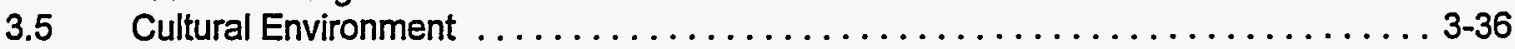

3.6 Resources Identified As Not Requiring Detailed Study .............. 3-36

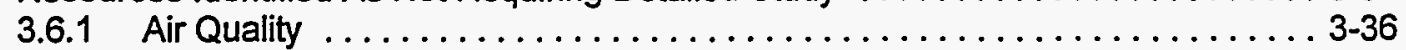

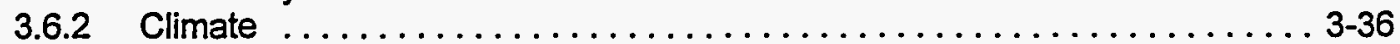

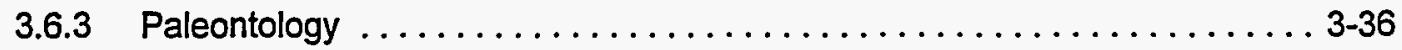

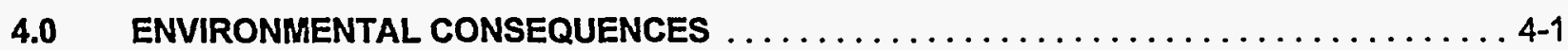

4.1 Human Environment. ............................

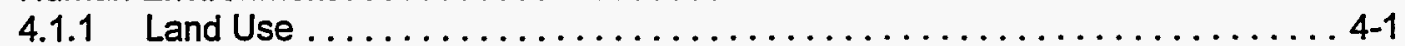

4.1.2 Electrical Characteristics and Public Safety $\ldots \ldots \ldots \ldots \ldots \ldots \ldots \ldots \ldots$ 4-1

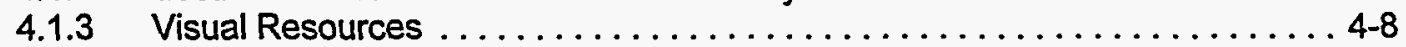

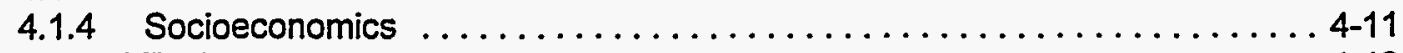

$4.2 \quad$ Natural Environment............................. 4.12

4.2.1 Earth Resources .............................. 4-12

4.2.2 Biological Resources ........................ 4.12

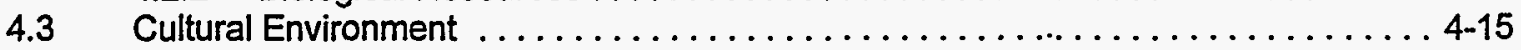

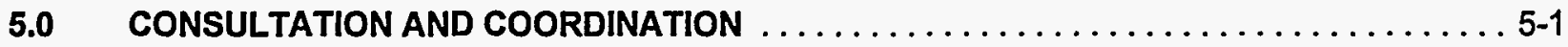

$5.1 \quad$ List of Agencies Contacted . . . . . . . . . . . . . . . . . .

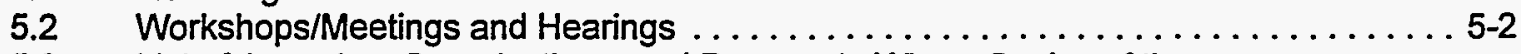

5.3 List of Agencies, Organizations, and Persons to Whom Copies of the

Environmental Assessment are Sent . . . . . . . . . . . . . . . . . . . 


\section{Appendices}

Appendix A Appendix B Appendix $C$ Appendix D Appendix E Appendix $F$ Appendix $G$ Appendix $\mathrm{H}$ Appendix I Appendix J
Bibliography

Glossary, Acronyms, And Abbreviations

Consultation Summaries

Biological Assessment

Floodplains/wetlands Assessment

Electric And Magnetic Field (Emf) Characteristics/bibliography

Alternative Route Impact Evaluation

Standard Construction Practices

Photographic Simulations

Construction and Restoration Guidelines

\section{Figures}

Figure 1-1, Figure 1-2 Figure 1-3 Figure 2-1 Figure 2-2 Figure 2-3 Figure 2-4 Figure 3-1 Figure 3-2 Figure 3-3 Figure 3-4 Figure 3-5 Figure 3-6 Figure D-1 Figure I-1 Figure 1-2 Figure 1-3 Figure $1-4$ Figure 1-5 Figure 1-6 Figure I-7 Figure I-8

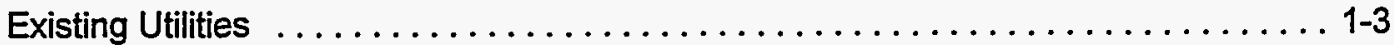

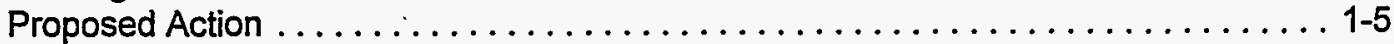

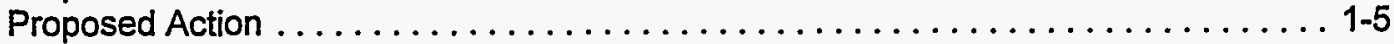

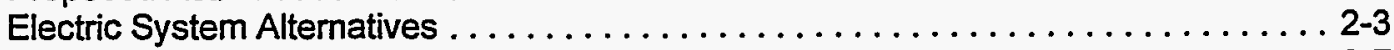

Opportunity/Constraint Composite ......................... 2-7

Alternative Transmission Line Routes, Including the Proposed Action ......... 2-9

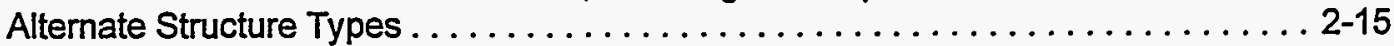

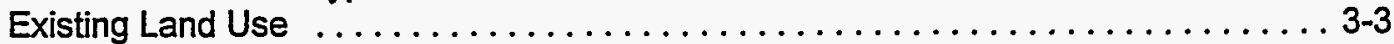

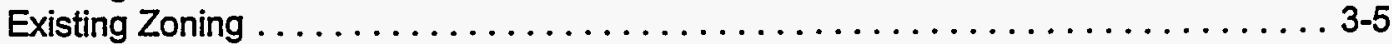

Visual Resources . . . . . . . . . . . . . . . . . . . . . . .

Earth Resources . . . . . . . . . . . . . . . . . . . . . . . . . . . . . . 3-25

Vegetation Communities and Potential Sensitive Plant Habitats . . . . . . . . . . . 3-29 Wildlife Resources and Potential Sensitive Wildlife Habitats $\ldots \ldots \ldots \ldots \ldots \ldots .3-31$

Proposed Action . . . . . . . . . . . . . . . . . . . . . . . . . . . D

Proposed Action, H-Frame Structure ....................... I

Proposed Action, $\mathrm{H}$-Frame Structure at Marys Lake $\ldots \ldots \ldots \ldots \ldots \ldots \ldots \ldots \ldots$ I-3

Proposed Action, Expansion of Marys Lake Substation $\ldots \ldots \ldots \ldots \ldots \ldots \ldots$ I-5

Proposed Action, Screening of Marys Lake Substation ............... 1-7

Screening of Marys Lake Substation (After 10-years of Growth) $\ldots \ldots \ldots \ldots \ldots \ldots$ 1-9

Alternative A1, Single-Circuit Single Steel Pole ................... l-11

Alternative A2, Double-Circuit, Single Steel Pole .................. I-13

Alternative A3, Self-Supported Angle Structure $\ldots \ldots \ldots \ldots \ldots \ldots \ldots \ldots \ldots \ldots$

\section{Tables}

Table 1-1 Marys Lake 69/115-kV Transmission Line Upgrade and Substation Expansion

Projects ..................................... 1-10

Table 2-1

Table 2-2

Table 2-3

Table 2-4

Table 2-5

Table 3-1

Table 3-2

Table 3-3

Table 3-4
Transmission Line Routing Exclusion, Avoidance, and Opportunity Criteria . . . . . . 2-6

Alternative Route Impact Evaluation Summary .................. 2-11

Typical Personnel and Equipment for Transmission Line Construction . . . . . . . 2-19

Typical Transmission Line Characteristics . . . . . . . . . . . . . . . . 2-22

Relative Cost Comparisons . . . . . . . . . . . . . . . . . . . . . . 2-24

Audible Noise (AN) Levels . . . . . . . . . . . . . . . . . . . . . 3-12

Audible Noise Decibel Ratings of Some Common Noises . . . . . . . . . . . . . 3-12

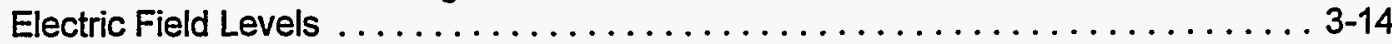

Magnetic Field Levels . . . . . . . . . . . . . . . 


\section{TABLE OF CONTENTS (Continued)}

Table 3-5 Table 3-6 Table 3-7 Table 3-8 Table 4-1 Table 4-2 Table 4-3 Table 4-4 Table 6-1 Table D-1
Magnetic Field Environment . . . . . . . . . . . . . . . . . . . . . . . . . 3-17 Magnetic Field Standards . . . . . . . . . . . . . . . . . . . . . . . 3-18

Population Growth in Estes Park and Estes Valley ................ 3-22 Threatened, Endangered, and Other Species of Concern ............. 3-33 Audible Noise (AN) Levels . . . . . . . . . . . . . . . . . . . . . . 4-2

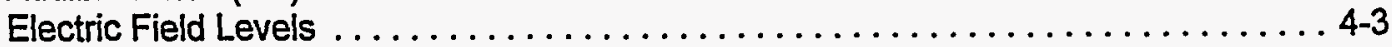
Magnetic Field Levels . . . . . . . . . . . . . . . . . . . . . . . . $4-5$

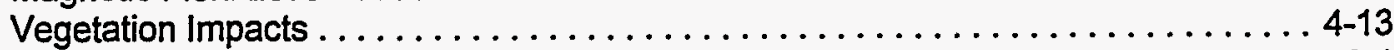
List Of Preparers ................................... 6-1 Threatened, Endangered, and Other Species of Concern .............. D-2 

SUMMARY

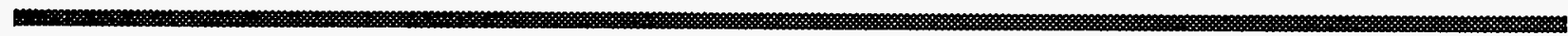


Western Area Power Administration (Western) and the Platte River Power Authority (Platte River) propose to upgrade portions of the existing electric transmission and substation system that serves the Town of Estes Park, Colorado. The existing transmission lines between the Estes Power Plant Switchyard and the Marys Lake Substation include a 115,000 volt (115-kV) line and 69,000 volt (69-kV) line. Approximately one mile is a double-circuit $115 / 69-\mathrm{kV}$ line on steel lattice structures, and approximately two miles consists of separate single-circuit $115-\mathrm{kV}$ and a $69-\mathrm{kV}$ lines, constructed on wood H-Frame structures. Both lines were constructed in 1951 by the U.S. Bureau of Reclamation. The existing transmission lines are on rights-of-way (ROW) that vary from 75 feet to 120 feet and are owned by Western. There are 48 landowners adjacent to the existing ROW. All of the houses were built adjacent to the existing ROW after the transmission lines were constructed.

Upgrading the existing 69-kV transmission line between the Marys Lake Substation and the Estes Power Plant Switchyard to 115-kV and expanding the Marys Lake Substation was identified as the most effective way in which to improve electric service to Estes Park. The proposed project involves:

- Removing a 115-kV to 69-kV transformer at the Estes Power Plant Switchyard and performing other associated work as required to allow upgrading the three-mile transmission line from $69-\mathrm{kV}$ to $115-\mathrm{kV}$;

- Begin operating at $115-\mathrm{kV}$ the one-mile section of the existing $69-\mathrm{kV}$ portion of the double-circuit transmission line between the Estes Power Plant Switchyard and the East Portal of the Adams Tunnel. This existing transmission line section has been in place since 1951 on steel-lattice towers, and is already insulated for operation at $115-\mathrm{kV}$;

- Removing two miles of existing 69-kV transmission line on wood $\mathrm{H}$-frame structures between the Estes Power Plant Switchyard (beginning after the one-mile section of double-circuit, steel-lattice towers) and the Marys Lake Substation, and rebuilding this section to operate at 115-kV utilizing wood $\mathrm{H}$-frame construction and connecting this line at Marys Lake Substation; and

- Installing a 115-kV to 69-kV transformer at the Marys Lake Substation and performing other associated work to maintain a $69-\mathrm{kV}$ connection between the Marys Lake Substation and the East Portal of the Adams Tunnel.

The primary purpose and need of the proposed project is to improve the reliability of electric service to the Town of Estes Park. Lack of reliability has been a historical concern, and reliability will always be less than desired until physical improvements are made to the electrical facilities serving Estes Park.

The electrical load of Estes Park has grown at a consistent rate and is now at a level that prevents the unrestricted exchange of load between the Marys Lake Substation and Estes Substation using the Town's distribution system. This has significant implications to Estes Park because the load served from the Marys Lake Substation cannot be fully restored following an unexpected outage until the faulty equipment is repaired, nor can maintenance be performed without possibly interrupting electric service. Since the distribution system within the Town is no longer capable of providing backup service to Marys Lake Substation during times of high customer usage, it is desirable to provide a second transmission source to Marys Lake Substation.

A joint study of the electrical system in the geographic area encompassing Estes Park and extending to Granby was conducted by all affected parties, and was completed in July 1994. Participants in the study were the Town, Western, Platte River, United States Bureau of Reclamation, Northern Colorado Water Conservancy District, and Tri-State Generation and Transmission. The objective of this study was to determine the short- and long-term transmission requirements. Thirty-two electric system alternatives were evaluated. The proposed project is one of the electric system alternatives recommended from this study.

The proposed project would provide a second transmission source to the Marys Lake Substation and would modify the configuration at the Estes Power Plant Switchyard. The reliability would be equivalent to 
that provided to the other urban areas served at wholesale by Platte River, and reflects a significant improvement.

Western and Platte River conducted public workshop/scoping meetings in Estes Park to discuss the project on June 14, 1995, October 4,1995, and February 15, 1996. The public workshop/scoping meetings were advertised in the local newspaper, through public service announcements on the local radio station, and on the local cable television channels. The public workshop/scoping meetings were held between 7:00 p.m. and 9:00 p.m. on each of these dates. An agency workshop/ scoping meeting was also conducted between 1:00 p.m. and 4:00 p.m. on June 14, 1995. The format for the workshop/scoping meetings consisted of a welcome/sign-in area and six information stations: (1) Project Need and Benefits (Electric System Planning); (2) Transmission Line and Substation Engineering; (3) Electrical Characteristics; (4) Visual Characteristics; (5) Environmental Planning; and (6) Land Rights. The purpose of the workshop/scoping meeting was to describe the project, initiate a project mailing list, share information with the public and agencies, and to receive input and comments to identify issues, concerns, and prioritize considerations in the Environmental Assessment.

As part of its marketing policies, Western encourages energy conservation through the promotion of efficient and economic uses of energy, and through the use of renewable resources such as hydro, wind, solar, and geothermal energy sources. However, the purpose and need for the Marys Lake transmission line and substation upgrade project can not be met by energy conservation. The purpose of this project is to improve the reliability of electric service to the Town of Estes Park by providing a second transmission source to the Marys Lake Substation and modifying the configuration at the Estes Power Plant Switchyard. Therefore, energy conservation is not considered as a reasonable alternative for this project.

Several actions were considered as alternatives to the Proposed Action including the "no action" alternative, alternative electrical systems, alternative structure designs, alternative methods of construction, and alternative routes.

Under the No Action Alternative, Western and Platte River would not upgrade the existing 69-kV transmission line to $115-\mathrm{kV}$ and the associated work at the Estes Power Plant Switchyard and the Marys Lake Substation would not be performed. Structures and hardware would be repaired and/or replaced as required during regular maintenance operations and in response to emergency outages on the transmission lines and at the substations. These repairs would have to be made with increasing frequency in the future as the facilities increase in age. The No Action Alternative would not provide the required reliability to Estes Park and therefore is not considered as a reasonable alternative for this project.

Electric system planning studies for the project area were conducted and 32 alternatives were identified and evaluated. Of these alternatives, 28 would not provide the required loop service to the Marys Lake Substation and therefore, would not address the purpose and need for the project. Four of these alternatives, including the Proposed Action, would provide the required loop service to the Marys Lake Substation. Electric System Alternative I, the Proposed Action, was selected. This alternative provides loop service to Marys Lake Substation by upgrading the existing $69-\mathrm{kV}$ transmission line between the Marys Lake Substation and the Estes Power Plant. This results in two direct $115-\mathrm{kV}$ connections between Marys Lake Substation and Estes Power Plant.

After the electric system configuration was determined, a route selection process was used to identify and evaluate potential routes for providing the required looped electric transmission service between the Estes Power Plant Switchyard and the Marys Lake Substation. This process involved several steps including:

- Collection of environmental, human, and cultural resource data;

- Mapping of environmental and human resources;

- Identification of exclusion, avoidance, and opportunity areas for transmission line siting based on resource sensitivity;

- Evaluation of potential routes;

- Selection of alternatives to be carried forward for full analysis in the environmental report; and

- Presentation of the results in public workshops/meetings. 
Several potential alternative routes were identified based on the review of aerial photography and field reconnaissance. The alternative routes included utilizing the existing ROW, Prospect Mountain-West, Highway 7-North, Highway 7-South, Fish Creek-North, and Fish Creek-South. All of these alternatives, except the existing ROW had impacts which resulted in them not being carried forward for full analysis in the EA. Utilizing the existing 69-kV ROW is Western and Platte River's proposed route. This alternative has more advantages and fewer constraints than the other alternative routes, and was carried forward for full evaluation as the Proposed Action in the EA. The Proposed Action alternative consists of upgrading the existing single-circuit $69-\mathrm{kV}$ transmission line to $115-\mathrm{kV}$ on wood $\mathrm{H}$-frame structures.

Wood $\mathrm{H}$-frame and single pole tubular steel structures are the structure design alternatives most technically and economically feasible for this upgrade. Approximately two miles of the existing $69-\mathrm{kV}$ transmission line is constructed as a single-circuit line on wood $\mathrm{H}$-frame structures that parallels an existing $115-\mathrm{kV}$ transmission line that is also constructed on wood $\mathrm{H}$-frame structures.

Alternative structures include a single-circuit single steel pole tubular structure, and a double-circuit single steel pole tubular structure. Single steel pole structures are taller than wood $\mathrm{H}$-frame structures because the conductors are arranged in a vertical configuration, and they are more costly. An additional alternative structure type was considered as a result of comments received at the public workshop held on October 4, 1995. This alternative would utilize self-supported structures at the angle points of the wood $\mathrm{H}$ frame alternative in order to eliminate the guy wires and to reduce the visual and land use impacts. The self-supported angle structures would be used only for the upgraded line.

Conventional overhead and underground construction alternatives were considered. The primary disadvantages of underground transmission line construction include cost; the time and expense required to locate and repair problems if outages occur; and the recurring environmental impacts associated with searching for and repairing problems. Rather than limiting construction disturbances to relatively small areas around each structure location for an overhead line, a continuous linear disturbance results from underground construction. This may result in increased impacts to the soil, water quality, cultural resources, and biological resources including sensitive habitats that support threatened and endangered species that could be avoided by spanning with overhead construction. The impacts to vegetation would likely be significant due to the sensitive nature of the area due to the altitude, short growing season, and reclamation difficulties associated with the south-facing slopes. Specific underground route alternatives were not considered and conventional overhead construction was selected for the proposed project.

As an alternative to conventional overhead construction, the use of a helicopter to transport crews and/or structures and/or equipment into each structure site were also considered for this project. In most areas along the proposed route, using helicopters would not be warranted by the terrain or by the expected impacts to environmental resources. Helicopters are sometimes utilized for portions of a project being constructed by conventional methods. In these cases, helicopters are used for delivering materials, setting poles, and conductor stringing.

Based on the selected route, type of structures, and type of construction, evaluation criteria was developed to assess the natural, human, and cultural environments. This analysis was quantified by determining the number of occurrences of the various environmental factors along each segment of each alternative. The criteria used in the impact evaluation included:

- Land use impacts such as existing residential parcels adjacent to, or crossed by, right-of-way; new residential parcels adjacent to, or crossed by, ROW; commercial parcels adjacent to, or crossed by, ROW; locations that would prohibit other development of property; parcels crossed where new ROW would be required; crossings through a developed park, or recreation areas; and crossings requiring a significant increase in construction time, traffic delays, or expense;

- Visual impacts including structures visible from primary transportation routes; existing residences from which the transmission line would be visible; new residences from which the transmission line would be visible; commercial developments from which the transmission line would be visible; structures visible from recreation areas; structures skylined; prominent deviations in the alignment; and structures visible in scenic landscapes; 
- Physical and biological environmental impacts such as structures in very steep slopes (>50\%) with soils susceptible to erosion, slump and creep; structures in steep soils $(25-50 \%)$ with slopes susceptible to erosion, slump and creep; water crossings; wells within the ROW; structures in the floodplain; acres of trees removed; structures through riparian habitat; structures potentially impacting threatened \& endangered species; acres of wildlife habitat removed; spans that may increase potential for bird collisions; instances requiring construction to be scheduled to avoid nesting or breeding periods critical to sensitive species; and miles of new ROW disturbance;

- Impact to cultural resources including structures potentially affecting archaeological sites; and structures potentially affecting historic sites; and

- Construction related impacts included miles of helicopter construction; structures with difficult access; structures that would result in conflicts with the operation of an airport, heliport or landing strip; number of angles in the alignment of $41^{\circ}$ to $90^{\circ}$; and number of angles in the alignment of $2^{\circ}$ to $40^{\circ}$.

Although existing land uses in the study area are generally sensitive to the construction and operation of transmission lines, the proposed project would result in reduced impacts to these land uses over the longterm because fewer new landowners would be impacted. Currently, the existing ROW crosses or is adjacent to 89 existing residential parcels. An additional 7 new residential parcels and 5 commercial parcels are adjacent to or would be crossed by the proposed project, and no new ROW would be required. This results in a total impact to 101 parcels. The alternative routes would impact 126, 266, 318, 216, and 268 parcels.

The Proposed Action would result in no long-term effects on the existing or planned land uses because the existing ROWs that have been in-place for over 40 years would be used, and local land use planning has considered the existing use of the transmission line corridor. The project would have minor short-term effects on existing residents due to noise, air quality, area traffic, and vegetation disturbances related to construction of the line. These effects would be limited primarily to short-term emissions from construction vehicles and fugitive dust generated by construction activities. Construction is scheduled to begin in the Spring and proceed through October in a sequential manner. The peak number of workers in the area at any one time would be 12-16. Cross-country travel along the ROW would only be necessary between three to four spans in the area that parallels Peak View Drive. All disturbed areas would be reseeded to minimize erosion and restored, as nearly as feasible, to their original condition. Except where clearing is required at the structure locations, vegetation would be protected from damage.

The operation of the transmission line would not present a safety or electrical hazard to the general public. Western and Platte River are committed to programs and policies that ensure a safe and healthy environment. Safety and health are essential elements of the working environment and are demonstrated daily in everyday work practices. By far, the greatest hazard from transmission lines is direct contact with the conductors. Powerlines, as with electrical wiring in homes and businesses, can cause serious electric shocks if precautions are not taken to minimize shock hazard. All of Western's transmission lines are designed and constructed in accordance with the National Electrical Safety Code (NESC) standards.

The additional corona resulting from upgrading the existing $69-\mathrm{kV}$ transmission line to $115-\mathrm{kV}$ will not be discernable.

The Audible Noise (AN) resulting from the proposed upgrade would not be significant. The calculated average (L50) value for wet weather at the edge of the ROW is $36.2 \mathrm{dBA}$, and the calculated average fair weather noise level at the edge of the ROW is 11.2 dBA for the Proposed Action. These values represent slight increases of 1.0 to $7.1 \mathrm{dBA}$ for the edges of the ROW.

The existing transmission lines have been in service for over 40 years and interference to radio (RI) and television (TVI) have not been significant problems. It was reported during the initial public workshop/ scoping meeting that RI on car radios occurs when driving in the vicinity of the transmission lines. While there may be several reasons for this interference, including weak signal strength, it is also likely that the cause is related to loose or dirty insulators, or by loose hardware and can be corrected by maintenance. The interference to radio (RI) and television (TVI) is not anticipated to significantly increase with the proposed upgrade, and would be similar for all alternatives. It is the policies of Western and Platte River 
to investigate RI and TVI problems and to correct those caused by their facilities. Western routinely investigates $\mathrm{RI}$ and TVI complaints and is prepared to resolve any interference problems resulting from the operation of the proposed project.

The maximum electric field in the ROW at the smallest conductor ground clearance of 22 feet is approximately $1.55-\mathrm{kV} / \mathrm{m}$ with the Proposed Action. These field levels are approximately the same as the existing conditions for the east/south edge of the ROW and the maximum in the ROW, and slightly higher for the west/north edge of the ROW.

In general, the electric fields around these lines are not great enough to produce perceivable shocks to persons contacting grounded objects. Spark discharge shocks theoretically could occur under the proposed transmission line upgrade just as they could under the existing transmission lines. However, the magnitude of the electric field is low enough for all of the alternatives that this type of shock rarely, if ever, would occur and then only in a small area under the transmission lines near mid-spans. The grounding policies of Western and Platte River eliminate the possibility of nuisance shocks due to induced currents from stationary objects such as fences and buildings.

The maximum magnetic field resulting from the Proposed Action at the edge of the ROW for normal operations and normal loading is $21.81 \mathrm{mG}$. The magnetic field level resulting from the Proposed Action would be slightly higher at the east/south edge of the ROW adjacent to the existing 115-kV line (21.71 mG vs. $14.88 \mathrm{mG}$ ), and significantly reduced at the west/north edge of the ROW ( $21.71 \mathrm{mG}$ vs. $47.10 \mathrm{mG}$ ). The maximum magnetic field level in the ROW would also be significantly reduced under the Proposed Action ( $21.81 \mathrm{mG}$ vs. $54.23 \mathrm{mG}$ ). These reductions are due to the use of taller structures, more evenly balanced line loading, and the use of less current to deliver the same amount of power with the upgraded $115-k V$ line.

The question of whether exposure to the electric and magnetic fields (EMF) from electrical sources causes biological or human health effects is a subject which has been researched for the past three decades. The voltage and current on the existing and proposed transmission lines, like others in the United States, vary at a frequency of $60 \mathrm{~Hz}$, or 60 cycles per second. Much of this research has involved fields at frequencies other than, and much different from, $60 \mathrm{~Hz}$ power frequency fields. Results of the research have led several scientific panels of independent experts to find that there is no basis to conclude that exposure to power frequency $(60 \mathrm{~Hz})$ electric and/or magnetic fields cause any specific or general diseases or illnesses, including cancer.

Impacts to the visual resources that could result from the construction, operation and subsequent reclamation of the proposed project would include any visibility of the modified landform, color and texture, potential glare from new conductors, and any dust resulting from construction. Visual resources were identified as an important issue by the Rocky Mountain National Park and several citizens through the public/agency scoping meetings. The primary visual concerns identified focused on physical disturbances on the existing ROW, the guy wires associated with the three-pole angle structures, the disturbance at Marys Lake Substation, and the existing distribution line that parallels portions of the transmission line adjacent to the residential area. The overall visual contrast of the project was assessed to be moderate to weak, and the project is located in an area characterized as a Class B variety class. When comparing the visual contrast and the landscape variety class, the overall scenic quality was assessed to be weak.

The proposed project would result in a small short-term increase in population in Estes Park due to employment of contract construction workers. As the Estes valley experiences a nearly four-fold increase during the summer months, this construction force represents an insignificant increase. Based on housing data available from the U.S. Census, the rental vacancy rate of 6.3 percent and 448 housing unit vacancies for seasonal, recreational, or occasional use should be more than adequate for the temporary population increase associated with construction.

It is unlikely that the proposed project would have a perceptible impact on the area economy as it will not - affect tourist visitation to the Rocky Mountain Park and Estes Park. The short-term nature of project construction and the limited number of workers employed should result in limited positive economic impacts to Estes Park in the form of increased spending on lodging, meals, and other consumer goods and services. 
Construction, operation, and maintenance of the proposed project should not increase or decrease the need for police, fire, medical, or other community resources in the project area. Although construction of the project could temporarily increase the local population, the increase for services by those associated with construction would be insignificant as the local population increases significantly on an annual basis during tourist seasons.

This EA was prepared with DOE's environmental justice guidelines in mind. The proposed project is located within an area characterized by a uniform population. The largest segment of the population in Estes Park, or nearly 99 percent, was described by the 1990 census as White, including those of Hispanic origin; other races made up a little less than one percent of the population. The project area is represented by a range of upper-middle income levels and fairly uniform backgrounds. Therefore, this project will not disproportionately impact minority and low-income populations.

The project would have no effect on soils as long as disturbances are revegetated to prevent erosion. Western's Standard Construction Practices include procedures to prevent soil erosion. The project would have no effect on geology and there are no geologic hazards present which would have an effect on the project.

The Proposed Action would not physically affect any identified surface water resources. The Proposed Action would only span Marys Lake at the existing location and any new disturbance to the banks or channels for pole placement would not result in significant impacts. Access to the transmission lines would occur on existing roads. Western and Platte River employ best management practices for sediment control. Western's Standard Construction Practices include procedures to prevent soil erosion into surface water bodies. These practices also include procedures to prevent spills into surface water bodies.

The Proposed Action would not affect any ground water resources. The water table along the existing transmission ROW is approximately 42 feet below the ground surface. The placement of the proposed wood $\mathrm{H}$-frame poles would be a maximum of only 8-10 feet into the ground. There are no wells located within the existing transmission line ROW.

No feature of the proposed project is located within a designated floodplain. There would be no floodrelated impacts associated with the proposed project.

Impacts to the existing wildlife resource is expected to be minimal. This consideration is based on both the nature of the project and the existing condition of the habitats in the area. Since there is no new disturbance planned for the Proposed Action, no wildlife habitats would be permanently impacted. Some species such as elk and deer may be temporarily displaced during construction. However, this displacement would be temporary and all habitats would be available immediately after construction. In

... addition, construction disturbances are not expected to be greater than human disturbances already occurring within the project area.

Several threatened, endangered, candidate or sensitive species are known to occur or potentially occur in the study area, based on information provided by the U.S. Fish and Wildlife Service (USFWS), the Colorado Division of Wildife (CDOW), and the Colorado Natural Heritage Program (CNHP). These species include the peregrine falcon, bald eagle, and greenback cutthroat trout. Since none of these species are known to occur in the project area, none are expected to be affected by the Proposed Action and no mitigation is recommended.

The existing $69-\mathrm{kV}$ transmission line currently spans a wetlands area. The EA recommends that the new $115-\mathrm{kV}$ structures be located so that this wetland will be spanned, and the installation of a temporary fence to restrict any access across the wetland during construction. If these recommendations are implemented, there would be no impact to wetlands by the Proposed Action. There are no important habitats that would be impacted by the Proposed Action.

Construction of the Proposed Action would not impact any significant archaeological or historic sites as no significant resources were encountered during an archaeological survey of the existing ROW. For compliance with the National Historic Preservation Act, Section 106, Western and Platte River consulted 
with the Colorado State Historic Preservation Officer (SHPO). On November 2, 1995, the SHPO concurred with the determination that no historic properties will be affected by the project.

The project would have very minor, local, short-term effects on air quality, limited primarily to short-term emissions from construction vehicles and fugitive dust generated by construction activities. The upgrade of the $69-\mathrm{kV}$ line to $115-\mathrm{kV}$ would have no measurable effects on ozone levels. The project would have no effect on climate.

Potentially important fossil bearing locales are not present along the route of the Proposed Action. Therefore, the project is not expected to affect paleontological resources. 


\subsection{Introduction}

Western Area Power Administration (Western) and the Platte River Power Authority (Platte River) propose to upgrade portions of the existing electric transmission and substation system that serves the Town of Estes Park, Colorado. The existing transmission lines between the Estes Power Plant Switchyard and the Marys Lake Substation include a 115,000 volt (115-kV) line and 69,000 volt $(69-\mathrm{kV})$ line. Approximately one mile is a double-circuit $115 / 69-\mathrm{kV}$ line on steel lattice structures, and approximately two miles consists of separate single-circuit 115-kV and a 69-kV line, constructed on wood H-Frame structures (Figure 1-1). Both lines were constructed in 1951 by the U.S. Bureau of Reclamation. The existing transmission lines are on rights-of-way (ROWs) that vary from 75 feet to 120 feet and are owned by Western. There are 48 landowners adjacent to the existing ROW. All of the houses were built adjacent to the existing ROW after the transmission lines were constructed.

Upgrading the existing 69-kV transmission line between the Marys Lake Substation and the Estes Power Plant Switchyard to 115-kV and expanding the Marys Lake Substation was identified as the most effective way in which to improve electric service to Estes Park. The proposed project involves:

- Removing a 115 to 69-kV transformer at the Estes Power Plant Switchyard and performing other associated work as required to allow upgrading the three-mile transmission line from $69-\mathrm{kV}$ to $115-\mathrm{kV}$;

- Begin operating at $115-\mathrm{kV}$, the one-mile section of the existing $69-\mathrm{kV}$ portion of the double-circuit transmission line between the Estes Power Plant Switchyard and the East Portal of the Adams Tunnel. This existing transmission line section has been in place since 1951 on steel-lattice towers, and is already insulated for operation at $115-\mathrm{kV}$;

- Removing two miles of existing 69-kV transmission line on wood $\mathrm{H}$-frame structures between the Estes Power Plant Switchyard (beginning after the one-mile section of double-circuit, steel-lattice towers) and the Marys Lake Substation, and rebuilding this section to operate at $115-k V$ utilizing wood $\mathrm{H}$-frame construction and connecting this line at Marys Lake Substation; and

- Installing a 115 to $69-\mathrm{kV}$ transformer at the Marys Lake Substation and performing other associated work to maintain a 69-kV connection between the Marys Lake Substation and the East Portal of the Adams Tunnel.

The Proposed Action is illustrated on Figures 1-2 and 1-3.

\subsection{Purpose and Need for Action}

Western and Platte River (the project sponsors) need to upgrade portions of the existing Estes-Marys Lake 69-kV transmission line and upgrade electrical equipment at Marys Lake and Estes substations that serve the town of Estes Park. The purpose of this upgrade is to improve reliability of electric service which has historically been a concern.

Between the years 1985 and 1990 (inclusive), there were seven incidents where electric service was lost to the entire Town. In addition, there were 15 incidents where electrical service was lost to half of the Town, one involving Estes Substation and 14 involving Marys Lake Substation. This was unsatisfactory to the citiziens, and this dissatisfaction was clearly communicated to the Electric Department of the Town and the transmission providers, Western and Platte River. A task force of technical experts was formed in 1990 to analyze the situation and recommend solutions. Some equipment was repaired, calibrated, and tested, resulting in a significant improvement in reliability. Since 1991, there have been four incidents where electric service was lost to half of Estes Park, one involving Estes Substation and three involving Marys Lake Substation. 
During the review conducted in 1990 , it was noted that reliability could not be brought up to a standard befitting an urban area (for example, Loveland, Longmont, and Fort Collins) until facility additions were made. The fixes that were implemented did improve the situation but the reliability is still less than desired. Marys Lake Substation, which serves the west side of Estes Park, is fed by a single (radial) three-mile line that is also the outlet for the Marys Lake Power Plant. This radial transmission line will never provide acceptable reliability to the Marys Lake Substation, and an alternate transmission source is required. The Estes Power Plant Switchyard, which is in the east part of Estes Park, serves Marys Lake Substation and Estes Substation. It is also susceptible to electrical disturbances that cause the entire Town to lose electric service. The configuration of the facilities at the Estes Power Plant Switchyard would need to be reconfigured to minimize this risk.

The electrical load of Estes Park has grown at a consistent rate and is now at a level that prevents the unrestricted exchange of load between the Marys Lake Substation and Estes Substation using the Town's distribution system. This has significant implications to Estes Park because the load served from the radial Marys Lake Substation cannot be fully restored following an unexpected outage until the faulty equipment is repaired, nor can maintenance be performed without possibly interrupting electric service. Since the distribution system within the Town is no longer capable of providing backup service to Marys Lake Substation during times of high customer usage, it is desirable to provide a second transmission source to Marys Lake Substation.

A joint study of the electrical system in the geographic area encompassing Estes Park and extending to Granby was conducted by all affected parties, and was completed in July 1994. Participants in the study were the Town, Western, Platte River, United States Bureau of Reciamation, Northern Colorado Water Conservancy District, and Tri-State Generation and Transmission. The objective of this study was to determine the short- and long-term transmission requirements. Thirty-two electric system alternatives were evaluated. The proposed project (Figure 1-2) is one of the electric system alternatives recommended in this study.

The proposed project would provide a second transmission source to the Marys Lake Substation and would modify the configuration at the Estes Power Plant Switchyard. The reliability would be equivalent to that provided to the other urban areas served at wholesale by Platte River, and reflects a significant improvement.

\subsection{Public Involvement and Scoping}

Public workshop/scoping meetings were held in Estes Park to discuss the project on June 14, 1995, and October 4, 1995. The public workshop/scoping meetings were held between 7:00 p.m. and 9:00 p.m. on each of these dates. An agency workshop/scoping meeting was also conducted between 1:00 p.m. and 4:00 p.m. on June 14, 1995. The format for the workshop/scoping meetings consisted of a welcome/signin area and six information stations: (1) Project Need and Benefits (Electric System Planning); (2) Transmission Line and Substation Engineering; (3) Electrical Characteristics; (4) Visual Characteristics; (5) Environmental Planning; and (6) Land Rights. The purpose of the workshop/scoping meeting was to describe the project, initiate a project mailing list, share information with the public and agencies, and to receive input and comments to identify issues, concerns, and prioritize considerations in the Environmental Assessment.

\subsubsection{June 14, 1995 Public Workshop/Scoping Meetings}

The agency workshop/scoping meeting was attended by six (6) agency personnel representing the Rocky Mountain National Park, the U.S. Bureau of Reclamation, the Town of Estes Park, the Estes Valley Recreation and Park District, and the Northern Colorado Water Conservation District.

The public workshop/scoping meeting was held between 7:00 p.m. and 9:00 p.m. and was attended by twenty-seven (27) citizens. 


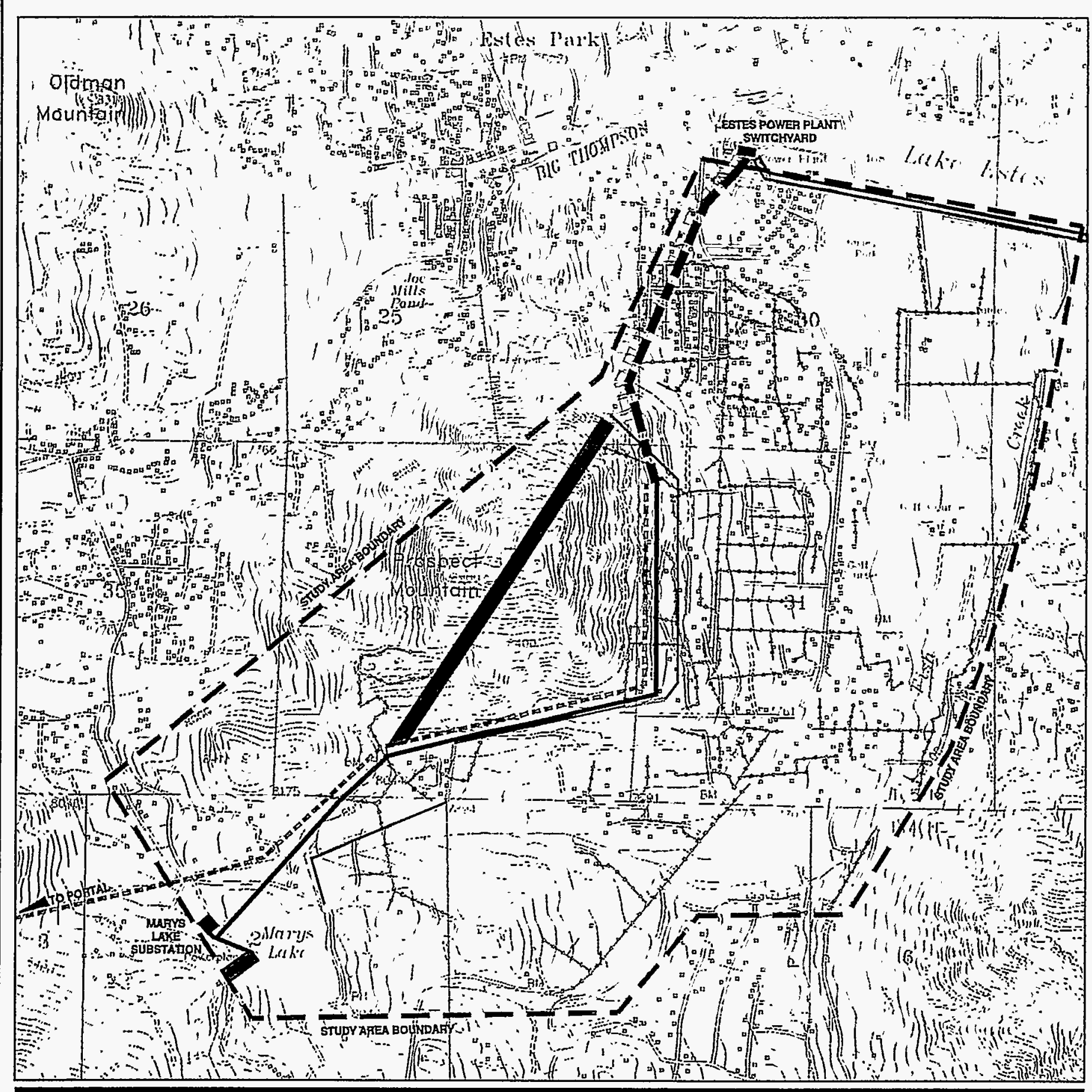

\begin{tabular}{|c|c|}
\hline $\begin{array}{c}\text { Platte River Power Authority } \\
\text { and } \\
\text { Western Area Power Administration }\end{array}$ & $\begin{array}{r}\text { Marys Lake } \\
\text { 69/115 kV Transmission Line Upgrade } \\
\text { and Substation Expansion Projects }\end{array}$ \\
\hline 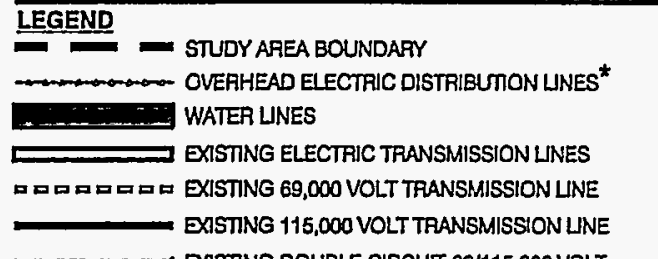 & \\
\hline 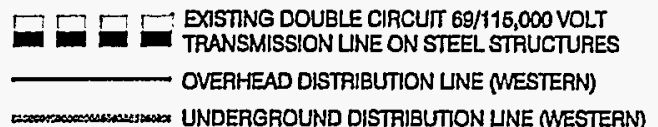 & $\begin{array}{l}1 \\
\text { EXISTING UTILITIES }\end{array}$ \\
\hline Source: Tokn of Esres Park ${ }^{*}$ & Figure $1-1$ \\
\hline
\end{tabular}


This page left intentionally blank. 


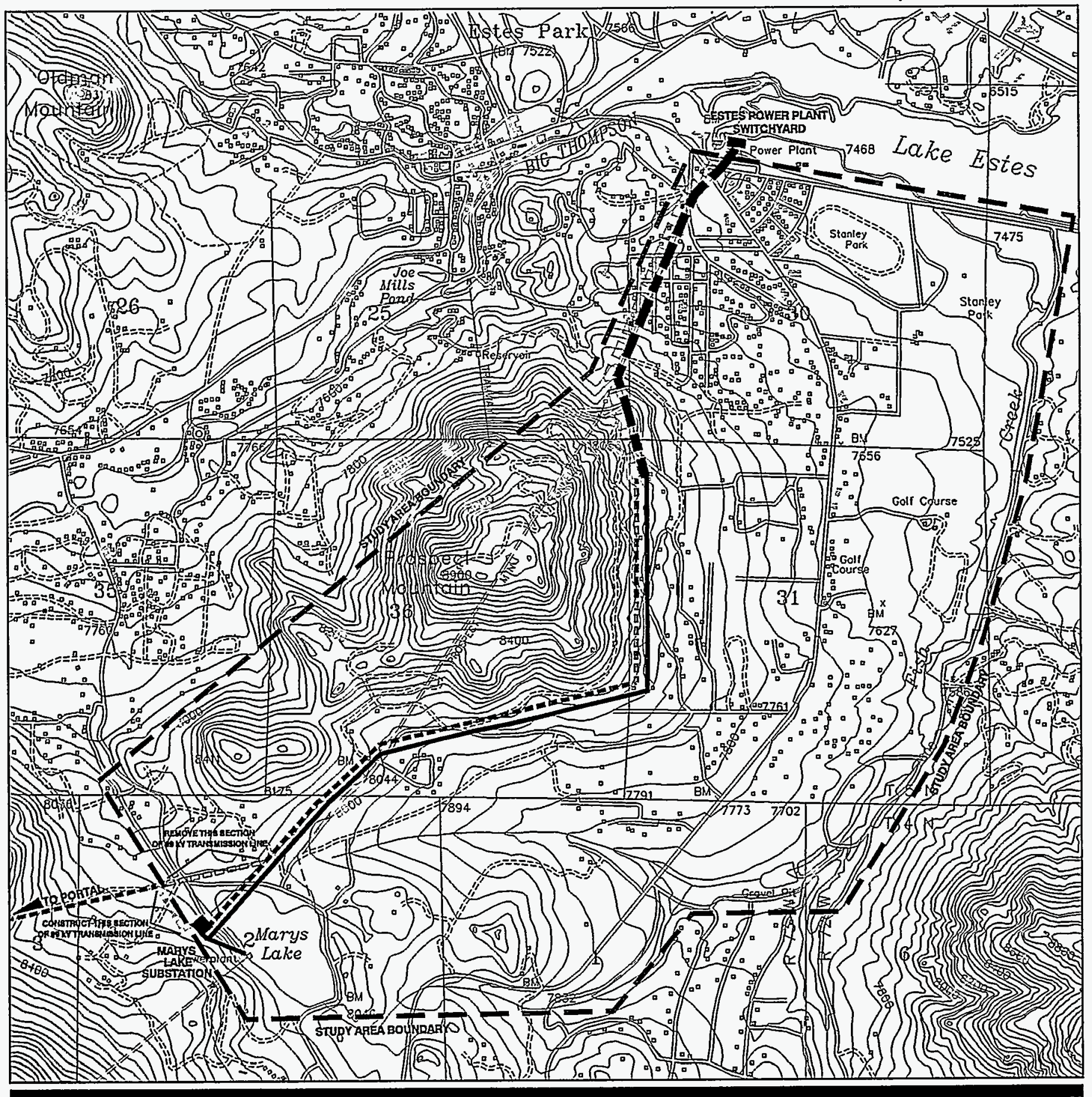

Platte River Power Autority and

Western Area Power Administration

\section{9/115 kV Transmission Line Upgrade and Substation Expansion Projects}
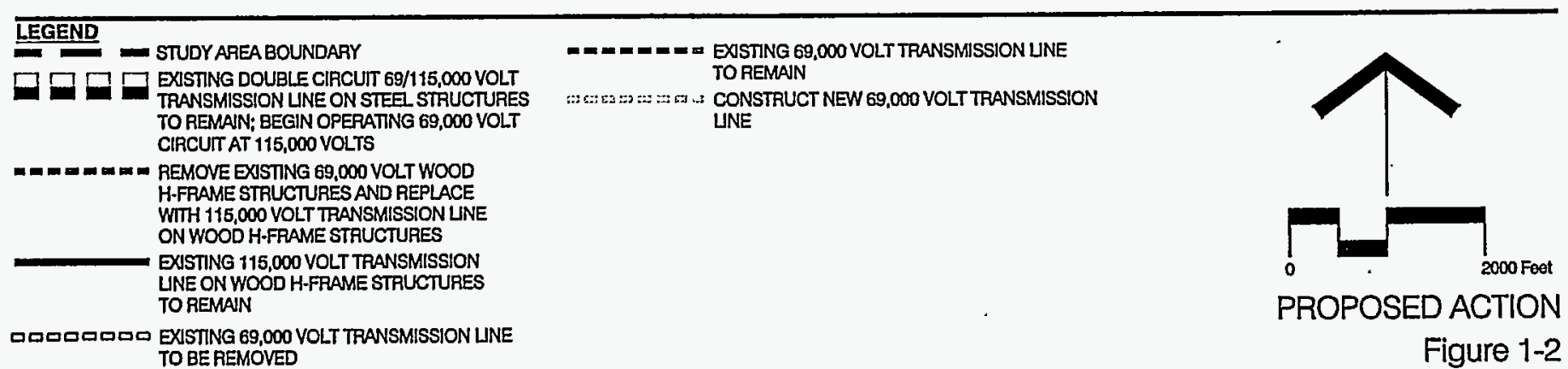
This page left intentionally blank. 


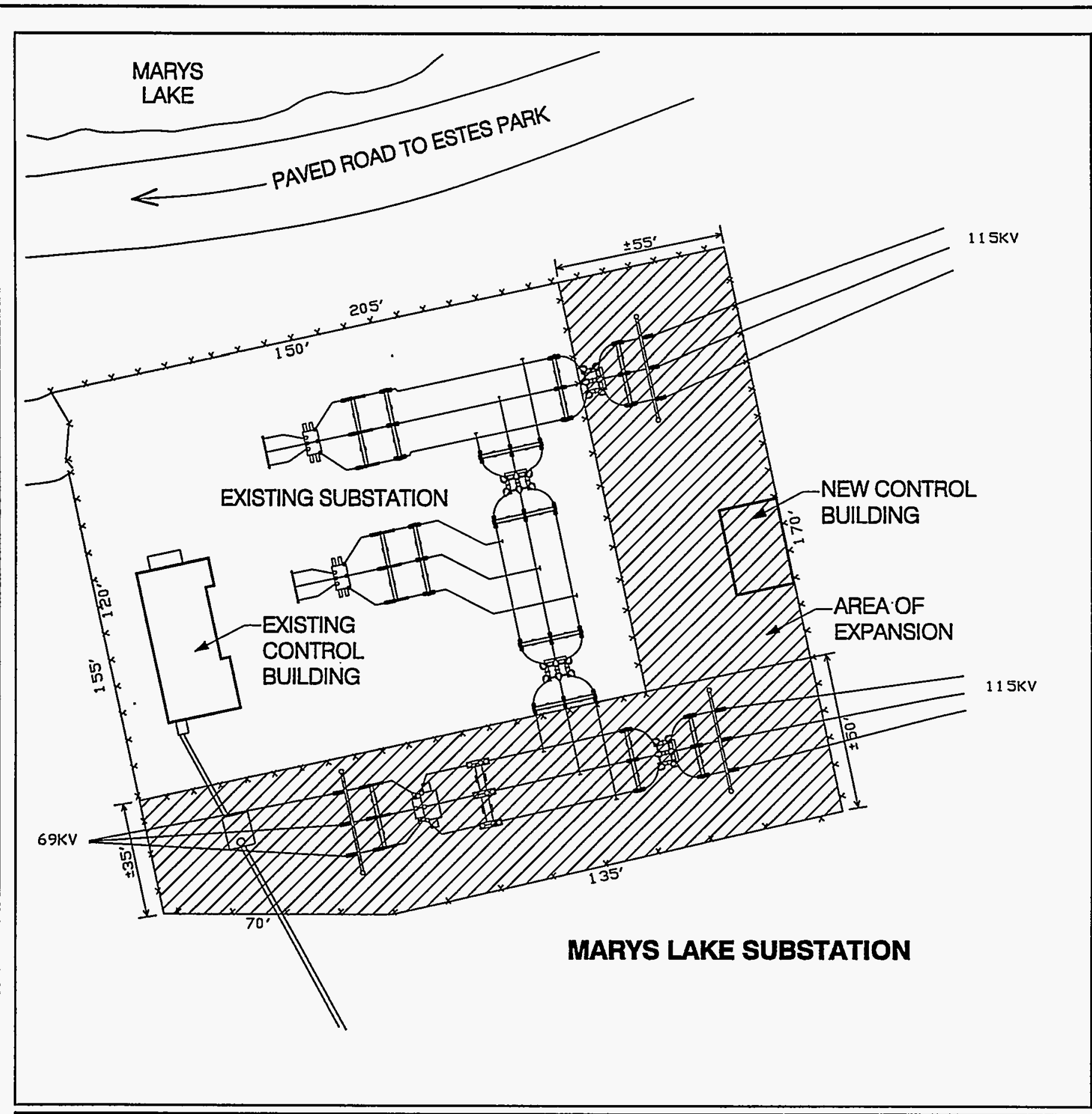

Platte River Power Authority and

Western Area Power Administration

69/115 kV Transmission Line Upgrade and Substation Expansion Projects

LEGEND

DPA area of Expansion

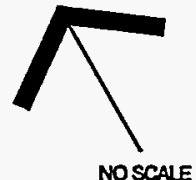

PLAN VIEW OF SUBSTATION

Figure 1-3 
This page left intentionally blank. 
The primary issues identified by the agencies and the public included the following:

- Project need;

- Visual impacts;

- Minimizing construction disturbances;

- Underground construction;

- Electric and magnetic fields (EMF);

- Project cost impact on rates; and

- Radio interference.

\subsubsection{October 4, 1995 Public Workshop}

The public workshop was held between 7:00 p.m. and 9:00 p.m. and was attended by five (5) citizens. There were no formal comments submitted at the workshop.

The primary issues identified by the public included the following:

- Construction disturbances;

- Visual impacts of the cut slopes at Marys Lake Substation;

- Visual and land use impacts of the guyed angle structures; and

- In comparing the alternative routes, quantify the impacts by using the number of occurrences related to each criteria rather than weighting different criteria and ranking within each criteria.

\subsubsection{February 15, 1996 Public Meeting}

The public meeting was held at 7:00 p.m. and was attended by ten (10) citizens. Following a presentation of the project and Draft EA, a discussion took place where approximately fifty-five (55) questions were asked and addressed. The primary issues associated with the questions included the following:

- The size of the Marys Lake Substation expansion;

- The location of the new H-frame wood poles;

- The size and visibility of the new conductors;

- The type of structures proposed at the angle points;

- The size (diameter) of the self-supporting steel angle structures;

- The lighting at Marys Lake Substation; and

- The construction disturbances, restoration or reclamation, and dust control.

Table 1-1 summarizes the issues that have been identified by the public and agencies through their input at the above meetings and comments that have been received by Western and/or Platte River. 
TABLE 1-1

\section{MARYS LAKE 69/115-kV TRANSMISSION LINE UPGRADE AND SUBSTATION EXPANSION PROJECTS}

\section{PUBLIC INPUT}

\section{Construction Impacts}

- Some statement of commitment should be made to protect trees and shrubs of a certain size on the right-of-way, and replace any that are disturbed "kind-with-kind."

- Special care should be taken to minimize the disturbances. Any disturbances that expose the soil should be approached "vigorously" to revegetate the areas so that dust is not blowing everywhere.

\section{Route Comparison}

- The number of occurrences of the various impacts should be used in the environmental analysis without any weights to present the public's perception of the impacts.

\section{Underground Construction}

- The utilities should work with the State Highway Department to put the lines underground when Highway 7 is improved.

\section{Marys Lake Substation}

- How much larger will the switchyard at Marys Lake be?

- In addition to the proposed screening illustrated in the photographic simulations, consideration should be given to reducing the contrast and visibility of the cut slopes.

- The existing lighting at Marys Lake Substation is objectionable, it is not shielded, and is visible for a long way.

Transmission Line Structures

- Mixing the single-circuit single steel pole and wood H-frame structures on the same right-of-way appears to be the alternative with the greatest visual impact and should not be used.

- The double-circuit single steel pole may present a cleaner appearance but would also be taller and more visible.

- Using wood H-frame structures similar to what exists appears to blend in with the environment better, the wood poles are about the same height as trees in the area and the wood blends in better than steel would.

- The location of the new H-frame wood poles.

- Consideration be given to using single steel poles or some other structure that does not need to be supported with guy wires at the angle locations in the line.

- The size and visibility of the new conductors.

\section{RESPONSE IN \\ ENVIRONMENTAL ASSESSMENT}

Section 4.2.2; Vegetation; pages 4-12, 4-13, and 4-14.

Appendix H; Standard Construction Practices; nos. 1, $3,4,5,6,7,8,14,15$, and 19.

Appendix J, Construction and Restoration Guidelines

Section 2.4; Alternative Routes Considered; pages 2-5, 2-12, 2-13, and 2-14; Table 2-2, page 2-11; Appendlx G, Table G-1.

Section 2.5.1; Underground Construction; pages 2-14 and 2-17; Table 2-5, page 2-24.

Section 1.0; Figure 1-3.

Section 4.1.3; Visual Resources; page 4-9, paragraphs 9 and 10; Appendix I, Figures I-3, I-4, and I-5.

Section 2.7.1; Altemative A - The Proposed Action; page 2-18; Section 4.1.3; Visual Resources; page 4- 9.

Section 4.1.3; Visual Resources; page 4-10, Alternative A1; Appendix I, Figure l-6.

Section 4.1.3; Visual Resources; page 4-10, Alternative A2; Appendix I, Figure 1-7.

Section 4:1.3; Visual Resources; page 4-10, Altemative A1; Appendix I, Figures $1-1$ and $1-2$.

Section 2.7.1; Alternative A - The Proposed Action; page 2-20.

Section 2.7.2; Structure Alternatives to the Proposed Action; Altemative A-3, Self-Supported Angle Structures; page 2-22; Section 4.1.3; Visual Resources; pages 4-10 and 4-11, Alternative A-3; Appendix l, Figure 1-8.

Section 2.0; Table 2-4; Section 4.1.3; Visual Resources; page 4-9. 
Several actions were considered as alternatives to the Proposed Action including the "no action" alternative, alternative electrical systems, alternative structure designs, alternative methods of construction, and alternative routes. Some alternatives were dropped from detailed study for various reasons. All considered alternatives are listed below and the reasons some were excluded from further consideration are described.

\subsection{No Action Alternative}

Under the No Action Alternative, Western and Platte River would not upgrade the existing 69-kV transmission line to $115-\mathrm{kV}$ and the associated work at the Estes Power Plant Switchyard and the Marys Lake Substation would not be performed. Structures and hardware would be repaired and/or replaced as required during regular maintenance operations and in response to emergency outages on the transmission lines and at the substations. These repairs would have to be made with increasing frequency in the future as the facilities increase in age.

Implementation of this alternative would preclude most of the impacts to the environment that would be associated with the other alternatives. Minor impacts would be associated with the increasingly frequent repair and maintenance activities. However, if this alternative were adopted, other actions would be required to improve the electric system that serves Estes Park and to provide adequate reliability. Whatever actions are taken to improve the Town's electric system reliability would have environmental impacts.

The No Action Alternative would not provide the required reliability to Estes Park and, therefore, would not address the purpose and need for the project. As a result, the No Action Alternative is not considered a reasonable alternative for this project.

\subsection{Conservation of Energy Alternative}

As part of its marketing policies, Western encourages energy conservation through the promotion of efficient and economic uses of energy, and through the use of renewable resources such as hydro, wind, solar, and geothermal energy sources. However, the purpose and need for the Marys Lake 69/115-kV transmission line upgrade and substation expansion projects cannot be met by energy conservation. The purpose of this project is to improve reliability of electric service by providing a second transmission source to the Marys Lake Substation and modifying the configuration at the Estes Power Plant Switchyard. Therefore, energy conservation is not considered as a reasonable alternative for this project.

\subsection{Electric System Alternatives}

Electric "system" alternatives refer to the various possible solutions to an electrical problem in a given area. For example, the addition of a transformer to an existing substation or the construction of a new substation could be two possible alternatives to resolving a particular electrical system problem. A highly desirable characteristic of a transmission system is that each substation would be supplied by two circuits (ideally not on the same ROW) to maintain service during equipment outages. Electrical loads supplied from a substation having only one line feeding into it would be subject to frequent interruptions because of the lack of an alternative source to feed the substation (such as the existing situation at Marys Lake Substation). Any outage suffered on the single feed line would likewise interrupt power to any load fed from the substation.

Electric system planning studies for the project area were undertaken in 1994 as part of the Windy Gap-Estes Park Planning Study, July 1994. Thirty-two alternatives were identified and evaluated. Of these alternatives, 28 would not provide the required looped service to the Marys Lake substation and therefore would not address the purpose and need for the project. Four of these alternatives, including the Proposed Action, would provide the required looped service to the Marys Lake Substation. These alternatives are described below.

\section{Electric System Alternative I}

This alternative would provide a second transmission source (or looped service) to the Marys Lake Substation. This would be accomplished by upgrading a section of the existing Estes Powerplant Switchyard to East Portal $69-\mathrm{kV}$ transmission line to $115-\mathrm{kV}$. This line passes near the Marys Lake Substation and connects the Adams Tunnel 
(East Portal) circuit to the Estes Powerplant. The upgraded line section would be routed into Marys Lake Substation. A 115/69-kV transformer would be installed at Marys Lake Substation to serve the remainder of the 69$\mathrm{kV}$ line to East Portal. The existing 115/69-kV transformer at Estes Powerplant Switchyard would be removed and the switchyard reconfigured to provide greater reliability without bypassing the switchyard as in Alternatives III and IV described below.

Because there is already one 115-kV connection between Marys Lake Substation and Estes Powerplant Switchyard, this alternative would result in a second 115-kV connection to Marys Lake Substation, thus providing looped service. This alternative represents the Proposed Action.

The Proposed Action includes maintaining the existing 69-kV Adams Tunnel circuit in service (i.e., connected to the electrical system) until either the circuit or the $115 / 69-\mathrm{kV}$ transformer fails. This would maximize the service life of the tunnel circuit. The existing circuit through the Adams tunnel was installed in the early $1950 \mathrm{~s}$. Due to the advanced age of the cable, there is the potential for the cable to fail. When this occurs, studies will be performed to determine if the cable should be replaced or abandoned.

Results of the Windy Gap-Estes Park Planning Study show that the east and west slope electrical systems can operate independently at the present time when the Adams Tunnel circuit is open. If future studies indicate the tunnel circuit is not necessary, the decision may be made to abandon the circuit if its replacement is cost prohibitive.

\section{Electric System Alternative II}

This alternative would provide the same looped service to Marys Lake Substation as Alternative I. However, under this alternative, a 115/69-kV transformer would not be installed at Marys Lake Substation and the Adams Tunnel circuit would be open (i.e., not connected electrically to Marys Lake Substation or Estes Powerplant Switchyard.)

\section{Electric System Alternative III}

This alternative would provide the same looped service to Marys Lake Substation as Alternatives I and II. However, for this alternative the upgraded line would not connect at Estes Powerplant Switchyard but would instead bypass the switchyard and connect directly to the existing Estes-Lyons 115-kV transmission line, providing a direct 115-kV connection between Marys Lake Substation and Lyons Substation. This Alternative creates a much longer transmission line, therefore increasing line exposure to lightning and other weather-related hazards. As in Alternative II, a 115/69-kV transformer would not be installed at Marys Lake Substation and the Adams Tunnel circuit would be open.

\section{Electric System Alternative IV}

This alternative would provide the same looped service to Marys Lake Substation as Alternatives I, II and III. However, for this alternative the upgraded line would not connect at Estes Powerplant Switchyard but would instead bypass the switchyard and connect directly to the existing Estes-Pole Hill 115kV transmission line, providing a direct $115-\mathrm{kV}$ connection between Marys Lake Substation and Pole Hill Powerplant. This Alternative also creates a much longer transmission line, therefore increasing line exposure to lightning and other weather-related hazards. As in Alternatives II and III, a 115/69-kV transformer would not be installed at Marys Lake Substation and the Adams Tunnel circuit would be open. This Alternative would require the construction of an additional 115-kV transmission line:

These electric system alternatives that would provide the required loop service to the Marys Lake Substation are illustrated on Figure 2-1. 


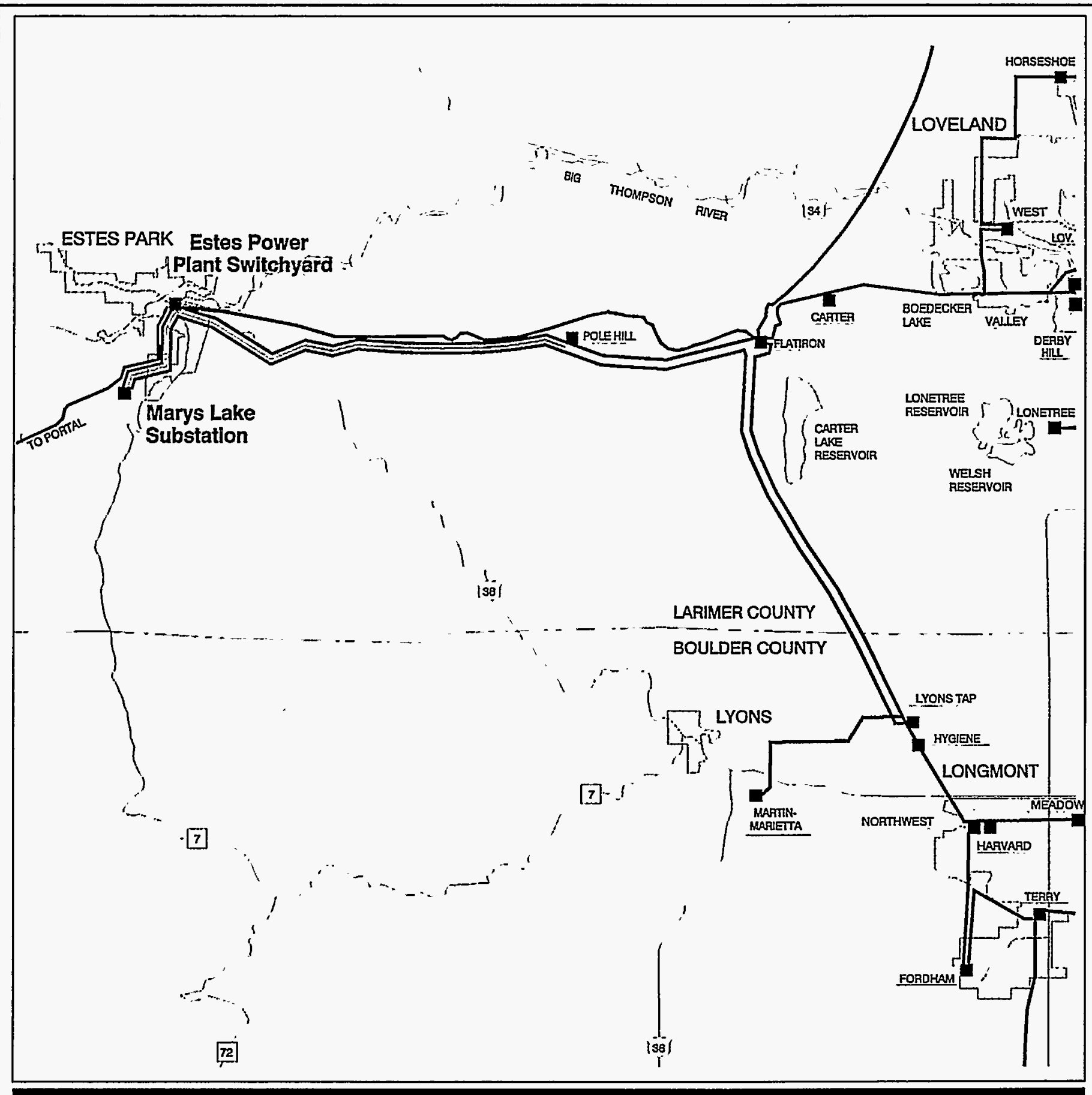

Platte River Power Authority and

Western Area Power Administration

69/115 kV Transmission Line Upgrade and Substation Expansion Projects

LEGEND

EXISTING 115,000 VOLT TRANSMISSION LINES

EXISTING 69,000 VOLT TRANSMISSION UNE

ELECTRIC SYSTEM ALTERNATIVES I AND II-

UPGRADE EXISTING 69,000 VOLT TRANSMISSION

UNE TO 115,000 VOLTS

ELECTRIC SYSTEM ALTERNATIVE III

ELECTRIC SYSTEM ALTERNATIVEIV

[......... CITY BOUNDARIES

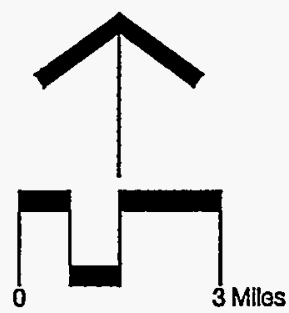

ELECTRIC SYSTEM ALTERNATIVES

Figure 2-1 
This page left intentionally blank. 


\subsection{Alternative Routes Considered}

After the preferred electric system configuration was selected, a route selection process was used to identify and evaluate potential routes for providing the required looped electric transmission service between the Estes Power Plant Switchyard and the Marys Lake Substation. This process involved several steps including:

- Collection of environmental, human, and cultural resource data;

- Mapping of environmental and human resources;

- Identification of exclusion, avoidance, and opportunity areas for transmission line siting based on resource sensitivity;

- Evaluation of potential routes;

- Selection of routes to be carried forward for full analysis in the Environmental Assessment; and

- Presentation of the results in a public meeting.

Information on environmental resources within the study area was collected from existing published and unpublished documents and files, contacts with governmental agencies, review of aerial photography, and field reconnaissance. Resource opportunity/constraint maps were then prepared for the resources that could be mapped. These resources were categorized as exclusion, avoidance, or opportunity for transmission line siting. These opportunity/constraint maps were based on the criteria presented in Table 2-1 as applied to the collected data and field observations.

Several potential alternative routes were identified based on the review of aerial photography and field reconnaissance. The alternatives were then compared to the resource opportunity/constraint map, Figure 2-2. These alternative routes, illustrated on Figure 2-3, are described below, along with the advantages and disadvantages of each. The advantages and disadvantages of each were evaluated to determine which alternatives to carry forward for full evaluation in the Environmental Assessment. The evaluation of alternative routes is discussed at the end of this section.

Alternative A. Existing 69-kV ROW. This route would follow the existing 69-kV ROW from the Estes Power Plant Switchyard to the Marys Lake Substation. This route consists of links 1, 2, 3 and 4 as shown on Figure 2-3 and Table 2-2.

Advantages: This alternative would utilize an existing Western ROW with existing access roads. It would not require any physical modifications for the approximate one-mile section of existing double-circuit $115 / 69-\mathrm{kV}$ that is already constructed to operate at 115-kV. Use of the existing ROW and similar wood $\mathrm{H}$-frame structures would minimize visual impacts, potential collision hazards for raptors and other avian species, and environmental disturbances.

Disadvantages: The south-southeast facing slope of Prospect Mountain presents sensitive conditions for reestablishing vegetation. Therefore, construction disturbances must be minimized and special care taken to assure successful revegetation. The existing route is adjacent to 48 residences, commercial properties, and/or institutional land ownerships.

This alternative has more advantages and fewer constraints than the other alternative routes. It has been carried forward for fuil evaluation as the Proposed Action in this Environmental Assessment.

Alternative B. Prospect Mountain - West. This route would follow the steel lattice double-circuit portion of the existing transmission line from the Estes Power Plant Switchyard to the top of the penstocks. The new 115-kV circuit would then cross Prospect Mountain on the north and west sides, and then angle south to intersect with the existing alignment along Marys Lake Road. This alternative route consists of links $1,2,5$ and 4 as shown on Figure 2-3 and Table 2-2.

Advantages: This alternative provides greater electric system reliability (due to the physical separation between the two transmission lines, there is less of a chance that both 115-kV lines would be taken out of service by a lightning strike or other natural or accidental force.) for approximately two-thirds of the new $115-k V$ circuit. It would not require any physical modifications for the approximate one-mile section of existing double-circuit $69,000 / 115-k V$ that is already constructed to operate at $115-k V$. Also, fewer residences would be adjacent to the ROW. 
Table 2-1

Transmission Line Routing

Exclusion, Avoidance, and Opportunity Criteria

Exclusion Areas

Avoidance Areas

Opportunity Areas
- Placement of a new transmission line over existing residences or other occupied buildings.

- Designated or registered national parks; memorial parks; historic sites and landmarks; natural landmarks; monuments; and wilderness areas.

- Areas critical to the lifestages of threatened or endangered animal and plant species.

- Existing or planned urban land uses, including residential, commercial, and industrial areas.

- Occupied dwellings, and impacts to landscaping and home improvements.

- Incompatible land uses including landfills, road or street expansions, mines, and gravel pits.

- Designated or registered national historic districts; wildlife areas; wild, scenic or recreational rivers; wildlife refuges; and grasslands.

- Designated or registered state wild, scenic or recreational rivers; game refuges; game management areas; forests; forest management lands; and grasslands.

- Properties eligible for listing on the National Register of Historic Properties.

- County parks and recreational areas; municipal parks; and parks owned or administered by other governmental subdivisions.

- Woodlands and wooded areas.

- Open space, shelterbelts, riparian areas, and other areas of conservation, recreational or ecological importance.

- Areas which are geologically unstable or highly erosive.

- Areas of recreational significance which are not designated as exclusion zones.

- Reservoirs and municipal water supplies.

- Water sources for organized rural water districts.

- Irrigated land, where the project would interfere with irrigation.

- Prime and unique farmlands.

- Existing utility ROWs (e.g., electric, gas, water, etc.).

- Along street and utility ROWs.

- Along section or property lines.

- Following natural features that provide a backdrop for screening to reduce visibility. 


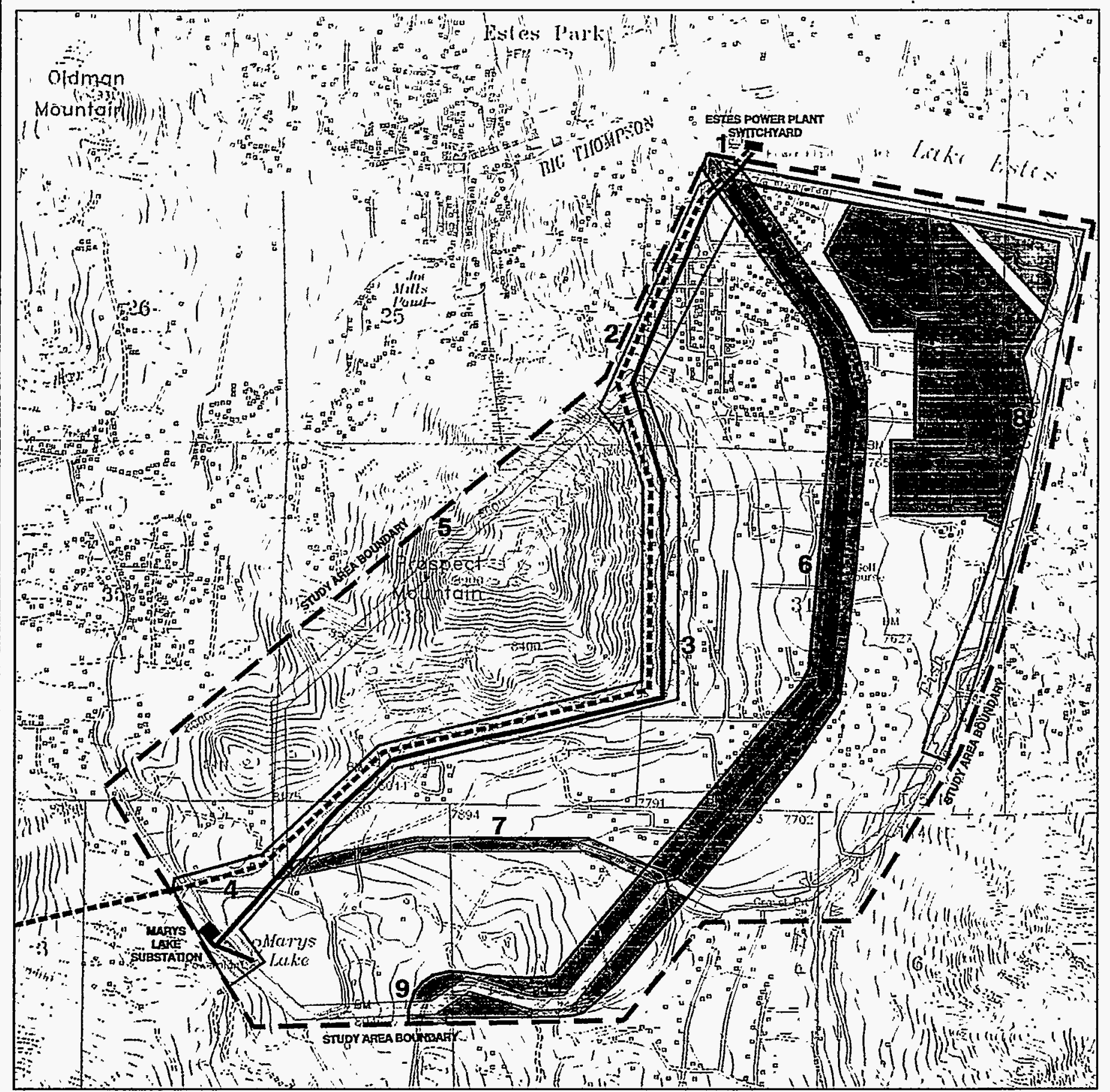

Platte River Power Authority and

Western Area Power Administration

Marys Lake 69/115 kV Transmission Line Upgrade and Substation Expansion Projects

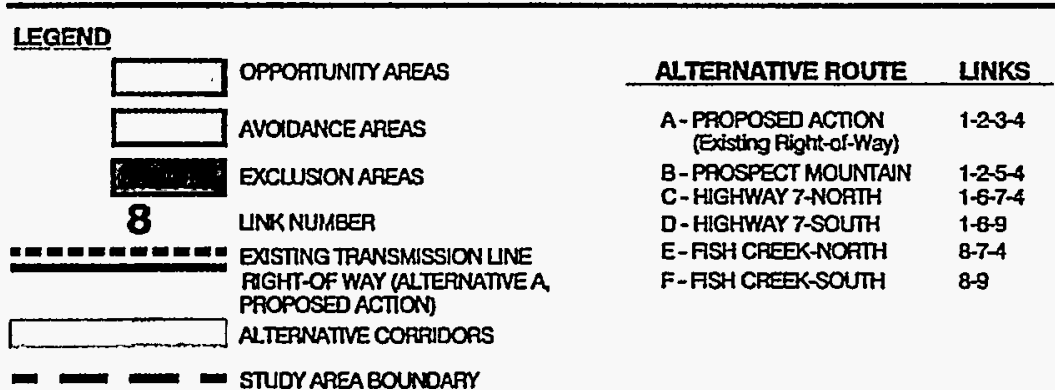

OPPORTUNITY/CONSTRAINT COMPOSITE

Figure 2-2 
$\varepsilon-2$ วมกต!

NOLIO व $\exists S O d O H d \exists H \perp$ פNION7ONI

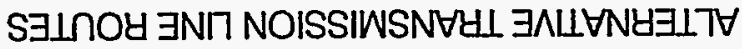

5000000

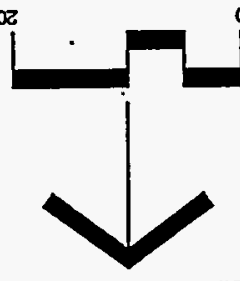

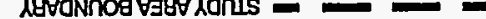

SHOAHBOS BhILHNEITS

(NOLNOY GJSOdOSd

$\forall$ FNIYNGEITH A $\forall M=O O-L H O I H$

JNTINOLSSIKSNALI DNLSXE

\begin{tabular}{|c|c|}
\hline $\begin{array}{r}6-9 \\
b-2-8 \\
6-9-1 \\
b-2-9-1 \\
b-z-2-1 \\
b-\varepsilon-2-1\end{array}$ & 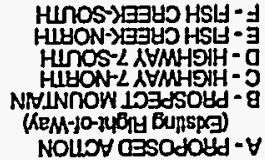 \\
\hline SXNก & 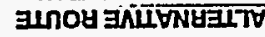 \\
\hline
\end{tabular}

वNGSE słoolodd uo! suedx $\exists$ uolpeisqns pue

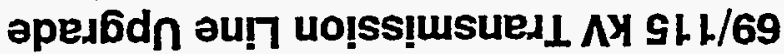
әYEך SKJEW

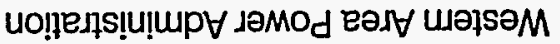
pue

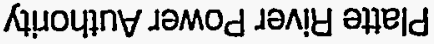

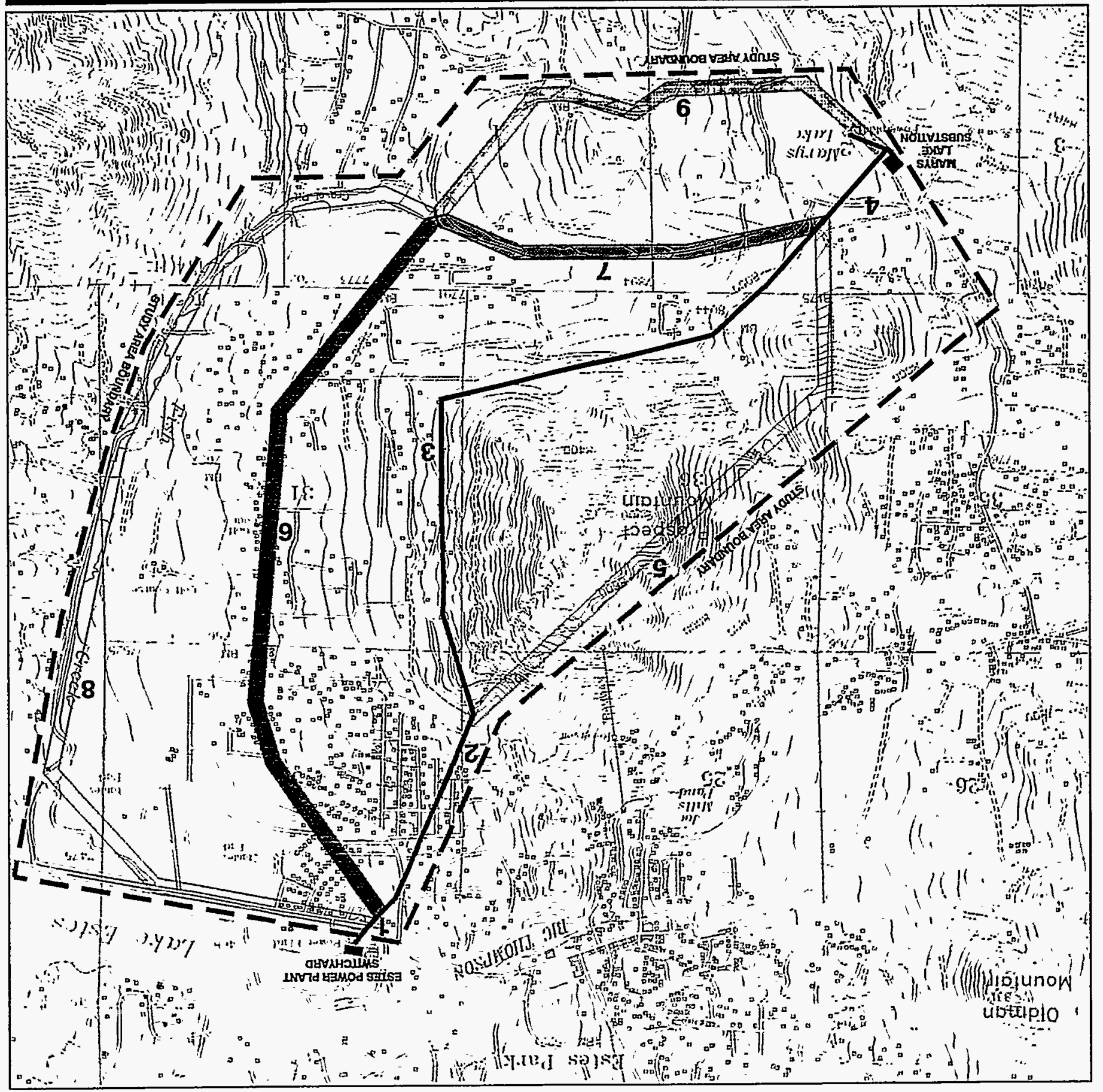


This page left intentionally blank. 
Table 2-2

Alternative Route Impact

Evaluation Summary

\begin{tabular}{|c|c|c|c|c|c|c|c|c|c|c|c|c|c|c|c|c|c|c|c|c|}
\hline Alternative Route & \multicolumn{4}{|c|}{ Alt. A } & \multicolumn{4}{|c|}{ Alt. B } & \multicolumn{4}{|c|}{ Alt. C } & \multicolumn{3}{|c|}{ Alt. D } & \multicolumn{3}{|c|}{ Alt. $E$} & \multicolumn{2}{|c|}{ Alt. F } \\
\hline Links & 1 & 2 & 3 & 4 & 1 & 2 & 5 & 4 & 1 & 6 & 7 & 4 & 1 & 6 & 9 & 8 & 7 & 4 & 8 & 9 \\
\hline Link Total' & 29 & 196 & 192 & 16 & 29 & 196 & 303 & 16 & 29 & 508 & 88 & 16 & 29 & 508 & 206 & 482 & 88 & 20 & 402 & 206 \\
\hline $\begin{array}{l}\text { Route Total } \\
\text { Occurrences }^{2}\end{array}$ & \multicolumn{4}{|c|}{433} & \multicolumn{4}{|c|}{544} & \multicolumn{4}{|c|}{641} & \multicolumn{3}{|c|}{743} & \multicolumn{3}{|c|}{590} & \multicolumn{2}{|c|}{608} \\
\hline Rank Total $^{3}$ & \multicolumn{4}{|c|}{72} & \multicolumn{4}{|c|}{98} & \multicolumn{4}{|c|}{91} & \multicolumn{3}{|c|}{108} & \multicolumn{3}{|c|}{110} & \multicolumn{2}{|c|}{121} \\
\hline $\begin{array}{c}\text { Route Rank by } \\
\text { Total } \\
\text { Occurrences }\end{array}$ & \multicolumn{4}{|c|}{1} & \multicolumn{4}{|c|}{2} & \multicolumn{4}{|c|}{5} & \multicolumn{3}{|c|}{6} & \multicolumn{3}{|c|}{3} & \multicolumn{2}{|c|}{4} \\
\hline $\begin{array}{l}\text { Route Rank by } \\
\text { Rank Totals }\end{array}$ & \multicolumn{4}{|c|}{1} & \multicolumn{4}{|c|}{3} & \multicolumn{4}{|c|}{2} & \multicolumn{3}{|c|}{4} & \multicolumn{3}{|c|}{5} & \multicolumn{2}{|c|}{6} \\
\hline
\end{tabular}

1 These numbers represent the total number of occurrences of various environmental factors (land use, visual, physical resources, biological resources, cultural resources, etc.) that occur within the corridor of each route link or segment (1 through 9).

2 These numbers represent the totals of the number of occurrences for each alternative (A through F).

3 For each environmental factor evaluated, a rank was assigned to each criteria as compared to the other alternatives with 1 being best (least occurrences) and 6 being worst (most occurrences). This number totals all of the rankings for each alternative. 
Disadvantages: This Alternative would require the clearing of existing vegetation for the ROW and building new access roads for construction, operation, and maintenance. The visual impacts to much of the Town and to Rocky Mountain National Park would be greater than the other Alternatives due to the forested ROW that would be cleared. The financial costs would also be higher.

This alternative was rejected because of the anticipated visual and environmental impacts, and the increased costs. Therefore, it was not carried forward for detailed analysis in the Environmental Assessment.

Alternative C. Highway 7 - North. This route would follow Colorado Highway 7 south from the Estes Power Plant Switchyard to Fish Creek; it would then follow Fish Creek to the west and intersect with the existing alignment along Marys Lake Road. Single steel pole structures would have to be used with all of the conductors hanging over the highway to minimize the ROW requirements, thus resulting in taller structures. The line would have to cross back and forth across the highway in order to locate the structures where adequate ROW exists. This alternative route consists of links 1, 6, 7 and 4 as shown on Figure 2-3 and Table 2-2.

Advantages: This alternative provides greater reliability for the new 115-kV circuit for the same reasons stated for Alternative B.

Disadvantages: This route would cross 97 parcels where new ROWs would be required; greater impacts would result with existing land uses along Colorado Highway $7 ; 72$ existing residential parcels would be crossed by or are adjacent to the ROW; this route would impact 69 new residential parcels; visual impacts resulting from the structure heights and criss-crossing the highway to locate the new transmission line where adequate ROW exists; new access roads would need to be constructed across the undeveloped areas adjacent to the intermittent stream between Marys Lake and Colorado Highway 7 for construction, operation, and maintenance; and increased costs.

This route was rejected because of the number of residential parcels where new ROWs would be required; the anticipated visual impacts resulting from criss-crossing Colorado Highway 7 , a major entrance into the Town and a designated state scenic highway, and the difficulty in acquiring the required ROWs. Therefore, this alternative was not carried forward for detailed analysis in the Environmental Assessment.

Alternative D. Highway 7 -South. This route would follow Colorado Highway 7 south to a point approximately due east of the south shoreline of Marys Lake. It would then follow a west and northwesterly route around the south and west sides of Marys Lake to the Marys Lake Substation. This alternative route consists of links 1, 6 and 9 as shown on Figure 2-3 and Table 2-2.

Advantages: This alternative provides greater reliability for the new 115-kV circuit for the same reasons stated for Alternatives $\mathrm{B}$ and $\mathrm{C}$.

Disadvantages: This route would cross 112 parcels where new ROWs would be required; 88 existing residential parcels would be crossed by or are adjacent to the ROW; this route would impact 91 new residential parcels; the visual impacts would be the same as described for Alternative $C$.

This route was rejected because of the anticipated visual impacts resulting from criss-crossing Colorado Highway 7 , a major entrance into the Town, and was not carried forward for detailed analysis in the Environmental Assessment.

Alternative E. Fish Creek - North. This route would follow U.S. Highway 36 east from the Estes Power Plant Switchyard on the south side of the highway to the west side of the lake west of Fish Creek Road; continue southeasterly between the lake and the recreation fields; then head south and westerly along Fish Creek Road and Fish Creek, crossing Colorado Highway 7 and intersecting with the existing alignment along Marys Lake Road. This alternative route consists of links 8, 7 and 4 as shown on Figure 2-3 and Table 2-2.

Advantages: This alternative provides greater reliability for the new $115-k V$ circuit for the same reasons stated for Alternatives B through D.

Disadvantages: This route would impact 96 new residential parcels; land use limitations along U.S. Highway 36 , where there is an existing double circuit 115-kV transmission line; new visual impacts would be created; environmental impacts associated with constructing new access roads for construction, 
operation, and maintenance along Fish Creek; locating structures in an active gravel pit area; and increased costs.

This route was rejected because of the new visual and land use impacts, and was not carried forward for detailed analysis in the Environmental Assessment.

Alternative F. Fish Creek - South. This route would follow U.S. Highway 36 east from the Estes Power Plant Switchyard along the south side of the highway to the west side of the lake west of Fish Creek Road; continue southeasterly between the lake and the recreation fields; then head south and westerly along Fish Creek Road and Fish Creek to Colorado Highway 7; continue south along Colorado Highway 7 to a point approximately due east of the south shoreline of Marys Lake; then head west and northwesterly around the south and west sides of Marys Lake to the Marys Lake Substation. This alternative route consists of links 8 and 9 as shown on Figure 2-3 and Table 2-2.

Advantages: This alternative provides greater reliability for the new $115-\mathrm{kV}$ circuit for the same reasons stated for Alternatives $B$ through $E$.

Disadvantages: This route would impact 118 new residential parcels; land use limitation along U.S. Highway 36 , where there is an existing double circuit 115-kV transmission line; new visual impacts would be created; environmental impacts associated with constructing new access roads for construction, operation, and maintenance in the area south and east of Marys Lake; locating structures in an active gravel pit area; and increased costs.

This route was rejected because of the new visual and land use impacts, and was not carried forward for detailed analysis in the Environmental Assessment.

Evaluation of Alternative Routes. Evaluation criteria were developed to assess the natural, human, and cultural environment; identify constraints and opportunities; and prioritize project route alternatives. This analysis was quantified by determining the number of occurrences of the various environmental factors along each segment of each alternative. These line links or segments are identified by number on Figure 2-3 and Table 2-2. Three evaluations were then performed: (1) the first utilizing weight factors assigned by the environmental consultant; (2) the second utilizing weight factors recommended by the public; and (3) the third utilizing only the number of occurrences for each criteria. The weight factors were assigned to reflect the relative impacts associated with each factor; the higher the weight, the greater the impact. The weights ranged from 1 to 10 , with 10 representing the highest degree of impact. Theoretically, the alternatives with the least occurrences - or lowest numerical scores represent the alternatives from which the environmentally preferred alternative will be selected. All three methods of evaluation showed the Proposed Action (route Alternative A) to have the lowest potential environmental effect. Through public comment received at the October 4, 1995 public workshop, it was decided to use the "unweighted" analysis as this method appears to better represent the public's perception of the actual impacts associated with the project. The criteria used in the impact evaluation included:

- Land use impacts such as existing residential parcels adjacent to, or crossed by, ROW; new residential parcels adjacent to, or crossed by, ROW; commercial parcels adjacent to, or crossed by, ROW; locations that would prohibit other development of property; parcels crossed where new ROW would be required; crossings through developed park or recreation areas; and crossings requiring a significant increase in construction time, traffic delays, or expense;

- Visual impacts inciuding structures visible from primary transportation routes; existing residences from which the transmission line would be visible; new residences from which the transmission line would be visible; commercial developments from which the transmission line would be visible; structures visible from recreation areas; structures skylined; prominent deviations in the alignment; and structures visible in scenic landscapes;

- Physical and biological environmental impacts such as structures on very steep slopes $(>50 \%)$ with soils susceptible to erosion, slump and creep; structures on steep soils (25-50\%) with slopes susceptible to erosion, slump and creep; water crossings; wells within the ROW; structures in the floodplain; acres of trees removed; structures through riparian habitat; structures potentially impacting threatened \& endangered species; acres of wildlife habitat removed; spans that may increase potential for bird collisions; instances requiring construction to be scheduled to avoid nesting or breeding periods critical to sensitive species; and miles of new ROW disturbance.; 
- Impacts to cultural resources including structures potentially affecting archaeological sites; and structures potentially affecting historic sites; and

- Construction related impacts including miles of helicopter construction; structures with difficult access; structures that would result in conflicts with the operation of an airport, heliport or landing strip; number of angles in the alignment of $41^{\circ}$ to $90^{\circ}$ (requiring heavier or guyed-structures and resulting in greater visual impacts; and number of angles in the alignment of $2^{\circ}$ to $40^{\circ}$.

The impact evaluation for the preliminary routes described above, utilizing the unweighted assessment is summarized below in Table 2-2. The entire assessment is included in Appendix $\mathbf{G}$.

\subsection{Design Alternatives}

\subsubsection{Underground Construction}

While underground construction is frequently used for lower voltage distribution lines, such construction for high voltage transmission lines has been used only occasionally in densely populated urban areas where adequate ROW is not available for overhead construction. In such situations, the costs associated with underground construction are generally offset by the costs associated with acquiring the necessary land rights for conventional overhead construction, and by the amount of energy delivered and purchased by the larger populations and businesses within the more densely developed areas. The placement of lower voltage electric distribution lines underground is more feasible and less costly because there are fewer environmental impacts associated with insulating each phase conductor from the others and from the surrounding environment, and of dissipating the heat the conductors generate. These same considerations are larger problems with high voltage transmission lines.

A comment received from the public at the June 14, 1995 public workshop/scoping meeting suggested that one reason for the public interest in underground construction, other than for visual and aesthetic reasons, is the perception that the electric and magnetic field (EMF) levels will be reduced or eliminated and therefore, no longer be of concern. In reality, while electric fields are eliminated, the magnetic fields can not be screened and the levels that result from different types of underground construction can vary from a few milligauss ( $m G$ ) to levels higher than those associated with the same line constructed overhead. This is due to two factors: (1) the type of underground construction (discussed below); and (2) a person standing in the center of the ROW is closer to an underground line than an overhead line. Other reasons for considering underground construction include the elimination of potential impacts on bird populations from collisions with overhead ground wires; and narrower ROWs are required than for overhead construction, thus reducing certain land use impacts.

The primary disadvantages of underground transmission line construction include cost; the time and expense required to locate and repair problems if outages occur, and the recurring environmental impacts associated with searching for and repairing problems. The cost to place a $115-\mathrm{kV}$ transmission line underground is approximately three to ten times per mile more than the cost for conventional overhead construction. These estimates vary greatly depending on the type of underground construction used, and the soil and rock characteristics. Rather than limiting construction disturbances to relatively small areas around each structure location for an overhead line, a continuous linear disturbance is necessary. This may result in increased impacts to the soil, water quality, cultural resources, and biological resources including sensitive habitats that support threatened and endangered species that could be avoided by spanning with overhead construction. The impacts to vegetation would likely be significant due to the sensitive nature of the area due to the altitude, short growing season, and reclamation difficulties associated with the south-facing slopes. 


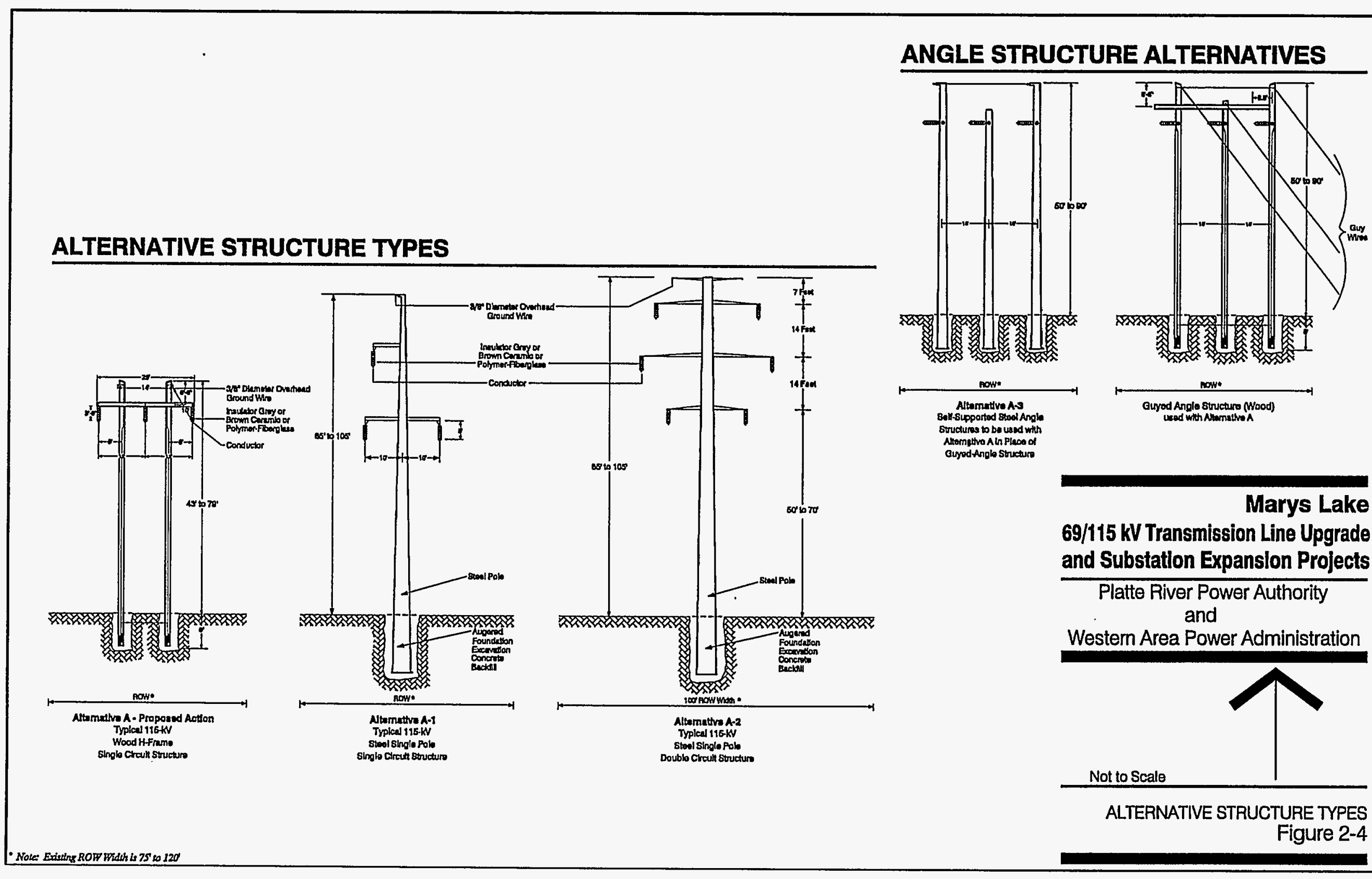


This page left intentionally blank. 
If only sections of the transmission line were to be placed underground, large transition structures are needed at any point where a transition is made between overhead and underground construction.

Underground transmission lines are expected to have a shorter service life than overhead transmission lines: 25-30 years versus $40-50$ years. The reliability of underground and overhead transmission lines is comparable. Overhead transmission lines that are subject to weather (particularly heavy, wet snow and icing conditions) may experience relatively frequent failures. However, these failures can generally be repaired within a relatively short period of time. Failures of underground transmission lines from dig-ins or mechanical failure (usually associated with splices) may be less frequent but repairs can require several weeks to locate and correct the problem.

There are three types of underground construction methods that are used for transmission lines:

- High pressure oil-filled pipe type cable (HPOF)

- Self-contained oil-filled (SCOF) type cable

- Solid dielectric

The HPOF carries the three insulated phase conductors of a circuit in a steel pipe filled with cooling fluid, a synthetic oil, for insulating purposes. Pumps and pumping stations are required, generally at each end of an underground transmission line to maintain the synthetic oil in an agitated state to insulate the conductors. The HPOF construction provides the greatest reduction in EMF levels due to the close spacing of the phases of the circuit which results in cancellation of the magnetic field associated with each phase. The EMF is further reduced by fields induced in the steel pipe that contains the three cables. Reliability of the HPOF system is substantially better than that of the other types of underground construction. This is due to the protection from dig-ins provided by the steel pipe. The cost of HPOF systems are in the middle range for underground electric construction. The disadvantages associated with HPOF construction include the possibility of oil spills in the event of a failure; the subsequent risk of fire; and the outage time, expense, and impacts that would recur in the event of a failure.

The SCOF system contains each phase conductor in a separate, fluid-filled cable that is laid separately in a wide trench. The SCOF type construction has thus far proven to be less reliable than the HPOF system, the EMF reduction is considerably less than the HPOF system (due to the arrangement and spacing of conductors), and the SCOF system cost is slightly greater than HPOF. The time and expense required to repair a SCOF system in the event of a failure would be slightly less than with the HPOF system. However, the environmental impacts would be far greater due to the disturbances resulting from three trenches that are required for each of the three phase conductors.

The solid dielectric system, while popular in Europe and Japan, has not been widely used in the United States. This system is installed in a relatively wide trench with each of the three phase conductors separated for heat dissipation. As a result of this separation of the phases, the EMF reduction is not as effective as with the HPOF system. Solid dielectric underground systems are less reliable than either the HPOF or SCOF construction methods, and are also less costly.

It is the policy of Platte River and its members, including the Town of Estes Park, that all electric transmission lines constructed at 115-kV or higher will be designed for overhead construction. Exceptions to this policy will be considered if the capital cost differential between overhead and underground construction is funded or committed in advance by an outside party. As no such funds or commitment have been made, specific underground route alternatives were not considered. Western supports this policy for this project.

\subsubsection{Overhead Construction}

Overhead construction is the conventional method for constructing higher voltage transmission lines. Several options were evaluated for overhead construction including various routes and structural designs.

\subsection{Helicopter Construction}

- More unconventional construction methods, such as the use of a helicopter to transport crews and/or structures and/or equipment into each structure site were considered for this project. In most areas along the proposed route, using helicopters was not warranted by the terrain or by the expected impacts to environmental resources. However, portions of the route represented by Alternative B could possibly require the use of helicopters. 
Helicopters are sometimes utilized for portions of a project being constructed by conventional methods. In these cases, helicopters are used for delivering materials, setting poles, and conductor stringing. Helicopter construction would not be necessary for the Proposed Action.

\subsection{Proposed Action}

Of the several alternatives considered for this project, those that were considered viable are described below and are evaluated in detail in this Environmental Assessment.

\subsubsection{Alternative A - The Proposed Action}

Upgrading the existing 69-kV transmission line between the Marys Lake Substation and the Estes Power Plant Switchyard to 115-kV and expanding the Marys Lake Substation was identified as the most effective way in which to improve electric service to Estes Park.

The Proposed Action involves:

- Removing a 115 to 69-kV transformer at the Estes Power Plant Switchyard and performing other associated work as required to allow upgrading the three-mile transmission line from $69-k V$ to $115-k V$;

- Begin operating, at $115-\mathrm{kV}$, the one-mile section of the existing 69-kV portion of the double-circuit transmission line between the Estes Power Plant Switchyard and the East Portal of the Adams Tunnel. This existing transmission line section has been in place since 1951 on steel-lattice towers, and is already insulated for operation at $115-\mathrm{kV}$;

- Removing two miles of existing 69-kV transmission line on wood H-frame structures between the Estes Power Plant Switchyard (beginning after the one-mile section of double-circuit, steel-lattice towers) and the Marys Lake Substation, and rebuilding this section to operate at $115-\mathrm{kV}$ utilizing wood $\mathrm{H}$-frame construction and connecting this line at Marys Lake Substation; and

- Installing a 115 to $69-k V$ transformer at the Marys Lake Substation and performing other associated work to maintain a 69-kV connection between the Marys Lake Substation and the East Portal of the Adams Tunnel.

The Proposed Action alternative consists of upgrading the existing single-circuit 69-kV transmission line to 115-kV. Wood $\mathrm{H}$-frame and single pole tubular steel structures are the structure design alternatives most technically and economically feasible for this upgrade.

Approximately one mile of the existing 69-kV transmission line is constructed as a double-circuit line with a 115-kV - transmission line on steel lattice structures. Because the size of the existing conductor used for the 69-kV transmission line is adequate for $115-\mathrm{kV}$ operation, and because the existing $69-\mathrm{kV}$ transmission line is insulated for $115-k V$ operation, no physical alterations are proposed for this portion of the line.

Approximately two miles of the existing $69-\mathrm{kV}$ transmission line is constructed as a single-circuit line on wood $\mathrm{H}$ frame structures that parallels an existing $115-\mathrm{kV}$ transmission line that is also constructed on wood $\mathrm{H}$-frame structures. The only structure type that will preserve the technical and visual unity of the proposed upgrade is a wood-pole H-frame type, similar to what presently exists. This is the alternative proposed by Western and Platte River.

The wood-pole H-frame type structure is illustrated on Figure 2-4, and in photographic simulations in Appendix 1. Guyed three-pole structures would be used at angle points.

The yard lighting at Marys Lake Substation will be modified to be directed down and shielded from the sides, similar to the new street lighting used by the Town of Estes Park. Brighter lighting may be required for use in emergency situations requiring night-time work at the substation.

The Proposed Action is shown on Figure 1-2 and with other alternatives on Figure 2-3. 
Construction. Most conventional, above-ground transmission lines are constructed in a relatively standard manner. This involves the movement of construction vehicles and equipment over the ground on a system of access ways that are either on, or in reasonable proximity to, the transmission line ROW. However, continuous access is required along the ROW. In general, on terrain with less than 12 to 15 percent slope, construction vehicles and equipment can move overland without requiring the construction of an improved road. On steeper terrain, however, an access way must be constructed by blading and grading. The Proposed Action may require the construction of three new spur roads for access to structures to the northwest of Devon Drive. If these access spurs are necessary, they would be approximately 100 to 150 feet in length, and approximately 10 feet in width. After construction, the spurs would be removed and reclaimed.

Conventional construction is the logical practice in areas where access already exists or on relatively gentle or moderately sloping terrain. One of these conditions exists along most of the existing ROW, and along most of the alternative routes, with the exception of Alternative B. With this exception, Western and Platte River have assumed conventional above-ground construction would be used for all of the project alternatives. Typical personnel and equipment required for conventional above-ground construction are described in Table 2-3.

Table 2-3

Typical Personnel and Equipment for Transmission Line Construction

\begin{tabular}{|c|c|c|}
\hline Activity & Number of Persons & Equipment \\
\hline Surveying & 4 & Pickup Truck \\
\hline Site Preparation & 2 & Blade, Pickup Truck \\
\hline Construction Yard Preparation & 2 & Blade, Pickup Truck \\
\hline Structure Demolition & $6-12$ & $\begin{array}{l}\text { Crane, Flatbed Truck, Pickup } \\
\text { Trucks, Tractor Trailer }\end{array}$ \\
\hline Materials Hauling & $8-12$ & $\begin{array}{l}\text { Tractor Trailer, Crane, Flatbed } \\
\text { Truck, Pickup Trucks }\end{array}$ \\
\hline Foundation Excavation & $4-8$ & $\begin{array}{l}\text { Tractor with Auger, Backhoe, } \\
\text { Pickup Trucks }\end{array}$ \\
\hline Structure Assembly & $6-12$ & $\begin{array}{l}\text { Crane, Flatbed Truck, Pickup } \\
\text { Trucks }\end{array}$ \\
\hline Structure Erection & 4-6 & $\begin{array}{l}\text { Crane ( } 50 \text { to } 100 \text { ton capacity), } \\
\text { Pickup Trucks }\end{array}$ \\
\hline $\begin{array}{l}\text { Groundwire and Conductor } \\
\text { Stringing }\end{array}$ & $5-10$ & $\begin{array}{l}\text { Reel Trailer, Tensioner, Puller, } \\
\text { Digger, Winch Truck, Bucket } \\
\text { Trucks, Pickup Trucks }\end{array}$ \\
\hline Cleanup & $3-6$ & Flatbed and Pickup Trucks \\
\hline Seeding & $1-2$ & $\begin{array}{l}\text { Hydroseeder, Tractor, and Disc } \\
\text { Plow and/or Pickup Trucks }\end{array}$ \\
\hline
\end{tabular}

Note: Most of the activities above are expected to progress sequentially, and the peak number of people at any one time during construction is expected to be 12-16.

Construction would begin in the Spring and continue through October and would proceed in the following sequential manner: 
ROW Access. Cross-country travel along the ROW would only be necessary between three to four spans in the area that parallels Peak View Drive.

Surveying. The transmission line ROW would be surveyed. The survey would locate the transmission line along the centerline, determine profiles for conductor clearances, and locate structures.

Line Removal. The portion of the existing $69-\mathrm{kV}$ transmission line constructed on wood $\mathrm{H}$-frame structures would be removed. The conductors would be wound on reels, and the hardware removed. The existing $\mathrm{H}$-frame structures would then be removed. The poles may be cut off at ground level or pulled completely out of the ground and removed. The holes would be backfilled and compacted. Some poles may be salvaged or sold by the contractor, and some poles may eventually be disposed at approved landfills.

Structure Spotting. Western uses a computer software program (TLCADD) which selects transmission line structure locations and structure types/heights. The program provides opportunities to identify zones in which sites are undesirable either due to existing obstructions (such as driveways, roads, fence lines and other utilities or prohibitively expensive due to lack of access, or inadequate soil conditions. New impacts would be minimized by placing the new wood poles as close as possible to the location of the existing poles. The new locations may be shifted a maximum of 5-10 feet.

Materials Handling and Hauling. Construction materials would be stored at a temporary staging area. The staging area would serve as a reporting location for workers, parking space for vehicles, and as a storage area for materials. Materials would be hauled to the staging area using existing roads and streets.

Structure Assembly. A truck-mounted auger would excavate holes for the new structures. Erection crews would then assemble the new structures at the individual sites. Alternately, portions of the structures may be assembled at the staging area and then hauled to the site. The new structures will be set in place and the structure holes will be backfilled using the soil from the excavations. Excess soil would be spread evenly around the base of the poles or removed from the site. Insulators and hardware would then be hung.

Conductor Stringing. Reels of conductor would be delivered to wire-handling sites, located at each end of the wood $H$-frame structure segments. The conductor pulling, sagging and clipping operations would take place quickly. Tension-stringing methods, which do not allow the conductor to touch the ground, would be used. Steel-pulling cables would be pulled down the line through large pulleys hanging from the insulator attached to each structure. These pulling cables and pulleys would pull the conductor into place under tension for the entire length of the project. In some instances, helicopters are used for conductor stringing.

Cleanup and Restoration. Old wood poles, waste construction materials and rubbish from all construction areas would be collected, hauled away, and disposed at approved sites. All disturbed areas not returned to cultivation would be reseeded to minimize erosion. The intent would be to restore all construction areas, as nearly as feasible, to their original condition. Any damaged gates, fences, or landscaping would be repaired. Except where clearing is required at the structure locations, vegetation would be protected from damage. All destruction, scarring, damage, and defacing of the landscape would be repaired. Landowners would be compensated for damage or repair.

Safety Program. The contractor would be required to prepare and conduct a safety program (subject to Western/Platte River approval) in compliance with all applicable Federal, state, and local safety standards and requirements and Western/Platte River general practices and policies.

Standard construction mitigation practices are described in Appendix $\mathrm{H}$. Western will have a construction inspector on site during all phases of construction. The construction inspector will be responsible for ensuring standard practices and specific environmental mitigation measures are implemented by the contractor.

\section{Operation and Maintenance}

The day to day operation of the transmission lines would be directed by system dispatchers in power control centers. These dispatchers use communication facilities to operate circuit breakers that control the transfer of power through the lines. These circuit breakers also operate automatically to ensure safety, e.g., in the event of a structure or conductor failure. 
Western's preventative maintenance program for transmission lines would include routine aerial and ground patrois. Aerial patrols would be conducted four times per year. Ground patrols would be conducted once a year to detect equipment needing repair or replacement (i.e., structures, insulators, and conductors). In addition, climbing inspections would be conducted on an on-going basis, with each structure being climbed and inspected once every five years.

Maintenance may include repairing damaged conductors, inspection and repair of structures, and replacing damaged and broken insulators. In addition to maintaining the structures, conductors, and ROW, Western would maintain gates installed by Western. Transmission lines are sometimes damaged by storms, floods, vandalism, or accidents and require immediate repair. Emergency repair would involve prompt movement of crews to repair the damage and replace any equipment. If access roads are damaged as a result of the repair activities, Western would repair them as required.

Various practices may be used at structures and along the transmission line ROW to prevent undesirable vegetation. Because of the semiarid, urban, and agricultural nature of the project area, very minor and infrequent measures would be necessary to control vegetation. Herbicides would not normally be used within the transmission line ROW unless requested by the landowner for the purposes of reducing noxious weeds around transmission line structures.

Abandonment. At the end of the useful life of the proposed project, the transmission lines would either be replaced or removed. In either case, the ground wires, conductors, insulators, and hardware would be dismantled and removed from the ROW. The structures would be removed along with any concrete foundations. Areas disturbed during the dismantling process would be regraded and reseeded.

Schedule. The project is scheduled for construction in 1997 and 1998. The following project schedule outlines major project milestones:

- Conduct Public Meeting/Workshop - Summer/Fall, 1995

- Issue Environmental Assessment - Spring 1996

- Complete Final Design - Spring 1997

- Select Construction Contractor - Spring 1997

- Complete Construction - Spring 1998

\subsubsection{Structure Alternatives to the Proposed Action}

\section{Alternative A1 - Single Steel Pole Structures}

Alternative $A 1$ is the same as the Proposed Action except that single-circuit single steel pole structures would be used instead of the wood $\mathrm{H}$-frame poles for the two miles where the 69-kV line will be upgraded to 115-kV. This alternative would follow the same route as Alternative A, the Proposed Action, along the existing ROW. This alternative structure type is shown on Figure 2-4. Construction would also be the same as described for Alternative A.

\section{Alternative A2 - Double-Circuit Single Steel Pole Structures}

Alternative A2 is the same as the Proposed Action except that both the existing 115-kV line and the new 115-kV line would be placed on double-circuit single steel pole structures for the two miles where the line will be upgraded. This alternative would follow the same route as Alternative $A$, the Proposed Action, along the existing ROW. This alternative structure type is shown on Figure 2-4. Construction would also be the same as described for Alternative A.

\section{Alternative A3 - Self-Supported Angle Structures}

Alternative $A 3$ is the same as the Proposed Action except that a self-supported structure would be used at the angle points along the route instead of guyed three-pole structures similar to those on the existing lines. This alternative was considered as a result of comments received at the public workshop held on October 4, 1995. This alternative was considered as an option to reduce the visual and land use impacts associated with the guyed three-pole structures. The existing and proposed wood pole angle structures have a diameter of approximately 15 to 18 
inches at the base and approximately 8 inches at the top of the poles. The self-supported angle structures would have a diameter of approximately 34 inches at the base and approximately 15 inches at the top. This alternative structure type is shown on Figure 2-4 and photo simulation 1-8 in Appendix I. Construction would also be the same as described for Alternative A. If this alternative is selected, the self-supported angle structures would be used only for the upgraded line.

The typical physical design characteristics for the existing, proposed, and alternative structure types are presented in Table 2-4.

Table 2-4

Typical Transmission Line Characteristics (Approximate Figures)

\begin{tabular}{|c|c|c|c|c|}
\hline $\begin{array}{l}\text { Description of Design } \\
\text { Component }\end{array}$ & $\begin{array}{c}\text { Existing } \\
\text { Transmission Line }\end{array}$ & Proposed Action & $\begin{array}{c}\text { Single-Circuit } \\
\text { Single Steel Pole } \\
\text { Structure }\end{array}$ & $\begin{array}{c}\text { Double-Circuit } \\
\text { Single Steel Pole } \\
\text { Structure }\end{array}$ \\
\hline Voltage & 69,000 & 115,000 & 115,000 & 115,000 \\
\hline ROW Width & $75^{\prime}-120^{\prime}$ & $80^{\prime}$ & $80^{\prime}$ & $100^{\prime}$ \\
\hline Average Span & $700^{\prime}$ & $700^{\prime}$ & $600^{\prime}$ & $600^{\prime}$ \\
\hline Maximum Span & $875^{\prime}$ & $875^{\prime}$ & $760^{\prime}$ & $760^{\prime}$ \\
\hline $\begin{array}{l}\text { Average Height of } \\
\text { Structures/Range }\end{array}$ & $43^{\prime}-79^{\prime}$ & $43^{\prime}-79^{\prime}$ & $85^{\prime}-105^{\prime}$ & $85^{\prime}-105^{\prime}$ \\
\hline $\begin{array}{l}\text { Structure Diameter at } \\
\text { Base }\end{array}$ & $15 "-18^{\prime \prime}$ & $15^{\prime \prime}-18^{\prime \prime}$ & $18^{\prime \prime}-24^{\prime \prime}$ & $24^{\prime \prime}-30^{\prime \prime}$ \\
\hline $\begin{array}{l}\text { Temporary Land Disturbed } \\
\text { at Base }\end{array}$ & 900 sq. ft. & 900 sq. ft. & 900 sq. ft. & 900 sq. ft. \\
\hline $\begin{array}{l}\text { Permanent Land Disturbed } \\
\text { at Base }\end{array}$ & 36 sq. ft. & 36 sq. ft. & 9 sq. ft. & 9 sq. ft. \\
\hline $\begin{array}{l}\text { Minimum Ground } \\
\text { Clearance Beneath } \\
\text { Conductor (at maximum } \\
\text { sag at } 120 \text { degrees F) }\end{array}$ & $22^{\prime}$ & 22 & $23^{\prime}$ & $23^{\prime}$ \\
\hline $\begin{array}{l}\text { Maximum Height of } \\
\text { Machinery that can be } \\
\text { Operated Safely Under } \\
\text { Line }\end{array}$ & $15^{\prime}$ & $15^{\prime}$ & $16^{\prime}$ & $16^{\prime}$ \\
\hline Circuit Configuration & Horizontal & Horizontal & Vertical - Delta & Vertical \\
\hline $\begin{array}{l}\text { Conductor Size (circular } \\
\text { mils) }\end{array}$ & 336,400 & 336,400 & 336,400 & 336,400 \\
\hline
\end{tabular}

*Note: The structure diameter at the base of the self-supported angle structures, Alternative $A 3$, would be approximately 34 inches. The structures are illustrated in photo simulation I-8 in Appendix I.

\subsection{Comparison of Alternatives}

The Proposed Action would utilize an existing Western ROW, most of which is accessible by existing roads. It would not require any physical modifications for the approximate one-mile section of existing double-circuit of $115 / 69-\mathrm{kV}$ that is already constructed to operate at $115-\mathrm{kV}$. Use of the existing ROW and similar wood $\mathrm{H}-$ frame structures would minimize visual impacts, potential collision hazards for raptors and other avian species, and environmental disturbance. 
Below, the effects of each alternative is compared to the Proposed Action.

No Action Alternative and Conservation of Energy. These alternatives would not meet the purpose and need of the project.

Routing Alternatives. Six different alternative routes were examined. These alternatives are described in Section 2.4. Routing along the existing ROW (the Proposed Action) was considered to be the only viable alternative route.

Structure Design Alternatives. Wood $\mathrm{H}$-frame and single pole tubular steel structures are the structure design alternatives most technically and economically feasible. The only structure type that will preserve the technical and visual unity of the proposed upgrade is a wood $\mathrm{H}$-frame, similar to what presently exists. This is the alternative proposed by Western and Platte River. The single pole tubular structures would be taller than the wood $\mathrm{H}$-frames, and would result in greater visual impacts because of their height and the need for additional structures.

Single steel poles were also considered at the angle points along the route instead of the guyed three-pole structures. This alternative was considered as an option to reduce the visual and land use impacts associated with the guyed poles.

Construction Alternatives. The cost of underground construction would be several times greater than conventional overhead construction of the Proposed Action, and therefore was not considered to be feasible. There would also be significant long-term environmental impacts associated with undergorund construciton along the existing ROW.

Relative Cost Estimates. The relative costs of the route, structure and underground construction alternatives are presented in Table 2-5. The alternatives to be evaluated in detail in Chapter 4 include Alternatives $A$ (the Proposed Action), $A 1, A 2$, and $A 3$. 
Table 2-5

Relative Cost Comparisons

\begin{tabular}{|c|c|c|c|c|c|c|c|c|c|c|c|c|}
\hline \multicolumn{7}{|c|}{ Route Alternatives } & \multicolumn{3}{|c|}{ Structure Alternatives } & \multicolumn{3}{|c|}{$\begin{array}{l}\text { Underground Construction } \\
\text { Alternatives }\end{array}$} \\
\hline Costs & Alt. $A^{*}$ & Alt. B & Alt. C & Alt. D & Alt. E & Alt. $F$ & Alt. A1 & Alt. A2 & Alt. A3 & HPOF & scof & $\begin{array}{c}\text { Solid } \\
\text { Dielectric }\end{array}$ \\
\hline $\begin{array}{l}\text { Transmission } \\
\text { Line }\end{array}$ & $\begin{array}{l}\$ 1,100,000= \\
" X "\end{array}$ & $\begin{array}{l}11.5 x= \\
\$ 1,650,000\end{array}$ & $\begin{array}{l}\alpha 1.8 \times= \\
\$ 1,980,000\end{array}$ & $\begin{array}{l}\approx 1.9 x= \\
\$ 2,090,000\end{array}$ & $\begin{array}{l}\approx 2.3 x= \\
\$ 2,530,000\end{array}$ & $\begin{array}{l}2.5 X= \\
\$ 2,750,000\end{array}$ & $\begin{array}{l}1.5 x= \\
\$ 1,650,000\end{array}$ & $\begin{array}{l}\approx 2.2 X= \\
\$ 2,420,000\end{array}$ & $\begin{array}{l}1.2 x= \\
\$ 1,320,000\end{array}$ & $\begin{array}{l}4.3 x= \\
\$ 4,700,000\end{array}$ & 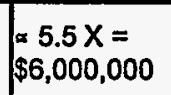 & $\begin{array}{l}3.2 x= \\
\$ 3,520,000\end{array}$ \\
\hline Substation & $\$ 2,700,000$ & $\$ 2,700,000$ & $\$ 2,700,000$ & $\$ 2,700,000$ & $\$ 2,700,000$ & $\$ 2,700,000$ & $\$ 2,700,000$ & $\$ 2,700,000$ & $\$ 2,700,000$ & $\$ 2,700,000$ & $\$ 2,700,000$ & $\$ 2,700,000$ \\
\hline Total & $3,800,000$ & $\$ 4,350,000$ & $\$ 4,680,000$ & $\$ 4,790,000$ & $\$ 5,230,000$ & $\$ 5,450,000$ & $\$ 4,350,000$ & $\$ 4,350,000$ & $\$ 4,020,000$ & $\$ 7,400,000$ & $\$ 8,700,00$ & $\$ 6,220,000$ \\
\hline
\end{tabular}

*Alternative $A$, the Proposed Action, is the only alternative for which detailed cost estimates were prepared. Multipliers (e.g., 1.5 X, $2 X$, etc.) were used to estimate the relative costs of the other alternatives. The multipliers are based on Western and Platte River's experience, the length of the route alternatives, difficulty of construction, amount of clearing, incremental costs for different structure types, and industry standards for underground construction. The multipliers were used only for the transmission line portions of the project. The substation costs would not change. 
This chapter presents a description of the study area's environmental conditions that could be affected by or affect transmission line construction, operation and maintenance. The development of project alternatives considered the information compiled for this chapter.

\subsection{Study Area Definition and Description}

The study area is comprised of approximately 3.75 square miles (approximately 2,400 acres) of land including portions of the Town of Estes Park and Larimer County (County). The study area boundaries were selected to include potential alternative routes through the Town and County between the two end points of the project, the Estes Park Power Plant Switchyard and the Marys Lake Substation. In general, the study area is bounded by U.S. Highway 36 on the north; the existing transmission line ROW, the Estes Park Tramway, and existing residential developments on the northwest; Marys Lake Road on the west and southwest; just beyond the southern shoreline of Marys Lake on the south; and Fish Creek Road on the east.

The study area consists of three distinct physiographic areas. The western portion is dominated by the steep slopes of Prospect Mountain where there are residential developments on the gentler slopes; the mid-slopes of the central portion consist primarily of residential, commercial, and transportation land uses; and the eastern portion is the Fish Creek valley and adjacent residential, public, recreation and open space land uses.

\subsection{Environmental Resources and Conditions}

The description of the affected environment is organized to discuss the environmental issues that were raised during project scoping (see Chapter 1, Section 1.3). They are discussed in their relative order of importance for this project. The issues most frequently raised during scoping are discussed first while those receiving less comment are discussed later.

The resources associated with the human environment that were assessed for impacts from the proposed project include existing and planned land use, visual resources, socioeconomics, and electrical characteristics and public safety. Assessment of the cultural environment includes a detailed survey of cultural resources. The natural resources evaluated include air quality, water resources, threatened and endangered species and wetlands/important habitats, floodplains, soils, geology, physiography, and paleontology. Limited field verification for biological resources and land use conditions were conducted as part of the analysis process.

The agencies that were consulted during the collection of data are listed in Chapter 5.0, Consultation and Coordination. Publications and other sources of information used in preparation of this Environmental Assessment are presented in Appendix A. Additional references on electric and magnetic fields (EMF) are provided in Appendix $\mathbf{F}$.

Environmental information was mapped at a scale of 1 inch equals 800 feet. The base map was derived from the USGS 1:24,000 scale ( 1 inch equals 2,000 feet) topographic 7.5 minute series quadrangles (Estes Park, Glen Haven, Longs Peak, and Panorama Peak).

The resources identified as not requiring detailed study are included at the end of this section.

\subsection{Human Environment}

\subsubsection{Land Use}

Current land use and land ownership in the project area and vicinity were mapped and tabulated. In addition, current and proposed land management plans for the area and their constraints were identified. These include the Larimer County Land Use Plan and the Estes Park Comprehensive Plan. Recreation data for the area has been updated with data from county and local sources. A field reconnaissance of 
the Marys Lake project area was conducted on May 30, 1995. Land uses along the proposed power line upgrade were identified. Land use and zoning designations for the area were also identified from land use and zoning maps provided by the Town.

Portions of the existing Marys Lake transmission line lie within the town of Estes Park, and the remainder of the line lies outside of the town limits in Larimer County. The Roosevelt National Forest surrounds Estes Park and the project area to the east and the south. The Forest boundary is located 2 miles to the east and approximately 0.8 miles to the south of Marys Lake Power Plant. A major use of the area is recreation, including activities such as sightseeing, camping, hiking, hunting, and fishing. The Estes Park area provides access to the adjacent Rocky Mountain National Park, whose east entrance is located approximately 1.5 miles northwest of the Marys Lake Power Plant along Marys Lake Road.

Most of the land along the existing transmission line ROW is private. Some of the land is owned by the federal government. The land around Marys Lake and Lake Estes, including both power plants, is administered by the U.S. Bureau of Reclamation. A portion of the transmission line corridor outside the Town limits is also owned by the U.S. Bureau of Reclamation.

The Larimer County Land Use Plan was adopted in 1988 for the purpose of guiding development decisions in the unincorporated area of Larimer County. The plan has designated the Town of Estes Park and the surrounding valley area with the land use category of Municipal Expansion Area/ Urban Development Area. This classification provides areas for projected future municipal boundaries. Within these areas, general urban development is expected, including commercial, residential, industrial and public uses. However, within Estes Park, densities are lower than those found in and adjacent to other municipalities in the county and densities within the projected future boundaries are expected to be the same as those in the existing areas.

The Estes Park Draft Comprehensive Plan has been developed and is currently being reviewed for approval in order to prepare the final draft. The Plan was designed to meet the needs of the entire Estes Valley. The Plan study area consists of the town of Estes Park and the areas within Larimer County that are inside the geographic confines of the Valley, including the entire proposed project area. The Plan emphasizes the desires of the community in relation to the physical and natural features of the area. Community values such as the desire for a strong commercial core are balanced with the desire to minimize development in sensitive areas.

Existing Land Use. Existing land uses in the project area consist primarily of residential, institutional, commercial, recreation and open space, and agriculture (grazing). These uses are generally sensitive to the construction and operation of a transmission line. Existing land uses in incorporated and unincorporated portions of the project area were provided by the Estes park Community Development Department and are shown in Figure 3-1. Approximately 0.6 miles of the northern portion of the transmission line is located within the town limits of Estes Park. The remaining 2.4 miles are located south and west of the town limits in unincorporated Larimer County.

Residential subdivisions and isolated residences are located throughout the project area. The Town of Estes Park is located in the northern and eastern portions of the project area, and includes moderate and high density residential areas. Residential areas are also located west of Prospect Mountain in the western part of the project area. Isolated residences are scattered throughout most of the project area. Most of the project area is zoned for residential uses (Figure 3-2). Residential zoning designations within the Estes Park town limits include single family residential, multi-family residential, condominium, and residential unimproved. The Larimer County zoning designation of Estate consists of a residential use with a density of 5 acres per unit. In the project area, most of the condominium and multi-family residences are located along Colorado Highway 7.

There are approximately 89 residences along links 2 and 3 of the existing ROW, all of which were constructed after the existing transmission lines were built. There are approximately 7 new residences adjacent to or crossed by the ROW along links 2 and 3. (Refer to Table 1 in Appendix G.) 


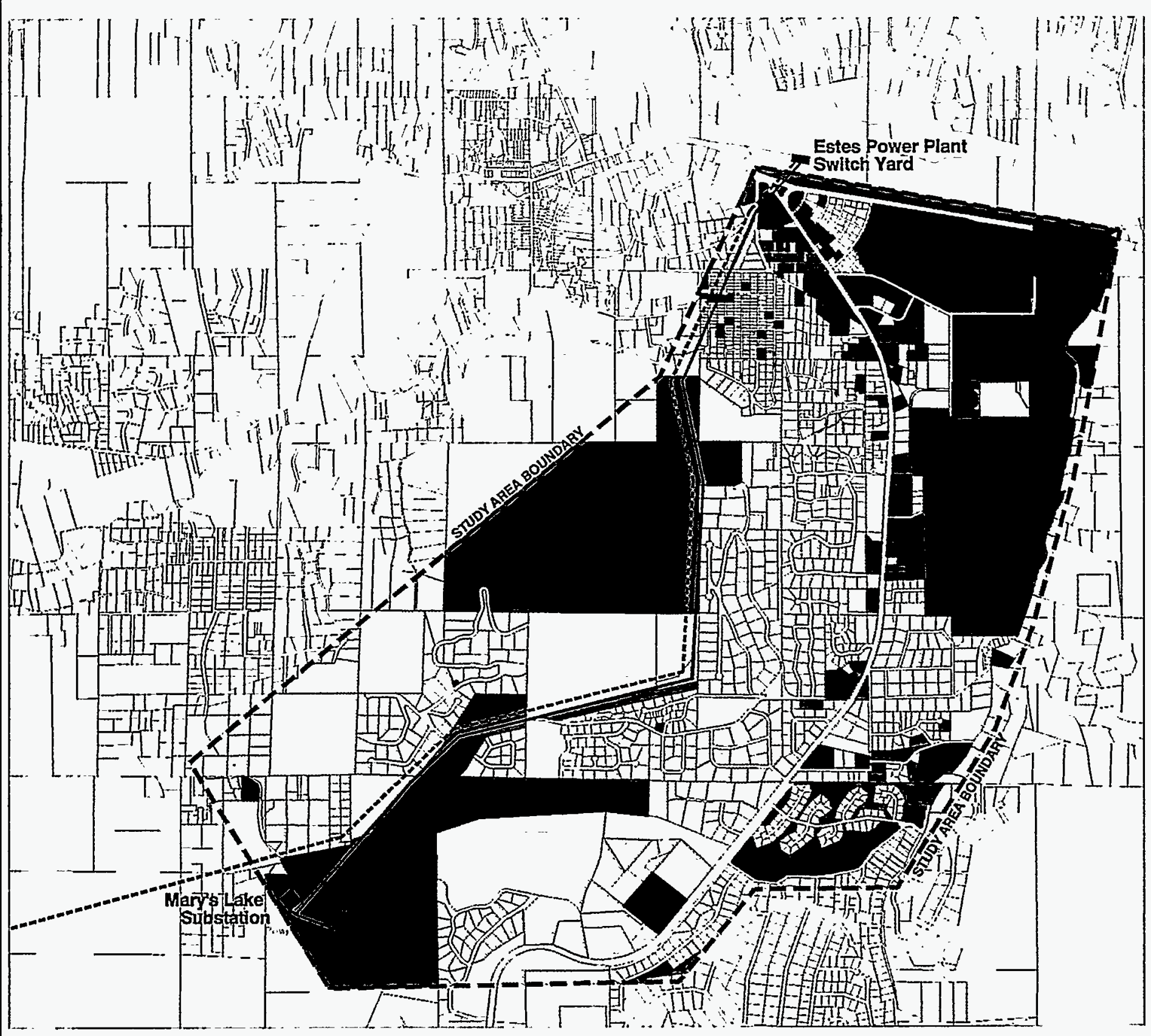

Platte River Power Authority and

Western Area Power Administration

Marys Lake

69/115 kV Transmission Line Upgrade and Substation Expansion Projects

LEGEND

\begin{tabular}{|c|c|}
\hline ACCOMMODATIONS & MULTPLEFAMILY \\
\hline AGRICULTURE & OFFCE \\
\hline COMMERCHAL & RESIDENTRLL UNIMPROOVED \\
\hline COMMERCAL UNDEVELOPED & $\begin{array}{l}\text { RETALL } \\
\text { SINGIE FAMUYYRESDENTAL }\end{array}$ \\
\hline INSTTUTIONAL & \\
\hline
\end{tabular}

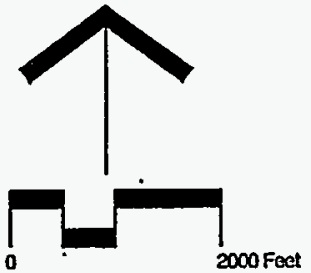

EXISTING LAND USE 
This page is intentionally left blank. 


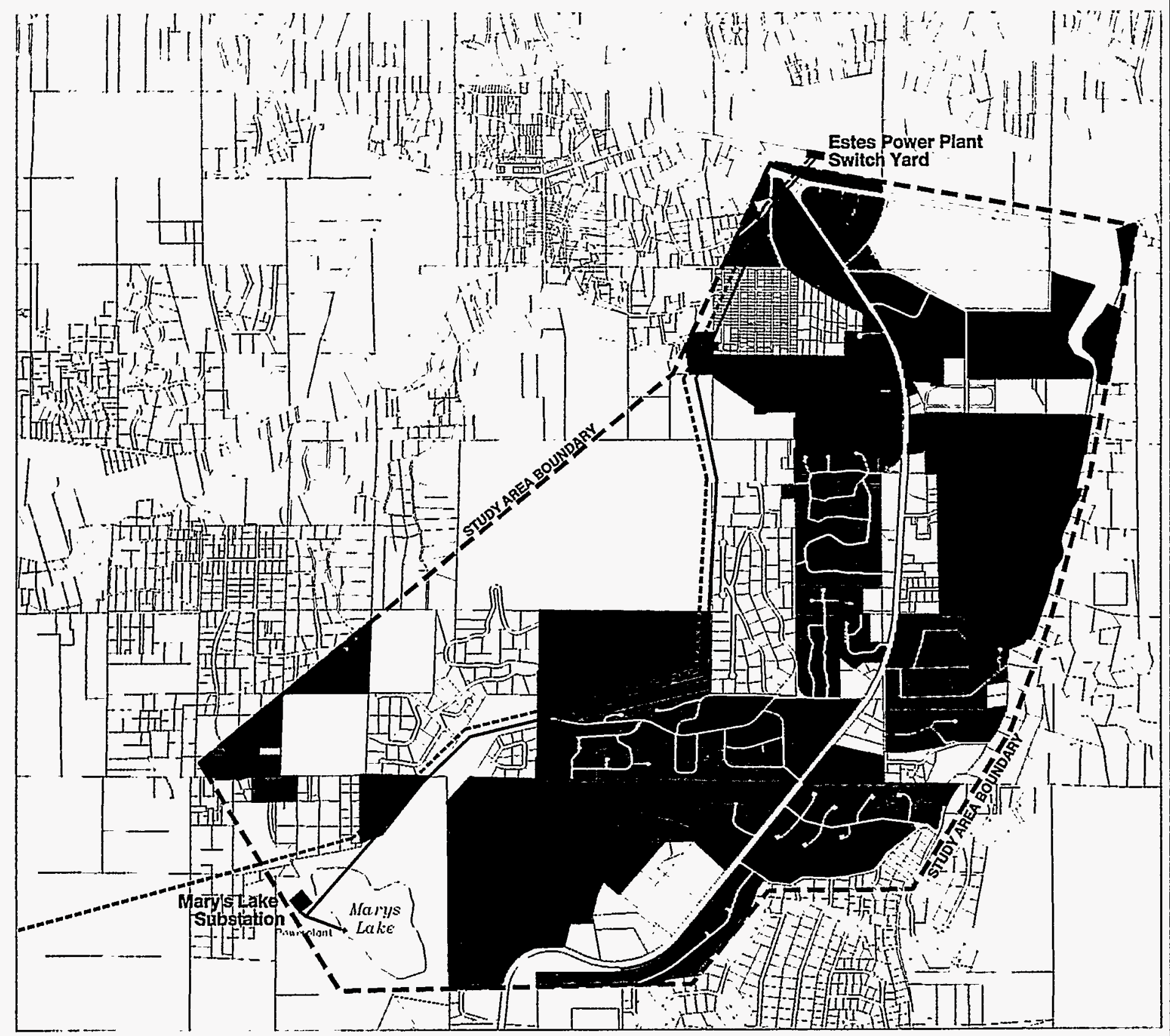

Platte River Power Authority and Western Area Power Administration

69/115 kV Transmission Line Upgrade and Substation Expansion Projects

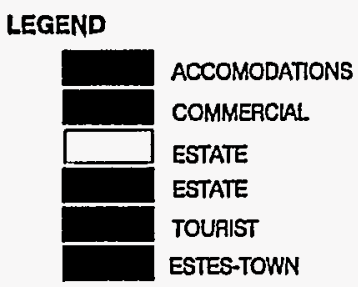

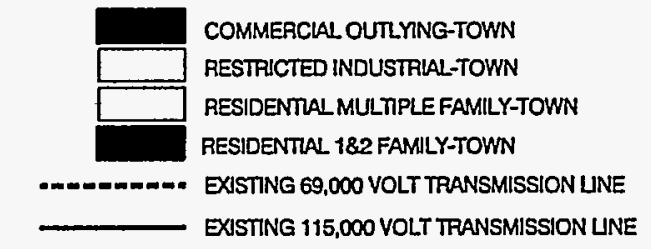

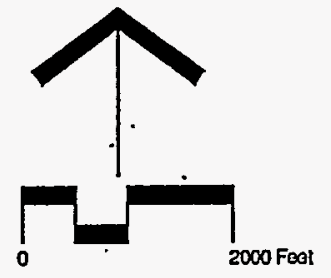

EXISTING TOWN OF ESTES PARK AND LARIMER COUNTY ZONING 
This page is intentionally left blank. 
Institutional land uses include schools, hospitals, and government owned land or facilities. In the project area, the largest areas of institutional uses include lands adjacent to Marys Lake and Lake Estes. Within Estes Park, areas zoned for institutional uses consist of municipal land and facilities, including schools and hospitals. A large institutional use area occupies the land south of U.S. Highway 36 and Lake Estes, between Colorado Highway 7 and Fish Creek Road. The area contains municipal recreational facilities, and an elementary school, a middle school, and a high school. Other institutional facilities located within the Town limits include a hospital, a water treatment plant, the municipal building, and police and fire protection facilities. Electric power plants are located at Marys Lake and at Lake Estes. The open space surrounding the power plants and transmission facilities at both lakes are also used for recreation.

Commercial and retail development is clustered in the northern portion of the project area, close to downtown Estes Park along U.S. Highway 36 and Colorado Highway 7. Commercial establishments are also sparsely scattered throughout the area. The Town and the county have designated these land use areas as commercial, commercial undeveloped, retail, office, and accommodations. About four percent of the existing line crosses through lands within the town limits that are zoned for commercial use. As shown on Table G-1 in Appendix G, there are approximately 5 commercial parcels adjacent to or crossed by the existing ROW along links 1,2 and 3.

Estes Park and the adjacent Rocky Mountain National Park are popular destinations for people seeking a variety of recreation activities. Numerous recreation opportunities exist on public lands in the vicinity of Estes Park, and include sightseeing, hiking, camping, picnicking, fishing, hunting, cross-country skiing, mountain climbing, and bicycling. The number of visitors utilizing these opportunities in the Rocky Mountain National Park was 3,153,695 in 1994 (Estes Park, 1995). There are five campgrounds in the park which include 577 sites in the summer and 186 sites in the winter. There are seven private campgrounds in the Estes Park area. Lodging and accommodations in the Estes Park area include 110 lodging establishments and 3,500 rooms.

The town features several attractions for both residents and visitors. Recreation sites within the project area include an aerial tramway to the top of Prospect Mountain; camping and fishing at Marys Lake; and boating, fishing, picnicking, and a hiking trail at Lake Estes. The area south of Lake Estes, between Colorado Highway 7 and Fish Creek Road includes a museum, Stanley Park, rodeo grounds, and a golf course. There is a paved biking and hiking path along Colorado Highway 7 within the town limits. An unpaved trail is located along Fish Creek, and is used for hiking, horseback riding, and biking. Figure 3-3 shows recreation facilities in the project area.

Marys Lake Campground is located on the north side of the lake, east of Peak View Road, across from the existing transmission line. The facilities include a campground with 150 sites, which accommodate tents and RVs between May 15 and September 30 . Fishing on the lake is for brown and rainbow trout. There is no boating on the lake.

The Estes Power Plant and the Estes Power Plant Switchyard are located on the southwestern side of Lake Estes. The lake is a regional recreational area, and features several recreation facilities. There are several picnic areas located around the lake. The nearest of these to the power plant facilities is the Cherokee Draw picnic area, the western edge of which lies about 800 feet east of the switchyard. The Lake Estes Golf Course is located on the north side of the lake, across from the power plant. The Lake Estes Trail is a pedestrian and bicycle path along the northern border of the lake. It connects with the Estes Park Downtown Riverwalk. In addition, there is fishing and boating on the lake. The Lake Estes Marina is located on the northeastern shore of the lake.

There are no other areas of special concern located in the vicinity of the proposed transmission line. The project is not located in or near any Wilderness Area or Wilderness project area. The nearest wilderness area is the Cache la Poudre located approximately 15 miles northeast of the project area. The project route does not cross any existing or potential wild and scenic rivers.

Portions of the project area in unincorporated areas have been designated as agricultural use areas. Agriculture in the Estes Valley consists primarily of grazing. Some land in the vicinity of Marys Lake is used for grazing horses. The designated land use for Prospect Mountain, located in the center of the project area, is also agriculture. However, there is no evidence of any agricultural use of Prospect Mountain. The agricultural portions of the project area are surrounded by residential developments. 
There are several child care facilities located in Estes Park. Most of these are located in the vicinity of the three schools in the area south of Stanley Park.

There are several areas of open space located along the existing transmission line ROW. These areas are not formally designated as open space, and are either located on government-owned lands or on private lands zoned for residential use. Some of the public lands contain recreation facilities. Included are Bureau of Reclamation lands located at both ends of the existing transmission line around Marys Lake and Lake Estes. These lands contain recreational facilities operated by the Estes Valley Recreation and Park District (EVRPD), which include the Lake Estes Marina, a 9-hole golf course, and picnic facilities at Lake Estes. The EVRPD also maintains an 18-hole golf course on Colorado Highway 7, the picnic and softball area at Stanley Park, tennis courts, a swimming pool operated jointly with schools, and Marys Lake Campground. Lake Estes Marina and Marys Lake Campground are leased to private operators.

Other open space areas along the existing transmission line ROW are not designated or zoned for recreational use, but may be informally used by the public for recreation, or as alternative routes used as shortcuts. Prospect Mountain consists of a large area of open space on private lands on the slopes above existing residential use areas. Trails cross the slopes, originating primarily from the residences below. Rock climbing occurs on bolted routes on rock outcrops near the summit of the mountain. Open space within the town limits are located along the existing transmission line ROW on the west side of the Stanley Avenue crossing. A well defined trail crosses the space, indicating regular use. Within both the Town limits and residential subdivisions in the unincorporated areas, the existing transmission line ROW adjoins the yards of several residences.

Local electric distribution lines are located throughout the project area. These lines are shown on Figure 1-1.

U.S. Highways 34 and 36 are the primary transportation routes through Estes Park. U.S. Highway 34 is an east-west route that connects the Estes Valley with the cities of Loveland and Greeley to the east. The highway is the primary access route into Rocky Mountain National Park, and continues through the park as the Trail Ridge Road. U.S. Highway 36 is a north-south route that connects Estes Park to Boulder and Denver to the south. The two highways converge at the eastern entrance to the park.

Access to the project area is available from several state, county, and city roads. The primary route through the project area is Colorado Highway 7 , which is a north-south road connecting Estes Park with Allenspark to the south. Numerous side roads connect the highway with residential and commercial areas within the project area.

\section{Planned Land Use}

Planned uses in the proposed project study area were determined from zoning maps (Figure 3-2), field observations, and interviews with local planning officials. Future development of Estes Valley would probably follow the existing pattern of compact or urban development close to the downtown core of Estes Park. Development as one moves away from the downtown area would also follow the existing pattern of lower density commercial, accommodation and residential uses. Future development in the Valley is constrained by environmental features such as steep slopes, visually sensitive areas, and wildlife and flood hazards. In recognition of Estes Park's role as the gateway community to Rocky Mountain National Park, lands in the vicinity of the park are proposed to have lower densities of development in order to provide a transition to park lands.

Future development in the currently undeveloped portion of Prospect Mountain would be limited due to the constraints of steep slopes and the high visibility of the area. The area would most likely continue as open space.

The Marys Lake area is developed primarily with low density residential uses. The area provides a transition between the more intensely developed portions of Estes Valley and rural areas, and is located near the natural resources of Larimer County public lands, including Rocky Mountain National Park, National Forest lands and Bureau of Reclamation land. Future development in this area will be consistent with existing uses. 


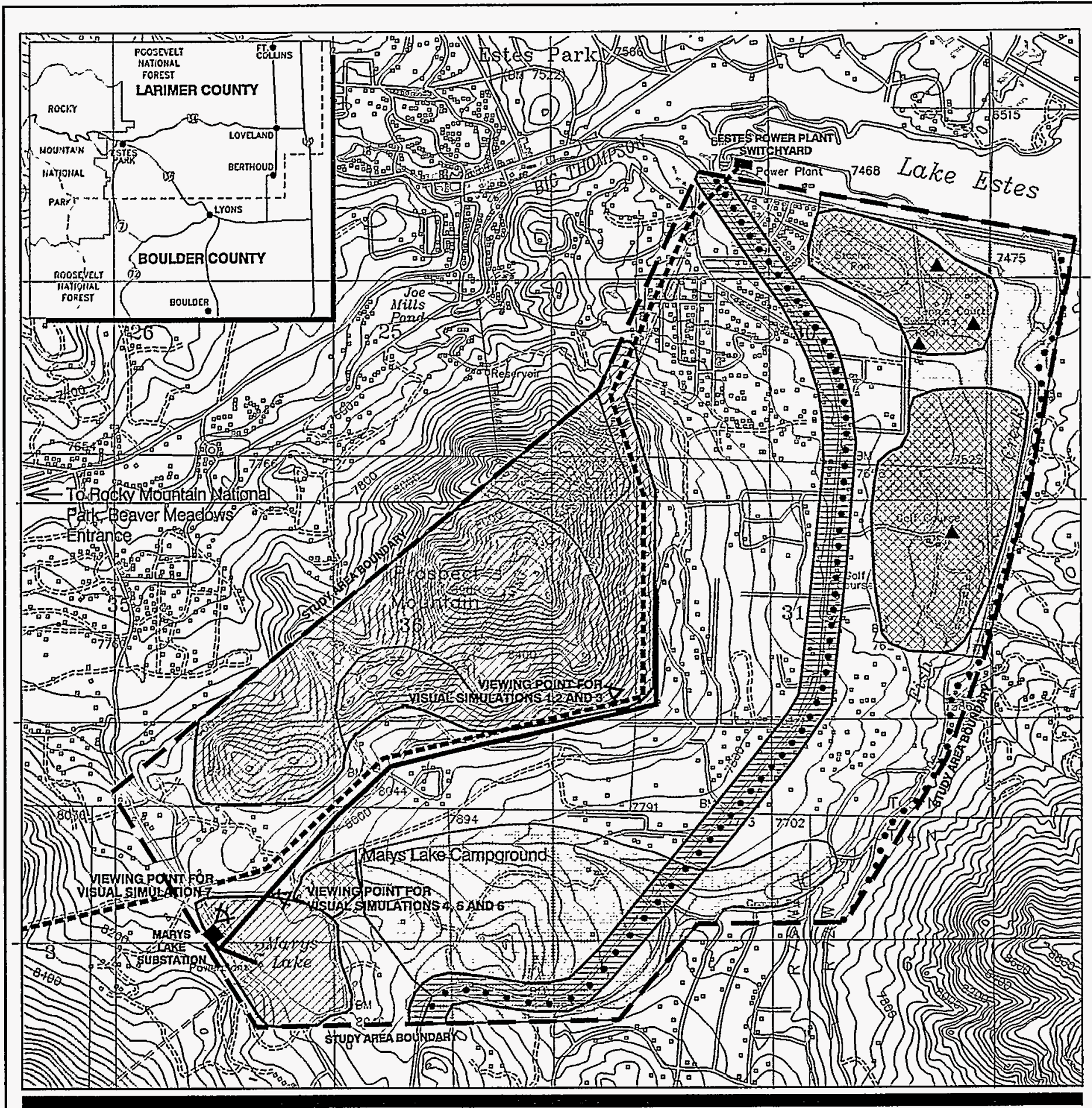

Platte River Power Authority and

Western Area Power Administration

Marys Lake

69/115 kV Transmission Line Upgrade and Substation Expansion Projects

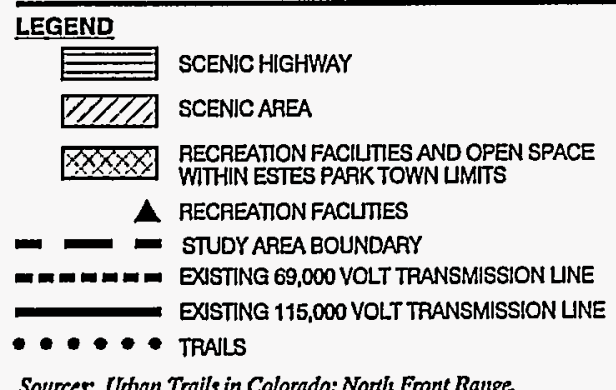

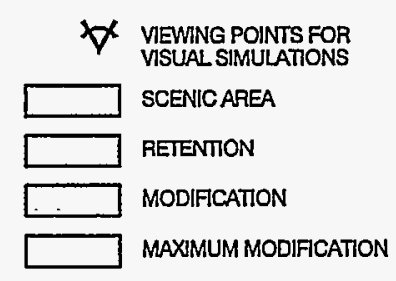

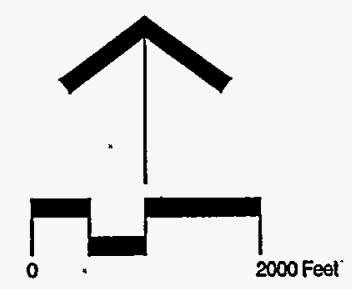

VISUAL RESOURCES

Figure 3-3 
This page is intentionally left blank.

$3-10$ 
In general, future development in the Valley will be consistent with and accommodate existing land uses, such as the existing Marys Lake transmission line.

\subsubsection{Electrical Characteristics and Public Safety}

Western and Platte River are committed to programs and policies that ensure a safe and healthy environment. Safety and health are essential elements of the working environment and are demonstrated daily in everyday work practices. Western and Platte River are both concerned with the health of their employees and the general public. This section discusses the electrical characteristics of transmission lines and the possible effects on public health and safety.

The electrical characteristics of the environment around transmission lines and substations are primarily due to the electric and magnetic fields (EMF) associated with the voltage and current running through the facilities. An electric field is associated with the voltage, and a magnetic field is associated with the current. Because the current and voltage on alternating current $(A C)$ transmission lines in the United States oscillate at a frequency of $60 \mathrm{Hertz}(\mathrm{Hz})$ or 60 cycles per second, the electric and magnetic fields also oscillate at $60 \mathrm{~Hz}$.

EMF extend out from the conductors of transmission lines and the substation equipment and decrease as distance from the facilities increases. The relative strength of the fields in the vicinity of the facilities is influenced by the location on the property or ROW, the arrangement and spacing of the electrical conductors, and the voltage and current on the line, as well as other engineering considerations.

The electric field at the surface of the conductors is responsible for an effect known as "corona" occurring at that location. Corona is the electrical breakdown of the air into charged particles. Corona may result in audible noise (AN), electromagnetic interference in the form of radio interference or television interference (RI/TVI), and visible light.

The EMF at ground level are responsible for induced currents and voltages. These phenomena are commonly referred to as field effects.

Analysis of the electrical characteristics of the existing environmental setting was conducted for the $\mathrm{H}$ frame configuration shown in Figure 2-4. The minimal conductor ground clearance used for analyzing characteristics was 22 feet. The assumptions and conditions for calculating all of the electrical characteristics associated with the existing transmission lines are identified in Appendix $F$.

Corona. The electric field from the energized conductors of a transmission line may cause corona to occur on the conductors, insulators, and hardware of electric lines. Corona is a "luminous discharge due to the ionization of the air surrounding a conductor caused by the voltage gradient exceeding a critical value. ${ }^{n 4}$ Corona on conductors occurs where the field has been enhanced by protrusions such as nicks, insects, or water drops. During fair weather, the number of these protrusions is small, and corona is insignificant. However, during rain and fog, the number of these protrusions increases substantially because of raindrops and condensation on the surface of the conductors. Therefore, corona is more likely to occur during wet weather.

Corona effects include audible noise (AN), communication interference, visible light, and photochemical oxidants. Corona from transmission lines has been studied extensively. The equations used to evaluate corona levels have been verified and shown to accurately represent the corona performance of the existing transmission lines. The parameters of importance in the calculations are the line voltage, line configuration or geometry, number and diameter of the conductors, and the weather conditions.

Audible Noise (AN). Corona-generated AN from transmission lines is generally characterized as a crackling, hissing, or humming noise. The noise is most noticeable during wet conductor conditions such as rain or fog. Since each oscillation of the $60 \mathrm{~Hz}$ power frequency cycle has both a positive and negative peak on the sinusoidal wavelength, this creates a $120 \mathrm{~Hz}$ hum that is also present during wet weather. During fair weather, AN from $69-\mathrm{kV}$ and $115-\mathrm{kV}$ transmission lines is a very sporadic crackling sound

4 IEEE Standard Dictionary of Electrical and Electronics Terms, ANSI/IEEE Std. 100-1988, Fourth Edition, (1988). 
which is barely perceptible. Transmission line AN is measured and predicted in units of decibels (Aweighted), abbreviated dBA. The A-weighted sound level scale weights the various frequency components of a noise to correspond to the way that the human ear responds, or hears the noise.

Transmission line noise is commonly expressed in terms of exceedance levels; e.g., L50 refers to the noise levels in dBA that are exceeded 50 percent of the time. Separate exceedance levels are generally given for fair weather and wet weather. The L50 wet weather level corresponds closely to an average value over all wet weather conditions for a long period of time, usually one year. The overall average noise level depends on the amount of foul weather at a particular location.

AN levels for the edge of the ROW of the existing lines during fair and wet weather are shown on Table 31. The average (L50) values for wet weather at the edges of the ROW of the existing 115-kV line and 69$\mathrm{kV}$ line are 35.2 and $29.1 \mathrm{dBA}$ respectively. The calculated average fair weather noise levels at the edges of the ROW are 10.2 and $4.1 \mathrm{dBA}$ for the $115-\mathrm{kV}$ and $69-\mathrm{kV}$ lines respectively.

Table 3-1

Audible Noise (AN) Levels

\begin{tabular}{llcc} 
& Location & $\begin{array}{c}\text { Fair Weather L50 } \\
\text { AN (dBA) }\end{array}$ & $\begin{array}{c}\text { Wet Weather L50 } \\
\text { AN (dBA) }\end{array}$ \\
\hline \hline Existing 69/115-kV & East/South Edge ROW (115-kV) & 10.2 & 35.2 \\
Transmission & West/North Edge ROW (69-kV) & 4.1 & 29.1 \\
Lines & Maximum in ROW & 10.7 & 35.7 \\
\hline
\end{tabular}

Typical noise levels encountered in everyday life are shown on Table 3-2.

Table 3-2

Audible Noise Decibel Ratings of Some Common Noises

\begin{tabular}{|c|c|c|c|}
\hline $\begin{array}{l}\text { Typical Decibel } \\
\text { Level (dBA) }\end{array}$ & Common Noises & & Resulting Effect \\
\hline 0 & Lowest Level Audible to Human Ear & & Audible Noise From \\
\hline 30 & Quiet Library, Soft Whisper & ه & Electric Transmission \\
\hline 40 & Quiet Office, Living Room & & \\
\hline 50 & Light Traffic, Refrigerator & & Lines Generally Occurs in \\
\hline 60 & Air Conditioner, Conversation & ه & This Range \\
\hline 70 & Busy Traffic, Noisy Restaurant & $\leftrightarrow$ & Critical Level Begins \\
\hline 80 & Subway, Heavy City Trafiic & & \\
\hline 90 & Truck Traffic, Shop Tools, Lawn Mower & & \\
\hline 100 & Chain Saw, Pneumatic Drill & & \\
\hline 120 & Rock Concert, Thunderclap & ه & Danger Level \\
\hline 140 & Jet Plane & & \\
\hline 180 & Rocket Pad During Launch & ه & Hearing Loss \\
\hline
\end{tabular}

Source: American Academy of Otolaryngology.

Radio Interference/Television Interference (RI/TVI). Corona on transmission line conductors can generate electromagnetic noise at the frequencies at which radio and television signals are transmitted. 
This noise can cause interference (primarily with AM radio stations) with the reception of these signals and is called radio interference (RI) and television interference (TVI), depending on the frequency.

Another more prevalent source of RI and TVI from electrical systems is spark gaps on distribution and low voltage transmission lines. If for some reason, such as mechanical failure, vibration, or corrosion, a connection between two parts that is usually conducting becomes nonconducting, a voltage can develop across the gap between the two components. If the voltage is large enough, a spark occurs which may generate RI, TVI, and sometimes AN. This type of interference is primarily a fair weather phenomenon. Water tends to short out the gaps during foul weather. Spark gaps will occur more often on old lines with loose or damaged hardware, or dirty insulators, than on new lines. Western conducts routine maintenance on transmission lines to minimize these occurrences.

Corona-generated interference can conceivably cause disruption on other communication bands such as the citizens (CB) and mobile bands. However, complaints or interference from transmission lines to $C B$ radio are rare. This is because the high operating frequency of $C B$ (about 27 megaHertz, $M H Z$ ) is above the frequency of most corona-generated noise. A more likely cause of interference to $C B$ is spark gaps on a transmission or distribution line. Mobile radio communications are not susceptible to transmission line interference because they are generally frequency modulated (FM). Routine maintenance also minimizes these occurrences.

Visible Light. Corona is visible as a bluish glow or as bluish plumes. Corona on the conductors of the existing transmission lines may be observable under the darkest and/or wettest conditions, when the corona is most intense. Even then, it would probably be visible only with the aid of binoculars. Without a period of adaptation for the eyes, and without intentionally looking for the corona, it is generally not noticeable on lines below 345-kV.

Photochemical Oxidants. When corona is present, the air surrounding the conductors is ionized and chemical reactions may take place producing small amounts of ozone and other oxidants. Measurements in the laboratory and near transmission lines have shown that the amount of oxidants produced by operating transmission lines is usually not measurable for $230-\mathrm{kV}$ lines and is barely measurable for larger lines.

Electric Fields. The electric field associated with a high voltage transmission line extends from the energized conductors to other objects such as the ground, towers, vegetation, buildings, and vehicles. The electric field strength is associated with the voltage of the transmission line and is expressed in units of volts $/$ meter $(\mathrm{V} / \mathrm{m})$ or kilovolts $/$ meter $(\mathrm{kV} / \mathrm{m})$. The unperturbed electric field at a height of one meter, or 3.3 feet, above the ground is used to describe the field under transmission lines. This quantity is easily measured or calculated. The most important parameters for determining the ground level electric field of a transmission line are conductor height above ground, line voltage, and phasing of nearby conductors.

Because of practical considerations, measured values of electric fields can, and do, deviate slightly from calculated values. Nearby objects can significantly shield (reduce) the electric field near ground level..$^{5}$ It is common practice to calculate the electric fields for a line under specific operating conditions. The computed electric field profiles at 1 meter above ground for the existing conductor configurations are shown on Table 3-3. The maximum electric field in the ROW at the smallest conductor ground clearance of 22 feet is approximately $1.53-\mathrm{kV} / \mathrm{m}$. As shown in Table 3-3, the resultant maximum edge of ROW electric field is also approximately $1.53-\mathrm{kV} / \mathrm{m}$.

3 Deno \& Silva (1987). 
Table 3-3

Electric Field Levels

\begin{tabular}{cccc}
\hline Location & $\begin{array}{c}\text { East/South } \\
\text { Edge of ROW } \\
(\mathbf{k V / m}) \\
\mathbf{1 1 5 - k V}\end{array}$ & $\begin{array}{c}\text { West/North } \\
\text { Edge of ROW } \\
(\mathbf{k V} / \mathrm{m}) \\
\mathbf{6 9 - k V}\end{array}$ & $\begin{array}{c}\text { Maximum in } \\
\text { ROW (kV/M) }\end{array}$ \\
\hline \hline $\begin{array}{c}\text { Existing 115-kV and 69-kV } \\
\text { Transmission Lines }\end{array}$ & 1.53 & 0.90 & 1.53 \\
\hline
\end{tabular}

The National Electrical Safety Code (NESC), in effect, limits the maximum electric field under transmission lines with voltages greater than $98-\mathrm{kV}$. It requires that the conductor clearance at a conductor temperature of $120^{\circ} \mathrm{F}$ be sufficient to keep the induced short-circuit current to the largest anticipated vehicle to less than 5 milliamperes $(\mathrm{mA}){ }^{6}$ Because the induced current is proportional to the electric field, this criteria establishes the maximum field that can occur for a known vehicle.

Shock Hazards. By far, the greatest hazard from transmission lines is direct contact with the conductors. Powerlines, as with electrical wiring in homes and businesses, can cause serious electric shocks if precautions are not taken to minimize shock hazard. All of Western and Platte River's transmission lines are designed and constructed in accordance with the NESC standards. The NESC standards specify the minimum allowable distance between the lines and the ground or other objects. These requirements determine the edge of the ROW, the height of the conductors, and the closest point to the conductors that buildings and vehicles can safely be allowed.

Still, extreme caution must be taken when operating tall equipment, such as cranes and drilling equipment, and when moving irrigation pipe near any powerline. Vehicles and large equipment up to 15 feet in height, including antennas, can normally travel safely under Western and Platte River's transmission lines. Trees adjacent to transmission lines should not be felled onto the lines. Kites should not be flown near transmission lines, and only nonmetallic string should be used. Western and Platte River provide free information for people living near transmission lines; Western's booklet is titled "Living and Working Around High Voltage Power Lines." This booklet is available from Western's Loveland Area Office (1-800472-2306).

Irrigation systems can be operated safely near transmission lines if certain precautions are taken:

- Irrigation equipment should not be raised to a vertical position anywhere near a powerline since irrigation pipe is often long enough to reach within flashover distance of the conductors.

- Steady streams of water contacting the conductor can provide a direct path to ground for the current or flashover. Therefore, irrigation nozzle risers should be equipped with spoilers and automatic shutoffs.

- Magnetically induced voltages can occur on long sections of irrigation pipe and other metallic, conducting, objects such as fences. Maintenance of long pipe systems should be done perpendicular to the transmission line and the system should be grounded at each end.

- Transferred potential during electrical faults can be avoided by not burying portions of the irrigation system or pipe near structures or structure grounding systems.

When there is any doubt, questions should be referred to Western at 1-800-472-2306.

Large fires near transmission lines represent a potential electrical hazard. Hot gases and smoke can create a conductive path to ground. Flashovers can cause electrical shocks to people near the line and also cause outages. Storage of flammables and construction of flammable structures on Western or

- National Electrical Safety Code (1993) ๆ232D3c. 
Platte River's ROW are prohibited. Refueling should not be done near transmission lines unless necessary. If refueling is necessary, proper grounding is recommended. Transmission lines can interfere with circuits used to detonate explosives, and explosives can also damage power lines. Western or the local utility should be contacted before initiating blasting.

Tall objects, including transmission line structures, are the most likely points to be struck by lightning during a thunderstorm. Western and Platte River transmission lines are designed with overhead ground wires and grounded structures to protect the system from lightning. If lightning strikes the overhead ground wire, the strike is conducted to ground at the structure locations.

Induced Currents. When a conducting object, such as a vehicle, is in an electric field, currents and voltages are induced, or flow, in the object. The magnitude of the induced current depends on the electric field strength, the size and shape of the object, and the degree of grounding. ${ }^{7}$ If the object is completely grounded, then the induced current flows to earth and is called the short-circuit current of the object. In this case, the voltage on the object is effectively zero. If the object is completely insulated (not grounded), then it assumes some voltage relative to ground. These induced currents and voltages can represent a potential source of nuisance shocks.

Steady-State Currents. Steady-state currents are those that flow continuously after a person contacts an object and provides a path to ground (acts as a conductor) for the induced current. The response of persons to such currents has been extensively studied and levels of response documented. ${ }^{8}$ Primary shocks are those that can result in direct physiological harm. The lowest category of primary shocks is "let go" which represents the steady-state current that cannot be released voluntarily. The let go threshold was established for adult males at 9.0 milliAmperes $(\mathrm{mA})$ and $6.0 \mathrm{~mA}$ for adult females. These thresholds have been established for adult men weighing 180 pounds and adult women weighing 120 pounds. Let go thresholds for adults have been established from actual experimentation. Thresholds for children, however, have been derived from the data for adults, since no actual measurements were taken from children. The derivation of a threshold for children was based on body weight, and is generally accepted as $5.0 \mathrm{~mA}$ - the value adopted by the NESC. No information is readily available on the body weight of the children for whom the $5.0 \mathrm{~mA}$ threshold was adopted. Primary shocks are not possible from the induced currents under the existing lines because of the relatively low field strengths and the grounding practices of Western.

Spark Discharge Shocks. Induced voltages appear on objects such as vehicles and people partially insulated from ground by non-conducting materials such as rubber tires or shoe soles. If the voltage is sufficiently high, then a spark discharge shock will occur when two objects come very close together (withing a fraction of a centimeter). ${ }^{9}$ Such shocks are similar to "carpet" shocks, which occur when reaching for a door knob after walking across a carpet on a dry day. Spark discharge shocks theoretically could occur under the existing and proposed transmission lines. However, the magnitude of the electric field is low enough that this type of shock rarely occurs and then only under certain conditions.

Handling conducting objects under the transmission line can also result in spark discharges that are a nuisance. Irrigation pipe, and other similar objects, should be carried as low to the ground as possible and preferably unloaded at a distance from the transmission lines to eliminate spark discharge nuisance shocks. The primary hazard with irrigation pipe, and other similar objects, is direct contact with the conductors.

Magnetic Fields. The magnetic field associated with a high voltage transmission line surrounds the conductor and decreases with increasing distance from the conductor. The magnetic field is expressed in units of magnetic flux density or gauss $(G)$, or milligauss $(m G)$. The magnetic field at a height of 1 meter, or 3.3 feet, above the ground is used to describe the magnetic field under transmission lines. This quantity can be measured or calculated. The most important parameters for determining the ground level

7 Deno \& Silva (1984), Silva, et al. (1985).

- E. G., Keesey (1969).

- Deno \& Silva (1985). 
magnetic field of a transmission line are conductor height above ground, the proximity of other conductors, and the current flowing in the conductors.

When public concerns about fields from powerlines were first raised over 20 years ago, the focus was on electric fields. Subsequent research has suggested that magnetic fields are probably more important to study. Although electric fields are easily shielded by trees, buildings, etc., magnetic fields can not be shielded. Magnetic fields travel through most materials including iron, steel, lead and the earth's soil. In fact, the earth exhibits a static, or direct current (DC) magnetic field resulting from charges moving deep within the molten core of the planet. The earth's magnetic field in northern Colorado is approximately 550 mG.

Table 3-4 provides the calculated magnetic field levels at 1 meter above the ground for the existing $69 / 115-k V$ transmission lines. Since the magnetic field levels are directly influenced by source current, these calculations have been performed for a variety of loading scenarios. As the table shows, the maximum field at the edge of the ROW for peak operations and peak loading is $47.10 \mathrm{mG}$.

Table 3-4

Magnetic Field Levels

\begin{tabular}{cccc}
\hline Location & $\begin{array}{c}\text { East/South } \\
\text { Edge of ROW } \\
(\mathrm{mG}) \\
115-\mathrm{kV}\end{array}$ & $\begin{array}{c}\text { West/North } \\
\text { Edge of ROW } \\
(\mathrm{mG}) \\
\text { 69-kV }\end{array}$ & $\begin{array}{c}\text { Maximum in } \\
\text { ROW (mG) }\end{array}$ \\
\hline \hline $\begin{array}{c}\text { Existing 69-kV and 115-kV } \\
\text { Transmission Lines }\end{array}$ & 14.88 & 47.10 & 54.23
\end{tabular}

Table 3-5 provides the magnetic field levels of common household appliances. As Tables 3-4 and 3-5 demonstrate, the magnetic field levels from the existing lines are similar to those encountered in everyday life.

Magnetically Induced Currents and Voltages. Alternating magnetic fields induce voltages at the open ends of conducting loops. The conducting loop can be formed by a fence, an irrigation pipe, a pipeline, an electrical distribution line, a telephone line, and other similar objects. The earth, to which one end of the conductor is grounded, forms the other portion of the loop. The possibility for a shock exists if a person closes the loop at the open end by contacting both the ground and the conductor. However, electric fields, and not magnetic fields, are the predominant source of induced currents.

Magnetically induced currents from powerlines have been extensively investigated. ${ }^{10}$ Shocks due to magnetically induced currents and voltages are of the same type as those due to electric field induced currents and voltages. In the case of magnetic induction, the voltages are generally quite low, and the currents are limited as compared to those induced by electric fields.

io See e.g., IEEE (1974); Taflove \& Dabkowski (1979); Taflove, et al. (1979); Jaffa \& Stewart (1981); Jaffa (1981); Olsen \& Jaffa (1984). 
TABLE 3-5

Magnetic Field Environment

\begin{tabular}{|c|c|c|}
\hline Sources of Exposure * & $\begin{array}{l}\text { Typical Range of Exposure } \\
\text { ( } \mathrm{mG} \text { ) }\end{array}$ & $\begin{array}{l}\text { Maximum Range of Exposure } \\
\text { (mG) }\end{array}$ \\
\hline Electric Alarm Clock & $1-12$ & $50-450$ \\
\hline Electric Blanket & $3-50$ & $65-250$ \\
\hline Waterbed Heater & $1-9$ & $20-51$ \\
\hline Electric Shaver & $50-300$ & $500-6875$ \\
\hline Hair Dryer & $1-75$ & $112-2125$ \\
\hline Sewing Machine & $1-23$ & $26-1125$ \\
\hline Computer & $1-25$ & 1875 \\
\hline Circular Saw & $19-48$ & $84-562$ \\
\hline Electric Drill & $56-194$ & $300-1500$ \\
\hline Clothes Dryer & $1-24$ & $45-93$ \\
\hline Clothes Washer & $1-10$ & $12-20$ \\
\hline Vacuum Cleaner & $1-11$ & $15-60$ \\
\hline Ceiling Fan & $1-11$ & 125 \\
\hline Stereo & $4-100$ & $200-500$ \\
\hline Television & $1-3$ & $5-100$ \\
\hline Portable Heater & $1-10$ & $100-200$ \\
\hline Refrigerator & $1-8$ & $12-187$ \\
\hline Electric Can Opener & $30-225$ & $288-2750$ \\
\hline Microwave Oven & $3-40$ & $65-812$ \\
\hline Dishwasher & $1-15$ & $28-712$ \\
\hline Electric Mixer & $2-11$ & $16-387$ \\
\hline Oven & $1-8$ & $14-67$ \\
\hline Garbage Disposal & $1-5$ & 8-33 \\
\hline Electric Range & $1-80$ & $175-625$ \\
\hline
\end{tabular}

* M.S. Silva, et al., 1988; Power Frequency Magnetic Fields in the Home; IEEE Transaction on Power Delivery; Vol. 4:1:465477; Paper No. 88WM101-8.

Normally, the resistance of shoes will limit the current to levels below the threshold for perception. Mitigation measures, such as grounding and breaking electrical continuity, that are implemented for electric field induction will also mitigate magnetic field induction.

EMF Regulation. Regulatory agencies in several states have taken various approaches to regulating EMF. The approaches include establishing electric and/or magnetic field level standards, and adopting prudent avoidance or field management guidelines. No field level standards or guidelines have been adopted by the federal government.

Regulatory agencies in at least eleven (11) states have adopted standards or guidelines for EMF. For example, two states, Florida and New York, have established magnetic field level standards that limit the EMF level at the edge of the ROW. The Florida standard limits the EMF level to $150 \mathrm{mG}$ at the edge of the ROW for transmission lines up to $230-\mathrm{kV}$, and $200 \mathrm{mG}$ at the edge of the ROW for transmission lines 
with voltages greater than $230-\mathrm{kV}$. New York has adopted an interim standard of $200 \mathrm{mG}$ at the edge of the ROW. These standards are not scientifically-based but rather were based on the highest EMF levels associated with existing transmission facilities and were adopted to maintain the status quo while EMF research continues. EMF standards are shown in Table 3-6.

Table 3-6

Magnetic Field Standards

\begin{tabular}{|c|c|c|}
\hline $\begin{array}{l}\text { State } \\
\text { or Group }\end{array}$ & $\begin{array}{l}\text { Standard at Edge } \\
\text { of ROW (mG) }\end{array}$ & Comments \\
\hline Florida & $\begin{array}{l}150 \mathrm{mG} \\
200 \mathrm{mG}\end{array}$ & $\begin{array}{l}\text { Up to } 230-k V \text { Transmission Lines } \\
\text { Transmission Lines Larger Than } 230-k V\end{array}$ \\
\hline New York & $200 \mathrm{mG}$ & Interim Standard \\
\hline $\begin{array}{l}\text { International Radiation } \\
\text { Protection Association } \\
\text { (IRPA) and International } \\
\text { Non-lonizing Radiation } \\
\text { Committee (INIRC) }\end{array}$ & $1,000 \mathrm{mG}$ & $\begin{array}{l}\text { General Public } \\
\text { (Occupational Exposure is } 5,000-50,000 \\
\text { mG; } 250,000 \text { mG if limbs only are exposed) }\end{array}$ \\
\hline $\begin{array}{l}\text { National Radiation } \\
\text { Protection Board (NRPB) }\end{array}$ & $20,000 \mathrm{mG}$ & United Kingdom \\
\hline
\end{tabular}

At least nine (9) states have endorsed policies requiring utilities to apply prudent avoidance or field management techniques when selecting routes for new transmission lines. These states include California, Colorado, Connecticut, Illinois, New Jersey, Ohio, Rhode Island, Texas, and Wisconsin. In general, the prudent avoidance/field management guidelines require utilities to provide information to state utility regulators regarding the EMF considerations that have been taken into account in routing, designing, and operating transmission lines. The EMF prudent avoidance considerations adopted by the Colorado Public Utilities Commission in Docket No. 92R-259E modified Rule 18 of the PUC's Electric Rules are as follows:

- "The utility shall include the concept of prudent avoidance with respect to planning, siting, construction, and operation of transmission facilities."

- "Prudent avoidance shall mean the striking of a reasonable balance between the potential health effects of exposure to magnetic fields and the cost impacts of mitigation of such exposure, taking steps to reduce the exposure at reasonable or modest cost."

- "Such steps might include, but are not limited to:

(1) Design alternatives considering the spatial arrangement of phasing of conductors;

(2) Routing lines to limit exposures to areas of concentrated population and group

(3) Installing higher structures;

(4) Widening right of way corridors; and

(5) Burial of lines."

The National Electric and Magnetic Research and Communication Program. Since EMFs are created during the generation, transmission, distribution, and use of electricity, everyone in the United States is exposed to various types and levels of EMF. Over the past 20 years, there has been an increasing public concern that exposure to electric and/or magnetic fields may result in adverse human health effects. To address these concerns, the Energy Policy Act of 1992 included provisions for a five (5) year National EMF Research and Communication Program. The goals of this program are: 
1. To determine if there are adverse effects on human health from EMF exposure;

2. To assess human exposures to EMF;

3. To develop options to reduce EMF exposures from various utility, residential, commercial, industrial, and transportation sources; and

4. To respond to the needs of the public, decision makers, and other interested parties by communicating understandable, credible, and balanced information of the results of EMF research.

The National EMF Research and Communication Program is intended to be national in scope, presenting a framework that will allow federal agencies, states, businesses, research organizations, unions, universities, and concerned citizens to sponsor, conduct, coordinate, or otherwise participate in EMF research and communications. The program goals, objectives and activities are the result of collaboration with the EMF research community, citizens, government and private sector policy makers, and other interested parties.

The program plan recommends activities that should be considered for the next five (5) years in four related program areas: (1)Scientific Research; (2) Engineering Research; (3) Communications; and (4) Policy Support.

The plan recommends the timing or sequencing of these activities and presents preliminary costs (unconstrained by availability of resources) to implement activities for the five-year period. The greatest funding emphasis is placed on the EMF Scientific Research component to determine if EMF exposures result in health effects, and emphasizes research on those potential health outcomes of greatest concern.

The scientific research program component seeks to determine the biological effects of EMF exposure on humans, animals, tissues, and cells; the mechanisms of interaction underlying these effects; biological indicators of exposure; and the association between EMF exposure and human health risks through welldefined epidemiologic studies.

The engineering research program component will assess EMF exposures and develop and evaluate technologies for mitigating fields and options for managing EMF exposures. The communications program component will gather, develop, and disseminate scientific and technical information on EMF issues in an easily understandable format. The EMF policy support program component will assist policy makers in developing effective public policies based on sound research findings and legal, economic, sociologic, and other studies.

The plan addresses research and communication activities from a national perspective. Therefore, the federal government is not intended to be the only sponsor of the activities presented. The following contributors will be instrumental in implementing and coordinating national EMF research and communication:

- The EMF Research and Public Information Dissemination Program (RAPID) established by the Energy Policy Act of 1992 . This is a federal program that authorizes $\$ 65$ million over five years to be appropriated to DOE for EMF research and information dissemination. Non-federal sources will contribute at least $50 \%$ of the total funding for all activities under the program. The health research activities and related communication efforts will be directed by the National Institute of Environmental Health Sciences (NIEHS) in cooperation with DOE, while DOE will direct the engineering research program and related communication efforts. A federal EMF Interagency Committee will facilitate the coordination of federal activities and develop the research agenda.

- Other Federal Agencies. In addition to DOE and NIEHS, several other federal agencies are involved in EMF research and communication including: the Environmental Protection Agency; the Food and Drug Administration; the National Cancer Institute; the National Institute of Occupational Safety and Health; the National Institute of Standards and Technology; the Occupational Safety and Health Administration; the Department of Transportation; and the Department of Defense. Exclusive of the Department of Energy ( $\$ 5$ million), and the Department of Defense ( $\$ 4$ million), other federal agencies have funded approximately $\$ 6$ million for EMF activities in fiscal year 1992.

- States and Private Sector Organizations. New York, Florida, and California are among the states that presently support EMF research activities.' In the private sector, the Electric Power Research Institute is the major EMF research sponsor, with a 1993 budget of approximately $\$ 15$ 
million for EMF health effects studies, field characterization and management research, and information services.

The EMF-related activities of various federal agencies will be coordinated through the Interagency Committee referred to above. The Interagency Committee will also maintain a liaison with state and private sector organizations to ensure the coordination of research activities nationwide. The Energy Policy Act of 1992 requires the Director of NIEHS to report the research findings from the National EMF Research and Communication Program to the Congress by March 31, 1997.

Future actions will be driven largely by the results of the research conducted under the National EMF Research and Communication Program. If scientists widely conclude that exposure to EMF poses adverse health effects, then the required actions to reduce or eliminate EMF exposure could be very expensive. The costs of mitigating EMF associated with existing and new electric transmission lines will vary with various geographic, engineering, and environmental factors. Nevertheless, the cost estimates that are beginning to emerge range from the tens of billions to hundreds of billions of dollars nationwide to reduce exposure from all transmission and distribution lines.

\subsubsection{Visual Resources}

Existing Conditions. The existing conditions relevant to the visual resources in Estes Park and the project study area have not been formally inventoried or classified. Data collected for preparation of the visual resource assessment includes photography of the project area taken from several observation points, 7.5-minute USGS topographic maps, and aerial photography. Views representative of the project from area residences and Marys Lake Road are shown in the "existing condition" photographs on Figures l-1 through $1-8$ in Appendix 1 .

The basis of the U.S. Forest Service Visual Management System (VMS) was utilized to assess the impacts to the visual resources. The VMS uses three visual resource inventory components to develop Visual Quality Objectives (VQOs): (1) variety classes; (2) sensitivity analysis; and (3) visibility. VQO class designations are used to manage the visual resource. These designations define the acceptable level of change that a proposed project or management action may introduce into the landscape.

Variety Class. Refining the landscape character types (e.g., alluvial valleys, uplands, mountains, etc.) into smaller units of similar physiographic and visual characteristics define the boundaries of variety class units. The greater the diversity of line, form, color and texture the greater the potential for high scenic value. The following three variety class designations are used to describe the aesthetic quality of the natural landscape.

Class A. Outstanding areas where characteristic features of landform, rock, water, and vegetation are distinctive or unique in the context of the surrounding region. These features exhibit considerable variety in line, form, color and texture.

Class B. Above average areas in which features provide variety in line, form, color and texture; and although the combinations are not rare in the surrounding region, they provide sufficient visual diversity to be considered moderately distinctive.

Class C. Common areas where characteristic features have moderate-to-little variety in line, form, color or texture in relation to the surrounding region.

Sensitivity Analysis. The existing transmission lines have contributed to the visual character of the project area for more than 40 years. The existing visual impacts are most evident from foreground views from within the residential subdivisions, Prospect Drive, and Marys Lake Road. The existing wood Hframe structures consist of similar material and are of similar height as many existing trees. Thus, they are less visible or blend in to the existing landscape from middleground and background viewpoints. The proposed modifications to the Marys Lake Substation will likely be the most evident from middleground viewpoints along Marys Lake Road.

Visibility. The VMS expresses visibility in terms of three distance zones; foreground, middleground and background. The distance zones are defined as follows: 
Foreground $(\mathrm{Fg})$. ( 0 - .5 mile) - The limit of a viewed area in which details are perceived and obvious. Textural and other aesthetic qualities of vegetation are normally perceptible within this zone.

Middleground (Mg). (.5 - 3 to 5 miles) - This zone includes viewed areas in which details of foliage and fine textures cease to be perceptible. Vegetation begins to appear as outlines or patterns.

Background $(\mathrm{Bg})$. (3-5 to 10 miles) - That portion of the landscape where texture and color are weak and landform becomes the most dominant element.

Visibility also accounts for the specific viewing conditions that could affect how a viewer sees from a viewpoint: including terrain backdrop, vegetation screening, and viewer position. For example, distant mountains that are a backdrop to the viewed area may reduce the level of change noticed in the landscape.

Visual Quality Objectives. VQOs are designed to provide objectives for visual management of the land. VQOs are based on several factors, including the public's concern for scenic quality (sensitivity levels), where the area is viewed from, and the diversity of the natural features in the characteristic landscape. These designations define the acceptable level of change that a proposed project or management action may introduce into the landscape. The Forest Service VMS Manual (Forest Service 1974) identifies five VQO classifications. These VQOs include:

Preservation (P). This VQO allows ecological changes only. Management activities, except for very low visual impact recreation facilities, are prohibited.

Retention (R). This VQO provides for management activities which are not visually evident. Activities may only repeat line, form, color and texture which are frequently found in the characteristic landscape. Any changes in their quality of size, amount, intensity, direction, pattern, etc., should not be evident. Immediate reduction in line, form, color and texture contrast should be accomplished either during operation or immediately after operations cease.

Partial Retention (PR). This VQO allows new lines, forms, color and texture to be introduced, but the changes must remain subordinate to the characteristic landscape. The activities may also introduce line, form, color or texture that are found infrequently or not at all in the characteristic landscape as long as they remain subordinate. Reduction of the contrast should be accomplished within the first year after operations cease.

Modification (M). This VQO allows activities that visually dominate the original characteristic landscape when the activities borrow from the naturally established line, form, color or texture, and at a similar scale so that its visual characteristics are those of natural occurrences within the surrounding areas or character type. Reduction of the contrast should be accomplished within the first year after operations cease, or at a minimum, should meet existing regional guidelines.

Maximum Modification (MM). This VQO allows management activities and landform alterations that dominate the characteristic landscape. When viewed as background, the visual characteristic must be those of natural occurrences within the surrounding area or character type. When viewed as foreground or middle ground, they may not appear to completely borrow from the naturally established line, form, color or texture. Activities may also be out of scale or contain detail that is incongruent with natural occurrences as seen in the foreground or middle ground. Reduction of the contrast should be accomplished within five years after operations cease.

The visual resources for lands surrounding the proposed project facilities have not been assessed. Due to the urban character and degree of development in the project area, this analysis assumes VQOs of "Maximum Modification" for the densely developed areas near the intersection of U.S. Highway 36 and Colorado Highway 7 and in the commercial and residential areas adjacent to Highway 7, "Modification" for the less densely developed residential areas, and for the areas around Marys Lake and the east side of Prospect Mountain, and "Retention" for the upper slopes of the north and west sides of Prospect Mountain. These VQOs are illustrated on Figure 3-3. 
Landscape Character Types. There are four general landscape character types in the project area: (1) coniferous forest; (2) montane meadow; (3) sagebrush shrubland; and (4) wetlands. These landscape character types are representative of the differences in physiography and vegetation found in the area. These landscape character types are illustrated on Figure 3-5, on page 3-29.

The combination of vegetation and development of this area is very complex and, thus, provides a high absorption capability.

\subsubsection{Socioeconomics}

This section describes the existing socioeconomic structure of the Town of Estes Park and the surrounding unincorporated areas of Estes Valley, and includes population, the economy, housing, and community services. This data will be used to examine the impacts to aspects of the socioeconomic environment that would result from implementation of the proposed project or the alternatives, and determine whether these impacts would be beneficial or negative. Available socioeconomic data was collected from local, state, and federal government sources.

The Town and the surrounding unincorporated areas of the Estes Valley in Larimer County comprise the study area for socioeconomic resources. Estes Park is located approximately 70 northwest of Denver and may be reached from the east by U.S. Highways 34 and 36, and Colorado Highway 7 . The region features numerous attractions and activities, and is a popular year-round tourist destination. In addition to Estes Park, the region includes the Rocky Mountain National Park and Roosevelt National Forest. Other communities in the vicinity of Estes Park are Glen Haven, Allenspark, and Meeker Park.

Population. Historically, population trends in Larimer County have been tied to resource development, particularly agriculture and tourism. The creation of Rocky Mountain National Park in 1917 helped establish Estes Park as a popular resort community. Tourist-related services provide employment for a significant portion of the population. The population of Estes Park and the Estes Valley has shown steady growth in the past 25 years, reflecting the region's continuing popularity and growth as a tourist destination. In the years between 1970 and 1980, the population of Estes Park increased by 67 percent, from 1,616 to 2,703 . The population grew to 3,672 in 1990 , an increase of 36 percent. Population growth and further development of the area are issues that currently concern residents of the valley. Table 3-7 summarizes population growth in Estes Park.

Table 3-7

Population Growth in Estes Park and Estes Valley

\begin{tabular}{lcc}
\hline Year & Estes Park Town Limits & Estes Valley \\
\hline 1970 & 1,616 & 3,554 \\
1980 & 2,703 & 6,773 \\
1990 & 3,672 & 9,139 \\
1992 & 3,870 & 9,200 \\
1995 projected & 4,258 & 10,595
\end{tabular}

Source: Estes Park, 1995

The year-round population of Estes Park in 1992 was 3,870 people. The population in the Estes Valley was approximately 9,200 . The population in the valley grows to nearly 40,000 in the summer months (League of Women Voters, 1993). This increase results from the influx of people who utilize the region's summer homes, recreation activities, and job opportunities with the government and recreation industry. 
Economy and Employment. The major industry in the Estes Park area is summer tourism. Estes Park is the gateway to Rocky Mountain National Park, the number one tourist attraction in the state of Colorado. Estes Park is a resort town which provides lodging and other resort services to the more than 3 million yearly visitors to the area (Blackhurst and Rosener, 1995). Service oriented industries and government employ the largest number of workers in Estes Park. Support services for tourists and residents account for about 60 percent of employment. Government jobs account for 22 percent. Approximately 10 percent work in the professions, and the remaining 8 percent work in light manufacturing industries (League of Women Voters, 1993).

Housing. The 1990 U.S. Census of Population and Housing estimates a total of 77,811 housing units in Larimer County, of which 44,297 units, or 57 percent, are owner occupied. Approximately 2,006 housing units are in the Town of Estes Park. Owner occupied housing units account for 822 , or 41 percent of units in the Town. Housing units for seasonal, recreational, or occasional use account for 448 of vacancies in the town. The homeowner vacancy rate is 2.5 percent and the rental vacancy rate is 6.3 percent (U.S. Census 1990).

Community Services. The project area is located in the Park R-3 School District. The District serves the towns of Allenspark, Pinewood Springs, and Glen Haven as well as Estes Park. There are 3 schools in the district, including an elementary school, a middle school, and a high school. In addition, there is a residential high school located in Estes Park.

Law enforcement in Estes Park and the Estes Valley is provided by the Estes Park Police Department and the Larimer County Sheriffs Department. Estes Park is patrolled by the Estes Park Police Department. The areas outside the town limits are patrolled by Larimer County, and the Colorado State Highway Patrol. The police department employs 16 full-time officers, and 7 additional part-time members hired for summer traffic control. The sheriff's department employs 5 deputies and the highway patrol employs 2 officers for the area. The town jail in the municipal building is used only as a holding facility.

Fire protection services in Estes Park are provided by a volunteer fire department manned by a crew of 33 volunteers. The fire department has mutual aid agreements with the fire departments in Loveland Pinewood Springs, Glen Haven, and Allenspark. Fire houses are located in Estes Park and at the east end of Rocky Mountain National Park.

There is one medical center in Estes Park which provides comprehensive health care facilities, including a hospital, skilled nursing facility, retirement cottages, specialty clinics and Home Health Care/Hospice. The hospital has 16 beds, a fully equipped emergency room, 24-hour ambulance service, emergency air transport, and surgical facilities. The medical center also provides emergency service to Rocky Mountain National Park (League of Women Voters, 1993).

Electricity was provided to about 7,800 customers in 1994 by the Town of Estes Park Light and Power Department. Electric power is purchased from the Platte River Power Authority.

Drinking water is provided to Estes Park by the Water Department of the Department of Public Works, which operates and maintains 3 water treatment plants. In addition, there are 6 private water companies in the area.

The Estes Park Sanitation District provides treatment of sewage in Estes Park. The Upper Thompson Sanitation District provides sewage treatment for areas not served by the Estes Park Sanitation District. Both districts operate treatment plants which discharge effluent into the Big Thompson River (Estes Park, 1995).

Local government agencies in the Estes Park area operate and maintain several recreational facilities. The facilities operated by the Estes Park Recreation and Park District (EVRPD) include the Lake Estes Marina, a 9-hole golf course, and picnic facilities at Lake Estes. The EVRPD also maintains an 18-hole golf course between Highway 7 and Fish Creek Road, the picnic and softball area of Stanley Park, tennis courts, a swimming pool operated jointly with schools, and Marys Lake Campground. The Lake Estes Marina and Marys Lake Campground are leased to private operators. 


\subsubsection{Earth Resources}

Soils. Detailed soils mapping is not available for the Estes Park area. Therefore, soils have been identified using the General Soils Map of Colorado (Heil et al. 1977). Soils within the project area include two general soil mapping units: 1) Typic Cryoboralfs, skeletal - Rock Outcrop: sloping to steep and 2) Aridic Argiborolls, loamy - Rock Outcrop: moderately steep and steep.

The first mapping unit consists of an intermingling of several types of soils found on the slopes of Prospect Mountain. Typic Cryoboralfs, skeletal are the predominant type. These are light colored, moderately deep to deep, well-drained, clayey to sandy soils. Most layers have more than 35 percent gravel, cobbles, and stones by volume. Typic Cryoboralfs commonly have moderate to low shrink-swell potential, moderate frost action potential, and moderate permeability.

The second mapping unit consists of an intermingling of several types of soils found in Stanley and Estes parks and Marys Lake valley. Aridic Argiborolls, loamy are the predominant type. These are dark colored, moderately deep to deep, well- to excessively-drained, loamy soils. Most layers have less than 35 percent rock fragments by volume. Aridic Argiborolls commonly have moderate shrink-swell potential, moderate frost action potential, and moderate permeability. Sensitive soils are shown on Figure 3-4.

Geology. The proposed project is located on the eastern slope of the Southern Rocky Mountains. This is an area of high mountains, and rugged topography with local relief exceeding 6000 feet. The project area itself includes Estes Park (a broad northeast-southwest trending montane valley) and Prospect Mountain (a granitic dome). Elevations range from 7500 feet at the north end of the project area at the Estes Park Power Plant to 8900 feet at the summit of Prospect Mountain. Therefore, total project area relief is 1400 feet. Slopes range from gentle ( 2 to 5 percent) east of the power plant to extremely steep (more than 100 percent) on portions of Prospect Mountain.

The project area lies in an area of ancient granitic and metamorphic bedrock which was uplifted and exposed during the Laramide Orogeny, a long period of mountain-building between 2 and 65 million years before the present. Two bedrock formations are exposed at the surface of the project area: Silver Plume Granite and Biotite Schist (Braddock and Cole 1990).

Bedrock in this area is cut by inactive faults in several locations (Braddock and Cole 1990). An east-west oriented fault zone runs along the southern margin of Prospect Mountain to the north of Marys Lake. Another roughly parallels the Fish Creek valley on the east side of the project area.

The study area lies within Seismic Risk Zone 1 (Algermissen 1969). Minor damage to structures from distant earthquakes is a possibility. Two intensity IV (minor) earthquakes have been centered within 20 miles of the proposed project (Stover et al. 1988). Moderate (intensity VII) earthquakes have been centered within 50 miles of the proposed project. None of these seismic events would have had a measurable impact within the study area. Potential landslide areas are shown on Figure 3-4.

Surface Water. There are two perennial streams and two major reservoirs in the project area. The Big Thompson River bounds the north side of the project area and Fish Creek flows north through the eastern quarter of the project area. Lake Estes is at the northern terminus of the existing transmission lines and Marys Lake is located in the southwestern corner of the project area. Two intermittent streams drain east to Fish Creek from Marys Lake and the adjacent area. Water resources in the area are predominately used for power generation. There is one ditch on Fish Creek and two small reservoirs. The Luce Ditch is used for irrigation and recreation. The transmission line ROW does not intersect any of these water rights (Colorado Division of Water Resources, 1995b). The surface water resources are shown on Figure 3-4.

Ground Water. There are approximately 190 well permits in the project area with well depths ranging from 10 feet to 760 feet (Colorado Department of Water Resources, 1995a). The average depth is 202 feet. Well yield, depth and water level information is available in whole or in part for 108 of these wells. Only eight wells appear to be less than 50 feet deep; two are located in the alluvium of the Big Thompson River upstream of Lake Estes; one is located in the Beaver Point community; one is located along Fish Creek; and four are located in colluvial materials on the east side of Prospect Mountain, near the transmission line. 


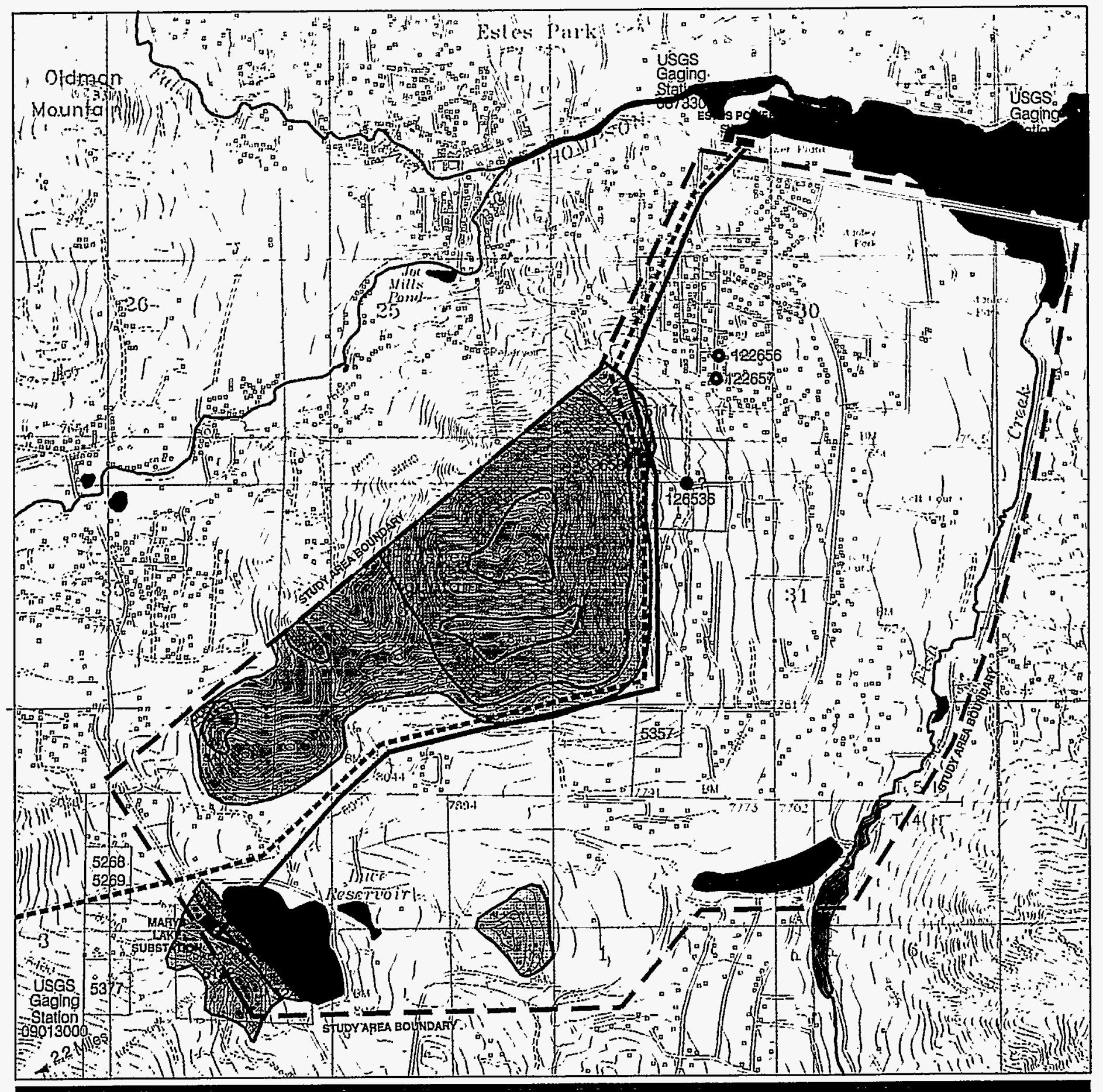

Platte River Power Authority and

Western Area Power Administration

69/115 kV Transmission Line Upgrade
and Substation Expansion Projects

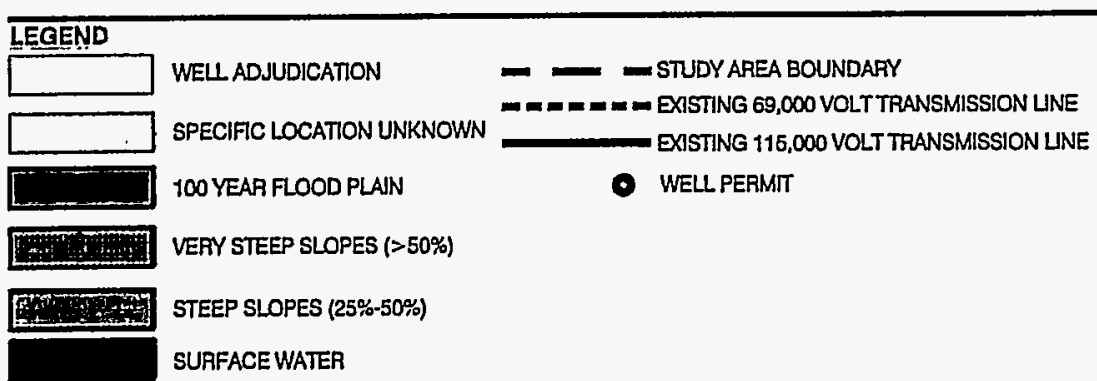

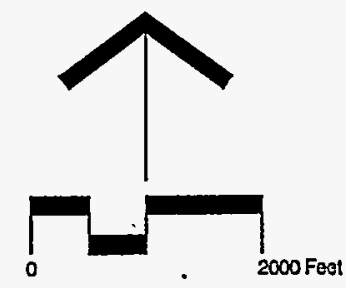

EARTH RESOURCES

Figure 3-4 
This page intentionally left blank. 
Forty-seven wells are adjudicated for one or more of the following uses in the project area: domestic, household use only, stock watering, irrigation, commercial, and industrial use. There is almost no publicly available information for groundwater quality in the Estes Park Area. The ground water resources are shown on Figure 3-4.

Floodplains. The Federal Emergency Management Agency (FEMA) maps floodplains for the National Flood Insurance Program, particularly special flood hazard areas inundated by 100 -year and 500 -year floods. This program is delegated to local political entities. Larimer County, Colorado maps 080101 0251B and 080101 0239C, and Town of Estes Park, Colorado maps 5N 72W 30NW and 5N 73W 25 SE portray those floodplains closest to the proposed project, and are included herein by reference. The floodplains in the vicinity of the project are shown on Figure 3-4.

\subsubsection{Biological Resources}

Vegetation. Four natural vegetation habitat types occur along the existing ROW. These habitat types include coniferous forest, montane meadow, sagebrush shrubland, and wetlands, and are shown on Figure 3-5. An additional habitat type (urban plantings) is shown and includes exotic and introduced trees, shrubs, and ornamentals primarily associated with adjacent homes.

Coniferous Forest. The coniferous forest habitat type occurring within and around the existing ROW is dominated by ponderosa pine (Pinus ponderosa). Associated species in the overstory include Rocky Mountain juniper (Juniperus scopulorum). Mid-story associates include wax currant (Ribes cereum), buckbrush (Ceanothus fendleri), common juniper (Juniperus communis), antelope bitterbrush (Purshia tridentata), and rubber rabbitbrush (Chrysothamnus nauseosus). Understory species include mountain ball cactus (Pediocactus simpsonii), common wild geranium (Geranium caespitosum), one-sided penstemon (Penstemon secundiflorus), western yarrow (Achillea lanulosa), sulphur flower (Eriogonum umbellatum), sand lily ( Leucocrinum montanum), needle and thread (Stipa comata), blue grama (Bouteloua gracilis), spike fescue (Leucopoa kingii), and mountain muhly (Muhlenbergia montana). This habitat type is the most dominant along the ROW and includes approximately 7.07 acres. Signs of overgrazing by elk are apparent.

Montane Meadow. This habitat type is characterized by dry to slightly mesic soil conditions, occurring primarily on south-facing slopes. No true overstory was present, but some shrubby vegetation exists. Big sagebrush (Artemisia tridentata ssp. vaseyana) and antelope bitterbrush were observed, but are limited and sporadic. Understory species include blue grama, junegrass (Koleria macrantha), mountain muhly, pasque flower (Pulsatilla patens), common dandelion (Taraxacum officinale), wooly cinquefoil (Potentilla hippiana), wild iris (Iris missouriensis), and mountain pussytoes (Antennaria parvifolia). This habitat type includes approximately 2.94 acres and was limited along the ROW.

Sagebrush Shrubland. Mountain big sagebrush, big sagebrush (Artemisia tridentata ssp. tridentata), and occasional bitterbrush and chokecherry (Prunus virginiana) occur along the ROW. The understory component of this habitat type is moderately sparse and is dominated by Wood's rose (Rosa woodsii), cheatgrass (Bromus tectorum), blue grama, mountain muhly, western wheatgrass (Agropyron smithii), fringed sage (Artemisia frigida), wavyleaf thistle (Cirsium undulatum), wild tarragon (Artemisia dracunculus), kochia (Kochia scoparia), and prickly pear cactus (Opuntia polyacantha). This habitat type was observed across about one-third of the ROW and includes approximately 5.69 acres.

Wetlands. Two small wetlands were observed during the site visit. One wetland was discrete, originating from a small seep at the base of a finger of the southeast-facing Prospect Mountain. The second wetland was observed just south of Peak View Drive below the road and formed a large wet meadow. Both wetlands had substantial surface water sheeting across them. The seep is intermittent, but the wet meadow is a perennial surface water source. These wetlands were dominated by grass-like sedges and rushes. These species include baltic rush (Juncus balticus), spike rush (Eleocharis palustris), bur-reed (Sparganium angustifolium), and subalpine rush (Juncus mertensianus). Associated forb species included wild iris, pasque flower, common yellow evening-primrose (Oenothera strigosa), onesided penstemon, and mariposa lily (Calochortus gunnisonii). The wetlands include approximately 1.74 acres.

Wildlife. Species occurring within the general project area are typically upland in nature. Although aquatic habitats exist they are limited in aerial extent. Species expected to occur within the area include 
elk (CLervus elaphus), mule deer( Odocoileus hemionus), coyote (Canis latrans), black bear (Ursus amercanus), porcupine (Erethizon dorsatum), skunk (Mephitis ssp.), deer mice (Peromyscus maniculatus), Cooper's hawk (Accipiter cooperii), red-tailed hawk (Buteo jamaicensis), Steller's jay (Cyanocitta cristata,) and black-capped chickadee (Parus atricapillus). Aquatic resources are restricted to Marys Lake. Species expected to occur there are rainbow trout, brook trout, fathead minnows, carp, and suckers. The USFWS has indicates the following threatened, endangered, and candidate wildlife species as potentially occurring within the general project area: bald eagle, peregrine falcon, greenback cutthroat trout, northern goshawk, boreal toad, and fringed-tailed myotis (Carlson 1995).

Habitats within the project area are comprised of four main types: coniferous forest, montane meadow, wetlands, and sagebrush shrubland. Wildlife species are expected to utilize all habitat types within the ROW. Also interspersed within the ROW are numerous homes and existing road ROWs. In general these areas are not highly conducive to wildlife habitation. Wildlife habitats are shown on Figure 3-6.

In general the area does not contain areas of high quality wildlife habitat. Elk and deer utilize the area primarily as winter range. However, some year-round use may occur (Bogart 1995) (refer to Figure 3-6). Raptor species such as red-tailed hawks, and Cooper's hawks may nest in the area. However, no nests were observed during the field reconnaissance. Species including coyotes and black bears may utilize habitats temporarily. However, better habitats occur in areas surrounding the project area. Passerine and songbird populations utilize the area and their density and populations would vary by season. Skunks and deer mice would be expected to occur near buildings and other disturbed sites.

Listed Threatened. Endangered, and Other Species of Concern. Twenty six threatened, endangered, candidate or sensitive species are known to occur or potentially occur in the study area, based on information provided by the USFWS, the Colorado Division of Wildlife (CDOW), and the Colorado Natural Heritage Program (CNHP). Table 3-8 provides information regarding each of these species. Listed species are discussed below.

Five plants were identified by the Colorado Natural Heritage Program for consideration and avoidance within the parameters of the transmission line upgrade project. These species included purple lady's slipper (Cypripedium fasciculatum), Rocky Mountain cinquefoil (Potentilla effusa var. rupincola), gayfeather (Liatris ligustylis), broad-leafed twayblade (Listera convallarioides), and wood lily (Lilium philadelphicum). No suitable habitat for any of these species lies within the proposed impact area. Table 3-8 presents the potential habitat requirements and the impacts analysis conclusion for each species.

Of the sixteen threatened, endangered and sensitive species of wildlife identified through agency contacts, nine have been eliminated from further consideration. These species were eliminated based on a lack of suitable habitat within the project area (Table 3-8). The species eliminated include the regal fritillary butterfly, Mexican spotted owl, eskimo curlew, mountain plover, whooping crane, black-footed ferret, boreal owl, Preble's jumping mouse, and swift fox.

Peregrine Falcon. The peregrine falcon is a federally-listed endangered species. Peregrines typically occur along river systems or reservoirs where an adequate food supply, primarily waterfowl and other birds, are available. Roost sites are generally cliffs, bluffs or large rock outcrops. Peregrines are known to occur within the general project area. The closest known nest site occurs almost a mile from the southern terminus of the project area. However, this site has not been occupied since 1990. The next closest sites occur four miles east and 8 miles north of the project area (Craig 1995). Peregrine falcons are known to occur within the general project area. In May of 1994 a male peregrine was killed as the result of a line strike. The CDOW determined that the bird, which had been released into Rocky Mountain National Park, had struck the wire while chasing prey. The strike occurred on a distribution line in the southern portion of Estes Park (Craig 1996). 


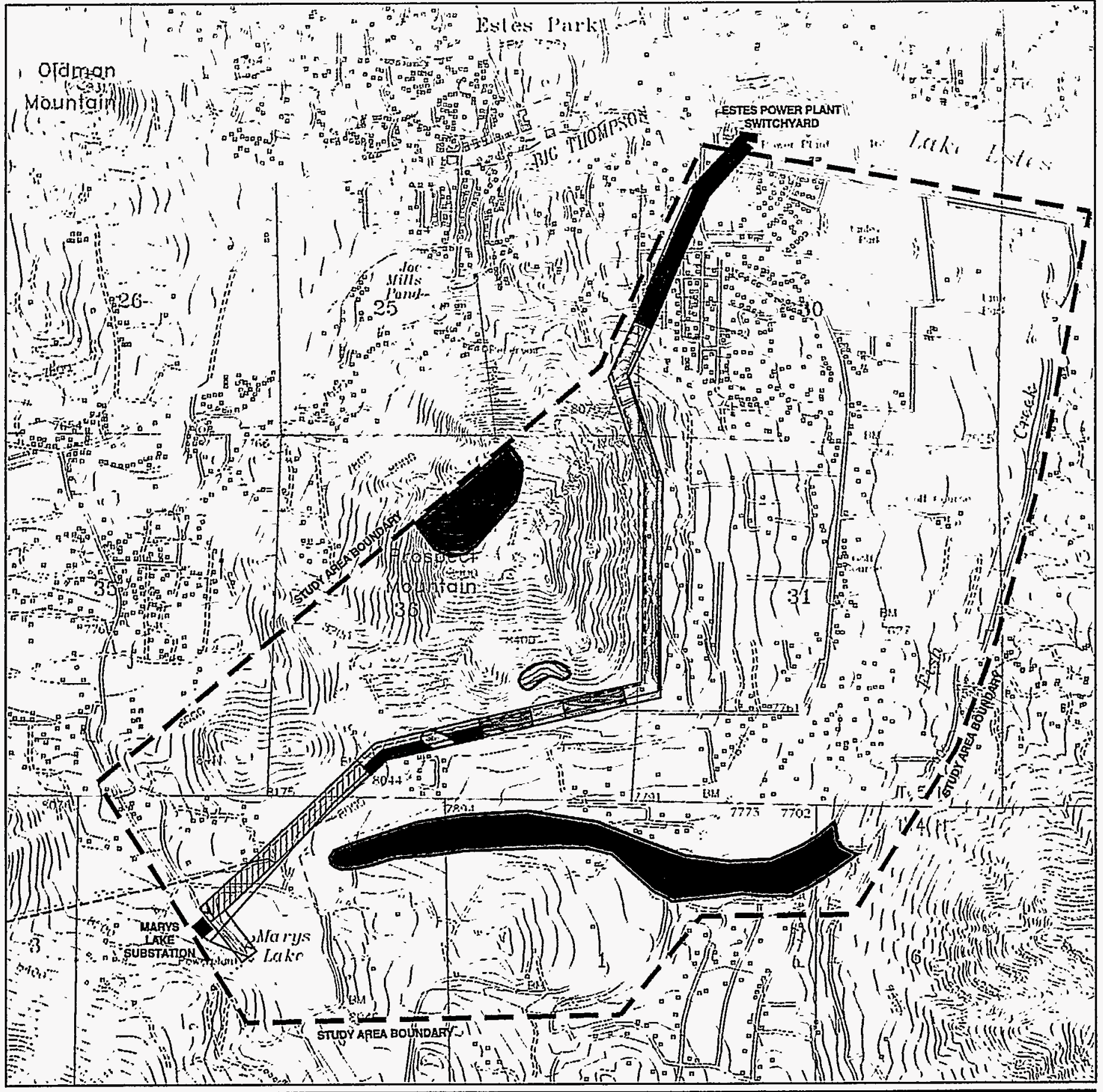

Platte River Power Authority and

Western Area Power Administration

Marys Lake

69/115 kV Transmission Line Upgrade and Substation Expansion Projects

LEGEND

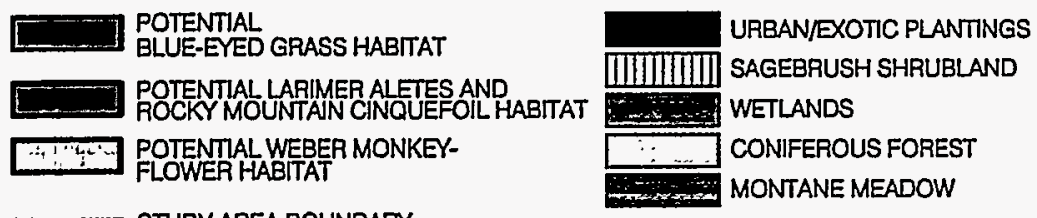

- STUDY AREA BOUNDAFY

EXISTING 69,000 VOLT TRANSMISSION LINE

EXISTING 115,000 VOLT TRANSMISSION LNNE

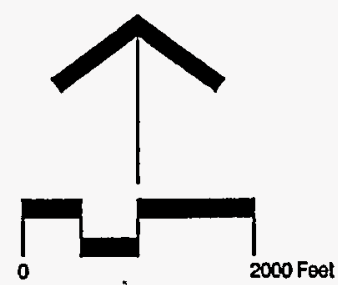

VEGETATION COMMUNITIES AND POTENTIAL SENSITIVE PLANT HABITATS

Figure 3-5 
This page intentionally left blank. 


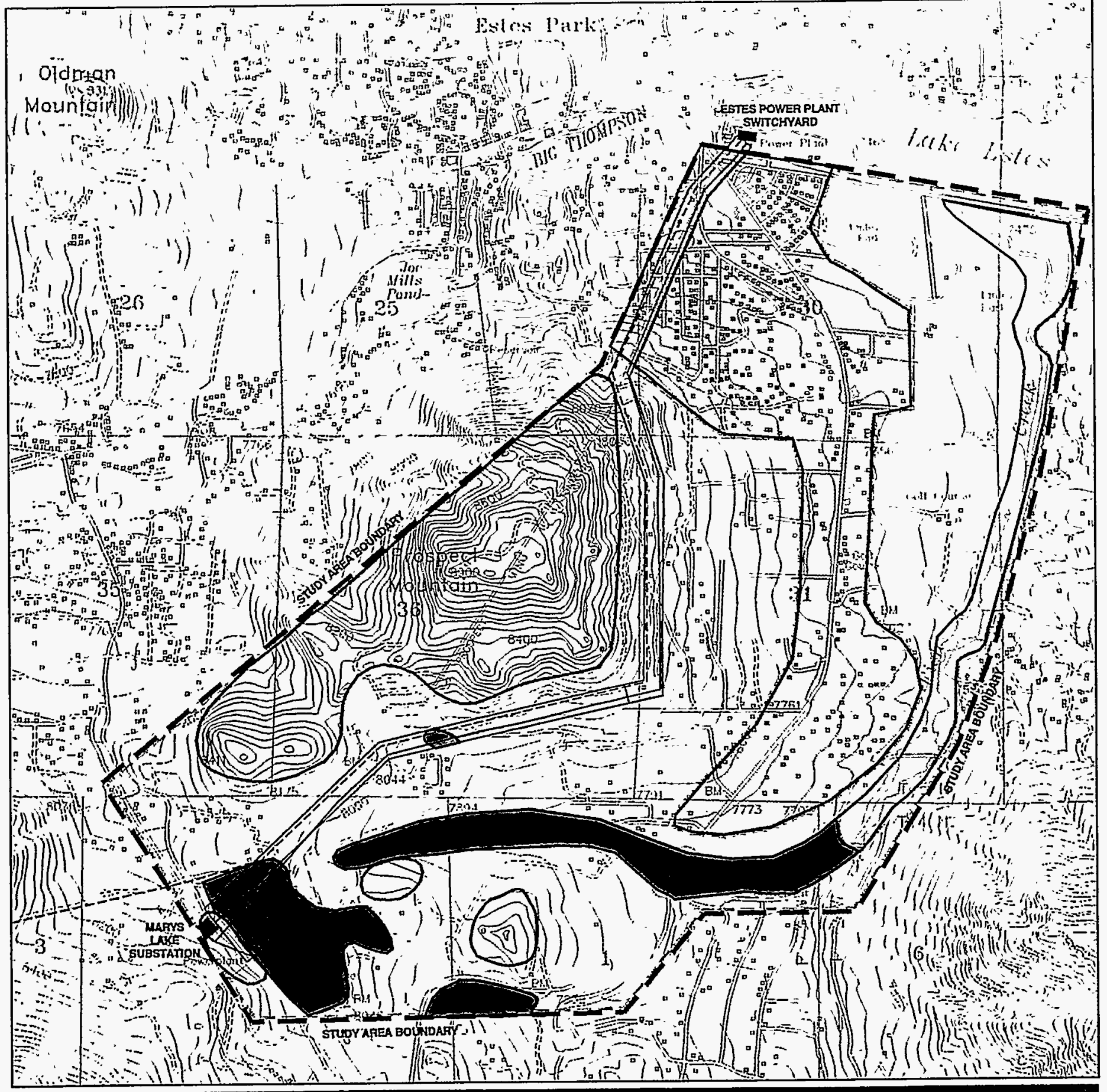

Platte River Power Authority and

Western Area Power Administration

69/115 kV Transmission Line Upgrade and Substation Expansion Projects

LEGEND

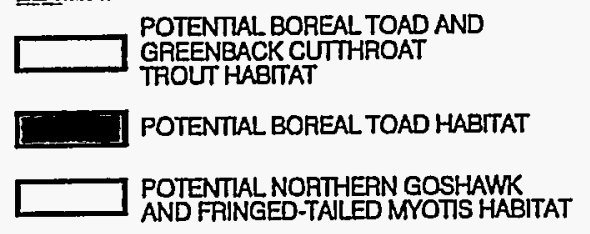

D DENSELY DEVELOPED URBAN AREA

- - - MULEDEER AND ELKRANGE,

- STUDY AREA BOUNDARY

EXISTING 69,000 VOLT TRANSḾISSION LINE EXISTING 115,000 VOLT TRANSMISSION UNE

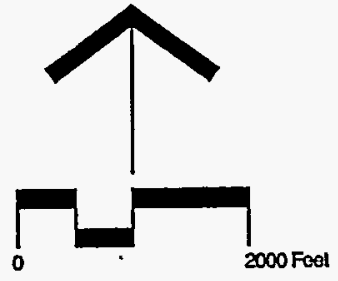

WILDLIFE RESOURCES AND

WILDLIFE RESOURCES AND
SENSITIVE WILDLIFE HABITATS 
this page intentionally left blank 


\begin{tabular}{|c|c|c|c|}
\hline $\begin{array}{l}\text { Common } \\
\text { Name/Scientific Name }\end{array}$ & Status & Habitat Requirements & Potential for Impacts \\
\hline $\begin{array}{l}\text { Peregrine falcon (Falco } \\
\text { peregrinus) }\end{array}$ & Endangered & $\begin{array}{l}\text { Rocky cliffs, marshes, and open } \\
\text { water. }\end{array}$ & $\begin{array}{l}\text { Moderate, suitable habitat } \\
\text { occurs within the ROW. }\end{array}$ \\
\hline $\begin{array}{l}\text { Bald eagle (Haliaeetus } \\
\text { leucocephalus) }\end{array}$ & Threatened & $\begin{array}{l}\text { Reservoirs, areas of open water, } \\
\text { and big game winter range. }\end{array}$ & $\begin{array}{l}\text { Moderate; suitable habitat } \\
\text { occurs within the ROW. }\end{array}$ \\
\hline $\begin{array}{l}\text { Greenback cutthroat trout } \\
\text { (Onchorhynchus clarki } \\
\text { stomias)' }\end{array}$ & Threatened & $\begin{array}{l}\text { Mountain and foothill headwaters of } \\
\text { the South Platte and Arkansas river } \\
\text { drainages. }\end{array}$ & None; no suitable habitat. \\
\hline $\begin{array}{l}\text { Boreal toad (Bufo boreas } \\
\text { boreas) }\end{array}$ & $\mathrm{C} 2$ & $\begin{array}{l}\text { Marshes, wet meadows, beaver } \\
\text { ponds, shallow lakes, and along } \\
\text { streams ranging from } 8,000 \text { to } \\
12,900 \text { feet in elevation. }\end{array}$ & $\begin{array}{l}\text { Moderate; suitable habitat } \\
\text { occurs within the ROW. }\end{array}$ \\
\hline $\begin{array}{l}\text { Northern goshawk (Accipiter } \\
\text { gentilis) }\end{array}$ & $\mathrm{C2}$ & $\begin{array}{l}\text { Nest within coniferous and mixed } \\
\text { coniferous-deciduous forests on } \\
\text { gentle to moderate slopes with } \\
\text { northerly exposures. }\end{array}$ & $\begin{array}{l}\text { Moderate; suitable habitat } \\
\text { occurs within the ROW. }\end{array}$ \\
\hline $\begin{array}{l}\text { Fringed-tailed myotis (Myotis } \\
\text { thysanodes pahasapensis) }\end{array}$ & $\mathrm{C} 2$ & $\begin{array}{l}\text { Ponderosa pine woodlands, } \\
\text { greasewood, oakbrush, and } \\
\text { saltbush shrublands. }\end{array}$ & $\begin{array}{l}\text { Moderate; suitable habitat } \\
\text { occurs within the ROW. }\end{array}$ \\
\hline $\begin{array}{l}\text { Larimer aletes (Aletes } \\
\text { humilis)' }^{\prime}\end{array}$ & $\mathrm{C2}$ & $\begin{array}{l}\text { Cracks and crevices on rocky } \\
\text { granite outcrops dominated by } \\
\text { ponderosa pine and on cool, north- } \\
\text { facing, near-vertical cliffs. }\end{array}$ & $\begin{array}{l}\text { None; habitat does not } \\
\text { occur within ROW. }\end{array}$ \\
\hline $\begin{array}{l}\text { Pale blue-eyed grass } \\
\text { (Sisyrinchium pallidum) }^{1}\end{array}$ & $\mathrm{C} 2$ & $\begin{array}{l}\text { Poorly drained mid-elevation wet } \\
\text { meadows from } 7,000 \text { to } 10,000 \text { feet } \\
\text { in elevation. }\end{array}$ & $\begin{array}{l}\text { Low; wetlands will be } \\
\text { protected through mitigatio } \\
\text { measures, i.e., silt fencing. }\end{array}$ \\
\hline $\begin{array}{l}\text { Weber monkey-flower } \\
\text { (Mimulus gemmiparus) }^{1}\end{array}$ & $\mathrm{C} 2$ & $\begin{array}{l}\text { Moist soils of forest seeps or springs } \\
\text { protected by granite overhangs } \\
\text { between elevations of } 8,500 \text { to } \\
10,500 \text { feet. }\end{array}$ & $\begin{array}{l}\text { None; no suitable habitat } \\
\text { within ROW. }\end{array}$ \\
\hline $\begin{array}{l}\text { Whooping crane (Grus } \\
\text { americana) }\end{array}$ & Endangered & $\begin{array}{l}\text { Mudflats, agricultural areas, } \\
\text { wetlands. }\end{array}$ & None; no suitable habitat. \\
\hline $\begin{array}{l}\text { Eskimo curlew (Numenius } \\
\text { borealis) }\end{array}$ & Endangered & $\begin{array}{l}\text { Plowed fields, shorelines of lakes } \\
\text { and reservoirs. None observed in } \\
\text { Colorado since } 1882 \text {. }\end{array}$ & None; no suitable habitat. \\
\hline $\begin{array}{l}\text { Mountain plover (Chadadrius } \\
\text { montanus) }\end{array}$ & $\begin{array}{l}\text { Candidate for } \\
\text { listing }\end{array}$ & $\begin{array}{l}\text { Shortgrass prairies, dry mudflats, } \\
\text { and shorelines of dry reservoirs. }\end{array}$ & None; no suitable habitat. \\
\hline $\begin{array}{l}\text { Mexican spotted owl (Strix } \\
\text { occidentalis /ucida) }\end{array}$ & Threatened & $\begin{array}{l}\text { Dense uneven aged mixed-conifer } \\
\text { or ponderosa pine forests with a } \\
\text { high canopy closure. }\end{array}$ & None; no suitable habitat. \\
\hline $\begin{array}{l}\text { Black-footed ferret (Mustela } \\
\text { nigripes) }\end{array}$ & Endangered & Prairie dog colonies & None; no suitable habitat. \\
\hline Swift fox (Vulpes velox) ${ }^{2}$ & $\begin{array}{l}\text { Candidate for } \\
\text { listing }\end{array}$ & Short- and mid-grass prairies. & None; no suitable habitat. \\
\hline $\begin{array}{l}\text { Prebles meadow jumping } \\
\text { mouse (Zapus hudsonius } \\
\text { preblel) }^{2}\end{array}$ & $\begin{array}{l}\text { Candidate for } \\
\text { listing }\end{array}$ & $\begin{array}{l}\text { A prairie species occurring in lush } \\
\text { vegetation along watercourses and } \\
\text { herbaceous understories in } \\
\text { woodlands }\end{array}$ & None; no suitable habitat. \\
\hline
\end{tabular}


Table 3-8

Threatened, Endangered, and Other Species of Concern

\begin{tabular}{|c|c|c|c|}
\hline $\begin{array}{l}\text { Common } \\
\text { Name/Scientific Name }\end{array}$ & Status & Habitat Requirements & Potential for Impacts \\
\hline $\begin{array}{l}\text { Ute ladies'-tresses (Spiranthes } \\
\text { diluvialis) }\end{array}$ & Threatened & $\begin{array}{l}\text { Wet meadows and floodplains near } \\
\text { the base of the Front Range in the } \\
\text { Boulder-Denver area }\end{array}$ & $\begin{array}{l}\text { None; species only known } \\
\text { to occur within the 100-year } \\
\text { floodplain of the South } \\
\text { Platte River, Boulder, } \\
\text { Larimer and Jefferson } \\
\text { counties, north-central and } \\
\text { western Utah, and extreme } \\
\text { eastern Nevada. }\end{array}$ \\
\hline $\begin{array}{l}\text { Colorado butterflyweed } \\
\text { (Gaura neomexicana subsp. }_{\text {coloradensis) }}\end{array}$ & $\begin{array}{l}\text { Candidate for } \\
\text { listing }\end{array}$ & $\begin{array}{l}\text { Plains and piedmont valleys in } \\
\text { Boulder, Larimer, and Weld counties }\end{array}$ & $\begin{array}{l}\text { None; no suitable habitat in } \\
\text { the ROW. }\end{array}$ \\
\hline $\begin{array}{l}\text { Purple lady's slipper } \\
\text { (Cypripedium fasciculatum) }^{3}\end{array}$ & $\begin{array}{l}\text { Under review for } \\
\text { Federal Listing; } \\
\text { Forest Service } \\
\text { Sensitive }\end{array}$ & $\begin{array}{l}\text { Forest openings and densely } \\
\text { shaded stands, in duff under } \\
\text { lodgepole pine, or, less frequently, } \\
\text { under Abies sp. }\end{array}$ & $\begin{array}{l}\text { None; no suitable habitat } \\
\text { present within the ROW. }\end{array}$ \\
\hline $\begin{array}{l}\text { Rocky Mountain cinquefoil } \\
\text { (Potentilla effusa var. } \\
\text { rupincola) }\end{array}$ & $\begin{array}{l}\text { Under review for } \\
\text { Federal Listing; } \\
\text { Forest Service } \\
\text { Sensitive }\end{array}$ & $\begin{array}{l}\text { Steep, often granite, outcroppings } \\
\text { on shelves or niches of cliffs, often } \\
\text { on granite or gravel. }\end{array}$ & $\begin{array}{l}\text { None; no suitable habitat } \\
\text { present within the ROW. }\end{array}$ \\
\hline Gay-feather (Liatris ligustylis) ${ }^{3}$ & G5?IS1S2 & $\begin{array}{l}\text { Wet meadows in the piedmont and } \\
\text { Wet Mountain Valley. }\end{array}$ & $\begin{array}{l}\text { None; known only to occur } \\
\text { in southern Colorado by the } \\
\text { Sangre de Cristo Mountains } \\
\text { and Wet Mountains. }\end{array}$ \\
\hline $\begin{array}{l}\text { Broad-leafed twayblade } \\
\text { (Listera convallarioides) }^{3}\end{array}$ & G5/S2 & $\begin{array}{l}\text { Moist places in leaf mold, in shaded } \\
\text { areas, or in wet places along small } \\
\text { streams high in the mountains. }\end{array}$ & $\begin{array}{l}\text { None; known only to occur } \\
\text { at higher elevations in } \\
\text { subalpine forests and cool } \\
\text { ravines. }\end{array}$ \\
\hline $\begin{array}{l}\text { Wood lily (Lilium } \\
\text { philadelphicum) }\end{array}$ & G5/S3 & Aspen groves & $\begin{array}{l}\text { None; no aspen habitat is } \\
\text { encountered within the } \\
\text { ROW }\end{array}$ \\
\hline $\begin{array}{l}\text { Regal fritillary butterfly } \\
\text { (Speyeria idalia) }^{3}\end{array}$ & $\begin{array}{l}\text { Under review for } \\
\text { Federal Listing; } \\
\text { Forest Service } \\
\text { Sensitive }\end{array}$ & $\begin{array}{l}\text { Wet meadows and virgin prairies } \\
\text { near marshes. }\end{array}$ & Low; no suitable habitat. \\
\hline Dwarf shrew (Sorex nanus) ${ }^{3}$ & $\begin{array}{l}\text { G5/S3; Forest } \\
\text { Service Sensitive }\end{array}$ & $\begin{array}{l}\text { Forests, open woodiands, and } \\
\text { rocky, shrubby foothill slopes. Also } \\
\text { on alpine and sub-alpine rockslides. }\end{array}$ & $\begin{array}{l}\text { Moderate; suitable habitat } \\
\text { within the ROW. }\end{array}$ \\
\hline $\begin{array}{l}\text { Boreal owl (Aegolius } \\
\text { funerous) }\end{array}$ & $\begin{array}{l}\text { G5/S2; Forest } \\
\text { Service Sensitive }\end{array}$ & $\begin{array}{l}\text { Mature spruce-fir or spruce- } \\
\text { fir/lodgepole pine forests } \\
\text { interspersed with meadows. }\end{array}$ & None; no suitable habitat. \\
\hline
\end{tabular}

Endangered= Species in danger of extinction throughout all or a significant portion of its range.

Threatened $=$ Species likely to become an endangered species within the foreseeable future throughout all or a significant portion of its range.

Category 2 = Species for which the USFWS indicates that proposing to list as endangered or threatened is possibly appropriate, but for which conclusive data on

biological vulnerability is lacking.

'August 4, 1995 USFWS letter

'September 26, 1995 USFWS Letter

${ }^{3}$ Natural Heritage List 6/5/95

Bald Eagle. The bald eagle is a federally-listed threatened species. Bald eagles are known to occur within the general project area. Bald eagles are occasionally sited in the winter near Lake Estes. Eagles may occasionally use Marys Lake during the winter, but this has not been documented. However, since Marys Lake is usually frozen during the winter months, it is unlikely eagles would be present on a regular basis. No bald eagle summer or nesting is known to occur within the general project area (Craig 1995). Feeding areas, diurnal perches, and night roosts are fundamental elements of bald eagle winter range. 
Although eagles can fly as far as $24 \mathrm{~km}$ (15 miles) to and from these elements, they primarily occur where all three elements are available in comparatively close proximity (Swisher 1964). None of these elements occur along the project ROW.

Greenback Cutthroat Trout. The greenback cutthroat trout is federally-listed as a threatened species. Greenback cutthroat trout typically occurs in mountain and foothill headwaters of the South Platte and Arkansas river drainages (Behnke 1992). The greenback is known to have been stocked in Larimer County in the North Fork of the Big Thompson and Roaring Fork Rivers. It is anticipated that it has extended it range from these stockings (Carison 1995). This species is easily displaced by non-native trout species (Behnke 1992).

The Ute ladies'-tresses is a federally listed threatened species. Ute ladies'-tresses is a member of the orchid family. The species is a perennial plant with stems 20 to 50 centimeters tall, arising from tuberously thickened roots. The species is characterized by whitish, stout, ringent flowers. It blooms, generally, from late July through August. It is endemic to moist soils in mesic or wet meadows near springs, lakes, or perennial streams. The elevational range of known Ute ladies'-tresses occurrences is 4,300 to 7,000 feet.

Other Species. The remaining species of concern are Category Two species. Although Category Two species have no protection under the Endangered Species Act (1972), as amended, it is within the spirit of the Act to address potential effects to these species to avoid future listing as either threatened or endangered. These species include the boreal toad, northern goshawk, fringed-tailed myotis (Carlson 1995), Larimer aletes (Aletes humilis), pale blue-eyed grass (Sisyrinchium pallidum), and Weber monkeyflower (Mimulus gemmiparus) (USFWS).

The boreal toad is restricted to wetland and riparian corridors above 8,000 feet in elevation. Within these areas they typically occur within marshes, wet meadows, and the margins of streams, lakes, beaver ponds, and glacial kettle lakes (Hammerson 1986). The boreal toad may occur within wetland habitats located in the project area (Hammerson and Langlois 1981). However, the presence of the boreal toad has not been documented within the project area (Pague 1995).

The northern goshawk generally nest in mixed coniferous and deciduous forests. They typically occur on moderate slopes (0-30\%), with north-northeast exposures. Typically these areas are near small quiet ephemeral streams (Reynolds et al. 1992). Although goshawks may occur in the area, none have been documented by either the CDOW or CHNP (Craig 1995 and Pague 1995).

Fringed-tailed myotis occur in coniferous forest at moderate elevations. This bat species may occur in ponderosa pine, pinyon-juniper, greasewood, saltbush, and scrub oak habitats (CDOW 1984). This species may occur in the area (Bissell 1978). However, they have not been documented (Pague 1995).

Larimer aletes is a member of the parsley family. The species has thick leathery leaves and it forms conspicuous clumps and mats on rock walls. Larimer aletes bloom in mid- to late-summer and the flowers are yellow. It occurs in cracks and crevices on rocky granite outcrops where it is shaded by ponderosa pine and on cool, north-facing, near-vertical cliffs.

Pale blue-eyed grass is a member of the iris family. It blooms in late July and August and has a pale blue flower atop a slender grass-like stem. It inhabits poorly drained mid-elevation meadows from 7,000 to 10,000 feet in elevation. It is associated with the Greenland primrose, grasses, and grass-like plants.

Weber monkey-flower is a member of the figwort family. It blooms from June through early August, has yellow flowers, and is small in stature. It typically grows in moist soils of forest seeps or springs protected by granite overhangs between elevations of 8,500 to 10,500 feet. It has also been discovered growing on an alluvial fan deposited by the Long Lake flood. It grows in association with other monkey-flowers.

Colorado butterflyweed is a member of the evening-primrose family. The species has not been found in the state of Colorado since 1988 (CNPS 1989). However, several isolated populations have been found in Wyoming. The plant occupies moist prairie meadows along the Front Range from Castle Rock, Colorado to Cheyenne, Wyoming in the transition zone between streams and floodplains. The plant grows in a candelabra shape up to four feet tall. It flowers from July through September. 
The dwarf shrew occupies a variety of habitat types. These shrews have been observed from the edges of alpine and subalpine rockslides to spruce-fir bogs. In addition, coniferous forests, sedge marshes, dry brushy hillsides, and open woodlands may be utilized. The dwarf shrew can also tolerate arid to semi-arid conditions, and have been observed up to half a mile from water sources (Fitzgerald et al 1994).

Potential habitats for these species are shown on Figures 3-5 and 3-6.

\subsection{Cultural Environment}

There are no known cultural resources in the immediate project area. The general region contains two historic debris scatters, several historic buildings in Estes Park, and a small number of prehistoric lithic scatters in the area. The existing ROW associated with the Proposed Action is on relatively steep (10$25 \%$ grade) rocky and unconsolidated slopes that are removed from water sources or other attractive resources.

An archaeological survey of the Proposed Action resulted in the recording of two prospect pits approximately 120 meters apart. Both are mostly backfilled and the brush regrowth indicates that they are probable 50-70 years old. There were no artifacts or debris found.

\subsection{Resources Identified As Not Requiring Detailed Study}

The environmental resource areas that were considered, but which are not described in detail in this analysis, include the following:

\subsubsection{Air Quality}

The project would have very minor, local, short-term effects on air quality, limited primarily to short-term emissions from construction vehicles and fugitive dust generated by construction activities. The upgrade of the $69-k V$ transmission line to $115-k V$ would have no measurable effects on ozone levels.

\subsubsection{Climate}

The project would have no effect on climate.

\subsubsection{Paleontology}

Potentially important fossil bearing locales are not present along the route of the Proposed Action. Therefore, the project is not expected to affect paleontological resources. 
This chapter presents an assessment of the environmental consequences associated with the project alternatives, primarily the Proposed Action, with respect to each of the environmental conditions as described in Chapter 3 . The analyses that have been conducted utilize a variety of terms to assess the effects that would result with respect to each resource. The terms used to assess the effects are identified and defined below.

cumulative: increasing in effect by successive additions; accumulated.

essential/essentially: basically, inherently

impact. to influence or change.

long-term: a long period of time (for the purposes of this project, more than five (5) years)

minimal: small quantity or degree.

moderate: within reasonable limits; avoiding extremes; of medium quality.

short-term: a short period of time (for the purposes of this project, less than five (5) years).

significant/significantly. important, exceeding a defined impact threshold.

slight/slightly. lacking weight, strength, significance, etc.; small in amount or extent.

strong: having a powerful effect.

weak: not strong; unconvincing; lacking force, power, effectiveness, or authority.

\subsection{Human Environment}

\subsubsection{Land Use}

Existing Land Use. As the existing transmission lines and ROWs have been in-place for over 40 years, there would be essentially no new long-term effects on the existing land uses. Construction of the Proposed Action would result in several short-term effects primarily as a result of construction and reclamation of disturbances. The project would have very minor, short-term effects on air quality and noise. The air quality effects would be limited primarily to emissions from construction vehicles, and fugitive dust and noise would be generated ruing construction activities. These effects would be limited to line construction that would proceed along the existing ROW during 1997 and 1998. The noise generated by the Proposed Action would be $1 \mathrm{dBA}$ greater than the existing conditions at the edges of the ROW; this increase would not be perceptible. Traffic congestion in the vicinity of the project would also increase slightly on a short-term basis with a number of 12 to 16 people working on the project at any one time during peak periods of construction. The primary impact to existing land uses would be the disturbance of existing vegetation at the structure locations and by the construction of temporary spur roads for access to up to three structure locations. Generally, access to each structure location would be from existing roads. Cross-country travel along the ROW would only be necessary between three to four spans in the area that parallels Peak View Drive. Disturbed areas would be reseeded and restored, as nearly as feasible, to their original condition. More specific construction and restoration guidelines are included in Appendix $\mathrm{J}$.

Planned Land Use. There would be essentially no effects on planned land uses because the existing ROWs that have been in-place for over 40 years would be used, and local land use planning has considered the existing use of the transmission line corridor.

\subsubsection{Electrical Characteristics and Public Safety}

This section discusses the environmental effects of the project alternatives including the Proposed Action compared to the existing conditions relative to public health and safety. Analysis of the electrical characteristics of the existing environmental setting was conducted for the configuration shown in Figure 2-4. The minimal conductor ground clearance used for analyzing characteristics was 22 feet. 
Corona. The additional corona resulting from upgrading the existing $69-\mathrm{kV}$ transmission line to $115-\mathrm{kV}$ will not be discernable.

Audible Noise (AN). AN levels for the edge of the ROW of the alternatives including the Proposed Action during fair and foul weather are shown on Table 4-1. The calculated average (L50) value for wet weather at the edge of the ROW is $36.2 \mathrm{dBA}$ for the Proposed Action.

Table 4-1

Audible Noise (AN) Levels

\begin{tabular}{llcc}
\hline \multicolumn{1}{c}{ Alternative } & \multicolumn{1}{c}{ Location } & $\begin{array}{c}\text { Fair Weather L50 AN } \\
\text { (dBA) }\end{array}$ & $\begin{array}{c}\text { Wet Weather L50 AN } \\
\text { (dBA) }\end{array}$ \\
\hline \hline $\begin{array}{llll}\text { Alternative A - The } \\
\text { Proposed Action }\end{array}$ & $\begin{array}{l}\text { East/South Edge ROW } \\
\text { West/North Edge ROW }\end{array}$ & 11.2 & 36.2 \\
& Maximum in ROW & 11.2 & 36.2 \\
Alternative A1 - & East/South Edge ROW & 11.8 & 36.8 \\
Single-circuit Single & West/North Edge ROW & 10.7 & 35.7 \\
Steel Pole Structures & Maximum in ROW & 7.7 & 32.7 \\
Alternative A2 - & East/South Edge ROW & 11.2 & 36.2 \\
Double-circuit Single & West/North Edge ROW & 9.6 & 34.6 \\
Steel Pole Structures & Maximum in ROW & 9.6 & 34.6 \\
Alternative A3 - Self- & East/South Edge ROW & 12.2 & 37.2 \\
supported Angle & West/North Edge ROW & 11.2 & 36.2 \\
Structures & Maximum in ROW & 11.2 & 36.2 \\
& & 11.8 & 36.8 \\
\hline
\end{tabular}

The calculated average fair weather noise level at the edge of the ROW is $11.2 \mathrm{dBA}$ for the Proposed Action. These values represent a slight increases for the edges of the ROW when compared to the existing conditions illustrated in Table 3-1. The AN levels for Alternatives A1 and A2 would range from 7.7 $\mathrm{dBA}$ to $10.7 \mathrm{dBA}$ during fair weather, and $32.7 \mathrm{dBA}$ to $35.7 \mathrm{dBA}$ during wet wether at the edges of the ROW. The AN levels associated with Alternative $A 3$ would be the same as for the Proposed Action. Table 3-2 provides a comparison of common noises.

Radio Interference/Television Interference (RI/TVI). The existing transmission lines have been in service for over 40 years and interference to radio (RI) and television (TVI) have not been significant problems. It was reported during the initial public workshop/ scoping meeting that RI on car radios occurs when driving in the vicinity of the transmission lines. While there may be several reasons for this interference, including weak signal strength, it is also likely that the cause is related to loose or dirty insulators, or by loose hardware, and can be corrected by maintenance.

The interference to radio (RI) and television (TVI) is not anticipated to significantly increase with the proposed upgrade, and would be similar for all alternatives. The primary source of this interference is still anticipated to be spark gaps. This is a condition generally found in older transmission lines and the upgrade should eliminate or improve potential existing problems. The policies of Western and Platte River are to investigate RI and TVI problems and to correct those caused by Western and/or Platte River facilities. Western routinely investigates $\mathrm{RI}$ and TVI complaints and is prepared to resolve any interference problems resulting from the operation of the proposed project.

Visible Light. It is not anticipated that the visibility of corona would be any more noticeable after the upgrade, with any of the alternatives, than the visibility of corona from the existing transmission lines. This is because the visibility is not cumulative, or additive, but is dependent on weather conditions, and because of the construction materials used and maintenance of the line hardware to minimize the corona (e.g., the use of corona rings and corona-free hardware). 
Photochemical Oxidants.

Because the resolution of ozone instrumentation is approximately 1.0 parts per billion (ppb), it is very unlikely that corona-generated ozone from the proposed project could even be measured.

Electric Fields. The computed electric field profiles at one meter above ground for the alternatives including the Proposed Action are shown on Table 4-2. The maximum field in the ROW at the smallest conductor ground clearance of 22 feet is approximately $1.55-\mathrm{kV} / \mathrm{m}$ with the Proposed Action. These field levels are approximately the same as the existing conditions for the east/south edge of the ROW and the maximum in the ROW, and slightly higher for the west/north edge of the ROW.

\begin{tabular}{|c|c|c|c|}
\hline \multicolumn{4}{|c|}{$\begin{array}{c}\text { Table 4-2 } \\
\text { Electric Field Levels }\end{array}$} \\
\hline Alternative & $\begin{array}{l}\text { East/South } \\
\text { Edge of ROW } \\
(\mathrm{kV} / \mathrm{m})\end{array}$ & $\begin{array}{l}\text { West/North } \\
\text { Edge of ROW } \\
(\mathrm{kV} / \mathrm{m})\end{array}$ & $\begin{array}{c}\text { Maximum in } \\
\text { ROW } \\
(\mathrm{kV} / \mathrm{m})\end{array}$ \\
\hline Existing Conditions & 1.53 & 0.90 & 1.53 \\
\hline Alternative A - Proposed Action & 1.55 & 1.55 & 1.55 \\
\hline $\begin{array}{c}\text { Alternative A1 - Single-circuit Single Steel } \\
\text { Pole Structures }\end{array}$ & 1.48 & 0.83 & 1.81 \\
\hline $\begin{array}{r}\text { Alternative A2 - Double-circuit Single } \\
\text { Steel Pole Structures }\end{array}$ & 0.25 & 0.25 & 1.09 \\
\hline $\begin{array}{c}\text { Alternative A3 - Self-supported Angle } \\
\text { Structures }\end{array}$ & 1.55 & 1.55 & 1.55 \\
\hline
\end{tabular}

The maximum electric field levels associated with Alternative A1 would be slightly higher $(1.81-\mathrm{kV} / \mathrm{m})$, and Alternative A2 would be slightly lower $(1.09-\mathrm{kV} / \mathrm{m})$ than the Proposed Action. The electric field levels associated with Alternative $A 3$ would be the same as the Proposed Action.

Induced Currents. In general, the electric fields around these lines are not great enough to produce perceivable shocks to persons contacting grounded objects. It is the policy of Western and Platte River that special cases such as long fences parallel to the transmission line can be addressed on a case-bycase basis.

Steady-State Currents. The maximum induced current criterion for vehicles is $5 \mathrm{~mA}$. Potential steadystate current shocks from vehicles under the proposed transmission line upgrade will be less than $5 \mathrm{~mA}$ for the largest vehicle anticipated and will not be perceptible for most vehicles. This standard would be maintained for all of the alternatives.

Several factors tend to reduce the opportunity for secondary shocks to occur. If activities are distributed over the whole ROW, then only a small percentage of time will be spent in areas where the field is at or close to the maximum value. ${ }^{11}$ The vehicular traffic in high-field-strength areas in limited since clearances are generally higher over road crossings, and farm machinery on soil or vegetation tends to reduce shock currents substantially. Because of these factors, most steady-state current shocks are below the $1.1 \mathrm{~mA}$ perception level for 50 percent of men and, in fact, less than the $0.5 \mathrm{~mA}$ standard for maximum leakage current from portable appliances. Thus, steady-state current shocks will rarely be perceptible and if perceptible will represent a nuisance rather than a hazard.

"Silva (1985); Silva, Zaffonella \& Hummon (1985). 
Potential steady-state current shocks from vehicles under the existing transmission lines are at or below the secondary shock level, where secondary shocks are defined as those that could cause an involuntary and potentially harmful movement but cause no direct physiological harm.

Spark Discharge Shocks. Spark discharge shocks theoretically could occur under the proposed transmission line upgrade just as they could under the existing transmission lines. However, the magnitude of the electric field is low enough for all of the alternatives that this type of shock rarely, if ever, would occur and then only in a small area under the transmission lines near mid-spans. As with the existing transmission lines, handling conducting objects under the lines can also result in spark discharges that are a nuisance. Irrigation pipe, and other similar objects, should be carried as low to the ground as possible and preferably unloaded at a distance from the transmission lines to eliminate spark discharge nuisance shocks. The primary hazard with irrigation pipe, and other similar objects, is direct contact with the conductors.

Field Perception. It is unlikely that the electric field under the proposed transmission line upgrade would be perceivable directly when standing on the ground. This would be true for all of the alternatives. When working on top of equipment there would probably be enough extraneous skin stimulation during normal activities to preclude any perception of the field.

Electric Field Mitigation. The grounding policies of Western and Platte River eliminate the possibility of nuisance shocks due to induced currents from stationary objects such as fences and buildings. Since the electric field extends beyond the ROW, grounding requirements extend beyond the ROW for very large objects or extremely long fences. Electric fences require a special grounding technique because they can only operate if they are insulated. Mobile objects such as vehicles and farm machinery cannot be grounded permanently like a fence or building. Limiting coupled currents to persons from such objects are accomplished in three ways:

1. The NESC requires that the conductor clearance for lines with voltage exceeding $98-k V$ be such as to keep the induced short-circuit current to the largest anticipated vehicle under the line less than $5 \mathrm{~mA}$.

2. A second method of reducing potential currents to persons is through the intentional use of grounds. For example, a chain or other conductor can be dragged by a vehicle; a ground strap can be attached to the vehicle when it is stopped.

3. The very nature of large vehicles and their use tend to provide some grounding and reduce the electrical resistance of the vehicle to ground. Tires tend to be conductive, farm machinery is usually in direct contact with the soil, and conducting vegetation is in contact with equipment. Because of these factors, the realization of a well insulated (worst-case) vehicle is a remote possibility.

Electric field reduction and the accompanying reduction in induced characteristics such as shocks is also accomplished by conductive shielding. Persons inside a conducting vehicle cab or canopy will be shielded from the electric field. ${ }^{12}$ Similarly, a row of trees or a lower voltage distribution line will reduce the field on or near the ground. ${ }^{13}$ Metal pipes, wiring, and other conductors in a residence or building will shield the interior from the electric field due to the transmission lines. Thus, impacts of electric field coupling can be mitigated through grounding policies and adherence to the NESC. Worst-case levels are used for safety analysis, but, in practice, currents and voltages are reduced considerably by inadvertent grounding. Shielding by conducting objects, such as vehicles and vegetation, also reduces the potential for electric field effects.

Magnetic Fields. Table 4-3 provides the calculated magnetic field levels at one meter above the ground for the alternatives including the Proposed Action. Since the magnetic field levels are directly influenced by source current, these calculations have been performed for a variety of loading scenarios. As the table shows, the maximum field resulting from the Proposed Action at the edge of the ROW for peak loading is $21.81 \mathrm{mG}$.

The magnetic field level resulting from the Proposed Action would be slightly higher at the east/south edge of the ROW adjacent to the existing 115-kV line, and significantly reduced at the west/north edge of the

12 Silva, et al. (1985).

13 Deno \& Silva (1987). 
ROW. The maximum magnetic field level in the ROW would also be significantly reduced under the Proposed Action. These reductions are due to the use of taller structures, more evenly balanced line loading, and the use of less current to deliver the same amount of power with the upgraded 115-kV line.

Table 4-3

Magnetic Field Levels

\begin{tabular}{|c|c|c|c|c|}
\hline Alternative & $\begin{array}{c}\text { Line Loading } \\
\text { 17.5 MVA } \\
\text { (87.9 AMPs) } \\
\end{array}$ & $\begin{array}{c}\text { East/South } \\
\text { Edge of ROW } \\
\text { (mG) }\end{array}$ & $\begin{array}{l}\text { West/North } \\
\text { Edge of ROW } \\
\text { (mG) }\end{array}$ & $\begin{array}{l}\text { Maximum in } \\
\text { ROW } \\
\text { (mG) }\end{array}$ \\
\hline Existing Conditions & Peak Loading & 14.88 & 47.10 & 54.23 \\
\hline $\begin{array}{l}\text { Alternative A - The } \\
\text { Proposed Action }\end{array}$ & Peak Loading & 21.71 & 21.71 & 21.81 \\
\hline $\begin{array}{l}\text { Alternative A1 - } \\
\text { Single-circuit Single } \\
\text { Steel Pole Structures }\end{array}$ & Peak Loading & 19.83 & 11.43 & 21.49 \\
\hline $\begin{array}{l}\text { Alternative A2 - } \\
\text { Double-circuit Single } \\
\text { Steel Pole Structures }\end{array}$ & Peak Loading & 2.66 & 2.66 & 11.94 \\
\hline $\begin{array}{l}\text { Alternative A3 - Self- } \\
\text { supported Angle } \\
\text { Structures }\end{array}$ & Peak Loading & 21.71 & 21.71 & 21.81 \\
\hline
\end{tabular}

The magnetic field levels resulting from Alternative $A 1$ would also be slightly higher at the east/south edge of the ROW and significantly reduced at the west/north edige of the ROW and for the maximum in the ROW when compared to the existing conditions shown on Table 3-4.

The magnetic field levels resulting from Alternative $A 2$ would be significantly lower for all conditions due to the taller structures located in the center of the ROW, the line geometry that places the conductors closer together, and using reverse phasing for maximum magnetic field cancellation.

The magnetic field levels resulting from Alternative $A 3$ would be the same as the Proposed Action.

Magnetically Induced Currents and Voltages. As with the existing transmission lines, alternating magnetic fields induce voltages at the open ends of conducting loops. The possibility for a shock exists if a person closes the loop at the open end by contacting both the ground and the conductor. Since the magnetic fields associated with the proposed upgraded transmission line will generally be less than the existing configuration, any magnetically-induced voltages or currents will be less than with the existing configuration. This would be true for all alternatives. It is unlikely that magnetically-induced voltages and currents would have an adverse impact.

Magnetic induction effects from the existing and proposed transmission lines are minimal because of Western and Platte River's knowledge of the phenomenon, and grounding practices and other mitigation measures. It is therefore unlikely that magnetically induced voltages and currents would have an adverse impact.

Magnetic Field Mitigation. As a comparison of Tables 3-4 and 4-3 illustrates, the magnetic field levels at the edge of the ROW would be slightly higher along the existing $115-\mathrm{kV}$ line $(21.71 \mathrm{mG}$ versus $14.88 \mathrm{mG})$, and significantly lower along the upgraded line $(21.71 \mathrm{mG}$ versus $47.10 \mathrm{mG})$. The maximum 
magnetic field level in the ROW would also be reduced significantly ( $21.81 \mathrm{mG}$ versus $54.23 \mathrm{mG})$. This is due to higher current levels required for the existing $69-\mathrm{kV}$ transmission line to deliver the same amount of power as can be delivered with less current on a 115-kV transmission line. The two 115-kV lines also allow for more balanced loading which reduces the magnetic field levels.

Potential Human Health Effects. The question of whether exposure to power-frequency $(60 \mathrm{~Hz})$ electric and/or magnetic fields can cause biological responses or even health effects has been the subject of considerable research for the past three decades. A number of potential health effects have been examined, including alterations in cellular properties that could lead to the development of cancer, alterations in reproductive function, and other alterations in the normal functioning of the human body. A thorough review of scientific evidence relevant to this topic would lead to an examination of over 10,000 scientific reports. This review focuses on the aspects that have received the most recent and most thorough attention, namely magnetic field exposure and the possibility of the development of cancer.

This review's conclusions are consistent with recent reviews of the EMF biological and health literature by U.S. and International scientific and regulatory agencies. Over twenty independent scientific groups in the past 18 years have evaluated the evidence from human, animal and exposure assessment research on the potential health effects associated with exposure to electric and magnetic fields.

Site Specific Exposure Assessment. In any analysis about possible health impacts of a given exposure (such as exposure to $60-\mathrm{Hz}$ electric and/or magnetic fields), it is important to specify the characteristics of the exposures. The expected levels of electric and magnetic fields associated with this project (Tables 3-3 and 4-3) fall within the range of values commonly found in residences and offices, and also fall within the range examined in the epidemiologic studies discussed below and by all of the expert panels that have reviewed this issue. It should be noted that these field levels are considerably lower than those commonly used in laboratory research.

The Health Issue. In the late 1960's and early 1970's the possibility of adverse health effects resulting from exposures to electric fields received considerable attention. After considerable research failed to confirm the original reports from the Soviet Union that gave rise to the concern, in the 1980's interest shifted primarily to magnetic fields. The main reason was the publication by Wertheimer and Leeper in 1979 of a paper reporting an association between the appearance and distance of power lines near a residence and childhood cancer. The shift away from the examination of electric fields appears justified by subsequent studies that are unanimous in failing to report even a weak association between measured electric fields and cancer in either children or adults.

In order to analyze the possibility that any exposure, such as that to $60-\mathrm{Hz}$ magnetic fields, could present a health risk to humans, one must consider the results from three complementary areas: epidemiologic and laboratory research studies, as well as exposure assessment. Epidemiologic studies have examined possible associations between the electric and/or magnetic fields from power lines and human health risks. Laboratory studies have examined the biological responses, both in humans, whole animals and in isolated cells and tissues, to electric and/or magnetic fields. Exposure assessment studies attempt to quantify the exposure that individuals may receive in the course of their normal life at home, in schools, at work, etc. It is generally agreed that the use of epidemiologic, laboratory, and exposure assessment data provides important complementary information needed for any balanced evaluation of potential risk.

\section{Cancer}

Epidemiologic Studies. Epidemiology is the science that examines the patterns of disease within human populations. The objective of epidemiology is to evaluate and measure the associations between exposures to environmental factors (e.g., asbestos, smoking cigarettes) and health outcomes (e.g., pleural mesothelioma, lung cancer). Epidemiologic studies look for associations between the exposure of a group of people to an agent (possible risk factor) and the occurrence of disease in that group.

Epidemiology deals with people in their natural environment, so exposures cannot be controlled or limited to the factors being studied. Thus, epidemiology is an observational science, not an experimental science. That is, epidemiology only addresses possible associations with disease outcome; it does not demonstrate whether or not a particular agent does or does not cause disease.

A positive association between an environmental exposure and a disease cannot be established by a single epidemiologic study, but rather requires positive evidence from a collection of epidemiologic studies 
conducted with sound methods. Since all associations are not causal, there is a need to identify objectively, exposures that may be causally related to disease. The most widely used of these criteria were originally set forth by the noted epidemiologist Sir Bradford Hill, and have subsequently been used by the Surgeon General of the United States and others in evaluating associations. According to the Hill criteria, some characteristics of the data add weight to the argument that the two factors may be related as cause and effect; these include: strong associations; consistency within and across studies, biological plausibility derived from laboratory data, and a dose-response relationship.

For epidemiologic studies to show an association between exposure to an agent and a specific health outcome, they must include accurate exposure assessments. There are many difficulties however, with determining people's exposure to $60-\mathrm{Hz}$ magnetic fields. Ideally, exposure in the studies would be assessed by measurements of total personal exposure of each individual. Since epidemiologic studies require either the reconstruction of exposures that occurred in the past, or a limited sample of ongoing exposure, none of the studies to date have studied total personal exposure. Since studies could not be designed to directly measure an individual's total exposure, researchers have used surrogate (substitute) exposure measures to magnetic fields.

In residential epidemiologic studies, surrogate measures of field exposures include wiring codes ${ }^{14}$, distance from the line or source ${ }^{15}$, calculated fields ${ }^{16}$ and spot or longer-term measurements ${ }^{17}$. As stated previously, a major problem and scientific limitation of these studies is that the estimation of exposure to magnetic fields falls well short of total personal exposure.

Some published studies have examined possible associations between childhood cancer and surrogate measures of magnetic field exposure from electrical facilities. Some of these residential studies have shown a weak but statistically significant association between surrogate measures and some types of childhood cancer (Wertheimer and Leeper, 1979; Savitz et al, 1988; London et al, 1991; Feychting and Ahlbom, 1992; 1993; Ahlbom et al, 1993; Olsen et al, 1993; Verkasalo et al, 1993). That is, children with cancer were reported to be more likely to live in homes with a higher wire code (or other surrogate measure) than were healthy children. It is noteworthy that in the studies that made spot and/or 24-72 hour continuous magnetic field measurements in the homes to estimate exposure, the investigators did not report a statistically significant association between childhood cancer and measured fields, (Savitz et al, 1988; London et al, 1991; Feychting and Ahlbom, 1992; 1993). Also noteworthy is that the associations reported in the childhood cancer studies are not consistent with respect to cancer type. For example, sometimes an association is reported for childhood leukemia (Wertheimer and Leeper, 1979; London et al, 1991; Feychting and Ahlbom, 1992; 1993) sometimes with brain tumors (Tomenius, 1986; Savitz et al, 1988) and sometimes for other cancers (Olsen et al, 1992). It is not known why in some studies cancer appears to be associated with some types of surrogate measures (e.g., wire codes or calculated fields) but is not significantly associated with other types of surrogate measures (e.g., actual measurements of magnetic fields). This area continues to be the focus of ongoing research.

Laboratory Studies. A wide range of magnetic field intensities at $60-\mathrm{Hz}$ have been studied in the laboratory to attempt to elicit biological responses. At present, there is no accepted physical mechanism that can readily explain how a cell could respond to $60-\mathrm{Hz}$ magnetic fields of low intensities (e.g., less than 200-500 mG). Nor is there a consistent, reproducible body of laboratory data that suggests that $60-\mathrm{Hz}$ magnetic fields can cause, promote or enhance the development of cancer. Most of the relevant laboratory studies have been conducted at intensities that greatly exceed the magnetic field intensities anticipated for the normal loads of the present project (see Table 4-3; typically, cancer laboratory studies

14 A wiring code is a description of the types, thickness and proximity of power lines outside of a residence. A two-level wire code was first introduced in 1979 by Wertheimer and Leeper, and subsequently refined into a five-level wire code in 1982. Variations of the 1982 code have been used by Savitz et al (1988) and others.

15 Since the strength of the magnetic field decreases with increasing distance from the source, distance has been used as a very crude surrogate measure of magnetic field exposure (e.g., Feychting and Ahlbom, 1992; 1993.)

16 The magnetic fields associated with the operation of power lines can be determined with the use of well-validated computer models, such as the ones used in the PTI report that is relied upon here.

17 This method actually provides a direct measure of indoor field levels, usually at a single time and at a few locations (e.g., Savitz et al, 1988; London et al, 1991, Feychting and Ahlbom, 1992, 1993.) 
have been conducted at magnetic field intensities of 1,000-20,000 mG). Thus, laboratory studies conducted to date cannot provide support for the Hill criterion that demands biological plausibility of observed epidemiologic associations.

Expert Panel Reviews of the Emf Health Issue. Many different groups of expert scientists have reviewed the data relevant to the question of whether exposure to power frequency electric and magnetic fields is associated with adverse health effects. All of these groups have concluded that the body of data, as large as it is, does not support the conclusion that exposure to power-frequency electric or magnetic fields (at intensities that span the lowest recorded environmental levels to those that far exceed environmental and usual occupational exposures) causes cancer or otherwise constitutes a health hazard. Although some epidemiologic studies using surrogate measures have reported associations, other studies have not. However, because of the few residential studies that have pointed to possible positive associations between exposure and development of cancer, all of the expert panels have acknowledged the need for further research and monitoring of the issue (e.g., CPUC/CDHS, 1989; IRPAINIRC, 1990; ACGIH, 1991; NRPB, 1992, 1993; Illinois, 1992; ORAU, 1992, 1993; ICNIRP, 1993; INSERM, 1993; Danish Ministry of Health, 1993; AMA, 1994).

Summary. In summary, a universal deficiency in the epidemiologic literature concerns exposure assessment. The weakness of the reported associations, the lack of consistency within and across studies, and the deficiencies in exposure assessment in the epidemiologic studies conducted to date indicate that, as a whole, these studies do not support the conclusion that exposure to power-frequency magnetic fields is a cause of cancer. This conclusion is founded on all of the available data, and derives from the well established approach (the Hill Criteria) for evaluating the extent to which associations observed in epidemiologic studies could support a cause and effect relationship. This conclusion is also consistent with the conclusions reached by numerous independent scientific groups that have evaluated this body of research.

EMF Requlation. The EMF prudent avoidance considerations adopted by the Colorado Public Utilities Commission (CPUC) have been reviewed by Western and Platte River with respect to planning, siting, construction, and operation of the project transmission facilities.

\subsubsection{Visual Resources}

Impacts to the visual resources that could result from the construction, operation and subsequent reclamation of the proposed project would include any visibility of the modified landform, color and texture, potential glare from new conductors, any dust resulting from construction, and visibility from existing and new residences, commercial developments, primary transportation routes, recreation areas, structures visible in scenic landscapes, and structures that are skylined.

Visual resources were identified as an important issue by the Rocky Mountain National Park and several citizens through the public/agency scoping meetings. The primary visual concerns identified focused on physical disturbances on the existing ROW, the guy wires associated with the three-pole angle structures, the disturbance at Marys Lake Substation, and the existing distribution line that parallels portions of the transmission line.

Portions of the existing transmission lines and the proposed project are visible in the foreground and middleground views from within the adjacent residential subdivisions, Peak View Drive, and Marys Lake Road. The visual impacts were analyzed by field observations and through the use of computer generated photographic simulations. Photographic simulations of the proposed project and alternatives are presented in Appendix I in Figures l-1 through 1-8.

Initially, an assessment of the visibility of the proposed project was conducted. The results of this assessment are detailed in Table G-1 in Appendix G. Following is a summary of the visual impacts of the proposed project:

Number of structures visible from primary transportation routes

Number of existing residences from which the transmission line would be visible

Number of new residences from which the transmission line would be visible 
Number of commercial developments from which the transmission line would be visible

While the number of existing residences from which the transmission line would be visible (230) is quite large, these residences are currently impacted by the existing $115-\mathrm{kV}$ and $69-\mathrm{kV}$ transmission lines that were constructed prior to when the homes were built, and would continue to be impacted by the $115-\mathrm{kV}$ line even if the upgraded $69 / 115-\mathrm{kV}$ line was constructed in another location. The remaining occurrences of visual impacts are not significant.

The basis of the U.S. Forest Service VMS was then utilized to assess the visual impacts to the existing landscape. The Forest Service VMS is described in Chapter 3. Visual impacts would be considered significant if the construction, operation and reclamation of the project ROW is found to be inconsistent with the VQO (Visual Quality Objective) of Modification presented in Chapter 3. The locations selected as observation points from which to conduct the VMS assessment are shown on Figure 3-3.

The sensitivity analysis, visibility, and compliance with the VQOs are assessed below for each alternative.

\section{Comparison of Alternatives}

No Action. There would be no impacts to visual resources other than those associated with the existing electric facilities.

Alternative A - The Proposed Action. The Proposed Action is described in detail in Section 1.1 and Section 2.2.3. As previously described, the Proposed Action would utilize wood $\mathrm{H}$-frame type structures similar to the existing transmission lines, and non-specular conductors the same size $(336,400$ mils) as the existing conductors. This structure type is illustrated on Figure $2-4$ and by photographic simulation in Figure $1-1$.

This alternative crosses each of the four vegetation habitat types identified in the project area: (1) coniferous forest; (2) montane meadow; (3) sagebrush shrubland; and (4) wetland. Based on the VMS methodology, the project area is classified as a Variety Class $B$, above average.

Utilizing the wood-pole $\mathrm{H}$-frame type structure has several benefits including: (1) the structure is not required to be as tall as other structure types because the conductors are arranged horizontally instead of vertically; (2) the shorter size, color and wood materials make this structure type less conspicuous; (3) the structural integrity and support provided by the two pole configuration of the $\mathrm{H}$-frame structure allow for greater span lengths, and thus, less structure sites; and (4) it is similar to other structures used in the area for the 115-kV transmission line and distribution lines and would, therefore, not introduce a new element into the landscape.

The visual contrasts (the landform line, form, color and texture) associated with the wood $\mathrm{H}$-frame structures of the transmission line and expansion of the substations range from moderate to weak depending on the viewing point. In general, the foreground views result in moderate contrasts and the middleground and background views result in weak contrasts. Overall, the contrasts resulting from the transmission line were assessed to be weak due to the variety of the existing landscape and urban development, the wood material and color of the $\mathrm{H}$-frame structures, and the use of non-specular conductors the same size as the existing conductors.

The visual impacts associated with views from Marys Lake Road and Marys Lake are shown in Figures 12, I-3, 1-4, I-5. Figure $1-2$ illustrates the addition of a wood $\mathrm{H}$-frame structure on the east side of Marys Lake. Other modifications in this area include the removal of approximately $1 / 2$ mile of existing $69-\mathrm{kV}$ transmission line on wood $\mathrm{H}$-frame structures along the north side of Marys Lake Road, and the addition of approximately $1 / 4$ mile of $69-\mathrm{kV}$ transmission line on wood $\mathrm{H}$-frame structures west of Marys Lake along the road to Marys Lake Substation. The area of expansion of Marys Lake Substation is shown on Figure 1-3. Figures 1-3, 1-4 and I-5 illustrate the visual impact of the expansion of the existing Marys Lake 
Substation, proposed screening, and proposed screening after 10-years growth, respectively. The yard lighting at Marys Lake Substation will be modified to be directed down and shielded from the sides, similar to the new street lighting used by the Town of Estes Park. Brighter lighting may be required for use in emergency situations requiring night-time work at the substation.

The Modification VQO assigned to the Marys Lake area would allow activities that visually dominate the original characteristics landscape when the activities borrow from the naturally established line, form, color and texture at a similar scale so that its visual characteristics are those of natural occurrences within the surrounding areas or character type. The contrasts resulting from expansion of the Marys Lake Substation were assessed to be moderate due to the increased scale of the facilities and landform modifications which will result in additional color contrasts from excavated rock. This contrast will be reduced by excavating to the west into the hillside rather than parallel to Marys Lake, and by proposed landscape screening, and possibly by the use of rock-staining techniques.

The contrasts resulting from expansion of the Estes Power Plant Switchyard were assessed to be weak as the scale of the proposed expansion is small when compared to the existing facility and equipment.

The scenic quality of the project area was determined by comparing the visual contrasts to the variety class. The overall visual contrast of the project was assessed to be moderate to weak, and the project is located in an area characterized as a Class B variety class. When comparing these two elements, the overall scenic quality was assessed to be weak.

Based on these assessments, the proposed project would comply with the VQO of Modification.

Alternative A1 - Single-circuit, Single Steel Pole Structures. This alternative would utilize the same existing ROW but would replace the existing wood $\mathrm{H}$-frame structures with single steel poles; the expansion of the substations would be the same. This structure type results in a taller visual profile and would require that the structures be placed closer together. This structure type is shown on Figure 2-4 and by photographic simulation in Figure I- 6 .

The visual contrasts resulting from Alternative A1 are assessed to be strong due to the taller profile of the poles, the need to space the poles closer together, the color contrasts resulting from the steel poles, additional impacts to vegetation that would result from additional structures, and the mixing of steel poles next to the existing wood $\mathrm{H}$-frame structures. In addition, since the span lengths of the existing wood $\mathrm{H}$ frame structures and the steel pole structures would be different, there would be a visual perception of even more structures and clutter.

In general, the foreground views would result in strong contrasts due to the increased height, the need to place the structures closer together, and the mixture of wood and steel structures. The middleground views would result in moderate to strong impacts, and the background views would result in weak to moderate contrasts. Overall, the contrasts resulting from Alternative A-1, using single steel poles for the transmission line, would be moderate to strong.

The scenic quality of the project area is weak, the same as Alternative A. Alternative $A 1$, while having a greater visual impact than the Proposed Action, would also comply with the VQO of Modification.

Alternative A2 - Double-circuit Single Steel Pole Structures. This alternative would also utilize the same existing ROW but would replace the existing wood $\mathrm{H}$-frame structures of both existing transmission lines with single steel poles; the expansion of the substations would be the same. The double-circuit single steel pole structures, while reducing the overall number of structures in the area, would also result in a taller visual profile and be spaced closer together. This structure type is shown on Figure $2-4$ and by photographic simulation in Figure I-7.

The visual contrasts resulting from Alternative A2 are assessed to be moderate due to the taller profile of the poles, the need to space the poles closer together, the color contrasts resulting from the steel poles, and additional impacts to vegetation that would result from additional structures.

In general, the foreground views would result in strong contrasts due to the increased height and the need to place the structures closer together. The middleground views would result in moderate impacts, and the background views would result in weak contrasts. Consolidating both existing transmission lines on 
double-circuit single steel pole structures would result in somewhat less visual impact than Alternative $A 1$ where the structure types are mixed. Overall, the contrasts resulting from Alternative A2, using doublecircuit single steel pole structures for the transmission line, would be moderate.

The scenic quality of the project area is weak, the same as Alternative A. Alternative A2, while having a greater visual impact than the Proposed Action, and would also comply with the VQO of Modification.

Alternative A3 - Self-supported Angle Structures. This alternative would be the same as the Proposed Action but would replace the existing guyed three-pole angle structures of the upgraded line with self-supported steel structures; the expansion of the substations would be the same. The selfsupported angle structures, while reducing the number of guy wires at the angles in the line, would also result in a taller and more prominent visual profile, and would mix the use of new steel poles with the existing guyed three-pole wood angle structures that would remain on the existing 115-kV line. The diameter at the base of the self-supported angle structure would be approximately 34 inches as compared to approximately 15 to 18 inches for the wood poles. The diameter at the top of these structures would be approximately 15 inches versus 8 inches for the wood poles. This structure type is shown on Figure 2-4 and by photographic simulation in Figure 1-8.

The visual contrasts at the angle sites resulting from Alternative $A 3$ are assessed to be moderate due to the taller profile of the structures, the color contrasts resulting from mixing the steel and existing wood poles, and additional impacts to vegetation that would result from additional structures.

In general, the foreground views would result in strong contrasts due to the increased height and bulk of the structures. The middleground views would result in moderate impacts, and the background views would result in weak contrasts. Overall, the contrasts resulting from Alternative A3 using self-supported angle structures for the transmission line would be moderate.

The scenic quality of the project area is weak, the same as Alternative A. Alternative A3, while having a greater visual impact than the Proposed Action, and would also comply with the VQO of Modification.

\subsubsection{Socioeconomics}

Population. The proposed project would result in a small short-term increase in population in Estes Park due to employment of contract construction workers. As described in Table 2-4, the number of workers that would be employed would be approximately 12-16 during the peak of construction. As the Estes valley experiences a nearly four-fold increase during the summer months (League of Women Voters, 1993), this construction force represents an insignificant increase.

Economy and Employment. It is unlikely that the proposed project would have a perceptible impact on the area economy as it will not affect tourist visitation to the Rocky Mountain Park and Estes Park. The short-term nature of project construction and the limited number of workers employed should result in limited positive economic impacts to Estes Park in the form of increased spending on lodging, meals, and other consumer goods and services.

Housing. As previously described, construction of the proposed project could temporarily increase the local population by 12 to 16 people (or 24 to 48 , if all families temporarily relocated to Estes Park). Based on housing data available from the U.S. Census, the rental vacancy rate of 6.3 percent and 448 housing unit vacancies for seasonal, recreational, or occasional use should be more than adequate for the temporary population increase associated with construction.

Community Services. Construction, operation, and maintenance of the proposed project should not increase or decrease the need for police, fire, medical, or other community resources in the project area. Although construction of the project could temporarily increase the local population, the increase for services by those associated with construction would be insignificant as the local population increases significantly on an annual basis during tourist seasons.

Executive Order 12898. On February 11, 1994, Executive Order 12898, "Federal Actions to Address Environmental Justice in Minority Populations and Low-Income Populations" (Order) was published in the Federal Register (59 FR 7629). The Order requires federal agencies to identify and address disproportionately high and adverse human health or environmental effects of its programs, policies, and 
activities on minority populations and low-income populations. Currently, no formal guidelines have been adopted to implement the Order. However, the Environmental Protection Agency (EPA) has published relevant studies and information on environmental justice and is leading an interagency task force to address the issues of environmental justice. Western, through the Department of Energy (DOE), is a participating member of this task force. In July 1993, DOE distributed a memorandum stating the Department's commitment to environmental justice, providing information to better understand environmental justice issues, and requesting input as to how DOE should consider environmental justice in its NEPA documents (DOE Memorandum of July 22, 1993, from the Office of NEPA Oversight).

This Environmental Assessment was prepared with these guidelines in mind. The proposed project is located within an area characterized by a uniform population. The proposed project is located on an existing ROW. Approximately one-quarter of the project is within commercial areas and the remaining three-quarters is bordered by residential and open areas. The largest segment of the population, or nearly 99 percent, was described by the 1990 census as White, including those of Hispanic origin; other races made up slightly less than one percent of the population. The project area is represented by a range of upper-middle income levels and fairly uniform backgrounds. Therefore, this project will not disproportionately impact minority and low-income populations.

\subsection{Natural Environment}

\subsubsection{Earth Resources}

Soils. The project would have no effect on soils as long as disturbances are revegetated to prevent erosion and soil compaction is minimized. None of the soils that would be disturbed by the Proposed Acton are considered "highly erosive." No prime agricultural soils would be disturbed by the Proposed Action. Western's Standard Construction Practices (see Table 2-5) include procedures to prevent soil erosion.

Geology. The project would have no effect on geology and there are no geologic hazards present which would have an effect on the project.

Surface Water. The Proposed Action would not physically affect any identified surface water resources. The Proposed Action would only span Marys Lake at the existing location and any new disturbance to the banks or channels for pole placement would not result in significant impacts. Access to the transmission lines would occur on existing roads. Western and Platte River employ best management practices for sediment control. Western's Standard Construction Practices (see Table 2-5) include procedures to prevent soil erosion from affecting surface water bodies. These practices also include procedures to prevent spills into surface water bodies.

Ground Water. The Proposed Action would not affect any ground water resources. The water table along the existing transmission ROW is approximately 42 feet below the ground surface. The placement of the proposed wood $\mathrm{H}$-frame poles would penetrate a maximum of only $8-10$ feet into the ground. There are no wells located within the existing transmission line ROW.

Floodplains. No feature of the proposed project is located within a designated floodplain. There would be no flood-related impacts associated with the proposed project.

\subsubsection{Biological Resources}

\section{Vegetation.}

Impacts Common to All Alternatives. Impacts to vegetation caused by the Proposed Action alternatives would be primarily confined to the immediate area of the structure assembly and erection. These areas have a relatively small extent. Roads, each approximately $150 \times 10$ feet in size, may be constructed to supply access to the ROW in three areas of poor accessibility. The anticipated impacts to each vegetation type are shown on Table 4-4.

Loss of native vegetation. Direct impacts to vegetation occur with the loss of cover and biomass as the vegetative layer is scraped away and removed at each structure site. These impacts would be short-term as vegetation (either in the form of natural reintroduction or reclamation seeding) grows back. It should be 
emphasized that generally natural succession will quickly revegetate the vast majority of the disturbed sites. The temporary roads would also be reclaimed with a suitable native seed mix.

Some impacts could be long-term if the existing seed source is lost with the removal of the topsoil. Some areas may not readily revegetate. If the topsoil (the first 12 -inches or so of soil with organic matter in it) is turned under and diluted with soils with no organic matter, the substrate may not adequately be able to support a seed bed. Therefore, natives may not re-establish and barren or weedy spots could remain.

Table 4-4

Vegetation Impacts

\begin{tabular}{|c|c|c|c|c|c|c|}
\hline & \multicolumn{3}{|c|}{ Transmission ROW } & \multicolumn{3}{|c|}{ Marys Lake Substation } \\
\hline & $\begin{array}{l}\text { Total Acres } \\
\text { within } \\
\text { Corridor }\end{array}$ & $\begin{array}{l}\text { Short-term } \\
\text { Impacts }\end{array}$ & $\begin{array}{l}\text { Long-term } \\
\text { Impacts }\end{array}$ & Total Acres & $\begin{array}{l}\text { Short-term } \\
\text { Impacts }\end{array}$ & $\begin{array}{l}\text { Long-term } \\
\text { Impacts }\end{array}$ \\
\hline $\begin{array}{l}\text { Urban } \\
\text { Plantings }\end{array}$ & $\begin{array}{l}307,969 \mathrm{ft}^{2} \\
(7.07 \text { acres })\end{array}$ & 0 & 0 & 0 & 0 & 0 \\
\hline Sagebrush & $\begin{array}{l}247,856 \mathrm{ft}^{2} \\
\text { (5.69 acres) }\end{array}$ & $\begin{array}{l}5,663 \mathrm{ft}^{2} \\
(0.13 \text { acre })\end{array}$ & $\begin{array}{l}218 \mathrm{ft}^{2} \\
(0.005 \text { acre })\end{array}$ & 0 & 0 & 0 \\
\hline Wetlands & $\begin{array}{l}75,794 \mathrm{ft}^{2} \\
\text { (1.74 acres) }\end{array}$ & $0^{*}$ & $0^{*}$ & 0 & 0 & 0 \\
\hline $\begin{array}{l}\text { Coniferous } \\
\text { Forest }\end{array}$ & $\begin{array}{l}652,093 \mathrm{ft}^{2} \\
(14.97 \text { acres })\end{array}$ & $\begin{array}{l}6,098 \mathrm{ft}^{2} \\
(0.14 \text { acre })\end{array}$ & $\begin{array}{l}261 \mathrm{ft}^{2} \\
(0.006 \text { acre })\end{array}$ & $\begin{array}{l}15,448 \mathrm{ft}^{2} \\
(0.35 \text { acre })\end{array}$ & $\begin{array}{l}15,448 \mathrm{ft}^{2} \\
(0.35 \text { acre })\end{array}$ & $\begin{array}{l}15,448 \mathrm{ft}^{2} \\
(0.35 \text { acre })\end{array}$ \\
\hline $\begin{array}{l}\text { Montane } \\
\text { Meadow }\end{array}$ & $\begin{array}{l}128,066 \mathrm{ft}^{2} \\
(2.94 \text { acres })\end{array}$ & $\begin{array}{l}3,485 \mathrm{ft}^{2} \\
(0.08 \text { acre })\end{array}$ & $\begin{array}{l}131 \mathrm{ft}^{2} \\
(0.003 \text { acre })\end{array}$ & 0 & 0 & 0 \\
\hline Total & $\begin{array}{l}1,411,787 \mathrm{ft}^{2} \\
(32.41 \text { acres })\end{array}$ & $\begin{array}{l}15,246 \mathrm{ft}^{2} \\
(0.35 \text { acre })\end{array}$ & $\begin{array}{l}610 \mathrm{ft}^{2} \\
(0.014 \text { acre })\end{array}$ & $\begin{array}{l}15,448 \mathrm{ft}^{2} \\
(0.35 \text { acre })\end{array}$ & $\begin{array}{l}15,448 \mathrm{ft}^{2} \\
(0.35 \text { acre })\end{array}$ & $\begin{array}{l}15,448 \mathrm{ft}^{2} \\
(0.35 \text { acre })\end{array}$ \\
\hline
\end{tabular}

The impacts illustrated on this table are based on an 80 -foot wide ROW and approximately 17,648 linear feet (approximately 3.1 miles) of transmission line. It is also assumed that the new wood poles would be placed close (within $\mathbf{5 0}$ feet) of the locations of the existing poles.

"Although wetland areas are crossed by the project, it is assumed that these areas will be spanned and access restricted by fencing (refer to 4.2.2 Biological Resources, Vegetation).

Indirect impacts include the compaction of soils and the invasion of weedy annuals onto the disturbed sites within the analysis areas.

Compaction of Soils. Soils would be disturbed at each structure location by vehicle movement and structure assembly and erection. Compacted soils leave little opportunities for perennial seed germination, root growth, and plant establishment. Thus, native vegetation could become displaced in a limited area. Plants would not become established and bare areas could remain. These barren areas would also be susceptible to wind and water erosion.

Opportunities created for weedy species invasion. With soil disturbance and exposure come the potential opportunities for weedy plant invasion. Weed seed is carried from site to site on the tires of equipment and vehicles, in soils, and on clothing. Many weedy species are annuals and need very minimal requirements for establishment and propagation. As weedy species increase, native plants are often displaced. This displacement leads to a decrease in palatable and suitable forage for wildlife, in nesting and resting habitat for birds, and natural diversity indicative of natural ecosystems. If best management practices are followed, establishment of weedy species will be minimal. 
Best Management Practices to Minimize Impacts to Vegetation Resources from Alternatives:

1. A native seed mix should be developed and used to reseed the disturbed areas after construction of the transmission line.

2. Reclamation should be conducted shortly after the construction is completed to eliminate opportunities for weedy annual species.

3. Minimize soil compaction by vehicle use between structure sites. Disk the compacted soils after construction is completed to break-up the hard soils. Soils will be stabilized and reclaimed as soon as possible after construction is completed.

4. Perform as much of the work as possible during the non-growing season (November through March). During this time, plants are dormant and less susceptible to trampling. Plan construction during the dry season to reduce, to the maximum extent, the potential for water erosion.

5. Use existing roads for the construction of the line whenever possible. This will help to minimize impacts to surrounding vegetation communities. Except where clearing of vegetation is required (at the structure sites and along the temporary access roads), all vegetation will be protected from damage by construction operations.

6. Any erosion'reclamation problems will be corrected immediately upon discovery. The ROW will be inspected regularly both during and after construction to insure that problem erosion areas are identified and revegetated promptly.

7. Delay the clearing of the vegetation from the structure sites until absolutely necessary, thereby reducing the time that bare soil is exposed. This will control erosion and minimize weedy plant opportunities.

8. Special emphasis will be taken to minimize vehicular traffic over soils susceptible to wind and water erosion.

9. Silt-fencing will be used to delineate the east and west wetland boundaries within the ROW. Access to the wetlands will be restricted and no driving in-between structures associated with the wetland areas will be allowed. The structures would be accessed from the northwest and north on Highway 7.

10. Wetlands will be spanned by the transmission line to eliminate the potential for impacts to them. If a pole must be placed within wetlands, the acreage would be calculated and the U.S. Army Corps of Engineers would be notified, if necessary, in writing for appropriate permitting.

Western has developed a good record over the past 15 years with respect to restoring disturbances resulting from construction activities. Initially, construction impacts are minimized by restrictions placed on the contractor in the project construction specifications. Western also assigns inspectors to the project on a daily basis to see that the specifications are being followed. The construction specifications require the contractor to minimize impacts and then to repair any disturbances that occur. In the event that the contractor does an inadequate job of restoration, Western is responsible for solving the problem on an individual's property immediately and settles with the contractor separately. More specific construction and restoration guidelines are included in Appendix $\mathbf{J}$.

Wildlife. Impacts to the existing wildlife resource is expected to be minimal. This consideration is based on both the nature of the project and the existing condition of the habitats in the area. Since there is no new disturbance planned for the Proposed Action, no wildlife habitats would be permanently impacted. Some species such as elk and deer may be displaced during construction. However, this displacement would be temporary and all habitats would be available immediately after construction. In addition, construction disturbances are not expected to be greater than human disturbances already occurring within the project area.

Bird species may have the greatest potential for impacts from the Proposed Action. Birds may potentially collide or be electrocuted by the line. Collisions are generally of greatest concern on transmission lines, while electrocution is of greatest concern with distribution lines (APLIC 1994). Although all birds may collide with transmission lines, waterfowl are the most common species associated with collisions. Waterfowl collide with 
lines due to their low altitude and high speed daily flights (APLIC 1994). Electrocution is typically of greatest concern for raptors due to their large wingspans. However, the spacing and configuration of transmission lines for $69-\mathrm{kV}$ lines and larger do not pose an electrocution hazard to raptors.

The following considerations reduce the potential for impacts to birds by the proposed action. First, the existing line does not have a history of bird electrocutions or collisions (T. McCormick Pers. Comm. 1995). Since the line would be placed in the same corridor, the potential for collisions is not expected to increase. Second, the line would be constructed using guidelines described in Suggested Practices for Raptor Protection on Power Lines: State of the Art in 1981, thereby reducing the potential for both electrocutions and collisions (Olendorff et al. 1981). Third, the new line would be slightly higher and support a larger diameter line. Mr. Jerry Craig, the CDOW raptor biologist, emphasized that by placing the line within the existing corridor the potential for bird collisions would be greatly reduced over that of a new line (Craig 1995).

Although the potential for collisions exists along the entire line, the potential for impact is greatest in the area of Marys Lake. The new line crossing the lake is an additional obstacle for birds using the area. The new line would be placed within 35 feet, and on the same plane as the existing line. This new line may increase the potential for collisions. However, studies have indicated that by routing lines adjacent to each other the potential for collisions is reduced since the birds only have to fly over one obstacle (APLIC 1994).

Listed Threatened. Endangered and Other Species of Concern. Several threatened, endangered, candidate or sensitive species are known to occur or potentially occur in the project area, based on information provided by the U.S. Fish and Wildlife Service (USFWS), and the Colorado Division of Wildlife (CDOW). These species are identified and the potential for impacts to each is discussed in Table 3-8.

Construction impacts to the peregrine falcon, bald eagle, and northern goshawk are expected to be minimal. This is based on the fact that no nests are known to occur within the project area. Although once the line is in place and a potential for collisions with these species exists, the potential for collision exists now and the risk may be somewhat decreased by using larger conductor which would be more visible to flying birds.

Impacts to the fringed-tailed myotis may occur during the construction phase of the project. Construction of the project may temporarily displace individuals occurring in the area. However, no individuals have been documented to occur in the area (Pague 1995). Once the line is in place no additional impacts to this species are expected since habitat would not be affected.

Impacts to both the boreal toad and dwarf shrew may occur during the construction phase of the project. Impacts to the boreal toad would be offset through the implementation of the wetland mitigation measures. By fencing the wetlands and prohibiting access into these areas, potential impacts to the toad should be eliminated. If present, impacts to the dwarf shrew may occur as the result of construction, but would be limited to loss of individuals. However, no additional impacts to either species are expected upon completion of the project.

Wetlands/Important Habitats.

No wetlands or important habitats would be impacted by the Proposed Action. It is assumed that the wetlands shown on Figure 3-5 would be spanned and access would be restricted during construction.

\subsection{Cultural Environment}

Construction of the Proposed Action would not impact any significant archaeological or historic sites as no significant resources were encountered during an archaeological survey of the existing ROW. For compliance with the National Historic Preservation Act, Section 106, Western and Platte River consulted with the Colorado State Historic Preservation Officer (SHPO). On November 2, 1995, the SHPO concurred with the determination that no historic properties will be affected by the project. 


\subsection{List of Agencies Contacted}

Arapahoe Business Council
Harvey Spoonhunter
Chairman

Bureau of Indian Affairs
L.W. Bill Collier

Colorado Department of Public Health and Environment, Water Quality Division

Bill Crick

Hydraulic Engineer

Colorado Division of Wildlife

Don Bogart

Jerry Craig

Raptor Biologist

Colorado Natural Heritage Program, Colorado State University

Susan Spakman Botanist

Katherine E. Pague Senior Information Officer

Colorado State Historical Preservation Officer (SHPO) James Hartman SHPO

Estes Park Urban Renewal Authority
Art Anderson
Executive Director

Estes Valley Improvement Association Margaret Clark President

Estes Valley Recreation and Park District Stan Grugler

Federal Emergency Management Agency, Denver District

Larimer County Parks and Recreation Department John McFarland Director

Larimer County Planning Department John Barnett Director

Town of Estes Park

Bob Joseph William Linnane

Planner Steve Stamey

Public Works Director

Department of Community Development

U.S.D.A. Arapahoe-Roosevelt National Forest

Laura Hundnell

Mike Lloyd

Soil Conservationist

District Ranger

U.S.D.I. Bureau of Reclamation John Girard

Physical Scientist

U.S.D.I. National Park Service, Rocky Mountain National Park
A. Duran Jones
Lawrence Gamble
Superintendent
Land Use Specialist

U.S. Fish and Wildlife Service

LeRoy W. Carlson Colorado Field Supervisor

UTE Mountain UTE Tribe Judy Knight-Frank Chairperson 


\subsection{Workshops/Meetings and Hearings}

June 8, $1995 \quad$ Public Hearing with Estes Park

June 14, $1995 \quad$ Agency Workshop/Scoping Meeting

June 14, $1995 \quad$ Public Workshop/Scoping Meeting

October 4, $1995 \quad$ Public Workshop

\subsection{List of Agencies, Organizations, and Persons to Whom Copies of the Environmental Assessment are Sent}

Trustee

Family Trust of Courtney A. McCord

1720 Regal ROW\#135

Dallas, TX 75235

Manager

O'Shea, Ltd.

1027 Romany Road

Kansas City, MO 64113

Mr. Vaughn Affleck

U.S. Bureau of Reclamation

Eastern Colorado Area Office

11056 West County Road 18E

Loveland, CO 80537

Mr. Robert E. Alsup

555-A Devon Drive

Estes Park, CO 80517

Mr. Art Anderson

Executive Director

Estes Park Urban Renewal Authority

P.O. Box 1200

Estes Park, CO 80517

Mr. Lee M. Barbour

P.O. Box 110368

Aurora, CO 80042

Mr. and Mrs. Rod Bartels

Box 4020

Estes Park, CO 80517

Mr. \& Mrs. Eric W. Blackhurst

P.O. Box 334

Estes Park, CO 80517

Mr. Don Bogart

Colorado Division of Wildlife

317 West Prospect

Fort Collins, CO 80526
Mr. and Mrs. Dennis K. Brown

P.O. Box 3222

Estes Park, CO 80517

Mr. Raymond F. Bush

P.O. Box 2733

Estes Park, CO 80517

Mr. LeRoy Carlson

Colorado State Supervisor

U.S. Fish \& Wildlife Service

730 Simms Street, Room 290

Golden, CO 80401

Ms. Margaret Clark

President

Estes Valley Improvement Association

P.O. Box 597

Estes Park, CO 80517

Ms. Donna Clark

P.O. Box 20637

Estes Park, CO 80511

Mr. Bill Collier

Bureau of Indian Affairs, WCD Office Complex

P.O. Box 368

Anadarko, OK 73005-0368

Ms. Catherine M. Conroy

690 High Street, \#3

Estes Park, CO 80517

Mr. Bernie Dannels

Box 1611

Estes Park, CO 80517

Mr. H.B. Dannels

Mayor

Town of Estes Park

P.O. Box 1200

Estes Park, CO 80517 
Mr. Douglas A. Deats

415 Elm Avenue, \#1

Estes Park, CO 80517

Mr. Robert L. Dekker

Mayor ProTem

Town of Estes Park

P.O. Box 1200

Estes Park, CO 80517

Mr. Rodney R. Farmer

P.O. Box 2414

Estes Park, CO 80517

Mr. Larry Gamble

Rocky Mountain National Park

Estes Park, CO 80517

Mr. Stan Gengler

Estes Valley Recreation \& Park District

P.O. Box 1379

Estes Park, CO 80517

Mr. Bob Goehring

Town of Estes Park Water Department

Estes Park, CO 80517

Mr. Truman E. Gray

P.O. Box 4808

Estes Park, CO 80517

Ms. Joan B. Griffen

Trustee

410 Glen Arbor Road

Kansas City, MO 64114

Mr. and Mrs. John Gulliksen

620 Landers Street

Estes Park, CO 80517

Ms. Mary A. Guyer

P.O. Box 2078

Estes Park, CO 80517

Mr. James Hartmann

State Historical Preservation Officer

Colorado Historical Society

1300 Broadway

Denver, CO 80203-2137

Mr. George T. Hills

P.O. Box 20602

Estes Park, CO 80517

Mr. George Hockman

1625 Prospect Est. Drive

Estes Park, CO 80517
Mr. and Mrs. Ronald L. Hodges

2660 Kohler Drive

Boulder, CO 80303

Mr. and Mrs. Robert Howell

P.O. Box 897

Estes Park, CO 80517

Ms. Jessie M. Hulbert

Ms. Lavine McDowell

P.O. Box 4426

Estes Park, CO 80517

Mr. A. Duran Jones

Superintendent

Rocky Mountain National Park

Estes Park, CO 80517

Mr. Evan Jones

1711 Dekker Circle

Estes Park, CO 80517

Mr. Leon Kemper

P.O. Box 2385

Estes Park, CO 80517

Ms. Carolyn Kilgore

P.O. Box 2625

Estes Park, CO 80517

Ms. Judy Knight-Frank

Chairperson

Ute Mountain Ute Tribe

Tribal Office Building

Towac, CO 81334

Mr. and Mrs. Robert J. Kunis

1065 Prospect Mountain Drive

Estes Park, CO 80517

Mr. Dennis M. Larue

61 Deer Mountain Court

Livermore, CO 80536

Mr. Russell Legg

Interim Director

Larimer County Planning Department

P.O. Box 1190

Fort Collins, CO 80522-1190

Mr. William F. Linnane

Public Works Director

Town of Estes Park

P.O. Box 1200

Estes Park, CO 80517 
Mr. Mike Lloyd

Dist. Ranger, USDA Forest Service

Estes-Poudre District

Roosevelt National Forest

1311 South College Avenue

Fort Collins, CO 80524

Mr. Rob Ludlum

P.O. Box 291

Allenspark, CO 80510

Mr. Mike Magnelsen

Box 1200

Estes Park, CO 80517

Mr. Cecil R. McGlothlin

446 Elm Avenue

Estes Park, CO 80517-7635

Trustee Maryella Pearson Trust

P.O. Box 93

Estes Park, CO 80517

Mr. Rex G. Maughan

1200 South Priest

Tempe, AZ 85281

Mr. John McFarland

Director

Larimer County Parks \& Recreation Department

1800 South County Road 31

Loveland, CO 80537

Mr. Michael E. Miller

Trustee

Town of Estes Park

P.O. Box 1200

Estes Park, CO 80517

Mr. George Mojica

13302 SE 122nd Avenue, \#D-9

Clackamas, OR 97015

Mr. Gary P. Murphy

P.O. Box 95

Estes Park, CO 80517

Mr. Charles L. Myers

P.O. Box 3302

Estes Park, CO 80517

Mr. James E. Neering

P.O. Box 1293

Estes Park, CO 80517

Mr. Gary R. Nelson

P.O. Box 3126

Estes Park, CO 80517
Mr. and Mrs. Gary Nelson

411 Columbine Avenue

Estes Park, CO 80517

Mr. Eric R. Northcutt

P.O. Box 3221

Estes Park, CO 80517

Mr. Frank Parks

555B Devon Drive

Estes Park, CO 80517

Mr. J. Donald Pauley

Trustee

Town of Estes Park

P.O. Box 1552

Estes Park, CO 80517

Mr. Gordon M. Pedersen

P.O. Box 4334

Estes Park, CO 80517

Ms. Marilyn F. Pickens

119 34th Street, SE

Cedar Rapids, IA 52403

Mr. Morris E. Pike

RR \#6, 18 Brian Drive

Bloomington, IL 61704

Mr. Pete Piper

1621 Juniper Drive

P.O. Box 3802

Estes Park, CO 80517

Ms. Mary Pratkelis

Ms. Irene Pratkelis

4964 Valkyrie Drive

Boulder, CO 80301

Mr. and Mrs. Jerry L. Ramsey

P.O. Box 1976

Estes Park, CO 80517

Mr. Robin Wade Randall

409 Columbine Avenue

Estes Park, CO 80517

Lynn Raveling

Northem Colorado Water Conservation District

$1250 \mathrm{~N}$. Wilson

Loveland, CO

Mr. King Recen

721 High Street

Estes Park, CO 80517

Mr. and Mrs. Harold Rehn

409 Steel Court M Route

Estes Park, CO 80517 
Mr. Darell Shull

1101 Prospect Mountain Road

Moraine Route

Estes Park, CO 80517

Mr. Harvey Spoonhunter

Chairman, Arapahoe Business Council

P.O. Box 396

Fort Washakie, WY 82514

Mr. Steve Stamey

Community Development Director

Town of Estes Park

P.O. Box 1200

Estes Park, CO 80517

Ms. Lynette R. Stemmerman

P.O. Box 485

Farmington, NM 87415

Mr. Keith D. Stephenson

P.O. Box 3516

Estes Park, CO 80517

Mr. Frank A. Stetson

P.O. Box 541

Estes Park, CO 80517

Mr. Norman D. Swanson

3306 Walden Avenue

Sioux City, IA 51106

Mr. \& Mrs. Robert Trumbull

P.O. Box 3350

Estes Park, CO 80517

Mr. George H. Volks

P.O. Box 4734

Estes Park, CO 80517

Mr. John Ward

P.O. Box 4019

Estes Park, CO 80517
Mr. and Mrs. Kenneth M. Wenzel

510 Moraine Route

Estes Park, CO 80517

Mr. Rich Widmer

913 Village Green Lane

Estes Park, CO 80517

Mr. Peter Wright

1313 Greenhills Court

Duncanville, TX 75137

Mr. John Witherspoon

1010 Bankfield Court

Naperville, IL 60540

Mr. William Owen

P. O. Box 37058

Raytown, MO 64138

Mr. Warren Pedersen

785 Prospect Mountain Road

Estes Park, CO 80517

Ms. Anne Vickery

Colorado Mountain Club 5255 Pennsylvania Avenue

Boulder, CO 80303

Ms. Susan Baker

Conservation Chair

P. O. Box 1176

Loveland, CO 80539

Ms. Madeline Framson

1155 South St. Vrain, \#C-8

Estes Park, CO 80517

Mr. Daniel Brown

P. O. Box 613

Estes Park, CO 80517

Mr. Tim Asbury

P.O. Box 1707

Estes Park, CO 80517 
Table 6-1

List Of Preparers

\section{NAME \\ EDUCATION/EXPERIENCE \\ RESPONSIBILITY}

\begin{tabular}{|c|c|c|}
\hline \multicolumn{3}{|c|}{ PLATTE RIVER POWER AUTHORITY } \\
\hline Thomas McCormick, P.E. & $\begin{array}{l}\text { B.S. Mathematics; B.S. Civil Engineering } \\
18 \text { Years Electric Utility Experience }\end{array}$ & $\begin{array}{l}\text { Project Management; Project Design } \\
\text { and Engineering; Coordination; and } \\
\text { Review }\end{array}$ \\
\hline Duane Braunagle & $\begin{array}{l}\text { M.S. Electrical Engineering } \\
23 \text { Years Electric Utility Experience }\end{array}$ & $\begin{array}{l}\text { Electric System Planning; Project } \\
\text { Purpose and Need }\end{array}$ \\
\hline John Fooks & $\begin{array}{l}\text { B.S. Chemistry } \\
21 \text { Years Electric Utility Experience }\end{array}$ & $\begin{array}{l}\text { EMF Communications and } \\
\text { Coordination }\end{array}$ \\
\hline Mark Curtis, P.E. & $\begin{array}{l}\text { B.S. Electrical Engineering } \\
13 \text { Years Electric Utility Experience }\end{array}$ & $\begin{array}{l}\text { Detailed Design and Coordination of } \\
\text { Electric Substations and } \\
\text { Transmission Lines }\end{array}$ \\
\hline John Collins & $\begin{array}{l}\text { B.S. Electrical Engineering } \\
10 \text { Years Electric Utility Experience }\end{array}$ & Transmission Planning Studies \\
\hline Stephanie Lane & $\begin{array}{l}\text { B.S. Chemical Engineering } \\
8 \text { Years Electric Utility Experience }\end{array}$ & EMF Communications \\
\hline Rae Todd & $\begin{array}{l}\text { AA Visual Communications \& Design } \\
20 \text { Years Electric Utility Experience }\end{array}$ & Public Relations \\
\hline \multicolumn{3}{|c|}{ WESTERN AREA POWER ADMINISTRATION } \\
\hline Rodney Jones & $\begin{array}{l}\text { M.S.E. Environmental Engineering } \\
25 \text { Years Electric Utility Experience }\end{array}$ & $\begin{array}{l}\text { Western Project Management; } \\
\text { Coordination; Review; and } \\
\text { Environmental Compliance }\end{array}$ \\
\hline Stacy Padget & $\begin{array}{l}\text { B.S. Electrical Engineering } \\
12 \text { Years Electric Utility Experience }\end{array}$ & Project Engineering \\
\hline Ken Olgilvie & $\begin{array}{l}\text { B.S. Electrical Engineering } \\
19 \text { Years Electric Utility Experience }\end{array}$ & $\begin{array}{l}\text { EMF Coordination and } \\
\text { Communications }\end{array}$ \\
\hline Chuck Miller, P.E. & $\begin{array}{l}\text { B.S. Mechanical Engineering; M.S. } \\
\text { Mechanical Engineering } \\
12 \text { Years Electric Utility Experience }\end{array}$ & Power facility construction \\
\hline David Gaul & $\begin{array}{l}\text { B.A. } \\
18 \text { Years Electric Utility Experience }\end{array}$ & Land Rights and ROW \\
\hline Carrie Ashton & $\begin{array}{l}\text { B.A. } \\
11 \text { Years Electric Utility Experience }\end{array}$ & Land Rights and ROW \\
\hline
\end{tabular}


Table 6-1

List Of Preparers

NAME

EDUCATION/EXPERIENCE

RESPONSIBILITY

\begin{tabular}{|c|c|c|}
\hline \multicolumn{3}{|c|}{ SALAZAR ASSOCIATES INTERNATIONAL, INC. } \\
\hline Germaine Reyes-French & $\begin{array}{l}\text { B.S. Zoology } \\
20 \text { Years Electric Utility and Pipeline } \\
\text { Experience }\end{array}$ & Project Coordination and Review \\
\hline \multicolumn{3}{|l|}{ GREYSTONE } \\
\hline Larry Keith & $\begin{array}{l}\text { B.L.A. Landscape Architecture } \\
20 \text { Years Professional Experience }\end{array}$ & $\begin{array}{l}\text { Greystone Project Management; } \\
\text { Environmental Assessment } \\
\text { Documentation; Coordination; Land } \\
\text { Use; Visual Resources; EMF } \\
\text { Coordination and Communications }\end{array}$ \\
\hline Randy Schroeder & $\begin{array}{l}\text { M.S. Environmental Science } \\
\text { B.S. Natural Resource Management } \\
18 \text { Years Professional Experience }\end{array}$ & $\begin{array}{l}\text { Review; Environmental Compliance } \\
\text { Environmental Assessment } \\
\text { Documentation }\end{array}$ \\
\hline Dave Cameron & $\begin{array}{l}\text { M.S. Animal Ecology } \\
\text { B.S. Biology } \\
16 \text { Years Professional Experience }\end{array}$ & $\begin{array}{l}\text { Wildlife; Threatened \& Endangered } \\
\text { Species; Biological Assessment }\end{array}$ \\
\hline Mike Bonar & $\begin{array}{l}\text { B.S. Environmental Biology } \\
5 \text { Years Professional Experience }\end{array}$ & $\begin{array}{l}\text { Wildlife; Threatened \& Endangered } \\
\text { Species; Biological Assessment }\end{array}$ \\
\hline Lisa Welch & $\begin{array}{l}\text { B.S. Earth Sciences } \\
4 \text { Years Professional Experience }\end{array}$ & $\begin{array}{l}\text { Land Use; Recreation; } \\
\text { Socioeconomics }\end{array}$ \\
\hline Darcy Tiglas & $\begin{array}{l}\text { M.S. Range Science } \\
\text { B.A. Biology and Political Science } \\
7 \text { Years Professional Experience }\end{array}$ & $\begin{array}{l}\text { Vegetation; Wetlands; Floodplains; } \\
\text { Threatened \& Endangered Species }\end{array}$ \\
\hline Catherine Begej & $\begin{array}{l}\text { B.S. Environmental Geology } \\
16 \text { Years Professional Experience }\end{array}$ & Water Resources \\
\hline Byron Walker, P.E. & $\begin{array}{l}\text { M.S. Civil Engineering } \\
35 \text { Years Professional Experience }\end{array}$ & Water Resources; Floodplains \\
\hline Don Douglas & $\begin{array}{l}\text { M.S. Meteorology } \\
25 \text { Years Professional Experience }\end{array}$ & Air Resources \\
\hline Will Mahoney, P.G. & $\begin{array}{l}\text { M.A. Geography } \\
\text { B.A. Geology } \\
13 \text { Years Professional Experience }\end{array}$ & Soils; Geology \\
\hline Mike Metcalf & $\begin{array}{l}\text { M.A. Anthropology } \\
23 \text { Years Professional Experience }\end{array}$ & Archaeology; Cultural Resources \\
\hline Mark Laverty & $\begin{array}{l}\text { Associate of Occupational Studies } \\
8 \text { Years Professional Experience }\end{array}$ & $\begin{array}{l}\text { Photographic Simulations; Graphics } \\
\text { and Exhibit Preparation }\end{array}$ \\
\hline Eric Cowan & $\begin{array}{l}\text { Drafting, Computer, and Business } \\
\text { Studies } \\
3 \text { Years Professional Experience }\end{array}$ & $\begin{array}{l}\text { Photographic Simulations; Graphics } \\
\text { and Exhibit Preparation }\end{array}$ \\
\hline
\end{tabular}

Antonio Sastre, Ph.D.
Ph.D. Applied Mathematics 24 years experience in biomedical research and EMF
Potential Health Effects Associated with EMF; Chapter 4; and Appendix F, EMF Bibliography 
Algermissen, S.T. 1969. Seismic Risk Studies in the United States. Presented to the Fourth World Conference on Algermissen, S.T. 1969. Seismic Risk Studies in the United States. Presented to the Fourth World Conference on Earthquake Engineering, Santiago, Chile, January 14, 1969. U.S. Dept. of Commerce, ESSA, Coast \& Geodetic Survey. Arwyn Map Company. Undated. Larimer County Maps. Arwyn Map Co., Arvada, Colorado.

Avian Power Line Interaction Committee (APLIC). 1994. Mitigating Bird Collisions with Power Lines: The State of the Art in 1994. Edison Electric Institute, Washington, D.C.

Behnke, R.J. 1992. Native Trout of Western North America. Amer. Fish. Soc. Monograph 6., Bethesda, Maryland.

Bissell, S.J. 1978. Colorado mammal Distribution Latilong Study. Colo. Div. of Wild., Denver, CO.

Blackhurst and Rosener Realty and Investments, Ltd. 1995. Straight Scoop; Facts About Estes Park, Colorado.

Bogart, D. 1995. Personal Communication. Environmental Biologist. Colo. Div. of Wildl., Ft. Collins, CO.

Braddock, W.A. and J.C. Cole. 1990. Geologic Map of Rocky Mountain National Park and Vicinity, Colorado. U.S. Geol. Surv. Map 1-1973.

Carlson, L. W. 1995. Personal Communication. Colorado Field Supervisor. USDI, fish and Wild. Serv., Golden, CO.

CDOW. 1984. The Bats of Colorado: Shadows in the Night. Colo. Div. of Wildl., Denver, CO.

Colorado Division of Parks and Outdoor Recreation. 1992. Urban Trails in Colorado; North Front Range. Colorado Trails Guides. Colo. Div. of Parks and Outdoor Recreation, Colorado Lottery. Denver, Colorado.

Colorado Department of Labor and Employment. 1991. Colorado Labor Force Review, Data Supplement, 1991. Colo. Dept. of Labor and Employment, Labor Market Information. Denver, Colorado.

Colorado Department of Water Resources, 1995a. Water Rights Report, July 1, 1994, selected locations in Division 1, Water District 4, Larimer County. Denver, CO.

Colorado Department of Water Resources, 1995b. Well Permit Retrieval, May 19, 1995, for Selected Locations in Larimer County. Denver, CO.

Craig, J. 1995. Personal Communication. Raptor Biologist. Colo. Div. of Wildl., Ft. Collins, CO.

Craig, J. 1996. Personal Communication. Raptor Biologist. Colo. Div. of Wildl., Ft. Collins, CO.

Estes Park, Town of. 1995. Map of Power Distribution Lines in the Town of Estes Park. Provided by the Light and Power Departiment, town of Estes Park.

Estes Park League of Women Voters. 1993. Know Your Government in Estes Valley, 1993. Estes Park, Colorado.

Estes Valley Recreation and Park District. 1995. 1995 Guide. EVRPD, Estes Park, Colorado. 
Estes Park, Town of. 1995. Map of Existing Town Zoning, Marys Lake Transmission Line. Provided by the Community Development Department, town of Estes Park.

Estes Park, Town of. 1995. Estes Park Community Profile. Community Development Department, town of Estes Park, Colorado.

Estes Park, Town of. 1995. Map of Existing County Zoning, Marys Lake Transmission Line. Provided by the Community Development Department, town of Estes Park.

Estes Park, Town of. 1995. Map of Existing Land Use, Marys Lake Transmission Line. Provided by the Community Development Department, town of Estes Park.

Fitzgerald, J.P. C.A. Meaney, and D.M. Armstrong. 1994. Mammals of Colorado. Denver Museum of Nat. Hist. and Univ. Press of Colo., Niwot, CO.

Hammerson, G.A. and D. Langlois. 1981. Colorado Reptile and Amphibian Distribution Latilong Study. 2nd ed., Colo. Div. of Wildl., Denver, CO.

Hammerson, G.A. 1986. Amphibians and Reptiles in Colorado. Colo. Div. of Wildl., Denver, CO.

Heil, R.D, D.S. Romine, D.C. Moreland, R.K. Dansdill, R.H. Montgomery, and J.E. Cipra. Soils of Colorado. Colo. St. Univ. Exp. Sta. Ft. Collins Bull. 566S.

Marys Lake Campground, Inc. 1994. Guide to Marys Lake Campground. Publ. by American Guide Services, Inc.

McCormick, T. 1995. Personal Communication. System Design Supervisor, Platte River Power Authority with M. Bonar, Greystone, Englewood, CO.

Olendorff, R.R., A.D. Miller, and R.M. Lehman. 1981. Suggested Practices for Raptor Protection on Power Lines: State of the Art in 1981. Raptor Research Foundation, Inc. St. Paul, Minn. Raptor Research Report No. 4.

Park School District R-3. 1995. Park School District information brochure. Estes Park, Colorado.

Prague, K.E. 1995. Personal Communication. Senior Information Manager. Colo. Nat. Heritage Pro., Ft. Collins, CO.

Reynolds, R.T, R.T. Graham, M.H. Reiser, R.L. Bassett, P.L. Kennedy, D.A. Boyce Jr., G. Goodwin, R. Smith, and E.L. Fisher. 1992. Management Recommendations for the Northern Goshawk in the Southwestern United States. USDA, For. Serv., Albuquerque, New Mexico. Gen. Tech. Rep. RM-217.

Stover, C.W., B.G. Reagor, and S.T. Algermissen. 1988. Seismicity Map of the State of Colorado. U.S. Geol. Surv. Map MF-2036.

Swisher, J.F. 1964. A Roosting Area of the Bald Eagle in Northern Utah. Wilson Bull. 76(2): 186-187.

The Colorado Native Plant Society. 1989. Rare Plants of Colorado. Rocky Mountain Nature Association.

U.S. Dept. of Commerce. 1990. 1990 Census of Population and Housing. Summary Population and Housing Characteristics; Colorado. USDOC Economics and Statistics Administration, Bureau of the Census.

U.S. Dept. of Commerce. 1990. 1990 Census of Population. Social and Economic Characteristics; Colorado. USDOC Economics and Statistics Administration, Bureau of the Census. 
USDI, Bureau of Reclamation, 1994. Annual Operating Plans, Colorado-Big Thompson Project, Fryingpan-Arkansas Project, North Platte Project, Western Division System-Power Operations, Water Year-1993 Operations, Water Year - 1994 Outlook. Billings, MT.

USGS, 1994. Water Resources Data Colorado Water Year 1994, Volume 1. Missouri River Basin, Arkansas River Basin and Rio Grande Basin. U.S. Geological Survey Water-Data Report C0-94-1. Denver, CO. 


\section{Glossary}

alluvial valley -A valley containing stream-deposited silt, sand, and gravel.

ampere - The unit of measurement of electric current. It is proportional to the quantity of electrons flowing past a given point in a conductor in one second.

aridic argiborolls - A soil which has developed in a cool, dry climatic regime and has an organic-rich surface horizon.

avian - Pertaining to or characteristic of birds.

biotite schist - A medium grained rock produced by recrystallization by intense heat and/or pressure. Its principal component is biotite, a member of the mica family of minerals. The mica crystals are oriented in a subparallel form.

circuit - A conductor or system of conductors through which an electric current is intended to flow.

clipping - Refers to the attachment of conductors (or wires) to insulators during construction of an electric transmission line.

colluvial -Consisting of a mixture of soil and angular fragments of rock which have accumulated at the foot and on slopes of mountainsides under the influence of gravity.

conductive shielding - A housing, screen, or other object, usually conducting, that substantially reduces the effect of electric or magnetic fields on its one side and upon devices or circuits on its other side.

conductor - Any material which is capable of carrying an electrical current.

coniferous - Referring to a cone-bearing, usually evergreen, tree

creep - An imperceptibly slow, relatively continuous downslope movement of rock and soil.

current - The movement of electricity through a conductor.

decibels (dBA) - Units for describing amplitude of sound frequencies to which the human ear is sensitive.

deciduous - Trees or shrubs which loose their leaves each year during a cold or dry season.

dielectric - A medium which does not conduct electricity.

double circuit - A transmission line consisting of two systems of conductors (or wires) through which electric current flows.

electric and magnetic fields (EMF) - Invisible lines of force, produced by voltage and current, that surround any electrical device or electrical power line.

epidemiologyl - The study of patterns and possible causes of diseases in human populations.

\section{extremely low frequency (ELF)}

fault - A fracture in bedrock along which there has been vertical and/or horizontal movement caused by differential forces in the earth's crust.

figwort - A plant characterized by loose, branching clusters of small purple or green flowers. 
flashover - An unintended electrical arc between electrical wires or devices.

forb - A broad-leaved flowering plant.

fugitive dust - Airborne particles generated from open sources and not discharged in a confined flow stream such as an exhaust.

granitic bedrock - A coarse grained rock consisting chiefly of quart and feldspar which has been formed by the slow cooling of molten magma within the earth's crust.

hematology -The science dealing with all aspects of blood.

in vitro - Taking place in an artificial environment outside a living organism.

in vivo - Taking place within a living organism.

kettle lake -A lake formed in a depression created by slow melting of a detached mass of glacial ice within glacial deposits of boulders, cobbles, sand, and silt.

mesic - A habitat characterized by moderate moisture and temperature conditions and by a profusion of plant life.

metamorphic bedrock - A class of rock which has recrystallized within the earth's crust in response to intense pressure and/or heat.

milligauss - A measurement of electrical current (mg).

orogeny - The process of forming mountains particularly from uplift caused by differential forces within the earth's crust.

ozone - A molecule containing three oxygen atoms $\left(\mathrm{O}_{3}\right)$ produced by passage of an electrical spark through air or oxygen $\left(\mathrm{O}_{2}\right)$.

paleontology - The science which deals with the history and evolution of life on earth.

passerine - A taxonomic order which includes perching birds and songbirds.

penstock - A pipe or other conduit used to carry water to a electrical power generating device.

photochemical oxidant - Any chemical which enters into oxidation reactions in the presence of light or other radiant energy.

physiographic - Pertaining to the genesis and evolution of landforms.

raptor $-A$ bird which preys on living animals.

riparian -Pertaining to the area adjacent to a river or stream.

rush - A grasslike marsh plant having pliant hollow or pithy stems.

sagging - The act of applying a predetermined tension to a conductor.

scarify - To soften or slit the outer coat of a seed in order to speed up the germination process.

scatter (archeological) - Random evidence of prior disturbance that is distributed about an area rather than concentrated in a single location.

sedge -Plants which resemble grasses but have hollow rather than woody stems.

seismic - Pertaining to or produced by earthquakes. 
shelterbelt $-A$ linear band of trees planted at a right angle to the prevailing wind to protect crops from soil blowing and reduce evaporation.

single circuit - A transmission line consisting of one system of conductors (or wires) through which electric current flows.

skyline -The outline of an object such as a transmission structure as seen against the sky without other background.

slump - Downslope movement of a mass of soil and/or rock as a unit.

spark gap - Any short air space between two conductors electrically insulated from or remotely electrically connected to each other.

tension-stringing - The use of "pullers" and "tensioners" to keep the conductor under tension and positive control during the stringing phase, thus keeping it clear of the earth and other obstacles which could cause damage.

turbidity - A measurement of the total suspended solids in water.

typic cryoboralfs - A soil which has developed in a cold, relatively moist climatic regime and has a subsurface horizon with clay accumulation.

volt - The unit of electrical pressure.

wetland - A landscape characterized by shallow or standing water for at least part of the year with vegetation rising above the water level. 
A-weighted

AC

AIBS

AN

$\mathrm{Bg}$

BPA

CB

CDOW

County

CPUC

$\mathrm{dBA}$

DC

DOE

e.g.

ELF

EMF

EPA

EVRPD

FEMA

FEMFSAC

$\mathrm{Fg}$

FM

G

HPOF

$\mathrm{Hz}$

INIRC

IRPA

$\mathrm{kV} / \mathrm{m}$

L50

$\mathrm{M}$

$\mathrm{mA}$

mG

$\mathrm{Mg}$

$\mathrm{MHZ}$

MM

NESC

NIEHS

NRPB

NYSPLP

ORAU

Order

OTA

$P$

Platte River

ppb

PR

$R$

RAPID

RI

$\mathrm{RI} / \mathrm{TV}$

ROW

SCOF

SHPO

TVI

USFWS

$\mathrm{V} / \mathrm{m}$

VMS

VQO

WEST.

Western
Scale for recording noise levels

Alternating Current

American Institute of Biological Sciences

Audible Noise

Background

Bonneville Power Administration

Citizens Band radio

Colorado Division of Wildlife

Larimer County

Colorado Public Utilities Commission

Decibels, A-weighted scale

Direct Current

Department of Energy

Exempli gratia, [L.], for example

Extremely Low Frequency

Electric and Magnetic Fields

Environmental Protection Agency

Estes Valley Recreation and Parks District

Federal Emergency Management Agency

Florida Electric and Magnetic Fields Science Advisory Commission

Foreground

Frequency Modulated

Gauss

High Pressure Oil-Filled

Hertz

International Non-lonizing Radiation Committee

International Radiation Protection Association

Kilovolts Per Meter

Average Occurrence $50 \%$ of the Time

Meter

Milliamperes

Millegauss

Middleground

Megahertz

Maximum Modification

National Electrical Safety Code

National Institute of Environmental Health Sciences

National Radiation Protection Board

New York State Power Line Project

Oak Ridge Associated Universities

Executive Order 12898; Federal Actions to Address Environmental Justice in Minority Populations and Low-Income Populations

Office of Technology Assessment

Preservation Platte River Power Authority

Parts Per Billion

Partial Retention

Retention

EMF Research and Public Information Dissemination Program

Radio Interference

Radio Interference/Television Interference

Right-Of-Way

Self-Contained Oil-Filled

State Historic Preservation Officer

Television Interference

U.S. Fish and Wildlife Service

Volts Per Meter

Visual Management System

Visual Quality Objective

West Energy Supply and Transmission Associates

Western Area Power Administration 


\section{Department of Energy}

Western Area Power Administration

Loveland Area Office

P.O. Box 3700

Loveland, CO 80539-3003

liny 5 inn

Mr. LeRoy Carlson

Colorado State Supervisor

U.S. Fish and Wildlife Service

730 Simms Street, Room 290

Golden, CO 80401

SUBJECT: Request for List of Endangered, Threatened or Sensitive Species or Critical Habitats for the Marys Lake Transmission Line Upgrade and Marys Lake Substation Expansion Projects

Dear Mr. Carison:

The Western Area Power Administration (Western) and the Platte River Power Authority are considering a project to upgrade a 3-mile section of the EstesEast Portal transmission line from 69 kilovolts (kV) to $115 \mathrm{kV}$. This project, which is located in Estes Park, Colorado, involves the reconductoring of an existing 1.1 mile section of line on existing steel lattice towers and the removal and rebuilding of 1.9 mile of wood pole $\mathrm{H}$-frame transmission line to the Marys Lake Substation. A 115/69-kV transformer at Estes Power P1ant wi11 be removed and other associated work performed as required to upgrade the line from $69 \mathrm{kV}$ to $115 \mathrm{kV}$. A $115 / 69-\mathrm{kV}$ transformer will be installed at Marys Lake and other associated work performed to maintain the $69 \mathrm{kV}$ Adams Tunnel

connection. A map showing the location of the proposed project is enciosed.

In accordance with the Endangered Species Act of 1973, Public Law 93-203 (87 Statute 884) as amended, Section 7, we are requesting that your agency furnish us with an updated listing of proposed, candidate, and listed threatened and endangered species that may occur in the area of the proposed action. The information received will be utilized in Western's environmental evaluation to be conducted for the proposal.

If you have questions or need additional information, please telephone Rodney Jones at (303) 490-7371.

Sincerely,

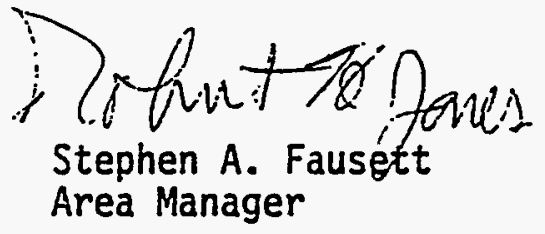

Enclosure 
Cc: (with enclosure)

Mr. Don Bogart

Wi ldlife Biologist

Colorado Division of Wildlife

317 West Prospect Street

Fort Collins, CO 80526

Mr. Thomas McCormick

Project Manager

Platte River Power Authority

2000 E. Horsetooth Road

Fort Collins, CO 80525

Mr. Larry Keith

Division Manager, Utility Services

Greystone

5990 Greenwood Plaza Blvd.

Suite 250

Engl ewood, CO 80111 


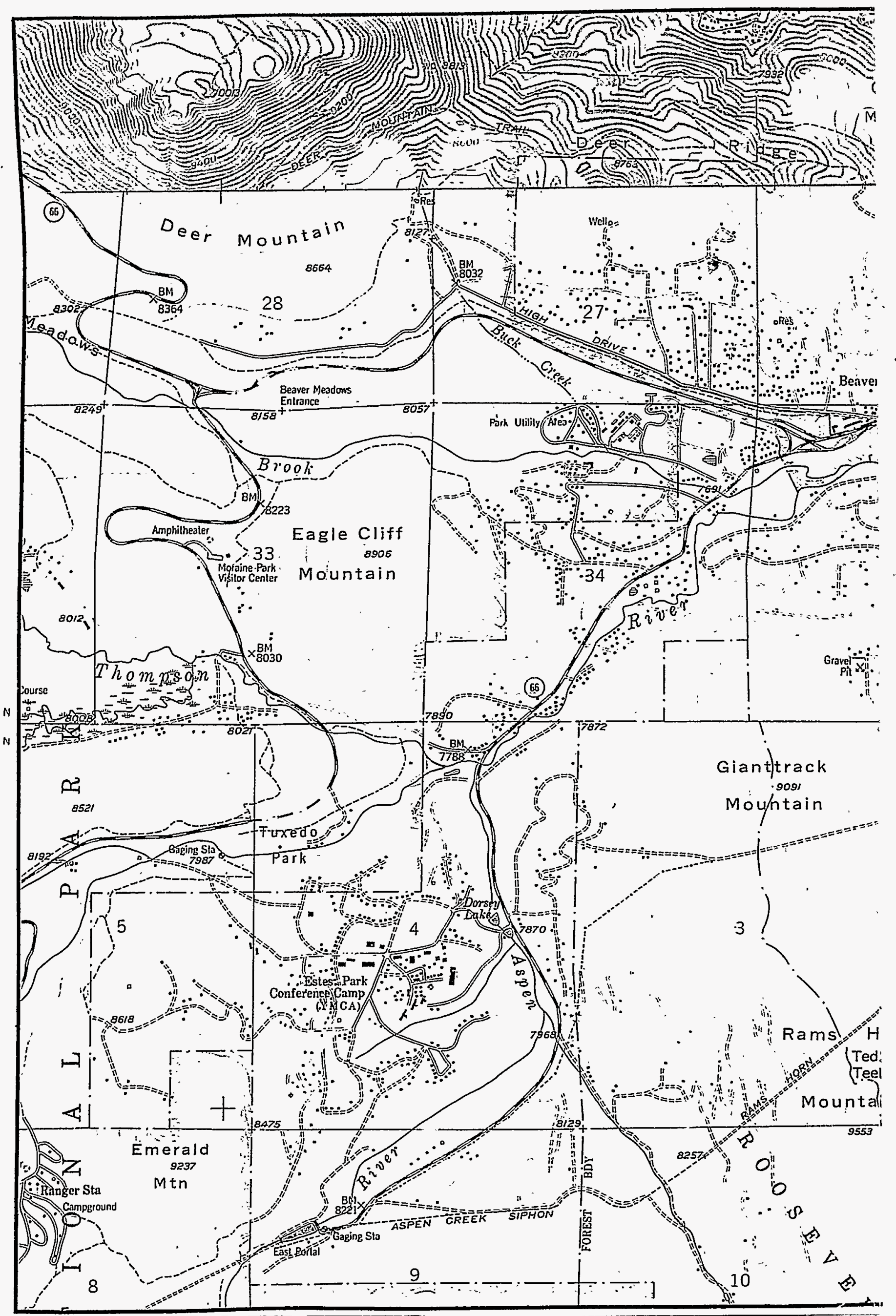




\section{GREYSTONE ${ }^{\mathbb{E}}$}

Environmental Planners, Scientists, and Engineers

May 25, 1995

Susan Spakman, Butionist

Colorado Natural Heritage Program

103 Natural Resources Building

Colorado State University

Fort Collins, Colorado 80523

Dear Susan,

Greystone is in the process of developing an environmental document for a proposed transmission line upgrade in Estes Park, Colorado. We would like to request data regarding threatened, endangered, and sensitive plant and wildlife locations in the area. We are also interested in any critical or important habitats that may occur in the area. The following provides a project description.

The Western Area Power Administration (Western) and the Platte River Power Authority are considering a project to upgrade a 3-mile section of the Estes-East Portal transmission line from 69 kilovolts $(\mathrm{kV})$ to $115 \mathrm{kV}$. This project; involves the reconductoring of an existing 1.1 mile section of line on existing steel lattice towers from the Estes Park Power Plant and the removal and rebuilding of the remaining 1.9 miles of wood pole $H$-frame transmission line to the Marys Lake Substation. A 115/69 transformer at Estes Power Plant will be removed and other associated work preformed as required to upgrade the line from $69 \mathrm{kV}$ to $115 \mathrm{kV}$. A 115/69-kV transformer will be installed at Marys Lake and other associated work preformed to maintain the $69 \mathrm{kV}$ Adams Tunnel connection. A map showing the location of the proposed project is enclosed. The proposed project is contained within $\mathrm{T} 5 \mathrm{~N}$, R73W Sections 25, 30, 31, and 36 and in T4N R73W Section 2.

If you have any questions or need additional information, please feel free to contact me at (303) 850-0930.

Sincerely,

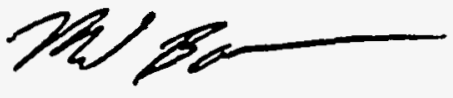

Mike Bonar Wildlife Ecologist 


\section{MARY'S LAKE \\ TELEPHONE \\ CONTACT REPORT}

\section{OUTGOING CALL $\square$ INCOMING CALL}

Date: 5/22/95 Project: Mary's Lake

\section{CONTACT}

Name: John Grard

Title: Hidraclic Engineer

Organization: USDI Bureav of Reclamation, Eastern colorado trea Office Phone: $970-667-4410$
Project No.: $413-03$

\section{GREYSTONE EMPLOYEE}

Cathy Begej

Address/Location:

Subject of Discussion: Information on Big Thompjon Iircanten Proect Items Discussed: He will send the Annual Operating Plan for the Big thompson project today and the 1994 tninual operating Plan in the next couple of weets when it's quarlable. These plans describe the previous years operation artion pian for The upcoming year. They include monthly powe: production in gigawatts for the entire year, the annial reports coxer the water year.

Action To Be Taken:

Route To:

Page of 


\section{Colorado}

Colorado Natural Heritage Program

College of Natural Resources 103 Natural Resources

June 5, 1995 Fort Collins. Colorado 80523-1401 (970) 491-1309 FAX: (970) 491-0279

Mr. Mike Bonar

Greystone

5990 Greenwood Plaza Blvd., Suite 250

Englewood, CO 80111

Dear Mr. Bonar:

The Colorado Natural Heritage Program (CNHP) is in receipt of your recent request for information regarding the proposed transmission line upgrade in Estes Park. In response, CNHP has searched it's Biological and Conservation Datasystem for natural heritage resources (occurrences of significant natural communities and rare, threatened or endangered plants and animals) documented from the Long's Peak and Estes Park quads. According to the information currently in our files, there are occurrences of five rare plants, one rare invertebrate, and two rare vertebrates in the general vicinity of Estes Park, Colorado.

The species reported below are all documented by records for which precise locational information is not available. Some of these records are quite dated as well. Therefore, we cannot say with any certainty whether or not these species actually occur in the project area. In any case, their presence in the vicinity indicates the potential for them to be found if suitable habitat exists.

Cypripedium fasciculatum (Purple lady's slipper) was documented in -1935, and again in 1993. This species is known from forest openings and densely shaded stands, in duff under lodgepole pine or, less frequently, under Abies species (Coles 1994, Jennings 1995). Purple lady's slipper is ranked common throughout its range (G4), but is considered uncommon to rare in Colorado (S3). Cypripedium fasciculatum is listed as a Sensitive Species by the U.S. Forest Service, and is currently under review for federal listing.

Potentilla effusa var. rupincola (Rocky Mountain cinquefoil) was documented in 1897 . This species has been found in steep, often granite, outcroppings on shelves or niches of cliffs, often on granite or gravel. This sub-species is extremely rare throughout its range (T1) and very rare in Colorado-(S2). Potentilla effusa-var: rupincola is listed as a. Sensitive Species by the U.S. Forest Service, and is under review for federal listing. 
Liatris ligustylis (Gay-feather) was documented in 1893. This plant has been found in wet hay meadows and wet open places (Weber 1987, Weber 1990). Although Gay-feather is thought to be common throughout its range (G5?), it is ranked very rare to extremely rare in Colorado (S1S2).

Listera convallarioides (Broad-leafed twayblade) was documented in 1927. This plant is known from moist places in leaf mold, in shaded areas or in wet places along small streams high in the mountains (Cronquist, et. al. 1977). Broad-leafed twayblade is ranked common across its range (G5) but very rare in Colorado (S2).

Lilium philadelphicum (Wood lily) was documented in 1897. - This plant has been found in moist woods, thickets, and wet meadows (Kettler 1993). Wood lily is ranked common throughout its range (G5) and uncommon to rare in Colorado (S3).

Speyeria idalia (Regal fritillary) has been documented near Estes Park, but no observation date is available. This butterfly has been found in wet meadows and virgin prairies near marshes (Ferris and Brown 1981). Regal fritillary is ranked uncommon to rare throughout its range (G3) and extremely rare in Colorado (S1). Speyeria idalia is listed as a Sensitive Species by the U:S. Forest Service and is under review for federal listing.

One breeding occurrence of Aegolius funereus (Boreal owl) was documented in 1979. This species breeds in mature spruce-fir or spruce-fir/lodgepole pine forests interspersed with meadows (Palmer 1984, Ryder et. al. 1987). Although Boreal owl is considered common across its range (G5), it is ranked very rare in Colorado (S2). Aegolius funereus is listed as a Sensitive Species by the U.S. Forest Service.

Sorex nanus (Dwarf shrew) has been documented in the vicinity, but no observation date is available. This mammal is known from forests, open woodlands, and rocky, shrubby foothill slopes, and also from alpine and sub-alpine rockslides (Armstrong 1972). Dwarf shrew is ranked common across its range (G5) and uncommon to rare in Colorado (S3). Sorex nanus is listed as a Sensitive Species by the U.S. Forest Service.

The Colorado Division of Wildlife has legal authority over wildlife in the state. CDOW would therefore be responsible for the evaluation of and final decisions regarding any potential effects a proposed project may have on wildlife. If you would like more specific information regarding these or other animal species in the vicinity of the area of interest, please contact the Colorado Division of Wildlife.

While the information contained herein represents a thorough search of the CNHP's Biological and Conservation Datasystem, any absence of data does not necessarily mean that other natural heritage resources do not occur on or adjacent to the project site, but rather that our files do not currently contain information to document their presence. Also, although every attempt is made 
to provide the most current and precise information possible, please be aware that some of our sources provide a higher level of accuracy than others, and some interpretation may be required. CNHP's datasystem is constantly updated and revised. Please contact CNHP for an update on this natural heritage information if a significant amount of time passes before it is utilized.

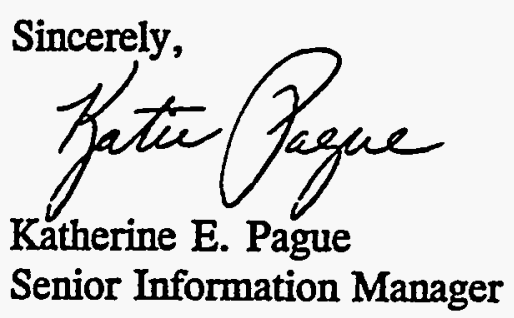

cc: CDOW 


\section{REFERENCES:}

Armstrong, David M. 1972. Distribution of Mammals in Colorado. Monograph of the Museum of Natural History, the University of Kansas. University of Kansas Printing Service, Lawrence. 415 pp.

Coles, Janet. 1994. Personal communication about Rare Plant Guide species.

Cronquist, A., A.H. Holmgren, N.H. Holmgren, J.L. Reveal, and P.K. Holmgren. 1977. Intermountain Flora, vol. 6. Columbia University Press, New York. 584 pp.

Ferris, Clifford and F.M. Brown. 1981. Butterflies of the Rocky Mountain States. University of Oklahoma Press, Norman. 442 pp.

Jennings, W.F. 1995. Personal communication about Rare Plant Guide species.

Kettler, S.M., N.D. Lederer, D. Bacher, and S. Spackman. 1993. Pike and San Isabel National Forests and Comanche and Cimarron National Grasslands Plants of Special Concern. Colorado Natural Heritage Program, Ft. Collins, Colorado.

Palmer, D.A. 1984. Current status of the boreal owl in Colorado. C.F.O. Journal 18:662.

Ryder, R.A., et. al. 1987. Distribution and status of the boreal owl in Colorado.

Pages 169-174 in Nero, R.W., et. al., eds. Biology and Conservation of Northern Forest Owls. USDA Forest Service, Gen. Tech. Rep. RM-142.

Weber, W.A. 1987. Colorado Flora: Western Slope. Colorado Associated University Press, Boulder, Colorado. $530 \mathrm{pp}$.

Weber, W.A. 1990. Colorado Flora: Eastern Slope. University of Colorado, Niwot, Colorado. 396 pp. 


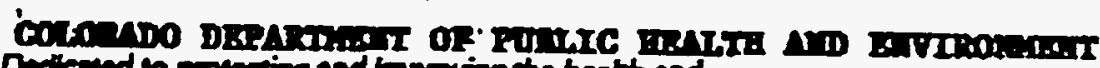
Davleand so prowcting and mproving the halch end mirosment of the puopho of Coloredo

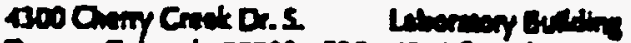

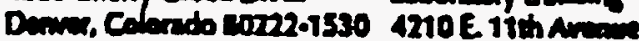
Phome a ois $632-2000$ Dume, Colomido comzonsins aor) Gratro.

Orind Imetion Offioe (303) 200-7394

maho ofileo (719) 583- 1441

IATER QUAIITY CONTROL DIVIEION ,303) 692-3500 FNX (303)782-0390

\section{FAX TRANSTMISSTON SHEET}

mandare dertvery to CoThy Begej. nax $721-9298$ :orpany/agarcy: Creystone Consultants

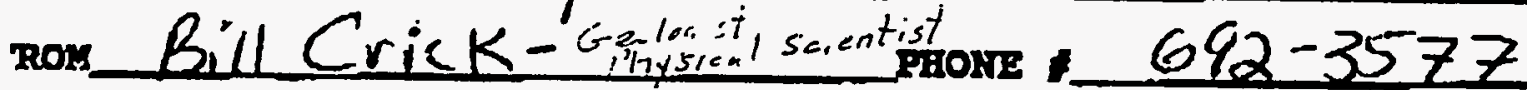

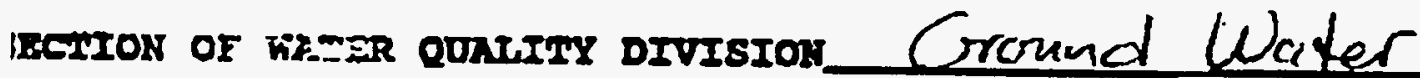
bensorme Ground Water, Estes Park area TE SENT: $6 / 22 / 95$ MBER OF PAGES TO FOTION: TI.R SE.T:

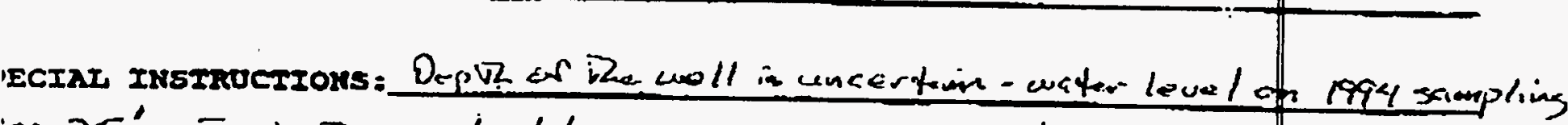
$r$ yane have guestions. BC

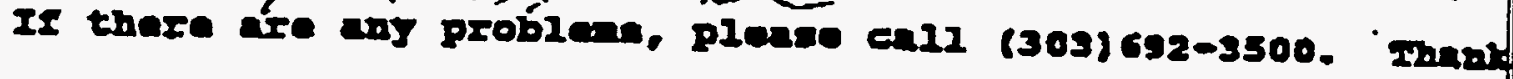


Colorado Department of Health Ground Water Quality Data System- QUALDA Date: 06/22/95 Report of Inorganic Analysis Page 1

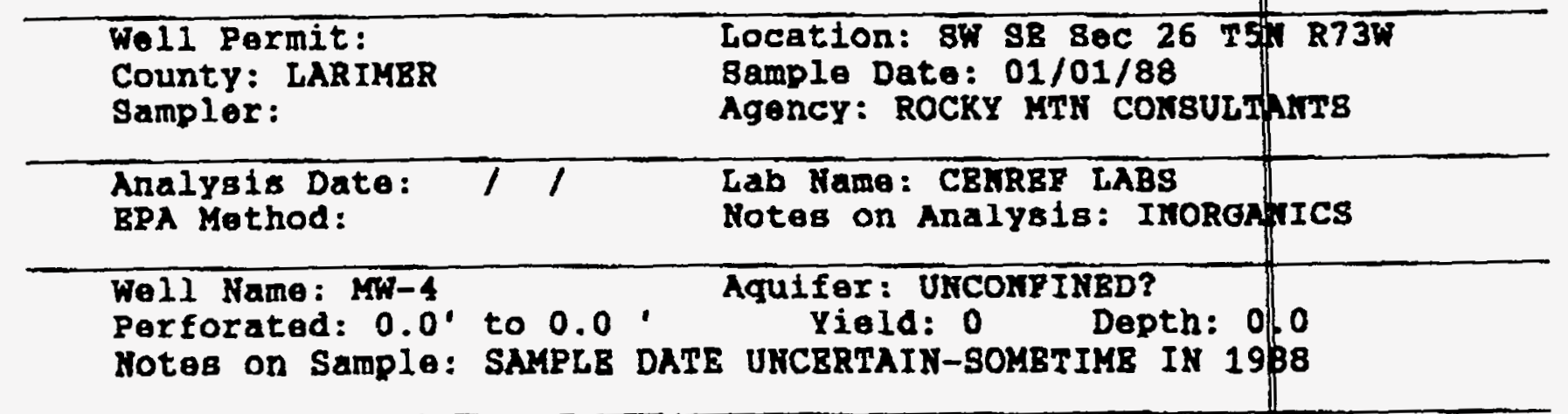

"-" = Not Detected at Level

"0.0"=Not Analysed

Water Temperature, Qeg. C Field pH, standaxa units Flold conductivity, umhos $/ \mathrm{cm}$ Chloride, total, Nitrate, total as $N$, $\mathrm{mg} / 1$ Nitrite, total as $N$, $\mathrm{mg} / 1$ pH,

sulfate, total, copper, diss., Iron, dis8., Manganese, dis8., $\mathrm{mg} / \mathrm{I}$ s.u. $\mathrm{mg} / \mathrm{l}$ ug/ 1 $u g / 1$ ug/l zinc, diss.,

0.0 0.0 0 41400 1480 $-0.01$ 660 58 60 44. 00 1180000 16400 8700 
Colorado Department of Health Ground Water Quality Data Date: 06/22/95 Report of Inorganic Analysis

WoIl Permit:

CountY: LARIMBR

Location: SW SB Sec 26 TS|X R73W

Samplor:

Sample Date: 01/01/89

Agency: ROCXY MTN CONBULThNTS

Analys18 Date:

BPA Method:

Lab Name: CBHRBE LABB

Notes on Analysis: IroReNyICS

Well Name: $M-4$

Porforated: $0.0^{\circ}$ to $0.0^{\prime}$

Aquifer: UKCOKFINBD?

Noter on Sample:

Yield: 0

Dopth: 0.0

"-" =Not Detected at Level

UKCBRTAIN-BOMBTIMB IN 1939

Water Temperaturo, deg. C

Fiold pH, standard units

Field Conductivity, umhos/cm

Chloride, total,

Nitrate, total as $N$,

$\mathrm{mg} / 1$

Nitrite, total as $N$,

$m g / 1$

pH,

$m g / 1$

sulfate, total,

B.u.

Copper, diss.,

mg/l

Iron, Ales.,

$u g / 1$

Manganese, dis8.

ug/1

Zinc, diss.,

ug/l

ug/1

0.0

0.0

0

408

73

$-0.01$

6. 91

52.30

205. 00

40900.00

520.00

66300 
Colorado Department of Health Ground Water Quality Data Date: 06/22/95 Report of Inorganic Analysis
YYotem- QUALDAT Page 1

\begin{tabular}{|c|c|c|}
\hline $\begin{array}{l}\text { Woll Pormit: } \\
\text { County: LARIMRR } \\
\text { Samplor: }\end{array}$ & $\begin{array}{l}\text { Location: 8W 8E Bec } 26 \text { T5 } \\
\text { Sample Date: OI/01/90 } \\
\text { Agency: ROCKY MTN CONBUL }\end{array}$ & RTTS \\
\hline $\begin{array}{l}\text { Analyols Date: } / \quad / \\
\text { BPA Method: }\end{array}$ & $\begin{array}{l}\text { Lab Name: CBNREF LAB8 } \\
\text { Moteg on AnalYBiB: INORG }\end{array}$ & NICS \\
\hline $\begin{array}{l}\text { Woll Name: } M W-4 \\
\text { Perforated: } 0.0^{\prime} \text { to } 0.0 \\
\text { Notes on Sample: SAMPLB }\end{array}$ & 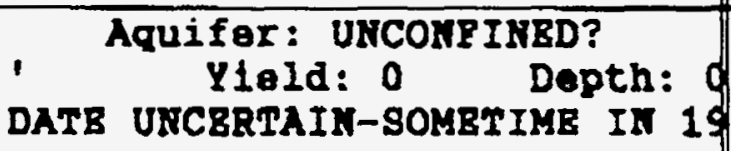 & .0 \\
\hline
\end{tabular}

"-" = Not Dotected at Level, "0.0"=Not Analybed

Water Temperature, deg. C

Pleld PH, standard units

Blold Conductivity, umhos/cm

Chloride, total,

Hitrate, total as $N$,

Nitrite, total as $N$,

ple,

Sulfato, total,

Total Dissolved solids,

Copper, dise.,

Iron, d188. .

Manganese, dise.,

Zinc, diss..
0.0

0.0

0

$m g / 1$

$\mathrm{mg} / \mathrm{l}$

$\mathrm{mg} / \mathrm{I}$

B.u.

$\mathrm{mg} / \mathrm{l}$

$\mathrm{mg} / \mathrm{I}$

$u g / 1$

$\lg / 1$

ug/I

ug/l
455.00

4.50

$-0.01$

6.80

22. 50

1710.00

110.00

$6600 \mathrm{~d} .00$

840.00

$48 \mathrm{a} .00$ 

Colorado Department of Hoalth Ground Water Quality Data
Date: $06 / 22 / 95$
Report of Inorganic Analysis SYBtom- QUALDAT Paga 1

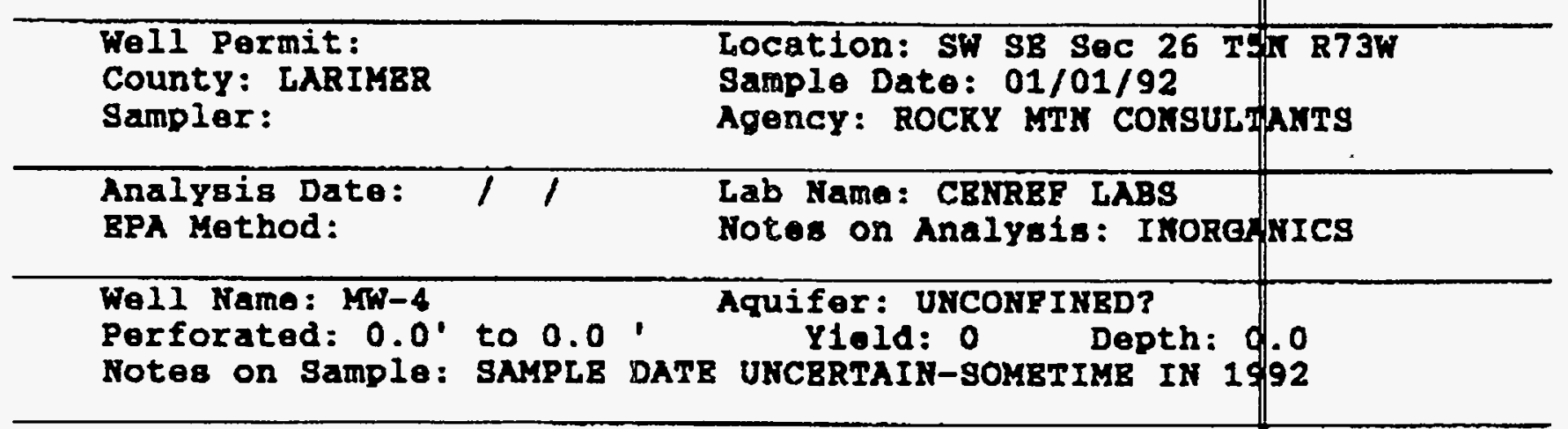

"-" = Not Detected at Lovel, "0.0"=Not Analyged

Water Temperature, deg. C

Flold pH, standard units

Field Conductivity, umhos/cm

Chlorlde, total,

Nitrate, total as $N$,

Nitrite, total as $N$.

PH,

Sulfate, total,

Total Dissolved solids,

Copper, als8.,

Iron, diss.,

Manganese, diss.,

zine, diss., $\mathrm{mg} / 1$

$\mathrm{mg} / \mathrm{I}$

$\mathrm{mg} / \mathbf{1}$

s.u.

$\mathrm{mg} / \mathrm{I}$

$\mathrm{mg} / \mathrm{l}$

ug/1

$\mathrm{ug} / \mathrm{I}$

ug/1

$\mathbf{u g} / 1$
0.0

0.0

0 500.00

16.50

$-0.01$

6. 32

84.00

1310.00

7.00

3280.00

60.00

61.00 
Colorado Department of Health Ground Water Quality Data Date: $06 / 22 / 95$ Report of Inorganic Anelysis

Bystem- QUALDAT Page 1

\begin{tabular}{|c|c|c|}
\hline $\begin{array}{l}\text { WeIl Parmit: } \\
\text { County: LARIMBR } \\
\text { gampler: }\end{array}$ & $\begin{array}{l}\text { Tocation: 9w 88 Sec } 26 \mathrm{~T} \\
\text { Sample Date: 07/07/93 } \\
\text { Agancy: ROCKY MTH Coksus }\end{array}$ & $\begin{array}{l}\text { R73h } \\
\text { ANT8 }\end{array}$ \\
\hline $\begin{array}{l}\text { Analysis Date: } / / \\
\text { BPA Method: }\end{array}$ & $\begin{array}{l}\text { Lab Name: CBNRBF LABS } \\
\text { Notes on Analysis: InORG }\end{array}$ & NICs \\
\hline $\begin{array}{l}\text { Well Name: MW-4 } \\
\text { Perforated: } 0.0^{\prime} \text { to } 0.0 \text {, } \\
\text { Notes on 8ample: }\end{array}$ & $\begin{array}{c}\text { Aquifer: URCONPINBD? } \\
\text { Yield: } 0 \quad \text { Depth: }\end{array}$ & 4.0 \\
\hline 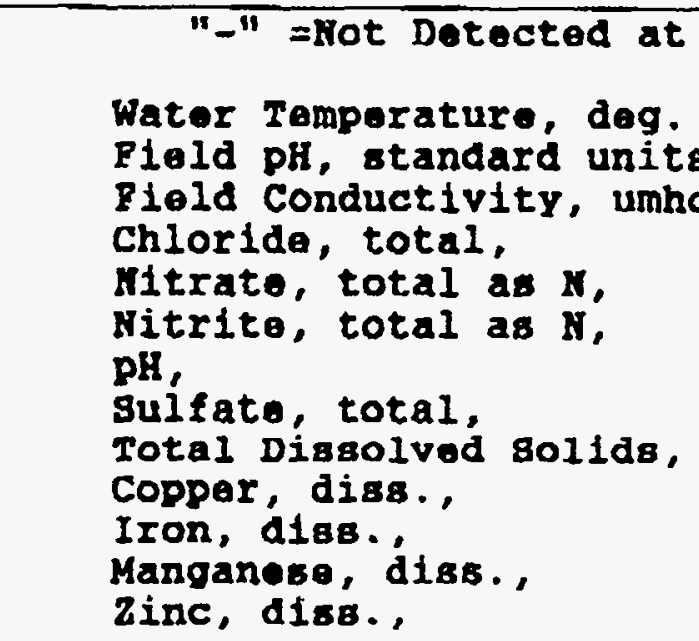 & 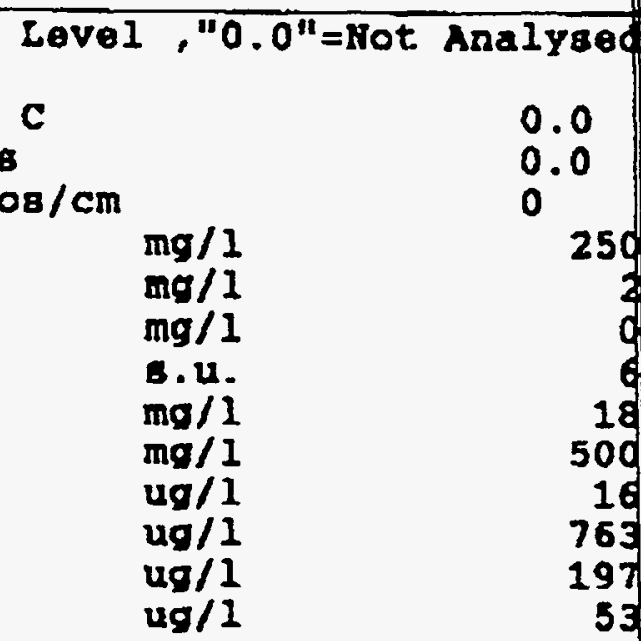 & $\begin{array}{l}.00 \\
.88 \\
.05 \\
.61 \\
.00 \\
.00 \\
.00 \\
.00 \\
.00 \\
.00\end{array}$ \\
\hline
\end{tabular}


CONFIRMATION/REPORT OF TELEPHONE CONVERSATION

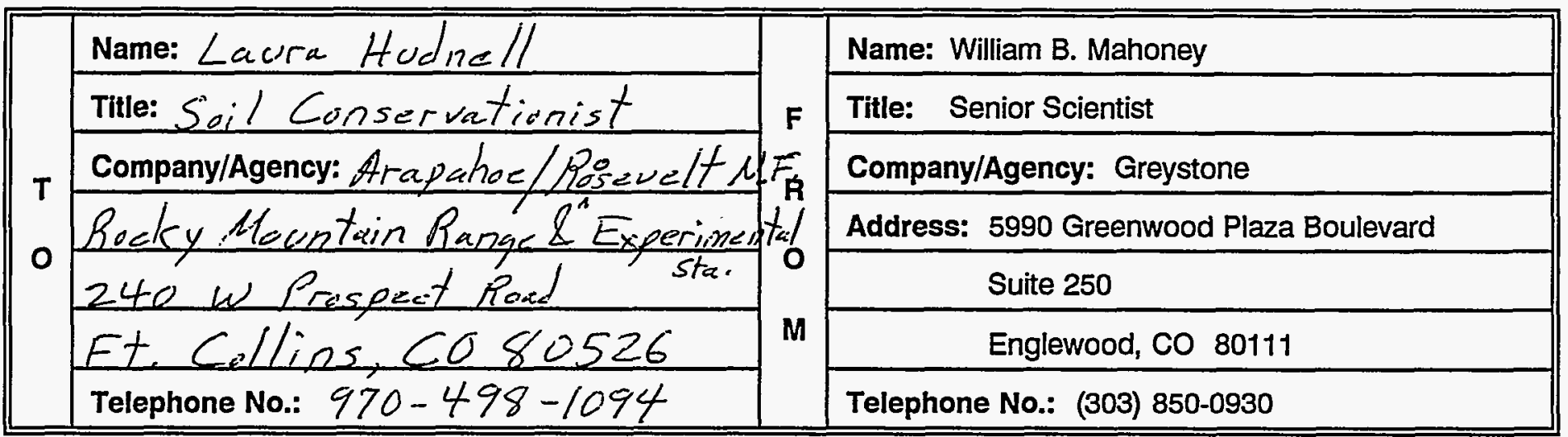

PROJECT: Mary Lake

PROJECT NO.: $.4 / 4$

Date: $6 / 20 / 94$

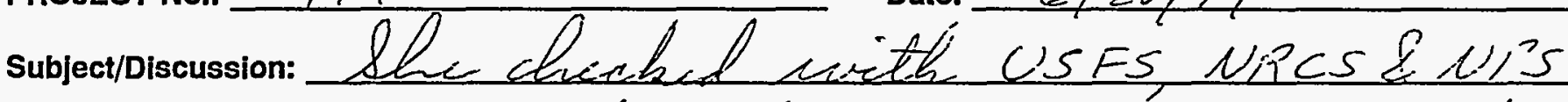

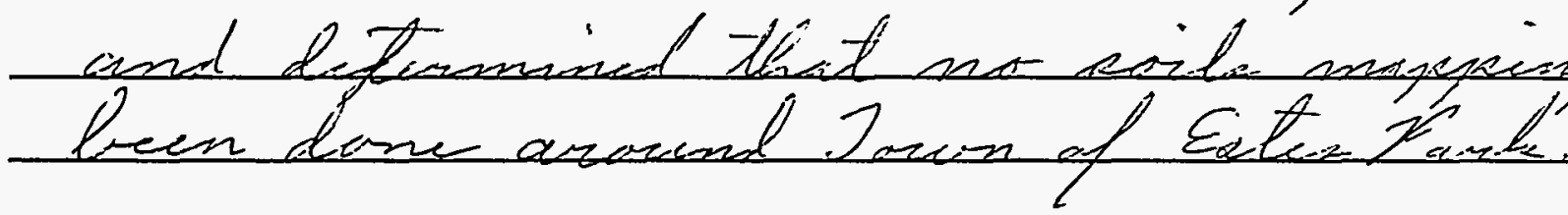


Estes-Poudre Ranger District $1311 \mathrm{~S}$. College Ave. Fort Collins, CO 80524 (970) 498-2775

Reply To: 1950

Date: June 29, 1995

GREYSTONE ENVIRONMENAL PLANNERS

5990 GREENWOOD PLAZA BLVD. SUITE 250

ENGLEWOOD, CO 80111

Dear Mr. Keith:

Your letter of June $/$ asked for comments on the proposed upgrading of the Marys Lake powerline near Estes Park. We will not be able to attend your agency scoping meeting, but we forsee no adverse effects on National Forest lands in the area. Thank you for including us in your mailing and for allowing us to comment.

Sincerely,

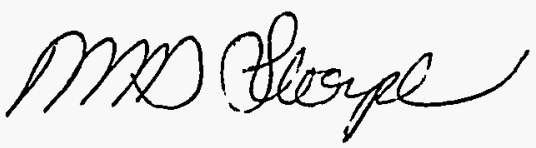

MICHAEL D. LIOYD

DISTRICT RANGER 


\title{
United States Department of the Interior
}

\author{
FISH AND WILDLIFE SERVICE \\ Ecological Services \\ Colorado Field Office \\ 730 Simms Street, Suite 290 \\ Golden, Colorado 80401
}

IN REPLY REFER TO:

ES/CO: REA

Mail Stop 65412

AUG 41995

Mr. Stephen A. Fausett, Area Manager

Department of Energy

Western Area Power Administration

Loveland Area Office

P.O. Box 3700

Loveland, Colorado 80539-3003

Dear Mr. Fausett:

In response to your letter of May 5, 1995, the U.S. Fish and Wildlife Service (Service) is providing the compendium of federally listed and candidate animal and plant species or critical habitats that may occur in the vicinity of the Marys Lake Transmission Line Upgrade and Marys Lake Substation Expansion Projects near Estes Park, Larimer County, Colorado. This office reviewed the proposed work, and we offer the following comments.

The federally listed species that could occur throughout the project area are the endangered peregrine falcon, Falco peregrinus, the threatened bald eagle, Haliaeetus leucocephalus, and the threatened greenback cutthroat trout, Onchorhynchus clarki stomias.

The bald eagle and peregrine falcon also are species that have the potential to be present at or near the proposed project area. Projects involving new construction and potential for electrocution of these species or collisions with the lines are of chief concerns to the Service. For bald eagles, the Service is most concerned with construction activities occurring on or near wetlands, lakes, and large trees. For peregrines, the Service is most concerned with construction or reconstruction activities in areas near falcon nests. The Colorado Division of Wildlife (CDOW) constantly updates its falcon nest data base with yearly surveys throughout the state. We suggest you contact Jerry Craig with CDOW in Fort Collins to find out if any eagles, falcons, or other raptors would be disturbed by the project.

The greenback cutthroat trout was stocked in Larimer County in the North Fork of the Big Thompson and Roaring Rivers and may have extended its range by now. Your agency should determine if any activity related to the project will impact this trout or its habitat (destruction or pollution of riverine habitat). Construction activities associated with the project, such as road building, may cause erosion that will degrade the quality of the greenback's habitats.

The Service also is interested in the protection of species which are candidates for official listing as threatened or endangered species (Federal Register, Vol. 56, No. 225, November 
21, 1991; Vol 55, No. 35, February 21, 1990) under the Endangered Species Act of 1973 (ESA), as amended (16 U.S.C. 1531 et seg.). While these species presently have no legal protection under the ESA, it is within the spirit of this act to consider project impacts to potentially sensitive candidate species. It is the intention of the Service to protect these species before human-related activities adversely impact their habitat to a degree that they would need to be listed and, therefore, protected under the ESA. Additionally, we wish to make you aware of the presence of Federal candidates should any be proposed or listed prior to the time that all actions related to the project are completed. If any candidate species will be unavoidably impacted, appropriate mitigation should be proposed and discussed with this office prior to commencement of project activities.

Amphibian: Boreal toad, Bufo boreas boreas, Category 2

Bird: $\quad$ Northern goshawk, Accipiter gentilis, Category 2

Mammal: $\quad$ Fringed-tailed myotis, Myotis thysanodes pahasapensis, Category 2

Plants: $\quad$ Larimer aletes, Aletes humilis, Category 2

Pale blue-eyed grass, Sisyrinchium pallidum, Category 2

Weber monkey-flower, Mimulus gemmiparus, Category 2

Northern goshawks are known to nest within the boundaries of the Roosevelt National Forest and are present west and east of U.S. Highway 287 in northern Larimer County. The activities that could impact raptors in forested areas would be timber clearance, road construction during nesting season, transmission or power lines along hunting or migrating routes, etc. Any foreseeable impacts to raptors should be avoided; but if there might be unavoidable impacts, mitigation measures should be discussed with this office.

The Service recommends that all new/rebuilt power lines conform to the design criteria of the publications by Ohlendorff, R.R., A.D. Miller and R. N. Lehman. 1981. Suggested practices for raptor protection on power lines. The state of the art in 1981. and Thompson. L.S. 1978. Mitigation through engineering and habitat modification. Pages 51-92 in M.L. Avery, ed. Impacts of transmission lines on birds in flight. U.S. Fish and Wildlife Service, Washington, D.C. . Raptors and other migratory species are protected in accordance with the Eagle Protection Act (16 U.S.C. 66-6680) and other Federal laws. Electrocution from collision with power lines could be a potential "take" of migratory birds.

Electrocution and collision protection measures should not be restricted to areas of known bird concentrations or within known migratory routes. The reason being that due to the characteristic behavior of raptors and waterfowl, the areas utilized by these birds are constantly changing; therefore, they can be expected to cross the project's service area even when they have not yet been observed in the area.

Boreal toads are known to exist along the Continental Divide. Road construction and maintenance activities and excavations are of particular concern to the Service as they might impact it if they occur in wetlands and riparian corridors above 8,000 feet in elevation. 
According to Rare Plants of Colorado, Weber monkey-flower "grows in the moist soil of forest seeps or springs protected by granite overhangs, at elevations of 8,500-10,500 feet . . . it often grows in association with other monkey-flowers. The pale blue-eyed grass is not a grass at all but a member of the iris family. It inhabits poorly drained mid-elevation meadows, 7,000 to 10,000 feet, dominated by true grasses and other grass-like plants." Larimer aletes "grows in cracks and crevices on rocky granite outcrops where it is shaded by ponderosa pine and on cool, north-facing, near vertical cliffs. It has thick leathery leaves that help maintain moisture. In the few canyons where it grows, the plant forms conspicuous clumps and mats on rock walls, and when in bloom present a showy yellow display." These species may be present in the project area.

The Service regards wetlands and riparian habitats as important resources due to their high value for fish and wildlife, erosion control, ground water recharge and water supply, flood control, and others. Therefore, we recommend the proposed project areas be inventoried for wetlands and riparian habitats. Wetlands should be defined according to "Classification of Wetlands and Deepwater Habitats of the United States" (Cowardin, et al., 1977). We recommend that any adverse impacts to wetlands within the project areas be avoided (Section 404 of the Clean Water Act regulates the fill of wetlands on public and private land). If unavoidable impacts to wetlands or riparian habitats are identified during the line construction itself, the Service should be contacted prior to any operations (including but not limited to filling, trampling, timber harvesting, road construction and use, etc.) that would affect wetlands. The Service has National Wetland Inventory (NWI) maps of the project area available. Maps can be obtained by calling 1-800-USA-MAPS.

For more detailed information on animal and plant distribution, habitat needs, and other characteristics contact:

Animals: Don Bogart, CDOW Northeastern Regional Office at (970) 484-2836.

Plants: Colorado Natural Areas Program of the Division of Parks and Outdoor Recreation at (970) 491-1309, and/or the Colorado Native Plant Society of the Rocky Mountain Nature Association.

The CDOW should be contacted regarding possible impacts to native fauna, especially State listed endangered or threatened species. If you wish to inspect the NWI maps of the area of the project or if the Service can be of further assistance, please contact Bernardo Garza of this office at (303) 231-5280.

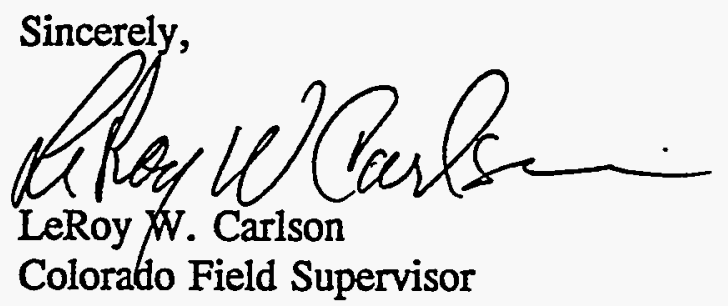


Stephen A. Fausett, Area Manager

cc: CDOW, Fort Collins, CO (Attn. Don Bogart)

Reading file

Project file

Refereace JBG'ESLMARYSL_AK.WPP

$\stackrel{9}{\longrightarrow}$ 


\section{TELEPHONE \\ CONTACT REPORT}

\begin{tabular}{lll}
\multicolumn{1}{c}{$\square$ OUTGOING CALL } & $\square$ INCOMING CALL \\
Date: 8/9/95 & Project: Mary's Lake Powerline & Project No.: 414-03 \\
\cline { 2 - 3 } CONTACT & & $\begin{array}{l}\text { GREYSTONE EMPLOYEE } \\
\text { Mike Bonar }\end{array}$ \\
\hline Title: Rame: Jerry Craig & \\
\hline Organization: CDOW & \\
\hline Phone: (970) 484-2836 ext. 307 & \\
\hline Address/Location: Fort Collins, Colorado & \\
\hline
\end{tabular}

Subject of Discussion: Raptor usage in the area of the upgrade

Items Discussed: I discussed with Jerry the potential for peregrines to occur within the general project area. He indicated that there is some potential for peregrines to occur within the area. The closest known nest is in the Rams Horn Mountain area southwest of the southern end of the line. The birds nested there in 1990, however, they have not nested there since. But he felt that they may be in the area somewhere. The next closest known location is approximately 4 miles east of the line and another 8 miles north of the line. He also indicated that a peregrine had collided with a distribution line in a residential development within Estes Park. Also, they used to think that peregrines hunted within 2 miles of the nest, however, now they are finding that the birds may hunt up to 20 miles away. This may increase the chance for collisions with wires due to the birds not knowing such a large area as well.

I asked about goshawks and there is no known goshawk nests in the area, but it may be goshawk habitat. They mainly occur within drainages containing aspen and conifers. Actually the right-of-way may open up areas for hunting for the goshawks.

There may be a few bald eagles that winter on Estes Lake, but there is no known roost sites. Also there is no known nesting or summering areas for bald eagles in the area.

Golden eagles may occur in the area, but they too not have any known nests or roosts in the area.

General recommendations: His recommendations for the project was to leave the line in the existing corridor, and use a bigger wire. The bigger the wire the better. Also if the static lines are on top of the poles use the largest wire possible. Also if the wire is bigger it may benefit birds by making the line more visible. The bigger the wire the less chance of a wire strike. The taller the poles the better. Also, he

Page of 
strongly recommended that the line be upgraded in place. A new right-of-way increases the chance of strikes and increases the potential for more adverse impacts to the birds. Right now the birds have adapted to the existing line decreasing the potential for any adverse impacts.

Action To Be Taken:

Route To:

Larry of 


\section{MEMO TO FILE}

Job No.: $\quad 414$, Mary's Lake

Date: $\quad 8 / 15 / 95$

From: $\quad$ Cathy Begej

I talked with an individual from the Denver District FEMA office who advised me on the classifications for floodplains. The 'A' designations refer to the 100 -year storm floodplain. The specific numbers (i.e. 'A2' vs 'A7' refer to different flood hazard risks associated with insurance premiums. The ' $X$ ' category came out in the mid-80s to replace the ' $B$ ', ' $C$ ', and ' $D$ ' categories. The shaded ' $X$ ' replaced the ' $B$ ' category of the 500-year floodplain, the unshaded ' $\mathrm{X}$ ' replaced the ' $\mathrm{C}$ ' (minimal hazard) and ' $\mathrm{D}$ ' (undetermined but possible flood zones). There may be both designations within a county's maps, depending on how recently panels were revised based on hydrologic studies. 


\section{United States Department of the Interior}

FISH AND WILDLIFE SERVICE

ES/CO: DOE, Species List

Mail Stop 65412
Ecological Services Colorado Field Office 730 Simms Street, Suite 290 Golden, Colorado 80401

Stephen A. Fausett, Area Manager

Department of Energy

Western Area Power Administration

Loveland Area Office

P.O. Box 3700

Loveland, Colorado 80539

Dear Mr. Fausett:

In response to your letter of May 5, 1995, the U.S. Fish and Wildlife Service (Service) is providing the updated list of threatened, endangered and candidate species you requeted concerning the Estes-East Portal 115-kV Transmission Line upgrade. These comments have been prepared under the provisions of the Endangered Species Act of 1973 (ESA), as amended (16 U.S.C. 1531 et. seq.).

If the Service can be of further assistance, contact Clay Ronish of this office at (303) 231-5280.

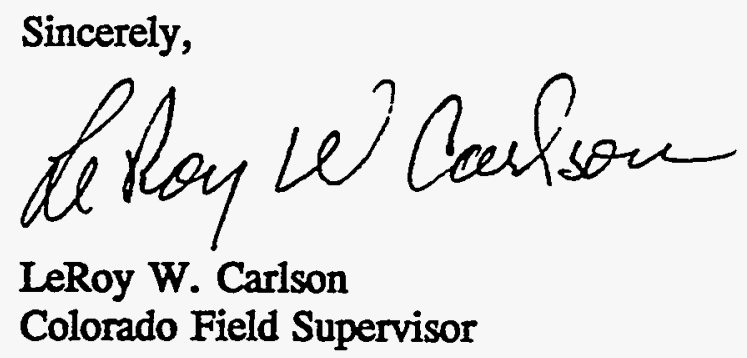

\section{cc: Reading file \\ Project file}

Refereace: CRR*SPECLIST.026 


\begin{tabular}{|c|c|c|c|c|c|c|c|c|c|c|c|c|c|c|c|c|}
\hline $\begin{array}{l}\text { rage } 1 / 0 \\
\text { U. S. Fish and Wildlife Service } \\
\text { Ecological Services } \\
\text { Colorado Field Office } \\
\text { (Effective September 26, 1995) } \\
\text { FEDERALLY LISTED AND CANDIDATE SPECIES \& THEIR STATUS IN COLORADO } \\
\downarrow\end{array}$ & $\begin{array}{l}A \\
D \\
A \\
M \\
S\end{array}$ & $\begin{array}{l}\text { A } \\
\text { L } \\
\text { A } \\
\text { M } \\
\text { O } \\
\text { S } \\
\text { A }\end{array}$ & $\begin{array}{l}\mathrm{A} \\
\mathrm{R} \\
\mathrm{A} \\
\mathrm{P} \\
\mathrm{A} \\
\mathrm{H} \\
\mathrm{O} \\
\mathrm{E}\end{array}$ & $\begin{array}{l}\mathrm{A} \\
\mathrm{R} \\
\mathrm{C} \\
\mathrm{H} \\
\mathrm{U} \\
\mathrm{L} \\
\mathrm{E} \\
\mathrm{T} \\
\mathrm{A}\end{array}$ & $\begin{array}{l}\mathrm{B} \\
\mathrm{A} \\
\mathrm{C} \\
\mathrm{A}\end{array}$ & $\begin{array}{l}B \\
E \\
N \\
T\end{array}$ & $\begin{array}{l}B \\
O \\
U \\
L \\
D \\
E \\
R\end{array}$ & $\begin{array}{l}\mathrm{C} \\
\mathbf{H} \\
\mathrm{A} \\
\mathbf{F} \\
\mathbf{F} \\
\mathrm{E} \\
\mathrm{E}\end{array}$ & $\begin{array}{l}\mathrm{C} \\
\mathrm{H} \\
\mathrm{E} \\
\mathrm{Y} \\
\mathrm{E} \\
\mathrm{N} \\
\mathrm{N} \\
\mathrm{E}\end{array}$ & $\begin{array}{l}\text { C } \\
\text { E } \\
\text { A } \\
\text { R } \\
\text { C } \\
\text { R } \\
\text { E } \\
\text { E } \\
\text { K }\end{array}$ & $\begin{array}{l}\mathrm{C} \\
\mathrm{O} \\
\mathrm{N} \\
\mathrm{E} \\
\mathrm{J} \\
\mathrm{O} \\
\mathrm{S}\end{array}$ & $\begin{array}{l}\text { C } \\
\text { O } \\
\text { S } \\
\text { T } \\
\text { I } \\
\text { L } \\
\text { L } \\
\text { A }\end{array}$ & $\begin{array}{l}\mathrm{C} \\
\mathrm{R} \\
\mathrm{O} \\
\mathrm{W} \\
\mathrm{L} \\
\mathrm{E} \\
\mathrm{Y}\end{array}$ & $\begin{array}{l}C \\
U \\
S \\
T \\
E \\
R\end{array}$ & $\begin{array}{l}D \\
E \\
L \\
T \\
A\end{array}$ & $\begin{array}{l}D \\
E \\
N \\
V \\
E \\
R\end{array}$ \\
\hline American peregrine falcon, Falco peregrinus, Listed Endangered & & & & $\checkmark$ & & & $\checkmark$ & $\checkmark$ & & & $\checkmark$ & & & $\checkmark$ & & $\checkmark$ \\
\hline Bald eagle, Haliaeetus leucocephalus, Listed Threatened & $\checkmark$ & $\checkmark$ & $\checkmark$ & $\checkmark$ & $\checkmark$ & $\checkmark$ & $\checkmark$ & $\checkmark$ & $\checkmark$ & $r$ & $\checkmark$ & $\checkmark$ & $\checkmark$ & $\checkmark$ & $\checkmark$ & $\checkmark$ \\
\hline Whooping crane, Grus americana, Listed Endangered & $\checkmark$ & $\checkmark$ & & $\checkmark$ & $\checkmark$ & & $\checkmark$ & & & & & & & $\checkmark$ & & $\checkmark$ \\
\hline Least tern (interior population), Sterna antillarum, Listed Endangered & & & & & $\checkmark$ & $\checkmark$ & & & & & & & & & & \\
\hline Piping plover, Charadrius melodus, Listed Threatened & & & & & $\checkmark$ & $\checkmark$ & & & & & & & & & & \\
\hline Eskimo curlew, Numenius borealis, Listed Endangered & $\checkmark$ & & & & $\checkmark$ & & $\checkmark$ & & & & & & & $\checkmark$ & & \\
\hline Mountain plover, Charadrius montanus, Candidate for listing & $\checkmark$ & $\checkmark$ & $\checkmark$ & & $\checkmark$ & $\checkmark$ & $\checkmark$ & & $\checkmark$ & & & & $\checkmark$ & & & \\
\hline Southwestern willow flycatcher, Empidonax trailli extimus, Listed Endang. & & & & $\checkmark$ & & & & & & & $\checkmark$ & $\checkmark$ & $\cdot$ & & & \\
\hline Mexican spotted owl, Strix occidentalis lucida, Listed Threatened & $\checkmark$ & $\checkmark$ & $\checkmark$ & ( & & & $\checkmark$ & $\checkmark$ & & $\checkmark$ & $\checkmark$ & $\checkmark$ & & $\checkmark$ & & $\checkmark$ \\
\hline Boreal toad, Bufo boreas boreas, Candidate for listing & & & & & & & $\checkmark$ & $\checkmark$ & & $\checkmark$ & $\checkmark$ & & & & $\checkmark$ & \\
\hline Black-footed ferret, "Mustela nigripes, Listed Endangered & $\checkmark$ & $\checkmark$ & $\checkmark$ & $\checkmark$ & $\checkmark$ & $\checkmark$ & $\checkmark$ & & $\checkmark$ & & $\checkmark$ & $\checkmark$ & $\checkmark$ & & $\checkmark$ & \\
\hline Preble's meadow jumping mouse, Zapus hudsonius preblei, Candidate & $\checkmark$ & & $\checkmark$ & & & & $\checkmark$ & & & & & & & & & $\checkmark$ \\
\hline Swift fox, Vulpes velox, Candidate for listing & $\checkmark$ & & $\checkmark$ & & $\checkmark$ & $\checkmark$ & $\checkmark$ & & $\checkmark$ & & & & $\checkmark$ & & & \\
\hline Razorback sucker, Xyrauchen texanus, Listed Endangered & & & & & & & & & & & & & & & - & \\
\hline Bonytail chub, Gila elegans, (presumed-historical) Listed Endangered & & & & & & & & & & & & & & & $\checkmark$ & \\
\hline Greenback cutthroat trout, Oncorhynchus clarki stomias, List. Threat. & & & & & & & $\checkmark$ & & & $\checkmark$ & & & & $\checkmark$ & & \\
\hline Arkansas darter, Etheostoma cragini, Candidate for listing & & & & & $\checkmark$ & $\checkmark$ & & & $\checkmark$ & & & & $\checkmark$ & & & \\
\hline Colorado squawfish, Ptychocheilus lucius, Listed Endangered & & & & & & & & & & & & & & & 0 & \\
\hline
\end{tabular}




\begin{tabular}{|c|c|c|c|c|c|c|c|c|c|c|c|c|c|c|c|c|}
\hline $\begin{array}{l}\text { Page 2/8 } \\
\qquad \begin{array}{c}\text { U. S. Fish and Wildlife Service } \\
\text { Ecological Services } \\
\text { Colorado Field Office } \\
\text { (Effective September 26, 1995) }\end{array} \\
\text { FEDERALLY LISTED/CANDIDATE SPECIES \& THEIR STATUS IN COLORADO } \\
\downarrow\end{array}$ & $\begin{array}{l}\mathrm{A} \\
\mathrm{D} \\
\mathrm{A} \\
\mathrm{M} \\
\mathrm{S}\end{array}$ & $\begin{array}{l}\text { A } \\
\text { L } \\
\text { A } \\
\text { M } \\
\text { O } \\
\text { S } \\
\text { A }\end{array}$ & $\begin{array}{l}\text { A } \\
\text { R } \\
\text { A } \\
\text { P } \\
\text { A } \\
\text { H } \\
\text { O } \\
\text { E }\end{array}$ & $\begin{array}{l}\text { A } \\
\text { R } \\
\text { C } \\
\text { H } \\
\text { U } \\
\text { L } \\
\text { E } \\
\text { T } \\
\text { A }\end{array}$ & $\begin{array}{l}\text { B } \\
\text { A } \\
\text { C } \\
\text { A }\end{array}$ & $\begin{array}{l}B \\
E \\
N \\
T\end{array}$ & $\begin{array}{l}\text { B } \\
\text { O } \\
\text { U } \\
\text { L } \\
\text { D } \\
\text { E } \\
\text { R }\end{array}$ & $\begin{array}{l}\text { C } \\
\text { H } \\
\text { A } \\
\text { F } \\
\text { F } \\
\text { E } \\
\text { E }\end{array}$ & $\begin{array}{l}\mathrm{C} \\
\mathrm{H} \\
\mathrm{E} \\
\mathrm{Y} \\
\mathrm{E} \\
\mathrm{N} \\
\mathrm{N} \\
\mathrm{E}\end{array}$ & $\begin{array}{l}\mathrm{C} \\
\mathrm{L} \\
\mathrm{E} \\
\mathrm{A} \\
\mathrm{R} \\
\mathrm{C} \\
\mathrm{R} \\
\mathrm{E} \\
\mathrm{E} \\
\mathrm{K}\end{array}$ & $\begin{array}{l}\mathrm{C} \\
\mathrm{O} \\
\mathrm{N} \\
\mathrm{E} \\
\mathrm{J} \\
\mathrm{O} \\
\mathrm{S}\end{array}$ & $\begin{array}{l}C \\
O \\
S \\
T \\
I \\
L \\
L \\
A\end{array}$ & $\begin{array}{l}\mathrm{C} \\
\mathrm{R} \\
\mathrm{O} \\
\mathrm{W} \\
\mathrm{L} \\
\mathrm{E} \\
\mathrm{Y}\end{array}$ & $\begin{array}{l}C \\
U \\
S \\
T \\
E \\
R\end{array}$ & $\begin{array}{l}\mathrm{D} \\
\mathrm{E} \\
\mathrm{L} \\
\mathrm{T} \\
\mathrm{A}\end{array}$ & $\begin{array}{l}D \\
E \\
N \\
V \\
E \\
R\end{array}$ \\
\hline $\begin{array}{l}\text { Uncompahgre fritillary butterfly, Boloria acrocnema, Listed } \\
\text { Endangered }\end{array}$ & & & & & & & & & & & & & & $\checkmark$ & & \\
\hline $\begin{array}{l}\text { Clay-loving wild buckwheat, Eriogonum pelinophilum, Listed } \\
\text { Endangered }\end{array}$ & & & & & & & & & & & & & & & $\checkmark$ & \\
\hline $\begin{array}{l}\text { Spineless hedgehog cactus, Echinocereus triglochidiatus var. inermis, } \\
\text { Listed Endangered }\end{array}$ & & & & & & & & & & & & & & & $\checkmark$ & \\
\hline Uinta Basin hookless cactus, Sclerocactus glaucus, Listed Threatened & & & & & & & & & & & & & & & $\checkmark$ & \\
\hline Ute ladies'-tresses orchid, Spiranthes diluvialis, Listed Threatened & $\checkmark$ & & $\checkmark$ & & & & $\checkmark$ & & & & & & & & & $\checkmark$ \\
\hline Brandegee wild buckwheat, Eriogonum brandegei, Candidate for listing & & & & & & & & $\checkmark$ & & & & & & & & \\
\hline $\begin{array}{l}\text { Colorado butterflyweed, Gaura neomexicana ssp. coloradensis, } \\
\text { Candidate for listing }\end{array}$ & $\checkmark$ & & $\checkmark$ & $\checkmark$ & & & $\checkmark$ & & & & & & & & & $\checkmark$ \\
\hline & & & & & & & & & & & & & & & & \\
\hline & & & & & & & & & & & & & & & & \\
\hline & & & & & & & & & & & & & & & & \\
\hline & & & & & & & & & & & & & & & & \\
\hline & & & & & & & & & & & & & & & & \\
\hline & & & & & & & & & & & & & & & & \\
\hline & & & & & & & & & & & & & & & & \\
\hline & & & & & & & & & & & & & & & & \\
\hline & & & & & & & & & & & & & & & & \\
\hline
\end{tabular}




\begin{tabular}{|c|c|c|c|c|c|c|c|c|c|c|c|c|c|c|c|c|}
\hline 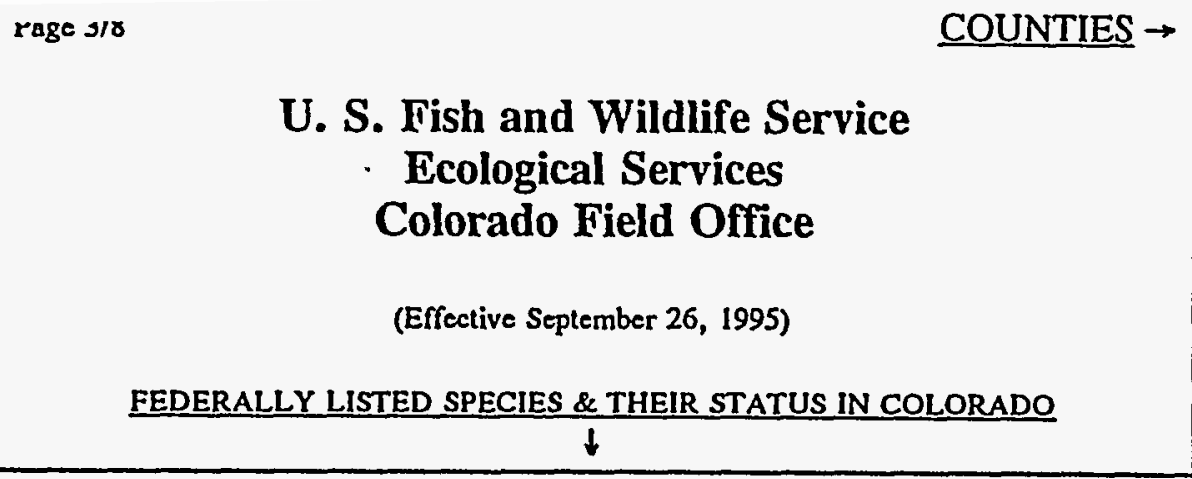 & $\begin{array}{l}D \\
O \\
L \\
O \\
R \\
E \\
S\end{array}$ & $\begin{array}{l}D \\
O \\
U \\
G \\
L \\
\text { A } \\
S\end{array}$ & $\begin{array}{l}\mathbf{E} \\
\mathbf{A} \\
\mathbf{G} \\
\mathbf{L} \\
\mathbf{E}\end{array}$ & $\begin{array}{l}\text { E } \\
\text { L } \\
B \\
E \\
R \\
T\end{array}$ & $\begin{array}{l}E \\
L \\
P \\
A \\
S \\
O\end{array}$ & $\begin{array}{l}\mathrm{F} \\
\mathrm{R} \\
\mathrm{E} \\
\mathrm{M} \\
\mathrm{O} \\
\mathrm{N} \\
\mathrm{T}\end{array}$ & $\begin{array}{l}\text { G } \\
\mathbf{A} \\
\mathbf{R} \\
\mathbf{F} \\
\mathbf{I} \\
\mathbf{E} \\
\mathrm{L} \\
\mathrm{D}\end{array}$ & $\begin{array}{l}\text { G } \\
\text { I } \\
\text { L } \\
\text { P } \\
\text { I } \\
\text { N }\end{array}$ & $\begin{array}{l}G \\
R \\
A \\
N \\
D\end{array}$ & $\begin{array}{l}\mathbf{G} \\
\mathrm{U} \\
\mathbf{N} \\
\mathrm{N} \\
\mathrm{I} \\
\mathrm{S} \\
\mathrm{O} \\
\mathrm{N}\end{array}$ & $\begin{array}{l}\text { H } \\
\text { I } \\
\text { N } \\
\text { S } \\
\text { D } \\
\text { A } \\
\text { L } \\
\text { E }\end{array}$ & $\begin{array}{l}\text { H } \\
\text { U } \\
\text { E } \\
\text { R } \\
\text { F } \\
\text { A } \\
\text { N } \\
\text { O }\end{array}$ & $\begin{array}{l}\mathrm{J} \\
\mathbf{A} \\
\mathrm{C} \\
\mathrm{K} \\
\mathbf{S} \\
\mathrm{O} \\
\mathbf{N}\end{array}$ & $\begin{array}{l}J \\
E \\
F \\
F \\
E \\
R \\
S \\
O \\
N\end{array}$ & $\begin{array}{l}\mathbf{K} \\
\mathbf{I} \\
\mathbf{O} \\
\mathbf{W} \\
\mathbf{A}\end{array}$ & $\begin{array}{l}\mathrm{K} \\
\mathrm{I} \\
\mathrm{T} \\
\mathrm{C} \\
\mathrm{A} \\
\mathrm{R} \\
\mathrm{S} \\
\mathrm{O} \\
\mathrm{N}\end{array}$ \\
\hline American peregrine falcon, Falco peregrinus, Listed Endangered & & $\checkmark$ & & & $\checkmark$ & $\checkmark$ & $\checkmark$ & & $\checkmark$ & $\checkmark$ & $\checkmark$ & $\checkmark$ & $\checkmark$ & $\checkmark$ & & \\
\hline Bald eagle, Haliaeetus leucocephalus, Listed Threatened & $\checkmark$ & $\checkmark$ & $\checkmark$ & $\checkmark$ & $\checkmark$ & $\checkmark$ & $\checkmark$ & & $\checkmark$ & $\checkmark$ & $\checkmark$ & $\checkmark$ & $\checkmark$ & $\checkmark$ & $\checkmark$ & $\checkmark$ \\
\hline Whooping crane, Grus americana, Listed Endangered & & & & $\checkmark$ & & & & & & & & $\checkmark$ & & & & \\
\hline Least tern (interior population), Sterna antillarum, Listed Endangered & & & & & & & & & & & & & & & $\checkmark$ & $\checkmark$ \\
\hline Piping plover, Charadrius melodus, Listed Threatened & & & & & & & & & & & & & & & $\checkmark$ & $\checkmark$ \\
\hline Eskimo curlew, Numenius borealis, Listed Endangered & & & & $\checkmark$ & & & $\checkmark$ & & & & & & & $\checkmark$ & $\checkmark$ & $\checkmark$ \\
\hline Mountain plover, Charadrius montanus, Candidate for listing & & $\checkmark$ & & $\checkmark$ & $\checkmark$ & & & & & & & $\checkmark$ & $\checkmark$ & & $\checkmark$ & $\checkmark$ \\
\hline $\begin{array}{l}\text { Southwestern willow flycatcher, Empidonax trailli extimus, Listed } \\
\text { Endangered }\end{array}$ & $\checkmark$ & & & & & & $\checkmark$ & & & & & & & & & \\
\hline Mexican spotted owl, Strix occidentalis lucida, Listed Threatened & $\checkmark$ & $\checkmark$ & & & $\checkmark$ & $\checkmark$ & & $\checkmark$ & $\checkmark$ & & & $\checkmark$ & $\checkmark$ & $\checkmark$ & & \\
\hline Black-footed ferret, Mustela nigripes, Listed Endangered & $\checkmark$ & $\checkmark$ & $\checkmark$ & $\checkmark$ & $\checkmark$ & $\checkmark$ & & & $\checkmark$ & $\checkmark$ & $\checkmark$ & & $\checkmark$ & & $\checkmark$ & $\checkmark$ \\
\hline Swift fox, Vulpes velox, Candidate for listing & & $\checkmark$ & & $\checkmark$ & $\checkmark$ & $\checkmark$ & & & & & & $\checkmark$ & $\checkmark$ & & $\checkmark$ & $\checkmark$ \\
\hline Preble's meadow jumping mouse, Zapus hudsonius preblei, Candidate & & $\checkmark$ & & $\checkmark$ & $\checkmark$ & & & & & & & & & $\checkmark$ & & \\
\hline $\begin{array}{l}\text { Greenback cutthroat trout, Oncorhynchus clarki stomias, Listed } \\
\text { Threatened }\end{array}$ & & $\checkmark$ & & & $\checkmark$ & & & & & & & $\checkmark$ & . & & & \\
\hline Razorback sucker, Xyrauchen texanus, Listed Endangered & & & & & & & - & & & & & & & & & \\
\hline Bonytail chub, Gila elegans, (presumed-historical) Listed Endangered & & & & & & & $\checkmark$ & & & & & & & & & \\
\hline Arkansas darter, Etheostoma cragini, Candidate for listing & & & & $\checkmark$ & $\checkmark$ & $\checkmark$ & & & & & & $\checkmark$ & & & $\checkmark$ & \\
\hline Colorado squawfish, Ptychocheilus lucius, Listed Endangered & & & & & & & ๑ & & & & & & & & & \\
\hline Pawnee montane skipper, Hesperia leonardus montana, List. Threat. & & $\checkmark$ & & & & & & & & & & & & $\checkmark$ & & \\
\hline
\end{tabular}




\begin{tabular}{|c|c|c|c|c|c|c|c|c|c|c|c|c|c|c|c|c|}
\hline $\begin{array}{l}\text { Page 4/8 } \\
\qquad \begin{array}{c}\text { U. S. Fish and Wildlife Service } \\
\text { Ecological Services } \\
\text { Colorado Field Office }\end{array} \\
\text { (Effective September 26, 1995) } \\
\text { FEDERALLY LISTED SPECIES \& THEIR STATUS IN COLORADO } \\
\downarrow\end{array}$ & $\begin{array}{l}\mathrm{D} \\
\mathrm{O} \\
\mathrm{L} \\
\mathrm{O} \\
\mathrm{R} \\
\mathrm{E} \\
\mathrm{S}\end{array}$ & $\begin{array}{l}D \\
O \\
U \\
G \\
L \\
A \\
S\end{array}$ & $\begin{array}{l}E \\
A \\
G \\
L \\
E\end{array}$ & $\begin{array}{l}\text { E } \\
\text { L } \\
B \\
E \\
R \\
T\end{array}$ & $\begin{array}{l}\mathrm{E} \\
\mathrm{L} \\
\mathbf{P} \\
\mathrm{A} \\
\mathrm{S} \\
\mathrm{O}\end{array}$ & $\begin{array}{l}\mathrm{F} \\
\mathrm{R} \\
\mathrm{E} \\
\mathrm{M} \\
\mathrm{O} \\
\mathrm{N} \\
\mathrm{T}\end{array}$ & $\begin{array}{l}\text { G } \\
\text { A } \\
\text { R } \\
\mathbf{F} \\
\mathbf{I} \\
\mathrm{E} \\
\mathbf{L} \\
\mathrm{D}\end{array}$ & $\begin{array}{l}\text { G } \\
\text { I } \\
\text { L } \\
P \\
\text { I } \\
\text { N }\end{array}$ & $\begin{array}{l}\mathrm{G} \\
\mathrm{R} \\
\mathrm{A} \\
\mathrm{N} \\
\mathrm{D}\end{array}$ & $\begin{array}{l}\mathrm{G} \\
\mathrm{U} \\
\mathrm{N} \\
\mathrm{N} \\
\mathrm{I} \\
\mathrm{S} \\
\mathrm{O} \\
\mathrm{N}\end{array}$ & $\begin{array}{l}\text { H } \\
\text { I } \\
\text { N } \\
\text { S } \\
\text { D } \\
\text { A } \\
\text { L } \\
\text { E }\end{array}$ & $\begin{array}{l}\mathbf{H} \\
\mathbf{U} \\
\mathrm{E} \\
\mathrm{R} \\
\mathrm{F} \\
\mathrm{A} \\
\mathbf{N} \\
\mathbf{O}\end{array}$ & $\begin{array}{l}J \\
\text { A } \\
\text { C } \\
\text { K } \\
\text { S } \\
\text { O } \\
\text { N }\end{array}$ & $\begin{array}{l}\mathrm{J} \\
\mathrm{E} \\
\mathrm{F} \\
\mathrm{F} \\
\mathrm{E} \\
\mathrm{R} \\
\mathrm{S} \\
\mathrm{O} \\
\mathrm{N}\end{array}$ & $\begin{array}{l}K \\
\mathrm{I} \\
\mathrm{O} \\
\mathrm{W} \\
\mathrm{A}\end{array}$ & $\begin{array}{l}\text { K } \\
\text { I } \\
\text { T } \\
\text { C } \\
\text { A } \\
\text { R } \\
\text { S } \\
\text { O } \\
\text { N }\end{array}$ \\
\hline $\begin{array}{l}\text { Uncompahgre fritillary butterfly, Boloria acrocnema, Listed } \\
\text { Endangered }\end{array}$ & & & & & & & & & & & $\checkmark$ & & & & & \\
\hline Boreal toad, Bufo boreas boreas, Candidate for listing & & & $\checkmark$ & & & & $\checkmark$ & $\checkmark$ & $\checkmark$ & $\checkmark$ & & & $\checkmark$ & & & \\
\hline Brandegee wild buckwheat, Eriogonum brandegei, Candidate for listing & & & & & $\checkmark$ & $\checkmark$ & & & & & & & & & & \\
\hline $\begin{array}{l}\text { Colorado butterflyweed, Gaura neomexicana ssp. coloradensis, } \\
\text { Candidate for listing }\end{array}$ & & $\checkmark$ & & & $\checkmark$ & & & & & & & & & $\checkmark$ & & \\
\hline Uinta Basin hookless cactus, Sclerocactus glaucus, Listed Threatened & & & & & & & $\checkmark$ & & & & & & & & & \\
\hline Osterhout milkvetch, Astragalus osterhoutii, Listed Endangered & & & & & & & & & $\checkmark$ & & & & & & & \\
\hline Debeque phacelia, Phacelia submutica, Candidate for listing & & & & & & & $\checkmark$ & & & & & & & & & \\
\hline Ute ladies'-tresses orchid, Spiranthes diluvialis, Listed Threatened & & $\checkmark$ & & & $\checkmark$ & & & & & & & & & $\checkmark$ & & \\
\hline North Park phacelia, Phacelia formosula, Listed Endangered & & & & & & & & & & & & & $\checkmark$ & & & \\
\hline Penland beardtongue, Penstemon penlandii, Listed Endangered & & & & & & & & & $\checkmark$ & & & & & & & \\
\hline Parachute beardtongue, Penstemon debilis, Candidate for listing & & & & & & & $\checkmark$ & & & & & & & & & \\
\hline & & & & & & & & & & & & & & & & \\
\hline & & & & & & & & & & & & & & & & \\
\hline & & & & & & & & & & & & & & & & \\
\hline & & & & & & & & & & & & & & & & \\
\hline & & & & & & & & & & & & & & & & \\
\hline & & & & & & & & & & & & & & & & \\
\hline & & & & & & & & & & & & & & & & \\
\hline
\end{tabular}




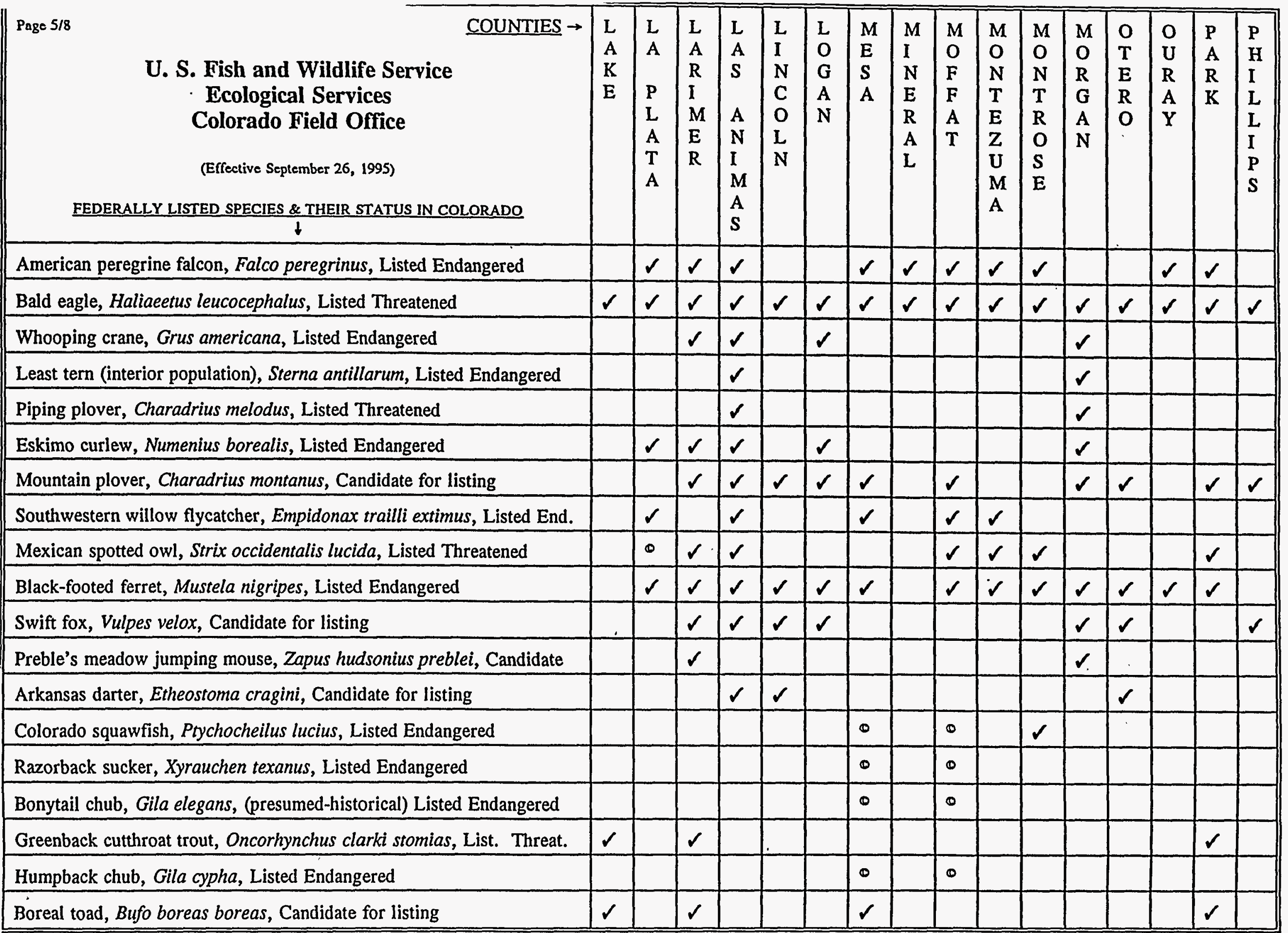




\begin{tabular}{|c|c|c|c|c|c|c|c|c|c|c|c|c|c|c|c|c|}
\hline $\begin{array}{l}\text { Page 6/8 } \\
\qquad \begin{array}{c}\text { U. S. Fish and Wildlife Service } \\
\text { Ecological Services } \\
\text { Colorado Field Office } \\
\text { (Effective September 26, 1995) } \\
\text { FEDERALLY LISTED SPECIES \& THEIR STATUS IN COLORADO } \\
\downarrow\end{array}\end{array}$ & $\begin{array}{l}\mathrm{L} \\
\mathbf{A} \\
\mathrm{K} \\
\mathrm{E}\end{array}$ & $\begin{array}{l}\mathbf{L} \\
\mathbf{A} \\
\mathbf{P} \\
\mathrm{L} \\
\mathrm{A} \\
\mathrm{T} \\
\mathrm{A}\end{array}$ & $\begin{array}{l}\mathrm{L} \\
\mathrm{A} \\
\mathrm{R} \\
\mathrm{I} \\
\mathrm{M} \\
\mathrm{E} \\
\mathrm{R}\end{array}$ & $\begin{array}{l}\text { L } \\
\text { S } \\
\text { A } \\
\mathrm{N} \\
\text { I } \\
\mathrm{M} \\
\mathrm{A} \\
\mathrm{S}\end{array}$ & $\begin{array}{l}\text { L } \\
\text { I } \\
\text { N } \\
\text { C } \\
O \\
\text { L } \\
N\end{array}$ & $\begin{array}{l}\mathrm{L} \\
\mathrm{O} \\
\mathbf{G} \\
\mathrm{A} \\
\mathrm{N}\end{array}$ & $\begin{array}{l}M \\
\mathrm{E} \\
\mathrm{S} \\
\mathrm{A}\end{array}$ & $\begin{array}{l}\text { M } \\
\text { I } \\
\text { N } \\
\text { E } \\
\mathbf{R} \\
\text { A } \\
\text { L }\end{array}$ & $\begin{array}{l}\mathrm{M} \\
\mathrm{O} \\
\mathrm{F} \\
\mathrm{F} \\
\mathrm{A} \\
\mathrm{T}\end{array}$ & $\begin{array}{l}\mathbf{M} \\
\mathbf{O} \\
\mathbf{N} \\
\mathrm{T} \\
\mathbf{E} \\
\mathbf{Z} \\
\mathbf{U} \\
\mathbf{M} \\
\mathrm{A}\end{array}$ & $\begin{array}{l}\mathrm{M} \\
\mathrm{O} \\
\mathrm{N} \\
\mathrm{T} \\
\mathrm{R} \\
\mathrm{O} \\
\mathrm{S} \\
\mathrm{E}\end{array}$ & $\begin{array}{l}\mathrm{M} \\
\mathbf{O} \\
\mathrm{R} \\
\mathbf{G} \\
\mathbf{A} \\
\mathbf{N}\end{array}$ & $\begin{array}{l}\mathrm{O} \\
\mathrm{T} \\
\mathrm{E} \\
\mathrm{R} \\
\mathrm{O}\end{array}$ & $\begin{array}{l}\mathrm{O} \\
\mathrm{U} \\
\mathrm{R} \\
\mathbf{A} \\
\mathrm{Y}\end{array}$ & $\begin{array}{l}\mathbf{P} \\
\mathbf{A} \\
\mathbf{R} \\
\mathbf{K}\end{array}$ & $\begin{array}{l}\mathrm{P} \\
\mathrm{H} \\
\mathrm{I} \\
\mathrm{L} \\
\mathrm{L} \\
\mathrm{I} \\
\mathrm{P} \\
\mathrm{S}\end{array}$ \\
\hline $\begin{array}{l}\text { Uncompahgre fritillary butterfly, Boloria acrocnema, Listed } \\
\text { Endangered }\end{array}$ & & & & & & & & & & & & & & $\checkmark$ & & \\
\hline $\begin{array}{l}\text { Pawnee montane skipper, Hesperia leonardus montana, Listed } \\
\text { Threatened }\end{array}$ & & & & & & & & & & & & & & & $\checkmark$ & \\
\hline Sleeping Ute milkvetch, Astragalus tortipes, Candidate for listing & & & & & & & & & & $\checkmark$ & $\checkmark$ & & & & & \\
\hline $\begin{array}{l}\text { Clay-loving wild buckwheat, Eriogonum pelinophilum, Listed } \\
\text { Endangered }\end{array}$ & & & & & & & & & & & $\checkmark$ & & & & & \\
\hline Mesa Verde cactus, Sclerocactus mesae-verdae, Listed Threatened & & & & & & & & & & $\checkmark$ & & & & & & \\
\hline Mancos milkvetch, Astragalus humillimus, Listed Endangered & & & & & & & & & & $\checkmark$ & & & & & . & \\
\hline Uinta Basin hookless cactus, Sclerocactus glaucus, Listed Threatened & & & & & & & $\checkmark$ & & & & $\checkmark$ & & & & & \\
\hline Debeque phacelia, Phacelia submutica, Candidate for listing & & & & & & & $\checkmark$ & & & & & & & & & \\
\hline Penland eutrema, Eutrema penlandii, Listed Threatened & $\checkmark$ & & & & & & & & & & & & & & $\checkmark$ & \\
\hline Knowlton's cactus, Pediocactus knowltonii, Listed Endangered & & $\checkmark$ & & & & & & & & & & & & & & \\
\hline Piceance twinpod, Physaria obcordata, Listed Threatened & & & & & & & & & $\checkmark$ & & & & & & & \\
\hline Ute ladies'-tresses orchid, Spiranthes diluvialis, Listed Threatened & & & $\checkmark$ & & & & & & & & & $\checkmark$ & & & & \\
\hline $\begin{array}{l}\text { Colorado butterflyweed, Gaura neomexicana ssp. coloradensis, } \\
\text { Candidate for listing }\end{array}$ & & & $\checkmark$ & & & & & & & & & & & & & \\
\hline $\begin{array}{l}\text { Spineless hedgehog cactus, Echinocereus triglochidiatus var. inermis, } \\
\text { Listed Endangered }\end{array}$ & & & & & & & & & & & & & & $\checkmark$ & & \\
\hline & & & & & & & & & & & & & & & & \\
\hline & & & & & & & & & & & & & & & & \\
\hline
\end{tabular}




\begin{tabular}{|c|c|c|c|c|c|c|c|c|c|c|c|c|c|c|c|}
\hline & & & & & & & & & & & & & & & \\
\hline $\begin{array}{l}\text { Page 7/8 } \begin{array}{l}\text { COUNTIES } \rightarrow \\
\text { S. Fish and Wildlife Service } \\
\text { Ecological Services } \\
\text { Colorado Field Office } \\
\text { (Effective September 26, 1995) } \\
\text { FEDERALLY LISTED SPECIES \& THEIR STATUS IN COLORADO } \\
\downarrow\end{array}\end{array}$ & $\begin{array}{l}\mathrm{P} \\
\mathrm{I} \\
\mathrm{T} \\
\mathrm{K} \\
\mathrm{I} \\
\mathrm{N}\end{array}$ & $\begin{array}{l}\mathrm{P} \\
\mathrm{R} \\
\mathrm{O} \\
\mathrm{W} \\
\mathrm{E} \\
\mathrm{R} \\
\mathrm{S}\end{array}$ & $\begin{array}{l}P \\
U \\
E \\
B \\
L \\
O\end{array}$ & $\begin{array}{l}\text { R } \\
\text { I } \\
\text { O } \\
\text { B } \\
\text { L } \\
\text { A } \\
\text { N } \\
\text { C } \\
\text { O }\end{array}$ & $\begin{array}{l}\mathrm{R} \\
\mathrm{I} \\
\mathrm{O} \\
\mathrm{G} \\
\mathrm{R} \\
\mathrm{A} \\
\mathrm{N} \\
\mathrm{D} \\
\mathrm{E}\end{array}$ & $\begin{array}{l}\mathrm{R} \\
\mathrm{O} \\
\mathrm{U} \\
\mathrm{T} \\
\mathrm{T}\end{array}$ & $\begin{array}{l}\text { S } \\
\text { A } \\
\text { G } \\
\text { U } \\
\text { A } \\
\text { C } \\
\text { H } \\
\text { E }\end{array}$ & $\begin{array}{l}\text { S } \\
\text { N } \\
\text { J } \\
\text { U } \\
\text { A } \\
\text { N }\end{array}$ & $\begin{array}{l}S \\
\mathrm{~A} \\
\mathrm{~N} \\
\mathrm{M} \\
\mathrm{I} \\
\mathbf{G} \\
\mathrm{U} \\
\mathrm{E} \\
\mathrm{L}\end{array}$ & $\begin{array}{l}S \\
\text { E } \\
\text { D } \\
\text { G } \\
\text { W } \\
\text { I } \\
\text { C } \\
\text { K }\end{array}$ & $\begin{array}{l}S \\
\mathbf{U} \\
\mathbf{M} \\
\mathbf{M} \\
\mathbf{I} \\
\mathbf{T}\end{array}$ & $\begin{array}{l}\mathrm{T} \\
\mathrm{E} \\
\mathrm{L} \\
\mathrm{L} \\
\mathrm{E} \\
\mathrm{R}\end{array}$ & $\begin{array}{l}\text { W } \\
\text { A } \\
\text { S } \\
\text { H } \\
\text { I } \\
\text { N } \\
\text { G } \\
\text { T } \\
\text { O } \\
\text { N }\end{array}$ & $\begin{array}{l}\text { W } \\
\text { E } \\
\text { L } \\
D\end{array}$ & $\begin{array}{l}\mathrm{Y} \\
\mathrm{U} \\
\mathrm{M} \\
\mathrm{A}\end{array}$ \\
\hline American peregrine falcon, Falco peregrinus, Listed Endangered & & & $\checkmark$ & & $\checkmark$ & $\checkmark$ & $\checkmark$ & $\checkmark$ & $\checkmark$ & & & $\checkmark$ & & & \\
\hline Bald eagle, Haliaeetus leucocephalus, Listed Threatened & $\checkmark$ & $\checkmark$ & $\checkmark$ & $\checkmark$ & $\checkmark$ & $\checkmark$ & $\checkmark$ & $\checkmark$ & $\checkmark$ & $\checkmark$ & $\checkmark$ & $\checkmark$ & $\checkmark$ & $\checkmark$ & $\checkmark$ \\
\hline Whooping crane, Grus americana, Listed Endangered & & $\checkmark$ & $\checkmark$ & & & & $\checkmark$ & & & $\checkmark$ & & & $\checkmark$ & $\checkmark$ & \\
\hline Least tern (interior population), Sterna antillarum, Listed Endangered & & $\checkmark$ & & & & & & & & $\checkmark$ & & & $\checkmark$ & $\checkmark$ & \\
\hline Piping plover, Charadrius melodus, Listed Threatened & & $\checkmark$ & & & & & & & & $\checkmark$ & & & $\checkmark$ & $\checkmark$ & \\
\hline Eskimo curlew, Numenius borealis, Listed Endangered & & $\checkmark$ & & & $\checkmark$ & & & & & $\checkmark$ & & & $\checkmark$ & $\checkmark$ & \\
\hline Mountain plover, Charadrius montanus, Candidate for listing. & & $\checkmark$ & $\checkmark$ & & $\checkmark$ & & $\checkmark$ & & & $\checkmark$ & & & $\checkmark$ & $\checkmark$ & $\checkmark$ \\
\hline Southwestern willow flycatcher, Empidonax trailli extimus, Listed Endang. & & & & $\checkmark$ & & & & $\checkmark$ & $\checkmark$ & & & & & & \\
\hline Mexican spotted owl, Strix occidentalis lucida, Listed Threatened & & & $\checkmark$ & & $\checkmark$ & & $\checkmark$ & & $\checkmark$ & & $\checkmark$ & $\checkmark$ & & $\checkmark$ & \\
\hline Black-footed ferret, Mustela nigripes, Listed Endangered & $\checkmark$ & $\checkmark$ & $\checkmark$ & $\checkmark$ & & $\checkmark$ & $\checkmark$ & $\checkmark$ & $\checkmark$ & & & & $\checkmark$ & $\checkmark$ & $\checkmark$ \\
\hline Preble's meadow jumping mouse, Zapus hudsonius preblei, Candidate & & & $\checkmark$ & & & & & & & & & & & $\checkmark$ & \\
\hline Swift fox, Vulpes velox, Candidate for listing & & $\checkmark$ & $\checkmark$ & & & & & & & $\checkmark$ & & . & $\checkmark$ & $\checkmark$ & $\checkmark$ \\
\hline Pawnee montane skipper, Hesperia leonardus montana, Listed Threatened & & & & & & & & & & & & $\checkmark$ & & & \\
\hline Uncompahgre fritillary butterfly, Boloria acrocnema, Listed Endangered & & & & & $\checkmark$ & & $\checkmark$ & $\checkmark$ & & & & & & & \\
\hline Colorado squawfish, Ptychocheilus lucius, Listed Endangered & & & & - & & & & & & & & & & & \\
\hline Arkansas darter, Etheostoma cragini, Candidate for listing & & $\checkmark$ & $\checkmark$ & & & & & & & & & & & & \\
\hline Greenback cutthroat trout, Oncorhynchus clarki stomias, Listed Threatened & & & $\checkmark$ & & & & & & & & & & & & \\
\hline Boreal toad, Bufo boreas boreas, Candidate for listing & $\checkmark$ & & & $\checkmark$ & & $\checkmark$ & & & & & $\checkmark$ & & & & \\
\hline Penland eutrema, Eutrema penlandii, Listed Threatened & & & & & & & & & & & $\checkmark$ & & & & \\
\hline
\end{tabular}




\begin{tabular}{|c|c|c|c|c|c|c|c|c|c|c|c|c|c|c|}
\hline 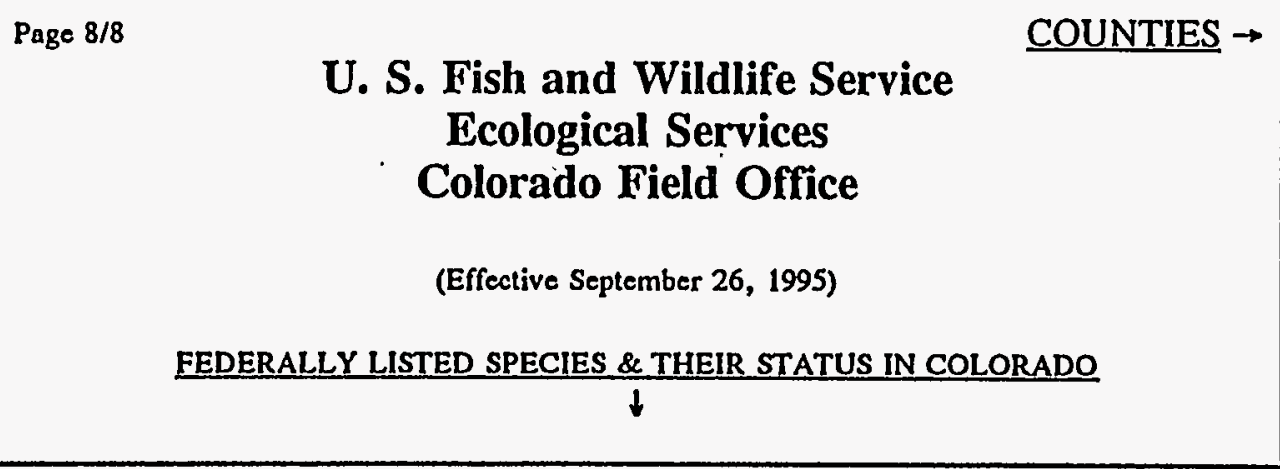 & \begin{tabular}{l|l}
$\mathrm{P}$ & $\mathrm{P}$ \\
$\mathrm{I}$ & $\mathrm{R}$ \\
$\mathrm{T}$ & $\mathrm{O}$ \\
$\mathrm{K}$ & $\mathrm{W}$ \\
$\mathrm{I}$ & $\mathrm{E}$ \\
$\mathrm{N}$ & $\mathrm{R}$ \\
& $\mathrm{S}$
\end{tabular} & $\begin{array}{l}\text { P } \\
\text { U } \\
\text { E } \\
\text { B } \\
\text { L } \\
\text { O }\end{array}$ & $\begin{array}{l}\mathrm{R} \\
\mathrm{I} \\
\mathrm{O} \\
\mathrm{B} \\
\mathrm{L} \\
\mathrm{A} \\
\mathrm{N} \\
\mathrm{C} \\
\mathrm{O}\end{array}$ & $\begin{array}{l}\mathrm{R} \\
\mathrm{I} \\
\mathrm{O} \\
\mathrm{G} \\
\mathrm{R} \\
\mathrm{A} \\
\mathrm{N} \\
\mathrm{D} \\
\mathrm{E}\end{array}$ & $\begin{array}{l}R \\
O \\
U \\
T \\
T\end{array}$ & $\begin{array}{l}\text { S } \\
\text { A } \\
\text { G } \\
\text { U } \\
\text { A } \\
\text { C } \\
\text { H } \\
\text { E }\end{array}$ & $\begin{array}{l}\text { S } \\
\text { A } \\
\text { N } \\
\text { J } \\
\text { U } \\
\text { A } \\
\text { N }\end{array}$ & $\begin{array}{l}\text { S } \\
\text { A } \\
\text { N } \\
\text { M } \\
\text { I } \\
\text { G } \\
\text { U } \\
\text { E } \\
\text { L }\end{array}$ & $\begin{array}{l}\text { S } \\
\mathrm{E} \\
\mathrm{D} \\
\mathrm{G} \\
\mathrm{W} \\
\mathrm{I} \\
\mathrm{C} \\
\mathrm{K}\end{array}$ & $\begin{array}{l}S \\
U \\
M \\
M \\
I \\
T\end{array}$ & $\begin{array}{l}\text { T } \\
\text { E } \\
\text { L } \\
\text { L } \\
\text { E } \\
\text { R }\end{array}$ & $\begin{array}{l}\text { W } \\
\text { A } \\
\text { S } \\
\text { H } \\
\text { I } \\
\text { N } \\
\text { G } \\
\text { T } \\
\text { O } \\
\text { N }\end{array}$ & $\begin{array}{l}\text { W } \\
\text { E } \\
\text { L } \\
\text { D }\end{array}$ & $\begin{array}{l}\mathrm{Y} \\
\mathrm{U} \\
\mathrm{M} \\
\mathrm{A}\end{array}$ \\
\hline Colorado butterflyweed, Gaura neomexicana spp. coloradensis, Candidate & & $\checkmark$ & & & & & & & & & & & $\checkmark$ & \\
\hline Graham beardtongue, Penstemon grahamii, Candidate for listing & & & $\checkmark$ & & & & & & & & & & & \\
\hline $\begin{array}{l}\text { White River beardtongue (penstemon), Penstemon scariosus var. albifluvis, } \\
\text { Candidate for listing }\end{array}$ & & & $\checkmark$ & & & & & & & & & & & \\
\hline Dudley Bluffs (Piceance) twinpod, Physaria obcordata, Listed Threatened & & & $\checkmark$ & & & & & & & & & & & \\
\hline Dudley Bluffs bladderpod, Lesquerella congesta, Listed Threatened & & & 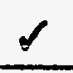 & & & & & & & & & & & \\
\hline $\begin{array}{l}\text { Spineless hedgehog cactus, Echinocereus triglochidiatus spp. inermis, Listed } \\
\text { Endangered }\end{array}$ & & & & & & & & $\checkmark$ & & & & & & \\
\hline Ute ladies'-tresses orchid, Spiranthes diluvialis, Listed Threatened & & & & & & & & & & & & & $\checkmark$ & \\
\hline & & & & & & & & & & & & & & \\
\hline
\end{tabular}

\section{TABLE TERMINOLOGY}

$\checkmark \quad$ The check mark indicates that the species is present in that county or that the county is within the historical range of the species

- This sign means that the species is present in the county and there is designated critical habitat for the species within the county

Candidate Means there is sufficient information indicating that formal listing under the ESA may be appropriate

Endangered Means the species could become extinct

Threatened Means the species could become endangered 
IV. Effects Determinations and Compliance Decisions - Effects determinations are the responsibility of the lead agency. Western has considered the nature of the undertaking and the presence of historic properties that may possess the qualities of integrity and meet at least one of the other criteria necessary to be considered for inclusion in the National Register of Historic Places. Western has determined that there are no historic properties. Western considers that the stipulations of Section 106 of the National Historic Preservation Act, as amended, and the implementing regulations, 36 CFR 800 , have been satisfied.

If you have any questions regarding this determinaticn, please telephone Rodney Jones at (970) 490-7371 or Mary Barger at (303) 275-1714.

Sincerely,

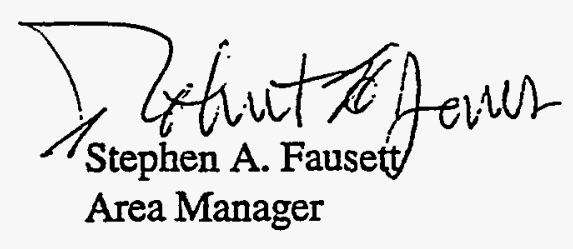

Enclosure

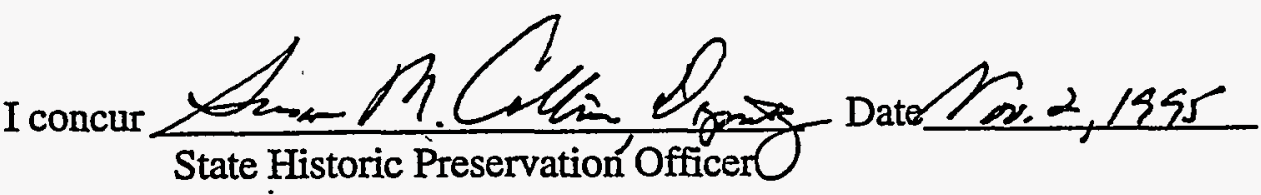




\section{United States Department of the Interior}

\section{FISH AND WILDLIFE SERVICE}

ES/CO: DOE, EA

Mail Stop 65412
Ecological Services

Colorado Field Office

730 Simms Street, Suite 290

Golden, Colorado 80401

Stephen A. Fausett, Area Manager

MAY 281996

Department of Energy

Western Area Power Administration

Loveland Area Office

P.O. Box $3700^{\circ}$

Loveland, Colorado 80539

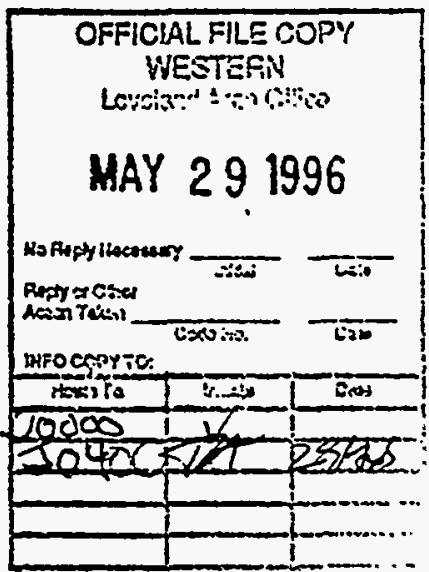

Dear Mr. Fausett:

This responds to your February 5, 1996 letter regarding comments on Appendix D of the draft environmental assessment for the proposed Mary's Lake 69/115-kV Transmission Line Project.

The U.S. Fish and Wildlife Service, concurs with your finding of no affect for listed species on this project.

We recommend that you contact the Colorado Division of Wildlife to address any concerns it may have for the State of Colorado.

If the Service can be of further assistance, contact Clay Ronish of this office at (303) 2315280 .

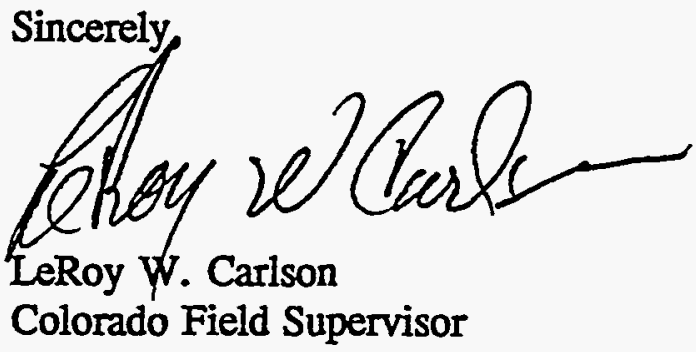

cc: Reading file

Project file

Reference:

CRR*SPECLIST.050 
Section $7(c)$ of the Endangered Species Act, as amended, requires federal agencies to determine if their action "may affect" any federally listed threatened or endangered species. This Biological Assessment was prepared by Western Area Power Administration (Western) and Platte River Power Authority (Platte River) to assess potential impacts to threatened and endangered species, and to meet their obligations under the Endangered Species Act.

The U.S. Fish and Wildlife Service (USFWS), in response to a request from Western, indicated that three threatened or endangered species and six candidate species may occur within the project area (Carlson 1995). Information provided by USFWS, the Colorado Division of Wildlife (CDOW), and the Colorado Natural Heritage Program (CNHP) indicates an additional seventeen species potentially occur within the project area. Table D-1 identifies the 26 species and summarizes the potential for impacts to each species.

\section{D.1 Project Description}

Western and the Platte River propose to upgrade portions of the existing electric transmission and substation system that serves the Town of Estes Park, Colorado. The existing transmission lines between the Estes Power Plant Switchyard and Marys Lake Substation include a 115-kV transmission line and a $69-k V$ transmission line. Approximately one mile is a double circuit 115/69-kV line on steel lattice structures, and approximately two miles consists of separate single circuit $115-\mathrm{kV}$ and a $69-\mathrm{kV}$ line, constructed on wood H-Frame structures (Figure D-1). Both lines were constructed in 1951 by the U.S. Bureau of Reclamation. The existing transmission lines are on rights-of-way (ROW) owned by Western that vary in width from 75 to 120 feet. There are 48 landowners adjacent to the existing ROW. All of the houses were built adjacent to the existing ROW after the transmission lines were constructed.

Upgrading the existing 69-kV transmission line between the Marys Lake Substation and the Estes Power Plant Switchyard to 115-kV and expanding the Marys Lake Substation was identified as the most effective way in which to improve electric service to Estes Park. The proposed project involves:

- Removing a 115-kV to 69-kV transformer at the Estes Power Plant Switchyard and performing other associated work as required to allow upgrading the three-mile transmission line from $69-\mathrm{kV}$ to $115-\mathrm{kV}$;

- Begin operating at $115-\mathrm{kV}$, the one-mile section of the existing $69-\mathrm{kV}$ portion of the double-circuit transmission line between the Estes Power Plant Switchyard and the East Portal of the Adams Tunnel. This existing transmission line section has been in place since 1951 on steel-lattice towers, and is already insulated for operation at $115-\mathrm{kV}$;

- Removing two miles of existing 69-kV transmission line on wood $\mathrm{H}$-frame structures between the Estes Power Plant Switchyard (beginning after the one-mile section of double circuit steel-lattice towers) and the Marys Lake Substation, and rebuilding this section to operate at 115-kV utilizing wood $H$-frame construction and connecting this line at Marys Lake Substation: and

- Installing a 115 to $69-\mathrm{kV}$ transformer at the Marys Lake Substation and performing other associated work to maintain a 69-kV connection between the Marys Lake Substation and the East Portal of the Adams Tunnel.

A detailed description of the construction and operation activities associated with these actions is presented in Section 2.7 of the Environmental Assessment.

\section{D.2 LISTED THREATENED AND ENDANGERED SPECIES}

Of the eight (8) listed threatened and endangered species known to occur or potentially occur in Larimer County, the four (4) species that may occur in the project area are discussed below. 
Table D-1

Threatened, Endangered, and Other Species of Concern

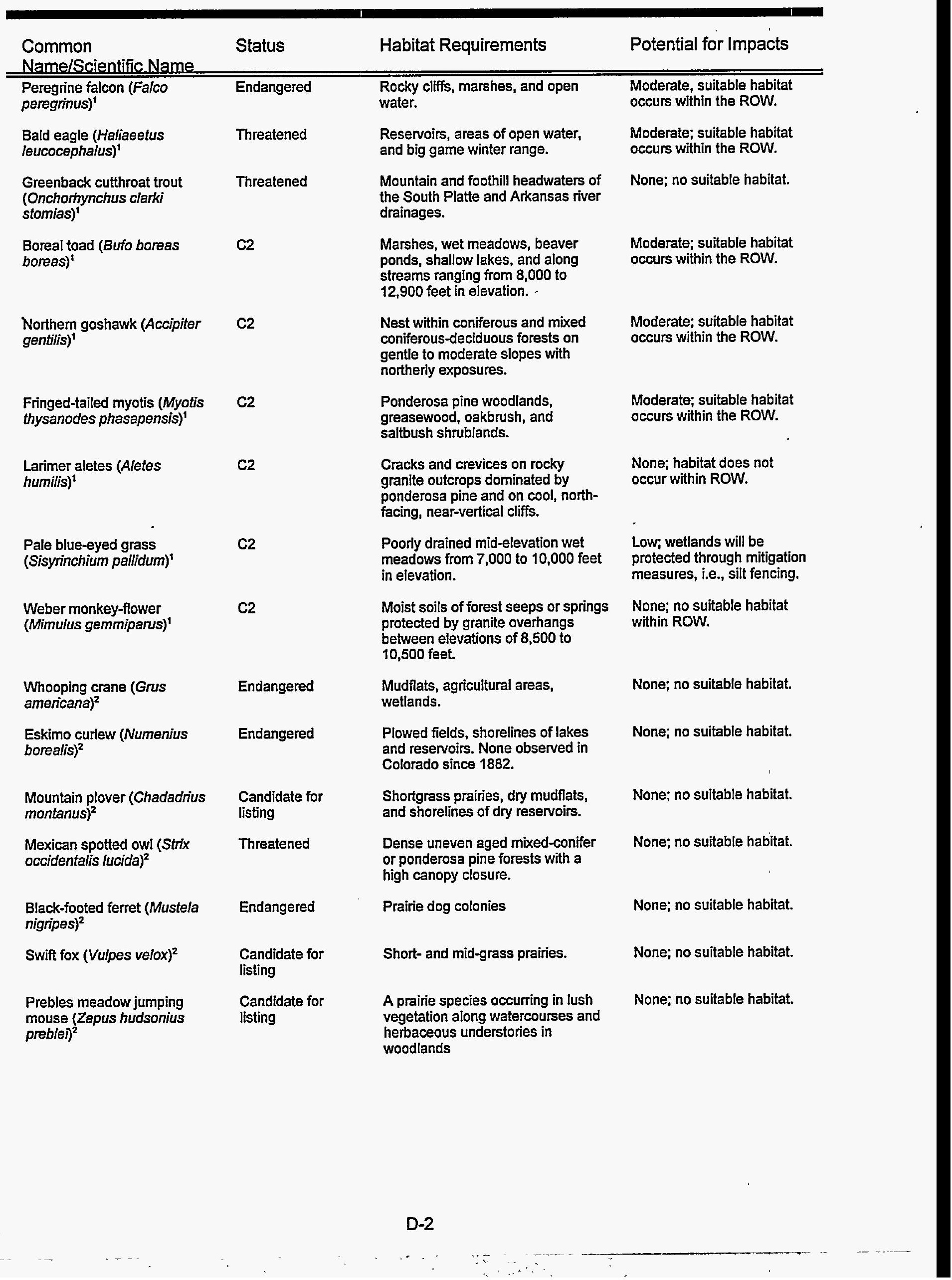


Table D-1

Threatened, Endangered, and Other Species of Concern

\begin{tabular}{|c|c|c|c|}
\hline $\begin{array}{l}\text { Common } \\
\text { Name/Scientific Name }\end{array}$ & Status & Habitat Requirements & Potential for Impacts \\
\hline $\begin{array}{l}\text { Ute ladies'-tresses (Spiranthes } \\
\text { diluvialis) }\end{array}$ & Threatened & $\begin{array}{l}\text { Wet meadows and floodplains near } \\
\text { the base of the Front Range in the } \\
\text { Boulder-Denver area }\end{array}$ & $\begin{array}{l}\text { None; species only known } \\
\text { to occur within the } 100 \text {-year } \\
\text { floodplain of the South } \\
\text { Platte River, Boulder, } \\
\text { Larimer, and Jefferson } \\
\text { Counties, North-Central and } \\
\text { Western Utah, and extreme } \\
\text { Eastern Nevada. }\end{array}$ \\
\hline $\begin{array}{l}\text { Colorado butterflyweed } \\
\text { (Gaura neomexicana subsp. } \\
\text { coloradensis) }\end{array}$ & $\begin{array}{l}\text { Candidate for } \\
\text { listing }\end{array}$ & $\begin{array}{l}\text { Plains and piedmont valleys in } \\
\text { Boulder, Larimer, and Weld counties }\end{array}$ & $\begin{array}{l}\text { None; no suitable habitat in } \\
\text { the ROW. }\end{array}$ \\
\hline $\begin{array}{l}\text { Purple lady's slipper } \\
\text { (Cypripedium fasciculatum) }^{3}\end{array}$ & $\begin{array}{l}\text { Under review for } \\
\text { Federal Listing; } \\
\text { Forest Service } \\
\text { Sensitive }\end{array}$ & $\begin{array}{l}\text { Forest openings and densely } \\
\text { shaded stands, in duff under } \\
\text { lodgepole pine, or, less frequently, } \\
\text { under Abies sp. }\end{array}$ & $\begin{array}{l}\text { None; no suitable habitat } \\
\text { present within the ROW. }\end{array}$ \\
\hline $\begin{array}{l}\text { Rocky Mountain cinquefoil } \\
\text { (Potentilla effusa var. } \\
\text { rupincola })^{3}\end{array}$ & $\begin{array}{l}\text { Under review for } \\
\text { Federal Listing; } \\
\text { Forest Service } \\
\text { Sensitive }\end{array}$ & $\begin{array}{l}\text { Steep, often granite, outcroppings } \\
\text { on shelves or niches of cliffs, often } \\
\text { on granite or gravel }\end{array}$ & $\begin{array}{l}\text { None; no suitable habitat } \\
\text { present within the ROW. }\end{array}$ \\
\hline Gay-feather (Liatris ligustylis) ${ }^{3}$ & G5?IS1S2 & $\begin{array}{l}\text { Wet meadows in the piedmont and } \\
\text { Wet Mountain Valley. }\end{array}$ & $\begin{array}{l}\text { None; known only to occur } \\
\text { in southern Colorado by the } \\
\text { Sangre de Cristo Mountains } \\
\text { and Wet Mountains. }\end{array}$ \\
\hline $\begin{array}{l}\text { Broad-leafed twayblade } \\
\text { (Listera convallarioides) }^{3}\end{array}$ & G5/S2 & $\begin{array}{l}\text { Moist places in leaf mold, in shaded } \\
\text { areas, or in wet places along small } \\
\text { streams high in the mountains. }\end{array}$ & $\begin{array}{l}\text { None; known only to occur } \\
\text { at higher elevations in } \\
\text { subalpine forests and cool } \\
\text { ravines. }\end{array}$ \\
\hline $\begin{array}{l}\text { Wood lily (Lilium } \\
\text { philadelphicum) }\end{array}$ & G5/S3 & Aspen groves & $\begin{array}{l}\text { None; no aspen habitat is } \\
\text { encountered within the } \\
\text { ROW }\end{array}$ \\
\hline $\begin{array}{l}\text { Regal fritillary butterfly } \\
\text { (Speyeria idalla) }^{3}\end{array}$ & $\begin{array}{l}\text { Under review for } \\
\text { Federal Listing; } \\
\text { Forest Service } \\
\text { Sensitive }\end{array}$ & $\begin{array}{l}\text { Wet meadows and virgin prairies } \\
\text { near marshes. }\end{array}$ & Low; no suitable habitat. \\
\hline Dwarf shrew (Sorex nanus) ${ }^{3}$ & $\begin{array}{l}\text { G5/S3; Forest } \\
\text { Service Sensitive }\end{array}$ & $\begin{array}{l}\text { Forests, open woodlands, and } \\
\text { rocky, shrubby foothill slopes. Also } \\
\text { on alpine and sub-alpine rockslides. }\end{array}$ & $\begin{array}{l}\text { Moderate; suitable habitat } \\
\text { within the ROW. }\end{array}$ \\
\hline $\begin{array}{l}\text { Boreal owl (Aegolius } \\
\text { funerous) }^{3}\end{array}$ & $\begin{array}{l}\text { G5/S2; Forest } \\
\text { Service Sensitive }\end{array}$ & $\begin{array}{l}\text { Mature spruce-fir or spruce- } \\
\text { fir/lodgepole pine forests } \\
\text { interspersed with meadows. }\end{array}$ & None; no suitable habitat. \\
\hline
\end{tabular}

Endangered $=$ Species in danger of extinction throughout all or a significant portion of its range.

Threatened $=$ Species likely to become an endangered species within the foreseeable future throughout all or a significant portion of its range.

Calegory $2=$ Species for which the USFWS Indicates that proposing to list as endangered or threatened is possibly appropriate, but for which conclusive data on blological vuinerability is lacking.

'August 4, 1995 USFWS letter

2September 26, 1995 USFWS Letter

JNatural Heritage List 6/5/95

Peregrine Falcon. The peregrine falcon is a federally-listed endangered species. Peregrines typically occur along River systems or reservoirs where an adequate food supply, primarily waterfowl and other birds, are available. Roost sites are generally cliffs, bluffs or large rock outcrops. Peregrines are known to occur within the general project area. The closest known nest site occurs almost a mile from the southern terminus of the project area. However, this site has not been occupied since 1990. The next closest sites occur four miles east and 8 miles north of the project area (Craig 1995). Peregrine falcons are known to occur within the Estes Park vicinity. In May of 1994 a male peregrine was killed as the result 
of a line strike with a distribution power line. The CDOW, determined that the bird, which had been released in to Rocky Mountain National Park, had struck the power line while chasing prey. The strike occurred on a distribution line in the southern portion of Estes Park (Craig 1995).

Bald Eagle. The bald eagle is a federally-listed threatened species. Bald eagles are known to occur within the general project area. Bald eagles are occasionally sited in the winter near Lake Estes. Eagles may occasionally use Marys Lake during the winter, but this has not been documented. However, since Marys Lake is usually frozen during the winter months, it is unlikely eagles would be present on a regular basis. No bald eagle summer or nesting is known to occur within the general project area (Craig 1995). Feeding areas, diurnal perches, and night roosts are fundamental elements of bald eagle winter range. Although eagles can fly as far as $24 \mathrm{~km}$ ( 15 miles) to and from these elements, they primarily occur where all three elements are available in comparatively close proximity (Swisher 1964). None of these elements occur along the project ROW.

The following considerations reduce the potential for impacts from the project to peregrine falcon and bald eagle. First, the existing transmission lines do not have a history of bird electrocutions or collisions (T. McCormick, personal communication 1995). The existing lines do not cross habitats that would provide migration or feeding corridors. Since the new line would be placed in the same corridor as the existing transmission line, the potential for collisions is not expected to increase. Second, the line would be constructed using guidelines described in Suggested Practices for Raptor Protection on Power Lines: State of the Art in 1981, (Olendorff et al 1981) thereby reducing the potential for both electrocutions and collisions. Third, the new transmission line would be slightly higher above the ground and would have a larger diameter conductor than the existing line. Mr. Jerry Craig, the CDOW raptor biologist, emphasized that by placing the line within the existing corridor the potential for bird collisions would be greatly reduced (Craig, personal communication, 1995).

Although the potential for bird collision exists along the entire line, the potential for impact is greatest in the area of Marys Lake. The new 115-kV transmission line crossing of the lake will be an additional obstacle for birds using the area. The old 69-kV transmission line did not cross the lake. The new $115-k V$ line would span the lake within 35 feet, and on the same horizontal plane, as an existing, adjacent, 115-kV transmission line. The placement of a second transmission line across Marys Lake may increase the potential for bird collision. However, studies have indicated that by routing transmission lines adjacent to each other the potential for collisions is reduced since the birds only have to fly over one obstacle (APLIC 1994).

Greenback Cutthroat Trout. The greenback cutthroat is federally-listed as a threatened species. Greenback cutthroat typically occurs in mountain and foothill headwaters of the south Platte and Arkansas River drainages (Behnke 1992). The greenback has been stocked in Larimer County in the North Fork of. the Big Thompson River and Roaring Forks River. It is anticipated that it has extended its range from these stockings (Carlson 1995). This species is easily displaced by non-native trout species (Behnke 1992). The proposed project would not affect aquatic resources. Therefore, no effects on greenback trout are expected.

Ute Ladies'-Tresses Orchid. The Ute ladies'-tresses orchid is a federally-listed threatened species. Ute ladies'-tresses is a member of the orchid family. It is a perennial plant with stems 20 to 50 centimeters tall, arising from tuberously thickened roots. The species is characterized by whitish, stout, ringent flowers. It blooms, generally, from late July through August. It is endemic to moist soils in mesic or wet meadows near springs, lakes or perennial streams. The elevation range of know populations is 4,300 to 7,000 feet. This species has been reported in Larimer County along the Front Range. Suitable habitat for the orchid does not exist within the project ROW.

\section{D.3 CANDIDATE SPECIES}

The remaining species of concern are primarily Category Two (C2) species. Although $\mathrm{C}_{2}$ species have no protection under the Endangered Species Act (1972), as amended, it is within the spirit of the Act to address potential effects to these species and other sensitive species to avoid future listing as either threatened or endangered. Sensitive wildlife species include the boreal toad, northern goshawk, fringedtailed myotis, and the dwarf shrew, considered a sensitive species by the Forest Service. Sensitive plant species include the Larimer aletes, pale blue-eyed grass, Weber monkey-flower and Colorado butterflyweed. 
Boreal Toad. The boreal toad is restricted to wetland and riparian corridors above 8,000 feet. Within these areas they typically occur within marshes, wet meadows, and the margins of streams, lakes, beaver ponds, and glacial kettle lakes (Hammerson 1986). The boreal toad may occur within the project area (Hammerson and Langlois 1981). However, it has not been documented to date (Pague 1995). Impacts to boreal toad would be offset through the implementation of mitigation measures to protect the wetlands within the project ROW. Silt fencing would be used to prohibit access across the wetlands. Currently, the existing transmission line spans the wetlands. New structures for the rebuilt line would be located outside the wetland areas. Construction crews would access the new transmission line structure sites from either side of the spanned wetland and would not drive across or otherwise affect the wet meadows. Therefore, no more than minimal impacts to boreal toad and wetlands habitat are expected.

Northern Goshawk. Northern goshawk generally nest in mixed coniferous and deciduous forests. They typically occur on moderate slopes (0-30\%), with north-northeast exposures. Typically these areas are near small quiet ephemeral streams (Reynolds et al. 1992). Although goshawks may occur in the area none have been documented (Craig 1995 and Pague 1995). Goshawks would be somewhat vulnerable to collisions, as discussed above for bald eagle and peregrine falcon. However, collision hazard would not increase significantly over existing conditions. The existing transmission line does not have a history of bird strikes.

Fringed-tailed Myotis. Fringed-tailed myotis occur in coniferous forest at moderate elevations. This bat species may occur in ponderosa pine, pinyon-juniper, greasewood, saltbush, and scrub oak habitats (CDOW 1984). This species may occur in the study area (Bissell 1978). However, they have not been documented to date (Pague 1995). Fringed-tailed myotis could be temporarily displaced by construction activity. Given their nocturnal habits, this is not expected to be a significant impact.

Dwarf Shrew. The dwarf shrew occupies a variety of habitat types. These shrews have been observed from the edges of alpine and subalpine rockslides to spruce-fir bogs. In addition, coniferous forest, sedge marshes, dry brush hillsides, and open woodlands may be utilized. The dwarf shrew can also tolerate arid to semi-arid conditions and have been observed up to half a mile from water sources (Fitzgerald et al 1994). If present, the dwarf shrew could be temporarily displaced or crushed by construction equipment. However, loss of a few individuals is not expected to adversely affect the population, especially given that habitat is not being removed.

Larimer Aletes. Larimer aletes is a member of the parsley family. The species has thick leathery leaves and it forms conspicuous clumps and mats on rock walls. Larimer aletes blooms in mid-late-summer and the flowers are yellow. It occurs in cracks and crevices on rocky granite outcrops where it is shaded by ponderosa pine and on cool, north-facing, near-vertical cliffs. No suitable habitat for this species occurs along the project ROW.

Pale Blue-Eyed Grass. Pale blue-eyed grass is a member of the iris family. It blooms in late July and August and has a pale blue flower atop a slender grass-like stem. It inhabits poorly drained mid-elevation meadows from 7,000-10,000 feet in elevation. It is associated with Greenland primrose, grasses, and grass-like plants. This species may occur in the wet meadow habitats within the project area. Since the wetlands will not be affected, no effects to this species are expected.

Weber Monkey-Flower. Weber monkey-flower is a member of the figwort family. It blooms from June through early August, has yellow flowers, and is small in stature. It typically grows in moist soils of forest seeps or springs protected by granite overhangs between elevations of 8,500 to 10,500 feet. It has also been discovered growing on an alluvial fan deposited by the Long Lake flood near Estes Park. It grows in association with other monkey flowers. No suitable habitat for this species occurs along the project ROW.

Colorado butterflyweed. Colorado butterflyweed is a member of the evening primrose family. The species has not been found in the state of Colorado since 1988 (CNPS 1989). However, several isolated populations have been found in Wyoming. The plant occupies moist prairie meadows along the Front Range from Castle Rock, Colorado to Cheyenne, Wyoming. It occurs in the transition zone between streams and flood plains. The plant grows in a candelabra shape up to four feet tall. It flowers from July through September. Suitable habitat for this species does not occur along the project ROW.

Five additional plants were identified by the Colorado Natural Heritage Program for consideration and avoidance within the perimeters of the transmission line project. These species included the purple lady's slipper, Rocky Mountain cinquefoil, gay-feather, broad-leafed twayblade, and wood lily. All five species have been documented by previous records as occurring in the Estes Park vicinity. However, no suitable 
habitat for any of these species lies within the project area. Table D-1 presents the potential habitat requirements and impact assessment for these species.

\section{D.4 SUMMARY}

Of the 26 threatened, endangered and sensitive species identified through agency contacts, 19 have been eliminated from further consideration (Table D-1). These species were eliminated based on a lack of suitable habitat within the project area or "footprint". Seven species, the peregrine falcon, bald eagle, boreal toad, northern goshawk, fringed-tailed myotis, dwarf shrew, and pale blue-eyed grass, have suitable habitat within the project right-of-way.

Construction impacts to the endangered peregrine falcon, the threatened bald eagle and the candidate northern goshawk are expected to be minimal. This is based on the fact that no nests are known to occur within the project area. The new line would present a potential collision hazard for these species. However, the collision hazard would be the same as existing conditions since the new 115-kV transmission line would replace an existing 69-kV transmission line. The existing corridor does not have a history of bird collisions and is not along a migration or hunting corridor. The project does not affect aquatic habitats and therefore the threatened greenback cutthroat trout would not be affected.

The boreal toad, fringed-tailed myotis, dwarf shrew, and pale blue-eyed grass, if present, could be affected by the construction phase of the project. Impacts to the boreal toad and pale blue-eyed grass would be offset through the implementation of the wetland mitigation measures. By fencing the wetlands and prohibiting access across these areas, potential impacts to the toad and iris should be eliminated. The fringed-tailed myotis may be temporarily displaced by construction activity. If present, a few individual dwarf shrew might be crushed by construction equipment. This would not likely affect shrew populations.

Western, as lead federal agency for the project, has determined that the proposed action is unlikely to adversely affect any federally-listed threatened or endangered species.

\section{D.5 REFERENCES}

Avian Power Line Interaction Committee (APLIC). 1994. Mitigating Bird Collisions with Power Lines: The State of the Art in 1994. Edison Electric Institute, Washington, D.C.

Behnke, R.J. 1992. Native Trout of Western North America. Amer. Fish. Soc. Monograph 6., Bethesda, Maryland.

Bissell, S.J. 1978. Colorado mammal Distribution Latilong Study. Colo. Div. of Wildl., Denver, CO.

Bogart, D. 1995. Personal Communication. Environmental Biologist. Colo. Div. of Wildl., Ft. Collins, CO.

Carlson, L. W. 1995. Personal Communication. Colorado Field Supervisor. USDI, fish and Wild. Serv., Golden, CO.

Craig, J. 1995. Personal Communication. Raptor Biologist. Colo. Div. of Wildl., Ft. Collins, CO.

Craig, J. 1996. Personal Communication. Raptor Biologist. Colo. Div. of Wildl., Ft. Collins, CO.

CDOW. 1984. The Bats of Colorado: Shadows in the Night. Colo. Div. of Wildl., Denver, CO.

Fitzgerald, J.P. C.A. Meaney, and D.M. Armstrong. 1994. Mammals of Colorado. Denver Museum of Nat. Hist. and Univ. Press of Colo., Niwot, CO.

Hammerson, G.A. and D. Langlois. 1981. Colorado Reptile and Amphibian Distribution Latilong Study. 2nd ed., Colo. Div. of Wildl., Denver, CO.

Hammerson, G.A. 1986. Amphibians and Reptiles in Colorado. Colo. Div. of Wildl., Denver, CO.

McCormick, T. 1995. Personal Communication. System Design Supervisor, Platte River Power Authority with M. Bonar, Greystone, Englewood, CO. 
Olendorff, R.R., A.D. Miller, and R.M. Lehman. 1981. Suggested Practices for Raptor Protection on Power Lines: State of the Art in 1981. Raptor Research Foundation, Inc. St. Paul, Minn. Raptor Research Report No. 4.

Prague, K.E. 1995. Personal Communication. Senior Information Manager. Colo. Nat. Heritage Pro., Ft. Collins, CO.

Reynolds, R.T, R.T. Graham, M.H. Reiser, R.L. Bassett, P.L. Kennedy, D.A. Boyce Jr., G. Goodwin, R. Smith, and E.L. Fisher. 1992. Management Recommendations for the Northern Goshawk in the Southwestern United States. USDA, For. Serv., Albuquerque, New Mexico. Gen. Tech. Rep. RM-217.

Swisher, J.F. 1964. A Roosting Area of the Bald Eagle in Northern Utah. Wilson Bull. 76(2): 186-187.

The Colorado Native Plant Society. 1989. Rare Plants of Colorado. Rocky Mountain Nature Association. 
1-व əun6!y

NOILOY Q $3 S O d O H d$

$100 \mathrm{j} 0002$

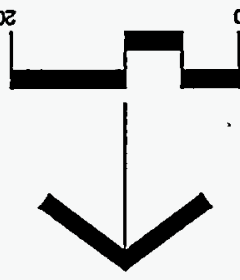

ann

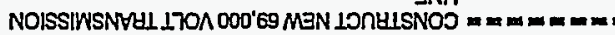

NOWEHOI

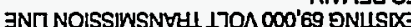

genONaY 38 OL

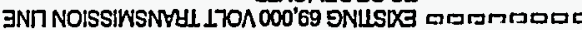

NINWEY O1

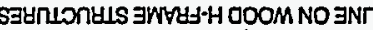

NOISSIW'SNEAL $170 \wedge 000$ 'SIL ONUSIX]

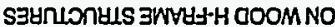

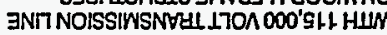

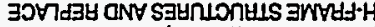

OOOM L TON 000 '69 ONLSIXG ENOKaY

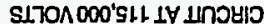

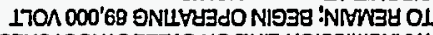

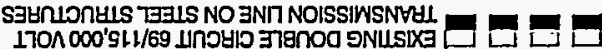

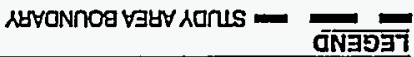

นo!̣edis!u!up pue

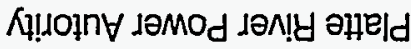

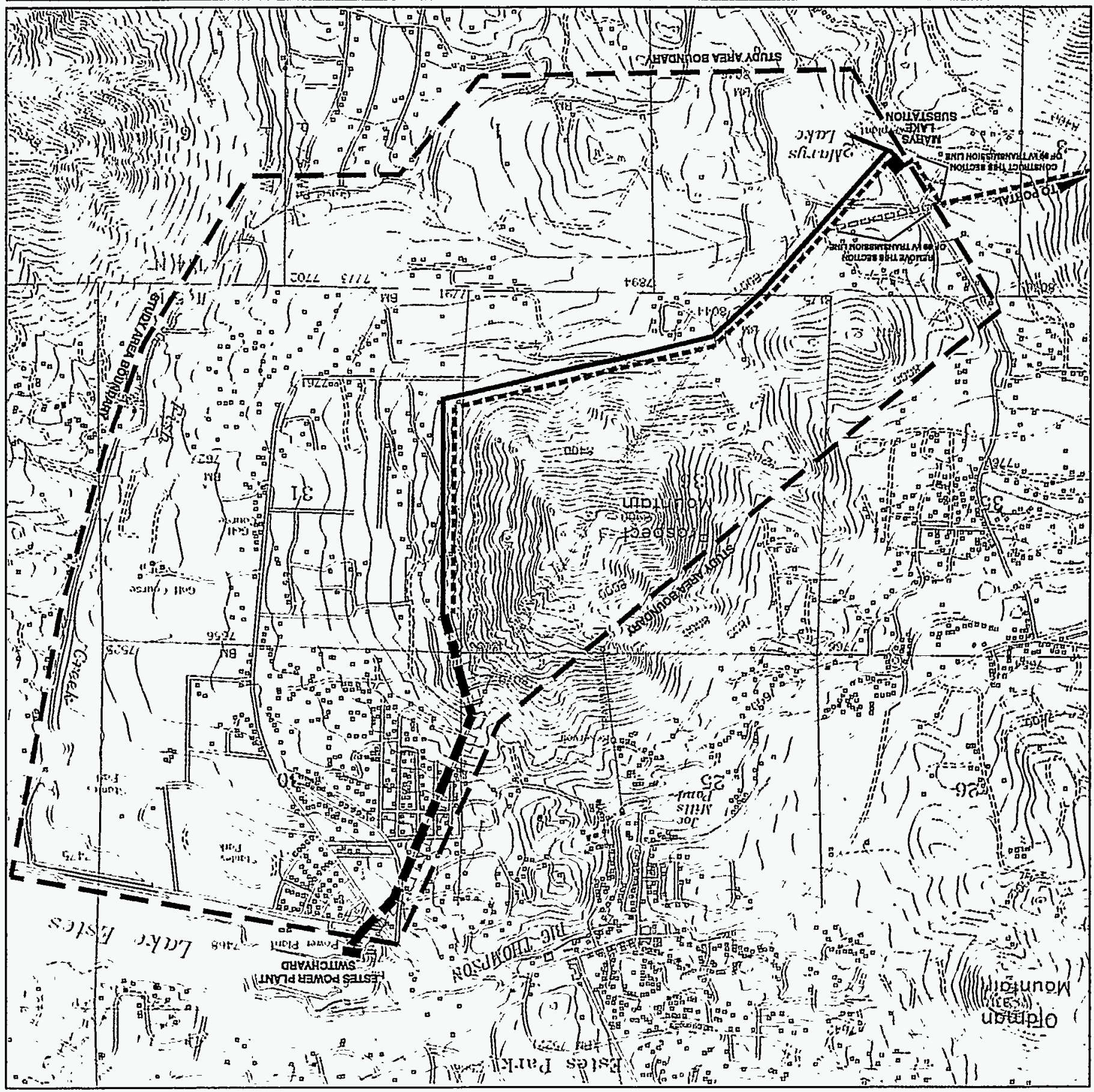


This Floodplains/Wetlands Assessment only addresses the Proposed Action, which consists of dismantling the existing $69-\mathrm{kV}$ wood-pole transmission line, and rebuilding a 115-kV transmission lines onto new wood $\mathrm{H}$-frame pole structures. About two miles of existing transmission line ROW would be affected.

In accordance with Executive Orders 11988 and 11990 and U.S. Department of Energy procedures, floodplains and wetlands were identified, mapped, and integrated into the planning and alternatives selection process.

No floodplains occur in or adjacent to the existing ROW. Two small wetlands exist along the existing ROW (refer to Figure 3-5). One originates from a small seep at the base of a finger of the southeastfacing Prospect Mountain. The second wetland is just south of Peak View Drive. It is assumed that the wetlands would be spanned and access would be restricted by fencing during construction. The Proposed Action will have no effects on floodplains or wetlands.

The following sources of information were used for identification of floodplains and wetlands:

- Federal Emergency Management Agency Flood Insurance Rate Maps, Larimer County, Colorado Maps 0801010251B and 0801010239C, and Town of Estes Park, Colorado Maps SN72W and SN73W 2.5SE.

- Reconnaissance of the proposed route by an experienced wetland scientist in May, 1995. 


\section{LABORATORY RESEARCH}

\section{CELL AND TISSUE (IN VITRO) STUDIES}

Blackman, C.F., L.S. Kinney, D.E. House, and W.T. Joines. 1989. Multiple Power-Density Windows and Their Possible Origin. Bioelectomagnetics 10:115-28.

Liboff, A.R. 1989. The Ion cyclotron Resonance: A Physical Basis for the ELF Interaction With Biological Systems. Extremely Low Frequency Electromagnetic Fields: The Question of Cancer. B.W., Wilson, R.g., Stevens, and L.E. Anderson (eds). Columbus, OH: Battelle Presss.

Loscher, W.; Mevissen, M.; Lehmacher, W.; Stamm, A. 1993. Tumor promotion in a breast cancer model by exposure to a weak alternating magnetic field. Cancer Letters 71:75-81.

Loscher, W.; Wahnschaffe, U.; Mevissen, M.; Lerchl, A.; Stamm, A. 1994. Effects of weak alternating magnetic fields on nocturnal melatonin production and mammary carcinogenesis in rats. Oncology 51:288-295.

McCann, J., F. Dietrich, C. Rafferty, and A. Martin. 1993. A Critical Review of the Genotoxic Potential of Electric and Magnetic Fields. Mutation Research 296:221-40.

McLean, J. R. N.; Stuchly, M. A.; Mitchel, R. E. J.; Wilkinson, D.; Yang, H.; Goddard, M.; Lecuyer, D. W.; Schunk, M.; Calgary, E.; Morrison, D. 1991. Cancer promotion in a mouse-skin model by a $60-\mathrm{Hz}$ magnetic field: II. Tumor development and immune response. Bioelectromagnetics 12:273-287.

Mevissen, M.; Stamm, A.; Buntenkotter, S.; Zwingelberg, R.; Wahnschaffe, U.; Loscher, W. 1993. Effects of magnetic fields on mammary tumor development induced by 7,12-dimethylbenz(a)anthracene in rats. Bioelectromagnetics 14:131-143.

Murphy, J., D. Kaden, J. Warren, and A. Sivak. 1993. Power Frequency Electric and Magnetic Fields: A Review of Genetic Toxicology. Mutation Research 296:221-40.

Parkinson, W.C., and C.T. Hanks. 1989. Search for Cyclotron Resonance in Cells in vitro. Bioelectromagnetics 10:129-45.

Rannug, A.; Ekstrom, T.; Mild, K. H.; Holmberg, B.; Gimenez-Contil, I.; Slaga, T. J. 1993a. A study on skin tumour formation in mice with $50 \mathrm{~Hz}$ magnetic field exposure. Carcinogenesis 14:573-578.

Rannug, A.; Holmberg, B.; Mild, K. H. 1993b. A rat liver foci promotion study with $50-\mathrm{Hz}$ magnetic fields. Environ. Res. 62:223-229.

Rannug, A.; Holmberg, B.; Ekstrom, T.; Mild, K. H.; Gimenez-Conti, I.; Slaga, T. J. 1994. Intermittent 50 Hz magnetic field and skin tumor promotion in SENCAR mice. Carcinogenesis 15:153-157.

Reiter, R. J. 1993. Reported effects on the circadian production of melatonin. J.Cell. Biochem. 51:394-403. 
Stuchly, M. A.; Lecuyer, D. W.; McLean, J. R. N. 1991. Cancer promotion in a mouse-skin model by a 60-Hz magnetic field: I. Experimental design and exposure system. Bioelectromagnetics 12:261-271.

Stuchly, M. A.; McLean, J. R. N.; Burnett, R.; Goddard, M.; Lecuyer, D. W.; Mitchel, R. E. J. 1992. Modification of tumor promotion in the mouse skin by exposure to an alternating magnetic field. Cancer Letters 65:1-7.

Weaver, J.C. and R.D. Astumian. 1990. The Response of Living Cells to Very Weak Electric Fields: The Thermal Noise Limit. Science 247:459-62.

Wilson, B.W.; Anderson, L.E.; Hilton, D.I.; Phillips, R.D. 1981. Chronic exposure to 60-Hz electric fields: Effects on pineal function in the rat. Bioelectromagnetics 2:371-380.

\section{WHOLE ANIMAL (IN VIVO) STUDIES}

Dowman, R., J.R. Wolpaw, R F. Seegal, and S. Satya-Murti. 1989. Chronic Exposure of Primates to 60-Hz Electric and Magnetic Fields. III. Neurophysiological Effects. Bioelectromagnetics 10:303-17.

Fam, W. Z.; Mikhail, E. L. 1993. Three-generation animal study of the carcinogenesis of a 25-mT, 60-Hz magnetic field. Annual Review of Research on Biological Effects of Electric and Maqnetic Fields from the Generation. Delivery and Use of Electricity, p. 10.

Liboff, A.R., J.R. Thomas, and J. Schrot. 1989. Intensity Threshold for 60-Hz Magnetically Induced Behavioral Changes in Rats. Bioelectromagnetics 10:111-113.

Rommereim, D.N., R.L. Rommereim, M.R. Sikov, R.L. Buschbom, and L.E. Anderson. 1990.

Reproduction, Growth and Development of Rats During Chronic Exposure to Multiple Strengths of 60- $\mathrm{Hz}$ Electric Fields. Fundamental and Applied Toxicology 14:608-21.

Seegal, R.F., J.R. Wolpaw, and R. Dowman. 1989. Chronic Exposure of Primates to 60-Hz Electric and Magnetic Fields. II. Neurochemical Effects. Bioelectromagnetics 10:289-301.

Wilson, B.W., E.K. Chess, and L.E. Anderson. 1987. 60-Hz Electric-Field Effects on Pineal Melatonin Rhythms: Time Course for Onset and Recovery. Bioelectromagnetics 7:239-42.

Wolpaw, J.R., R.F. Seegal, and R. Dowman. 1989. Chronic Exposure of Primates to 60-Hz Electric and Magnetic Fields. I. Exposure System and Measurements of General Health and Performance. Bioelectromagnetics 10:277-88.

\section{HUMAN STUDIES}

Graham, C., M.R. Cook, and H.D. Cohen. 1990. Immunological and Biochemical Effects of 60-Hz Electric and Magnetic Fields in Humans. Kansas City, MO: Midwest Research Institute, January 30, 1990. DOE/CE/76246-T1. Prepared for U.S. Department of Energy Office of Energy Storage and Distribution.

Graham, C.; Cook, M. R.; Cohen, H. D.; Riffle, D. W.; Hoffman, S. J.; McClernon, F. J.; Smith, D.; Gerkovich, M. M. 1993. EMF suppression of nocturnal melatonin in human volunteers. Annual Review of Research on Biological Effects of Electric and Magnetic Fields from the Generation. Delivery and Use of Electricity, p. 98-99. 
Graham, C.; Cook, M. R.; Cohen, H. D.; Riffle, D. W. 1994. Nocturnal melatonin levels in men exposed to magnetic fields: a replication study. Annual Review of Research on Biological Effects of Electric and Magnetic Fields from the Generation. Delivery and Use of Electricity, p. 51-52.

\section{DOSIMETRY}

Bracken, T. D. 1994a. The EMDEX Project: Residential Study. Volume 1: Summary. EPRI TR-104325-V1.

Bracken, T. D.1994b. The EMDEX Project: Residential Study. Volume 2: Project Description and Results. Epri TR-104325-V2.

Bracken, T. D. 1994c. The EMDEX Project: Residential Study. Volume 3: Appendices. Epri TR-104325-V3.

Deno, D.W. 1977. Currents Induced in the Human Body by High-Voltage Transmission Line Electric Fields. IEEE Transactions on Power Apparatus and Systems PAS-96:1517-26.

Dovan, T.; Kaune, W. T.; Savitz, D. A. 1993. Repeatability of measurements of residential magnetic fields and wire codes. Bioelectromagnetics 14:145-159.

Kaune, W.T. and R.D. Phillips. 1980. Comparison of the Coupling of Grounded Humans, Swine, and Rats to Vertical, 60-Hz Electric Fields. Bioelectromagnetics 1:117-29.

Tenforde, T.S. 1986. Interaction of ELF Magnetic Fields with Living Matter. Polk and Postow (eds). CRC Handbook of Biological Effects of Electromagnetic Fields. CRC Press, Inc. Boca Raton, Florida.

Tenforde, T.S. and W.T. Kaune. 1987. Interaction of Extremely Low Frequency Electric and magnetic Fields With Humans. Health Physics 53:585-606.

\section{EPIDEMIOLOGY STUDIES}

Afii, A., R.S. Banks, L.I. Kheifets, and B. Newman. 1990. Proceedings: Discussion of an EMF Protocol. Palo Alto, CA: EPRI, July 1990. EPRI EN-6829. Prepared by Robert S. Banks Associates, Inc.

Minneapolis, MN.

Ahlbom, A.; Feychting, M.; Koskenvuo, M.; Olsen, J. H.; Pukkala, E.; Schulgen, G.; Verkasalo, P. 1993. Electromagnetic fields and childhood cancer. Lancet 342:1295-1296.

Ahlbom, A.; Feychting, M.; Koskenvuo, M.; Olsen, J. H.; Pukkala, E.; Schulgen, G.; Verkasalo, P. 1993. Electromagnetic fields and childhood cancer. Lancet 342:1295-1296.

Armstrong, B.; Theriault, G.; Guenel, P.; Deadman, J.; Goldberg, M.; Heroux, P. 1994. Association between exposure to pulsed electromagnetic fields and cancer in electric utility workers in Quebec, Canada, and France. Am. J. Epidemiol. 140:805-820.

Barnes, F., H. Wachtel, D. Savitz, and J. Fuller. 1989. Use of Wiring Configuration and Wiring Codes for Estimating Externally Generated Electric and magnetic Fields. Bioelectromagnetics 10:13-21.

Bowman, J.D., D.H. Garabrant, E. Sobel, and J.M. Peters. 1988. Exposures to Extremely Low Frequency (ELF) Electromagnetic Fields in Occupations with Elevated Leukemia Rates. Applied Industrial Hygiene 6:189-94.

Bracken, T.D. 1986. Analysis of BPA Occupational Electric Field Exposure Data. Portland, OR: T. Dan Bracken, Inc. January 1986, DOE/BP-36303-1. Prepared for Bonneville Power Administration. 
Broadbent, D.E., M.H.P. Broadbent, J.C. Male, and M.R.L. Jones. 1985. Health of Workers Exposed to Electric Fields. British Journal of Industrial Medicine. 42:75-84.

Bunin, G.R., E. Ward, S. Kramer, C.A. Rhee, and A.T. Meadows. 1990. Neuroblastoma and Parental Occupation. American Joumal of Epidemiology 131:776-80.

Calle, E.E. and D.A. Savitz. 1985. Leukemia in Occupational Groups With Presumed Exposure to Electrical and Magnetic Fields. (letter). New England Journal of Medicine 313:1476-77.

Caola, R.J., D.W. Deno, and V.S. W. Dymek. 1983. Measurements of Electric and Magnetic Fields in and Around Homes Near A 500-kV Transmission Line. IEEE Transactions on Power Apparatus and Systems PAS-102:3338-47.

Coleman, M., C.M.J. Bell, and R. Skeet. 1983. Leukemia Incidence in Electrical Workers. (letter). The Lancet i:982-83.

Coleman, M.P., C.M.J. Bell, H.L. Taylor, and M. Primic-Zakelj. 1989. Leukemia and Residence Near Electricity Transmission Equipment: A Case-Control Study. British Joumal of Cancer 60:793-98.

Deadman, J.E., M. Camus, B.G. Armstrong, P. Herouz, D. Dyr, M. Plante, and G. Theriault. 1988. Occupational and Residential $60-\mathrm{Hz}$ Electromagnetic Fields and High-Frequency Electric Transients: Exposure Assessment using a New Dosimeter. American Industrial Hygiene Association Joumal 49:409-19.

Deno, D.W. 1987. Sources and Structures of Magnetic Fields in and Around Homes Near a 500-kV Transmission Line. IEEE Transactions on Power Apparatus and Systems PAS-102:3338-47.

Dlugosz, L.J., T. Byers, J. Vena, and M. Zielezny. 1989. Ambient 60-Hz Magnetic Flux Density in an Urban Neighborhood. Bioelectromagnetics 10:187-96.

EMDEX Project: Technology Transfer and Occupational Measurements, Vols. 1-3. Palo Alto, CA: EPRI, November 1990, EPRI EN-7048. Prepared by T. Dan Bracken, Inc., Portland, OR.

Feychting, M. and Ahlbom, A. 1994. Magnetic fields, leukemia, and central nervous system tumors in Swedish adults residing near high-voltage power lines. Epidemiology 5:501-509.

Feychting, M.; Ahlbom, A. 1992. Magnetic fields and cancer in people residing near Swedish high voltage power lines. Institutet for Miljomedicin (IMM) Report 6/92.

Feychting, M. and Ahlbom, A. 1993. Magnetic fields and cancer in children residing near Swedish high-voltage power lines. Am. J. Epidemiol. 138:467-480.

Feychting, M. and Ahlbom, A. 1993. Magnetic fields and cancer in children residing near Swedish high-voltage power lines. Am. J. Epidemiol. 138:467-48000.

Feychting, M. and Ahlbom, A. 1992. Magnetic Fields and Cancer in People Residing Near Swedish High Voltage Power Lines. Institute for Miljömedicin, Karolinska Institutet, Stockholm, June, 1992.

Feychting, M. and Ahlbom, A. 1993. Magnetic fields and cancer in children residing near Swedish high-voltage power lines. Am. J. Epidemiol. 138:467-480.

Feychting, M. And A. Ahlbom. 1992. Magnetic Fields and Cancer in People Residing Near Swedish High Voltage Power Lines. IMM Institutet for Miljomedicin, Karolinska Institutet, Stockholm. 
Floderus, B.; Persson, T.; Stenlund, C.; Wennberg, A.; Ost, A.; Knave, B. 1993. Occupational exposure to electromagnetic fields in relation to leukemia and brain tumors: A case-control study in Sweden. Cancer Causes Control 4:465-476.

Floderus, B., S. Tornqvist, and C. Stenlund. 1994. Incidence of Selected Cancer in Swedish Railway Workers, 1961-79. Cancer Causes and Control 5:189-94.

Floderus, B.; Persson, T.; Stenlund, C.; Linder, G.; Johansson, C.; Kiviranta, J.; Parsman, H.; Lindblom, M.; Wennberg, A.; Ost, A.; Knave, B. 1992. Occupational exposure to electromagnetic fields in relation to leukemia and brain tumors. A case-control study. Natl. Inst. of Occupational Health, Solna, Sweden.

Floderus, B., T. Persson, C. Steniund, G. Linder, C. Johannson, J. Kiviranta, H. Parsman, M. Lindboim, A. Wennberg, A. Ost, and B. Knave. 1992. Occupational Exposure to Electromagnetic Fields in Relations to Leukemia and Brain Tumors. A Case-Control Study. Litohuset, National Institute of Occupational Health.

Florig, H.K., J.F. Hoburg, and M.G. Morgan. 1987. Electric Field Exposure from Electric Blankets. IEEE Transactions on Power Delivery PWRD-2:527-36.

Florig, H.K., and M.G. Morgan. 1988. Measurements of Housing Density Along Transmission Lines. Bioelectromagnetics $987-94$.

Fulton, J.P., S. Cobb, L. Preble, L. Leone, and E. Forman. 1980. Electrical Wiring Configurations and Childhood Leukemia in Rhode Island. American Joumal of Epidemiology 111:292-96.

Gauger, J.R. 1986. Household Appliance Magnetic Field Survey. IEEE Transactions on Power Apparatus and Systems PAS-104:2436-44.

Guenel, P., P. Raskmark, X. Andersen, and E. Lynge. 1993. Incidence of Cancer in Persons with Occupational Exposure to Electromagnetic Fields in Denmark. British Journal of Industrial Medicine 50:758-764.

Jacobs, P.D., and F.M. Dietrich. 1984. Measurements of Transmission Line Electric Fields in a Residential Environment. IEEE Transactions on Power Apparatus and Systems PAS-103:2237-43.

Kaune, W.T., R.G. Stevens, N.J. Callahan, R.K. Severson, and D.B. Thoma. 1987. Residential Magnetic and Electric Fields. Bioelectromagnetics 8:315-35.

Knave, B., F. Gamberale, S. Bergstrom, E. Birke, A. Iregren, B. Kolmodin-Hedman, and A. Wennberg. 1979. Long-Term Exposure to Electric Fields. A Cross-Sectional Epidemiologic Investigation of Occupationally Exposed Workers in High-Voltage Substations. Scandinavian Journal of Work, Environment and Health 5:115-25.

Lin, R.S., P.C. Dischinger, J. Conde, and K.P. Farrell. 1985. Occupational Exposure to Electromagnetic Fields and the Occurrence of Brain Tumors. Joumal of Occupational medicine 27:413-19.

London, S.J., D.C. Thomas, J.D. Bowman, E. Sobel, T.C. Cheng and J.M. Peters. 1991. Exposure to Residential Electric and Magnetic Fields and risk of Childhood Leukemia. American Journal of Epidemiology 134:923-37. 
London, S.J.; Thomas, D.C.; Bowman, J.D.; Sobel, E.; Cheng, T.; Peters, J.M. Exposure to residential electric and magnetic fields and risk of childhood leukemia. American Journal of Epidemiology, 134:923-937, 1991.

London, S. J.; Thomas, D. C.; Bowman, J. D.; Sobel, E.; Cheng, T-C.; Peters, J. M. 1991. Exposure to residential electric and magnetic fields and risk of childhood leukemia. Am. J. Epidemiol. 134:923-937.

Lovely, R. H.; Buschbom R. L.; Slavich, A. L.; Anderson, L. E.; Hansen N. H.; Wilson B. W. 1994. Adult leukemia risk and personal appliance use: a preliminary study. Am. J. Epidemiol. 140:510-517.

Matanowski, G.M., E.A. Elliott, and P.N. Breysse. 1989. Cancer Incidence in New York Telephone Workers. Poster presented November 15, 1989 at EPRI/DOE Contractors Review.

McDowall, M.E. 1983. Leukemia Mortality in Electrical Workers in England and Wales. (letter). The Lancet i:246.

McDowall, M.E. 1986. Mortality of Persons Resident in the Vicinity of Electricity Transmission Facilities. British Journal of Cancer 53:271-79.

McMahan, S. 1994. Depression Research. Doctoral Dissertation. School of Social Ecology, University of Irvine, Irvine, California.

Milham, S. Jr.. 1988. Increased Mortality in Amateur Radio Operators Due to Lymphatic and Hematopoietic Malignancies. American Journal of Epidemiology 127:50-54.

Milham, S. Jr.. 1985. Mortality in Workers Exposed to electromagnetic fields. Environmental Health Perspectives 62:297-300.

Milham, S. Jr. 1982. Mortality From Leukemia in Workers Exposed to Electrical and Magnetic Fields. New England Joumal of Medicine 307:249.

Myers, A., A.D. Clayden, R.A. Cartwright, and S.C. Cartwright. 1990. Childhood Cancer and Overhead Powerlines: A case-Control Study. British Journal of Cancer 62:1008-14.

Nordeson, I., K. Hansson-Mild, U. Ostman, and H. Ljungberg. 1988. Chromosomal Effects in Lymphocytes of 400-kV Substation Workers. Radiation and Environmental Biophysics 27:39-47.

Nordstrom, S., E. Birke, and L. Gustavsson. 1983. Reproductive Hazards Among Workers at HighVoltage Substations. Bicelectromagnetics 4:91-101.

Norris, W.T., J.C. Male, and B.J. Maddock. 1987. Magnetic and Electric Power Frequency Fields in the Home. Twenty-Third Hanford Life Sciences Symposium. Interaction of Biological Systems with Static and ELF Electric and Magnetic Fields; October 2-4, 1984, Richland, Washington. L.E. Anderson, B.J. Kelman, and R.J. Weigel (eds). Richland, WA: Pacific Northwest Laboratory, 1987, 197-205. Available from NTIS as CONF-84101.

Olsen, J. H.; Nielsen, A., Schulgen, G. 1993. Residence near high voltage facilities and risk of cancer in children. British Medical J. 307:891-895.

Olsen, J.H., A. Nielsen, and G. Schulgen. 1993. Residence Near High Voltage Facilities and Risk of Cancer in Children. British Medical Journal 307:891-895. 
Olsen, J. H.; Nielsen, A., Schulgen, G. 1993. Residence near high voltage facilities and risk of cancer in children. British Medical J. 307:891-895.

Pearce, N.E., R.A. Sheppard, J.K. Howard, J. Fraser, and B.M. Lilley. 1985. Leukemia in Electrical Workers in New Zealand (letter). The Lancet i:811-12.

Peters, J.M., S. Preston-Martin, S.J. London, J.D. Bowman, J.D. Buckley, and D.C. Thomas. 1994. Processed Meats and Risk of Childhood Leukemia (California, USA). Cancer Causes and control 5:195-202.

Peters, J.M., D.C. Thomas, J.D. Bowman, E. Sobel, S.J. London, and T.C. Chen. 1991. Exposure to Residential Electric and Magnetic Fields and Risk of Childhood Leukemia. Palo Alto, CA: EPRI, November 1991, EPRI EN-7464. Prepared by University of Southern California, Los Angeles, CA.

Petridou, E., D. Kassimos, M. Kamanti, H. Kosmidis, S. Haidas, V. Flytzani, D. Tong, and D. Trichopoulos. 1993. Age of Exposure to Infections and Risk of Childhood Leukemia. British Medical Journal September 25:307:774.

Poole, C. R. Kavet, D.P. Funch, K. Donelan, J.M. Charry, and N.A. Dreyer. 1993. Depressive Symptoms and Headaches in Relation to Proximity to Residence to an Alternating-Current Transmission Line Right-of-Way. American Journal of Epidemiology 137(3):318-30.

Preston-Martin, S., J.M. Peters, M.C. Yu, D.H. Garabrant, and J.D. Bowman. 1988. Myelogenous Leukemia and Electric Blanket Use. Bioelectromagnetics 9:207-13.

Sahl, J. D.; Kelsh, M. A.; Greenland, S. 1993. Cohort and nested case-control studies of hematopoietic cancers and brain cancer among electric utility workers. Epidemiology 4:104-114.

Sahl J., J.M. Kelsh, and S. Greenland. 1993. Mortality Study on Electric Utility Workers at Southern California Edison. March 1993 Epidemiology.

Savitz, D.A. 1987a. Case-Control Study of Childhood Cancer and Residential Exposure to Electric and Magnetic Fields. Final Report to the New York State Department of Health. Power Lines Project.

Savitz, D.A. 1987b. Final Results of Case-Control Study of Childhood Cancer and Electromagnetic Field Exposure, Abstract and Presentation to the DOE/EPRI Contractors Review. Kansas City, Missouri. November 1987.

Savitz, D.A.; Kaune, W.T. 1993. Childhood cancer in relation to a modified residential wire code. Environmental Health Perspectives. 101:76-80.

Savitz, D.A.; Wachtel, H.; Barnes, F.A.; John, E.M.; Tvrdik, J.G. 1988. Case-control study of childhood cancer and exposure to 60-hertz magnetic fields. American Journal of Epidemiology. 128:21-38.

Savitz, D.A., and W.T. Kaune. 1993. Childhood Cancer in Relation to a Modified Residential Wire Code. Environmental Health Perspectives 101(1):76-80.

Savitz, D.A.; Loomis, D.P. 1995. Magnetic field exposure in relation to leukemia and brain cancer mortality among electric utility workers. Am. J. Epidemiol. 141:123-134.

Savitz, D.A.; Wachtel, H.; Barnes, F.A.; John, E.M.; Tvrdik, J.G. 1988. Case-control study of childhood cancer and exposure to 60-hert magnetic fields. Am. J. Epidemiol. 128:21-38. 
Savitz, D.A., C.A. Boyle, and P. Holmgreen. 1994. Prevalence of Depression Among Electrical Workers. American Journal of Industrial Medicine 25:165-76.

Savitz, D.A., and E.E. Calle. 1987. Leukemia and Occupational Exposure to Electromagnetic Fields. Review of Epidemiologic Surveys. Joumal of Occupational Medicine. 29:47-51.

Savitz, D.A., and W.T. Kaune. 1993. Childhood Cancer in Relation to a Modified Residential Wire Code. Environmental Health Perspectives 101(1):76-80.

Savitz, D.A., H. Wachtel, F.A. Barnes, E.M. John, and J.G. Tvrdik. 1988. Case-Control Study of Childhood Cancer and Exposure to 60-Hertz Electric and Magnetic Fields. American Journal of Epidemiology 128:21-38.

Savitz, D.A., E.M. John, and R.C. Kleckner. 1990. Magnetic Field Exposure From Electric Blankets and Childhood Cancer. American Journal of Epidemiology 131:763-73.

Severson, R.K., R.G. Stevens, W.T. Kaune, D.B. Thomas, L.D. Heuser, and L.E. Sever. 1988. Acute Nonlymphocytic Leukemia and Residential Exposure to Power Frequency Magnetic Fields. American Journal of Epidemiology 128:10-20.

Severson, R.K.; Stevens, R.G.; Kaune, W.T.; Thomas, D.B.; Heuser, L; Davis, S; Sever, L.E. 1988. Acute nonlymphocytic leukemia and residential exposure to power frequency magnetic fields. Am. J. Epidemiol. 128:10-20.

Silva, M., H. Hummon, D. Rutter, and C. Hooper. 1989. Power Frequency Magnetic Fields in the Home. IEEE Transactions on Power Delivery 4:465-78.

Skyberg, K., I.L.-Hansteen, and A.I. Vistnes. 1993. Chromosome Aberrations in Lymphocytes of HighVoltage Laboratory Cable Splicers Exposed to Electromagnetic Fields. Scandinavian Journal of Work, Environment and Health 19:29-34.

Stevens, R.G. 1986. Epidemiological Studies of Cancer and Residential Exposure to Electromagnetic Fields. Final Report. Power Lines project 21082-18. Albany, New York. Health Research, Inc.

Stevens, R. G. 1993. Electric power and the risk of breast cancer. Radiation Research 133:132-134.

Stevens, R. G. 1987. Electric power use and breast cancer: A hypothesis. Am. J. Epidemiol. 125:556-561.

Stuchly, M.A. and D.W. Lecuyer. 1989. Exposure to Electromagnetic Fields in Arc Welding. Health Physics 56:597-602.

Stuchly, M.A. 1986. Human Exposure to Static and Time-Varying Magnetic Fields. Health Physics 51:215-25.

Swedish National Electrical Safety Board. 1993. Magnetic Fields and Cancer, 1993. Internal Report.

Theriault, G.; Goldberg, M.; Miller, A. B.; Armstrong, B.; Guenel, P.; Deadman, J.; Imbemon, E.; To, T.; Chevalier, A.; Cyr, D.; Wall, C. 1994. Cancer risks associated with occupational exposure to magnetic fields among electric utility workers in Ontario and Quebec, Canada, and France: 19701989. Am. J. Epidemiol. 139:550-572.

Theriault, G., M. Goldberg, A.B. Miller, B. Armstrong, P. Guenel, J. Deadman, E. Imbernon, T. To, A. Chevaller, D. Cyr, and C. Wall. 1994. Cancer Risks Associated with Occupational Exposure to 
Magnetic Fields Among Electric Utility Workers in Ontario and Quebec, Canada, and France: 1970-1989. American Journal of Epidemiology 139(6):550-571.

Tomenius, L. 1986. 50-Hz Electromagnetic Environment and Incidence of Childhood Tumors in Stockholm County. Bioelectromagnetics 7:191-208.

Tomenius, L., L. Hellstrom and B. Enander. 1982. Electrical Constructions and 50-Hz Magnetic Fields at the Dwellings of Tumor Cases (0-18) Years of Age in the County of Stockholm. Presented at the Institute Symp. Occup. Health Saf. Min. Tunneling. Prague. June 21 to 25, 1982.

Tomenius, L. 1986. 50- $\mathrm{Hz}$ electromagnetic environment and the incidence of childhood tumors in Stockholm County. Bioelectromagnetics (Sweden). 7:191-207.

Tornquist, S., S. Norrell, A. Ahlbom, and B. Knave. 1986. Cancer in the Electric Power Industry. British Journal of Industrial Medicine 43:212-13.

Tornqvist, S., B. Knave, A. Ahlbom, and T. Persson. 1991. Incidence of Leukemia and Brain Tumors in Some Electrical Occupations. British Journal of Industrial Medicine 48:597-603.

Vena, J.E.; Freudenheim, J.L.; Marshall, J.R.; Laughlin, R.; Swanson, M.; Graham, S. 1994. Risk of premenopausal breast cancer and use of electric blankets. Am. J. Epidemiol. 140:974-979.

Verkasalo, P. K.; Pukkala, E.; Hongisto, M. Y.; Valjus, J. E.; Jarvinen, P. J.; Heikkila, K. V.; Koskenvuo, M. 1993. Risk of cancer in Finnish children living close to power lines. British Medical Journal 307:895-898.

Verkasalo, P.K., E. Pukkala, M.Y. Hongisto, J.E. Valjus, P.J. Jarvinen, K.V. Heikkila, and M. Koskenvuo. 1993. Risk of Cancer in Finnish Children Living Close to Power Lines. British Medical Journal October 9:307:895-99.

Verkasalo, P. K.; Pukkala, E.; Hongisto, M. Y.; Valjus, J. E.; Jarvinen, P. J.; Heikkila, K. V.; Koskenvuo, M. 1993. Risk of cancer in Finnish children living close to power lines. British Medical Journal 307:895-898.

Wachtel, H., F.A. Barnes, and D. Savitz. 1987. Two Alternative Interpretations on the Denver-Boulder ELRF Epidemiology Study. Abstract presented at the Bioelectromagnetics Society Meeting. Portland, Oregon. June 21-25, 1987.

Wertheimer, N; Leeper, E. 1979. Electrical wiring configurations and childhood cancer. American Journal of Epidemiology. 109:273-284.

Wertheimer, N. And E. Leeper.. 1989. Fetal Loss Associated with Two Seasonal Sources of Electromagnetic Field Exposure. American Journal of Epidemiology 129:220-24.

Wertheimer, N. And E. Leeper.. 1986. Possible Effects of Electric Blankets and Heated Waterbeds on Fetal Development. Bioelectromagnetics 7:13-22.

Wertheimer, N. And E. Leeper.. 1982. Aduit Cancer Related to Electrical Wires Near the Home. International Journal of Epidemiology 11:345-55.

Wertheimer, N. And E. Leeper. 1979. Electrical Wiring Configurations and Childhood Cancer. American Journal of Epidemiology 199:273-84. 
Wright, W.E., J.M. Peters, and T.M. Mack. 1982. Leukemia in Workers Exposed to Electrical and Magnetic fields. (letter). The Lancet ii:1160-61.

Zaffanella, L.E. 1989. Pilot Study of Residential Power Frequency Magnetic Fields. Palo Alto, CA: EPRI, September 1989, EPRI EL-6509. Prepared by General Electric Company, Lennox, MA.

\section{EXPERT PANEL REVIEWS}

American Institute of Biological Sciences (AIBS). 1985. Biological and Human Health Effects of Extreme Low Frequency Electromagnetic Fields. Report of the committee on Biological Effects of Extremely Low Frequency Electric and Magnetic fields. Graves, H.B., Chairman, American Institute of Biological Sciences. Arlington, VA.

American Institute of Biological Sciences. 1985. Biological and Human Health Effects of Extremely Low Frequency Electromagnetic Fields. Post-1977 Literature Review. Report of the committee on Biological and Human Health Effects of Extremely Low Frequency Electromagnetic Fields. Arlington, VA. Available from NTIS as ADA152731.

American Conference of Governmental Industrial Hygienists 1994-1995. Threshold Limit Values for Chemical Substances and Physical Agents. Cincinnati, OH. 1994. ISBN: 1-882417-03-8.

American Medical Association (AMA) 1994. Report "7" to the Council of Scientific Affairs. Chicago, Illinois.

California Public Utilities Commission/California Department of Health Services (CPUC/CHDS). 1989. Potential Health Effects of Electric and Magnetic Fields from Electric Power Facilities. September $15,1989$.

Danish Ministry of Health's Group of Experts on Non-lonising Radiation. 1993. The Risk of Cancer in Children Living in Residences Exposed to 50-Hz Magnetic Fields from High-Tension Lines. Pts. 1 \& II. Danish Ministry of Health.

Environmental Protection Agency. 1990. DRAFT - Evaluation of the Potential Carcinogenicity of Electromagnetic Fields. Office of Health and Environmental Assessment. EPA/600/6-90-005B.

Florida Electric and Magnetic Fields Science Advisory Commission (FEMFSAC). 1985. Biological Effects of $60-\mathrm{Hz}$ Power Transmission Lines. Report Submitted to the Department of Environmental Regulation. Tallahassee, Florida.

Florida Electric and Magnetic Fields Science Advisory Commission. 1985. Biological Effects of $60-\mathrm{Hz}$ Power Transmission Lines. Prepared for Florida Department of Environmental Regulation, Tallahassee, and funded by Florida Electric Power Coordinating Group, Inc., Tampa. Available from NTIS as PB85200871.

Illinois Department of Public Health; The Illinois Environmental Protection Agency. 1992. Report to the Illinois State Legislature: Possible Health Effects of Extremely Low Frequency Electric and Magnetic Field Exposure: A Review. March, 1992.

Institut National de la Sante et de la Recherche Medical (INSERM). 1993. Health Effects of Very Low Frequency Electric and Magnetic Fields. National Institute of Health and Medical Research [France]. 
International Non-ionizing Radiation Committee of the International Radiation Protection Association (IRPAINIRC). 1990. Interim guidelines on limits of exposure to $50 / 60-\mathrm{Hz}$ electric and magnetic fields. Health Physics. 58:113-122.

International Commission on Non-lonizing Radiation Protection (ICNIRP). 1993. Press Release, Neuherberg, Germany, May 12, 1993

National Radiological Protection Board (NRPB). Electromagnetic Fields and the Risk of Cancer. Report of an Advisory Group on Non-ionising Radiation. Vol. 3, No. 1, 1992. ISBN 0-85951-346-7.

National Academy of Science. 1977. Biological Effects of Electric and Magnetic Fields Associated With Proposed Project Seafarer: Report of Committee on Biosphere Effects of Extremely-LowFrequency Radiation. Division of Medical Sciences, Assembly of Life Sciences, National Research Council. Washington, DC: National Academy of Sciences, 1977.

National Radiological Protection Board (NRPB). 1993. Electromagnetic Fields and the Risk of Cancer. Report of an Advisory Group on Non-ionising Radiation Press Release.

Oak Ridge Associated Universities Panel (ORAU). 1993. EMF and cancer. Science. 260:13-16.

Oak Ridge Associated Universities Panel (ORAU). 1992. Health effects of low-frequency electric and magnetic fields. Oak Ridge Associated Universities for the Committee on Interagency Radiation Research and Policy Coordination (CIRRPC), ORAU 92/F8, June, 1992.

Western Energy Supply and Transmission (WEST) Associates. 1986. A Critical Review of the Scientific Literature and Low Frequency Electric and Magnetic Fields: Assessment of Possible Effects on Human Health and Recommendations for Research. Energy Task Force project ET-84-11. Project Manager: Southern California Edison. Rosemead, California.

World Health Organization. 1984. Environmental Health Criteria for Low Frequency (ELF) Fields. Environmental Health Criteria 35. Geneva: Switzerland.

World Health Organization. 1984. Environmental Health Criteria 35. Extremely Low Frequency (ELF) Fields. Geneva: Switzerland. Prepared under joint sponsorship of the United Nations Environment Programme, the World Health Organization, and the International Radiation Protection Association. ISBN 92-4-154095-8.

World Health Organization. 1987. Environmental health Criteria 69. Extremely Low Frequency (ELF) Fields. Geneva: Switzerland. Prepared under joint sponsorship of the United Nations Environment Programme, the World Health Organization, and the International Radiation Protection Association. ISBN 92-4-154269-1.

\section{SCIENTIFIC OPINION}

Adey, W.R. 1981. Tissue Interactions With Nonionizing Electromagnetic Fields. Physiological Review 61:435-514.

Ahlbom, A. 1988. A Review of the Epidemiologic Literature on Magnetic Fields and Cancer. Scandinavian Journal of Work, Environment and Health 14:337-43.

Ahlbom, A. Et al. 1987. Biological Effects of Power fields. New York State power Lines Project, Scientific Advisory Panel Report. July 1, 1987. 
Ahlbom, A., E.N. Abert, A.C. Fraser-Smith, A.J. Grodzinsky, M.T. Marron, A.O. Matin, M.A. Persinger, M.L. Shelanski, and E.R. Wolpow. 1987. Biological Effects of Power Line Fields. New York State Power Lines Project Scientific Advisory Panel Final Report. Albany: New York State Department of Health, July 1, 1987. Available from NTIS as DE88002346/NDE.

Aldrich, T.E. and C.E. Easterly. 1985. Handbook of Epidemiological Methods With Special Emphasis on Extremely Low-Frequency Electromagnetic Fields. Oak Ridge, TN: Oak Ridge national Laboratory, November 1985. Available from NTIS as ORNL-6237.

Aldrich, T.E. and C.E. Easterly. 1987. Electromagnetic Fields and Public Health. Environmental Health Perspective 75:159-71.

Chernoff, N., J. Rogers, R. Kavet. 1992. A Review of the Literature on Potential Reproductive and Development Toxicity of Electric and magnetic Fields. Toxicity 74:91-126.

Coleman, M. And V. Beral. 1988. A Review of Epidemiological Studies of the Health Effects of Living Near or Working With Electricity Generation and Transmission Equipment. International Journal of Epidemiology 17:1-13.

Creasey, W.A. and R.B. Goldberg. 1989. Extremely Low Frequency Electric and magnetic Fields and Cancer: A Literature Review. Palo Alto, CA: EPRI, December 1989, EPRI EN-6674. Prepared by Information Ventures, Inc., Philadelphia, PA.

Justesen, D.R., J.M. Peters, J.D. Sahl, A.R. Sheppard, R.F. Smith, and W.E. Wright. 1986. A Critical Review of the Scientific Literature on Low-Frequency Electric and magnetic Fields: Assessment of Possible Effects on Human Health and Recommendations for Research. Project ET-84-11. Western Energy Supply and Transmission (WEST) Associates, July 15, 1986. Project management provided by Southern California Edison Company, Rosemead.

Kavet. R.I. and R.S. Banks. 1986. Emerging Issues in Extremely-Low-Frequency Electric and Magnetic Field Health Research. Environmental Research 39:386-404.

Lee, J.M., J.H. Brunke, G.E. Lee, G.L. Reiner an F.L. Shon. 1985. Electrical and Biological Effects of Transmission Lines: A Review. Bonneville Power Administration, U.S. Department of Energy. Portland, Oregon. Report DOE/BPA-524.

Lee Jr., J.M., V.L. Chartier, D.P. Hartmann, G.E. Lee, K.S. Pierce, R.L. Shon, R.D. Sterns, and M.T. Zeckmeister. 1989. Electrical and Biological Effects of Transmission Lines. A Review. DOE/BPA945. Portland, OR: U.S. Department of Energy, Bonneville Power Administration.

Liburdy, R. P.; Hariand, J. D.; Herleman, C.; Dunham, E. 1993. Human breast cancer growth, melatonin, and magnetic fields: $60-\mathrm{Hz}$ magnetic fields block melatonin's natural oncostatic action on MCF-7 cell growth. Annual Review of Research on Biological Effects of Electric and Magnetic Fields from the Generation. Delivery and Use of Electricity, p. 95.

Marino, A.A. and D.M. Morris. 1985. Chronic Electromagnetic Stressors in the Environment: A Risk in Human Cancer. Journal of Environmental Sciences and Health 3:189-219.

Meyer, R.E., T.E. Aldrich, and C.E. Easterly. 1989. Effects of Noise and Electromagnetic Fields on Reproductive Outcomes. Environmental Health Perspectives 81:193-200.

Michaelson, S.M. 1987. Influence of Power Frequency Electric and Magnetic Fields on Human Health. Annals of the New York Academy of Sciences. Environmental Science 502:55-75.

414-APP.F

F-12 
Miller, M.W. 1980. Electric Wiring Configuration and Childhood Cancer - Comment. American Journal of Epidemiology 112:165.

Nair, I., M.G. Morgan, and H.K. Florig. 1989. Biological Effects of Power Frequency Electric and Magnetic Fields. Background Paper. OTA-BP-E-53. Washington, DC: U.S. Government Printing Office, May 1, 1989. Prepared by the Department of Engineering and Public Policy, Carnegie Mellon University, Pittsburgh, PA, for the U.S. Congress Office of Technology Assessment.

Roth, H.D. 1985. An Evaluation of Published Studies Analyzing the Association of Carcinogenesis With Exposure to magnetic Fields (EA-3904). Roth Associates for Electric Power Research Institute. Palo Alto, California.

Savitz, D.A., N.E. Pearce, and C. Poole. 1989. Methodological Issues in the Epidemiology of Electromagnetic Fields and Cancer. Epidemiologic Reviews 11:59-78.

Savitz, D.A. and E.E. Calle. 1987. Leukemia and Occupational Exposure to Electromagnetic Fields: Review of Epidemiologic Surveys. Journal of Occupational Medicine 29:47-51.

Stern, R.M. 1987. Cancer Incidence Among Welders: Possible Effects of Exposure to Extremely Low Frequency (ELF) Electromagnetic Radiation and to Welding Fumes. Environmental Health Perspectives 76:221-29.

Stevens, R.G. 1987. Electric Power Use and Breast Cancer: A Hypothesis. American Journal of Epidemiology 125:556-61.

Washburn, E. P.; Orza, M. J.; Berlin, J. A.; Nicholson, W. J.; Todd, A. C.; Frumkin, H.; Chalmers, T. C. 1993. Residential proximity to electricity transmission and distribution equipment and risk of leukemia, lymphoma, and nervous system tumors: overview, evaluation and meta-analysis. Annual Review of Research on Biological Effects of Electric and Magnetic Fields from the Generation, Delivery and Use of Electricity, p. 116.

\section{EFFECTS ON VEGETATION}

Hodges, T.K. and C.A. Mitchell. 1984. Influence of High Intensity Electric Fields on Yield of Sweet corn and Dent Corn - 1982. A Report for the American Electric Power Service Corporation, North Liberty, IN.

Hodges, T.K. and C.A. Mitchell. 1989. Growth and Yield of Field Crops in the Proximity of an Ultra-High Voltage Electric Test Line. American Electric Power System, North Liberty, IN 38 pp.

McKee, G.W. et al. 1978. Effects of 60-Hz High Intensity Electric Fields on Living Plants, IEEE Transactions Power Apparatus System 97:1177-1181.

McKee, G.W. et al. 1985. Effects of $60 \mathrm{~Hz}$ Electric Fields on Living Plants Exposed for Extended Periods. EA-4159 Research Project 1064, Prepared by Westinghouse Electric Corporation and Pennsylvania State University, for Electric Power Research Institute (EPRI), Palo Alto, CA.

Rogers, L.E., et al. 1982. Environmental Studies of a 1100-kV Prototype Transmission Line. Prepared for Bonneville Power Administration, U.S. Department of Energy, Portland, OR. 


\section{EFFECTS ON LIVESTOCK AND HONEY BEES}

Algers, B., I. Ekesbo and K. Hennichs. 1981. The Effects of Ultra High-Voltage Transmission Lines on the Fertility of Dairy Cow. A Preliminary Study, Report No. 5. Swedish University of Agricultural Sciences, Department of Animal Hygiene with Farrier's School, Skara, Sweden.

Algers, B. And J. Hunltgren. 1987. Effect of Long-Term Exposure to a 400-kV, 50-Hz Transmission Line on Estrous And Fertility of Cows. Preventive Veterinary Medicine 5:21-36.

Amstutz, H.E. and D.B. Miller. 1980. A Study of Farm Animals Near 765-kV Transmission Lines. Bovine Practitioner 15:51-62.

Bindokas, V.P., J.R. Gauger, and B. Greenberg. 1988a. Exposure Scheme Separates Effects of Electric Shock and Electric Field for Honey Bees (Apis mellifera L.) Bioelectromagnetics 9:275-284.

Bindokas, V.P., J.R. Gauger, and B. Greenberg. 1988b. Mechanisms of Biological Effects observed in Honey Bees (Apis mellifera L.) Hived Under Extra High Voltage Transmission Lines: Implications Derived from Bee Exposure to Simulated Intense Electric Fields and Shocks. Bioelectromagnetics 9:285-301.

Gustafson, R.J. and V.D. Albertson. 1982. Neutral-to-Earth Voltage and Ground Current Effect in Livestock Facilities. IEEE Transactions on Power Apparatus and Systems PAS-101(7):2090-2095.

Hennichs, K. 1982. Cows Exposed to 400-kV Lines, Inventory and Fertility Study. Report No. 7. Swedish University of Agricultural Science, Department of Animal Hygiene with Farrier's School. Skara, Sweden.

Lee, J.M., et al. 1989. Electrical and Biological Effects of Transmission Lines: A Review. Bonneville Power Administration, U.S. Department of Energy, Portland, OR. Report DOE/BP-945.

Mahmond, A.A., D.R. Zimmerman and C.D. Cowan. 1982. A Study of Swine Performance and Farm Machinery Safety Under 345-kV Lines. Paper Presented to the Missouri Valley Electric Association, Fifty-Third Annual Engineering Conference. April, 1982. Kansas City, MO.

Mahmond, A.A. and D.R. Zimmerman. 1984. Reproductive Performance of Pigs Exposed to High Voltage Electric Field: Second Generation. ASAE Paper No. 8403034, Presented at 1984 Summer Meeting of American Society of Agricultural Engineers, June 24-27, 1984. Knoxville, TN.

Williams, J.H. and E.J. Beiler. 1979. An Investigation of Dairy Farm Operations in Association with 765-kV Transmission in Ohio. Ohio Power Siting Commission and Cleveland Electric Illuminating Company. Cleveland, $\mathrm{OH}$.

\section{ELECTRICAL CHARACTERISTICS AND HAZARDS}

Bonneville Power Administration. 1979. Tips on How to Behave Near High Voltage Power Lines. Bonneville Power Administration. Portland, Oregon. Report No. DO/E/BP-8.

Chartier, V.L. no date. Radio Interference Limits that Exist in Five Countries. Contribution to IEEE Task Force. Bonneville Power Authority, Vancouver, BC.

Dabkowski, J. And A. Taflova. 1979. Mitigation of Buried Pipeline Voltages Due to 60-Hz AC Inductive Coupling: Part II-Pipeline Grounding methods. IEEE Transactions on Power Apparatus and Systems PAS(98):1814-1823. 
Electric Power Research Institute (EPRI). 1982. Transmission Line Reference Book - 345-KV and Above. Second Edition.

Elek, G.R. and B.E. Rokas. 1979. A Case of Inductive coordinations. IEEE Transactions on Power Apparatus and Systems PAS(96):834-840.

Ewy, K.A., D.R. Kallesen, L.E. Stetson and R.E. Hanson. 1981 Investigation of Power Line and Irrigation System Compatibility. IEEE Paper 81 WM 204-4. Presented at the IEEE Power Engineering Society Winter Meeting, February 1-6, 1981. Atlanta: GA.

Herrold, J.E. 1979. Health and Safety Effects of EHV Transmission Lines: A Review of the Literature. Michigan Public Service Commission, April, 1979 Lansing, MI.

IITRI. 1979. The effects of $60-\mathrm{Hz}$ Electric and Magnetic Fields on Implanted Cardiac Pacemakers. EPRI Report EA-1174.

Institute of Electronic and Electrical Engineers (IEEE). 1972. EHV Transmission Line Corona Effects. 72CH0644-5PWR.

Institute of Electronic and Electric Engineers. 1971. Radio Noise Design Guide for High-Voltage Transmission Lines. Radio Noise Subcommittee Report, Working Group No. 3, Paper 70TP631PWR.

Institute of Electronic and Electric Engineers. 1976. The Location, Correction, and Prevention of RI and TVI Sources from Overhead power Lines. IEEE, 76-CH1163-R-PWR, Interference Sources, Complaint Statistics, and Limits.

Jaffa, K.C. 1981. Magnetic Field Induction from Overhead Transmission and Distribution Power Lines on Parallel Fences. IEEE Transactions on Power Apparatus and Systems PAS(100):1624-1636.

Jaffa, K.C. and J.B. Stewart. 1981. Magnetic Field Induction from Overhead Transmission and Distribution Lines on Buried Irrigation Pipelines. IEEE Transactions on Power Apparatus Systems PAS(8):315335.

Mohan, N., F. Mahjouri and J.R. Gemayel. 1982. Electrical Induction on Fences Due to Faults on Adjacent HVDC Transmission Lines. IEEE Transactions on Power Apparatus and Systems PAS(101):285159.

National Research Council. 1986. The Earth's Electrical Environment. National Academy Press, Washington, DC.

Olsen, R.G. and K.C. Jaffa. 1984. Electromagnetic Coupling from Power Lines and Magnetic Field Safety Analysis. IEEE Power Engineering Society Paper No. 84WM189-7.

Silva, M. Et al. 1988. Power Frequency Magnetic Fields in the Home. IEEE Transactions on Power Deliver. 4(1):465-477. Paper No. 88WM101-8.

Taflove, A. And J. Dabkowski. 1979. Prediction Method for Buried Pipeline voltages Due to $60-\mathrm{Hz}$ Inductive Coupling: Part 1 - Analysis. IEEE Transactions on Power Apparatus and Systems. PAS(98):780-787. 
Taflove, A., M. Genge and J. Dabkowski. 1979. Mitigation of Buried Pipeline voltages Due to $60-\mathrm{Hz} \mathrm{AC}$ Inductive Coupling: Part 1 - Design of Joint Rights-of-way. IEEE Transactions of Power Apparatus and Systems PAS (98):1806-1813.

U.S. Environmental Protection Agency (EPA). 1974. Information on Levels on Environmental Noise Requisite to Protect Public Health and Welfare with an Adequate margin of Safety. Washington, DC.

University of Rochester. 1985. Evaluation of the Effects of Electric Fields on Implanted Cardiac Pacemakers. EPRI Report EA-3917.

\section{MISCELLANEOUS}

Carstensen, E.L. 1987. Biological Effects of Transmission Line Fields. New York: Elsevier Science Publishing Co., Inc. ISBN 0-444-01018-1.

Sheppard, A.R. and M. Eisenbud. 1977. Biological Effects of Electric and Magnetic Fields of Extremely Low Frequency. New York: New York University Press. ISBN 0-8147-2562-7. 

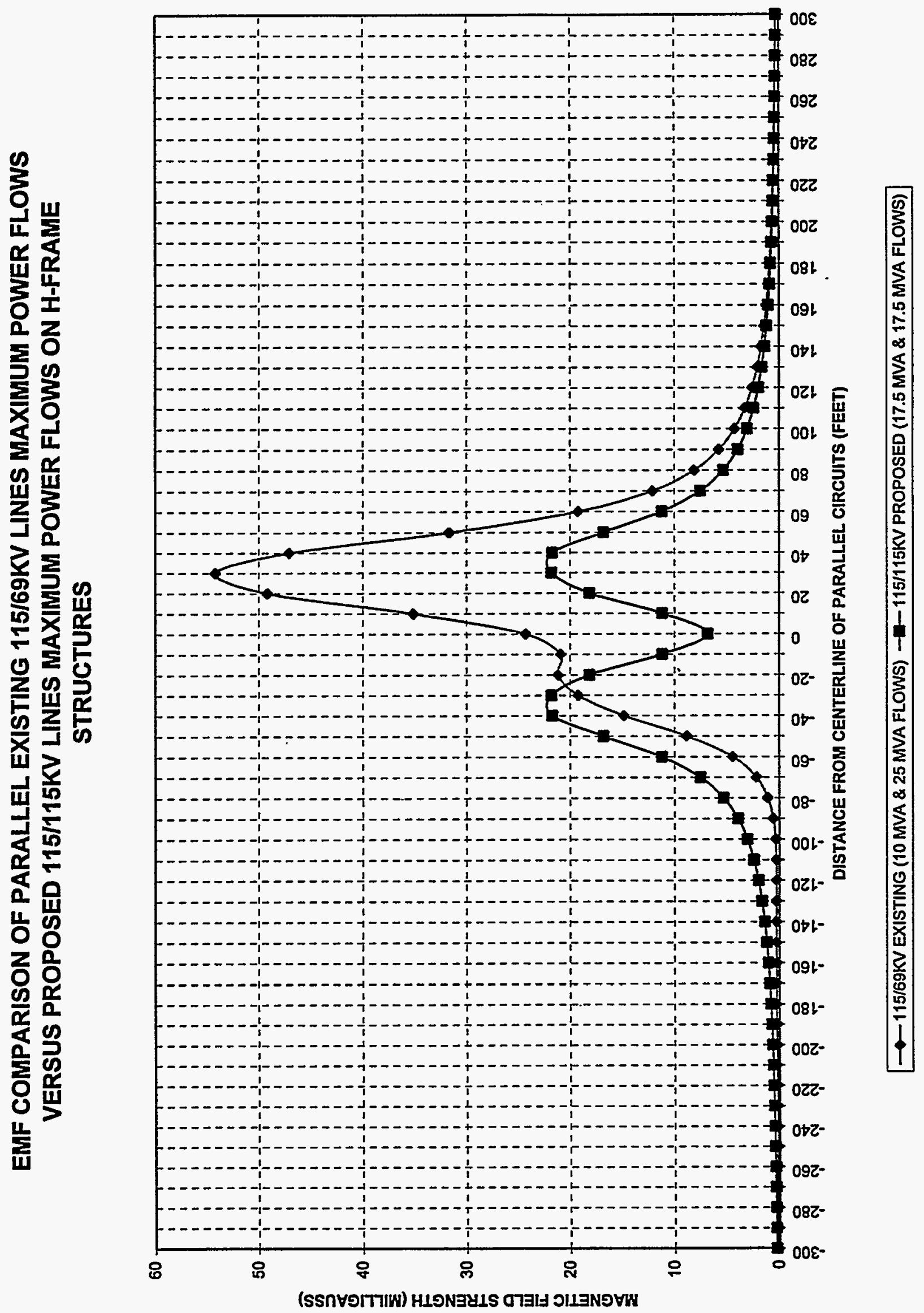

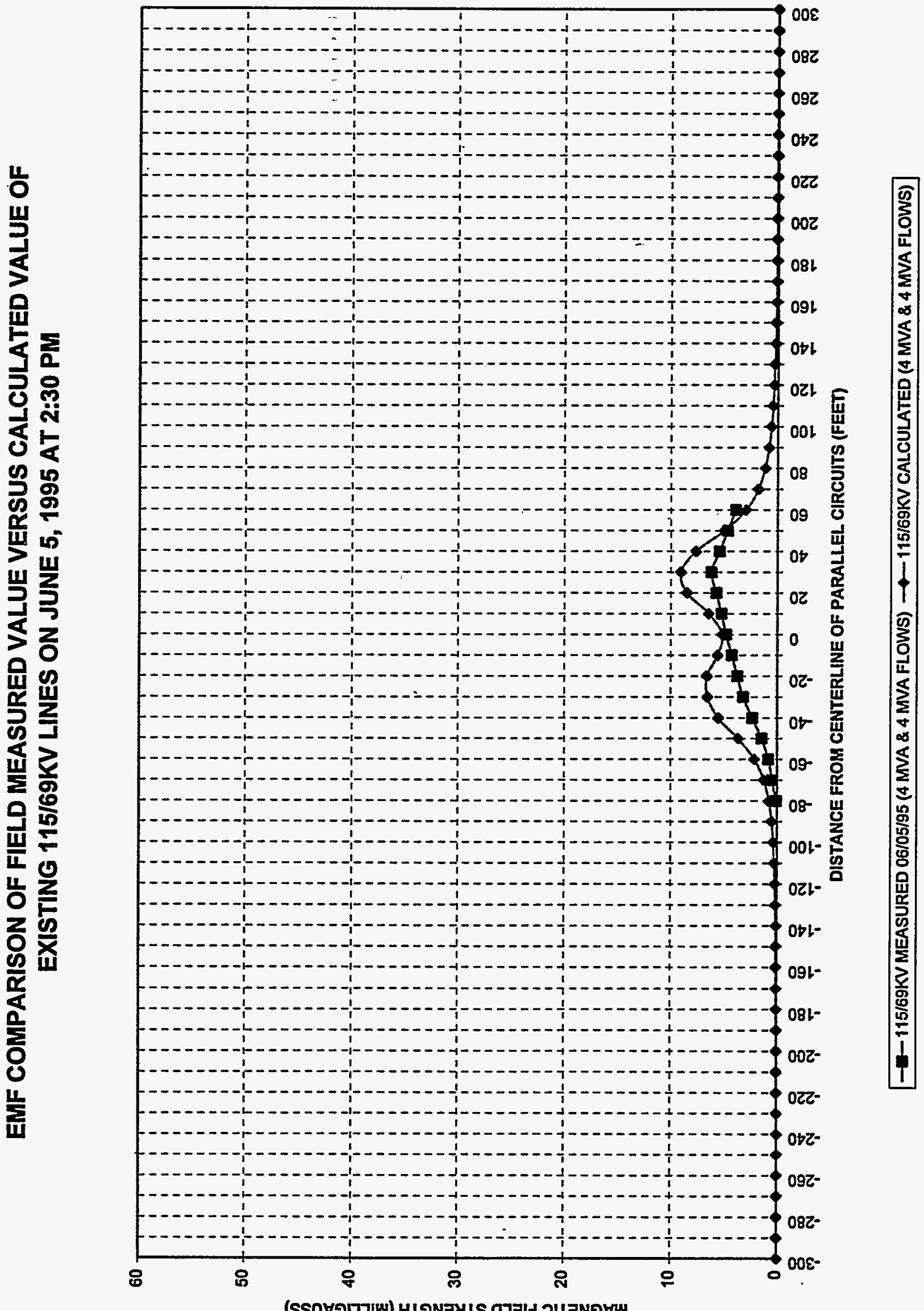

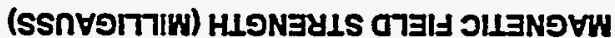




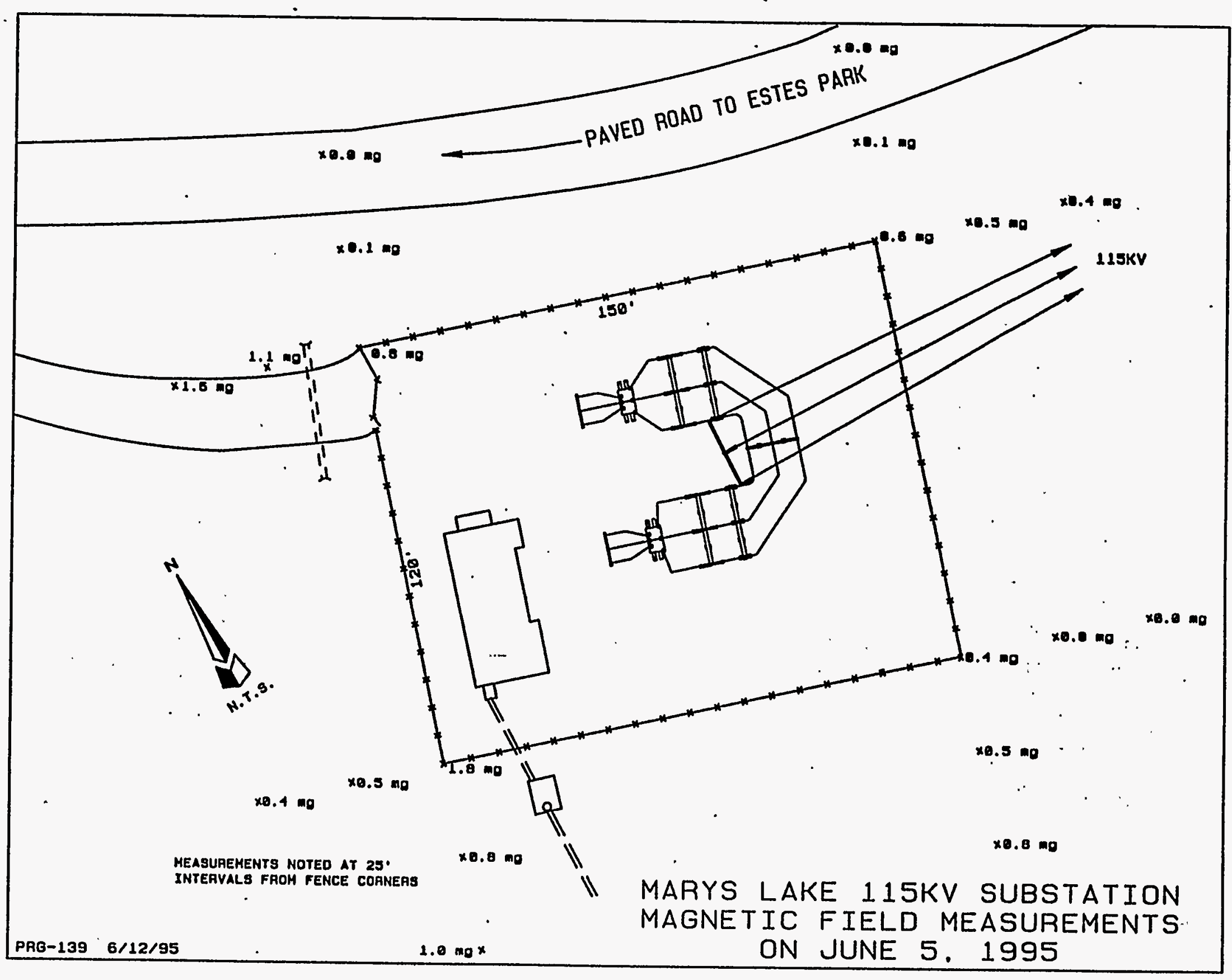


COMBINED qUTPUT: AUDIBLE NOIBE, RADID NDIBE, TVI, OZONE CONCENTRATION, GRDUND GRADIENT, MAONETIC FLD

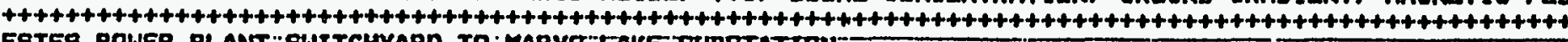
EgTES POWER PLANT BWITCHYARD TO MARYE LAKE BUBBTATIDN PARALLEL. 115HV AND 69KV TRANBMIBBION LINEB

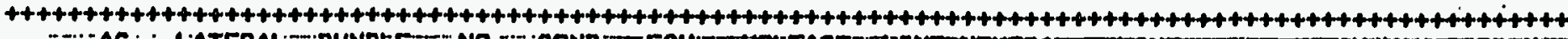

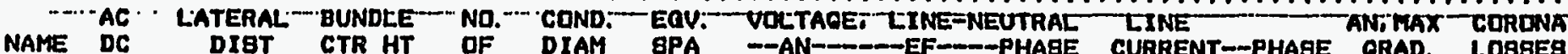

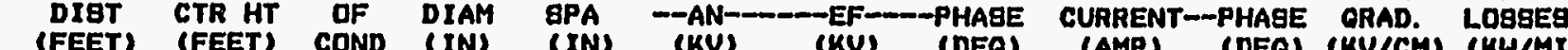

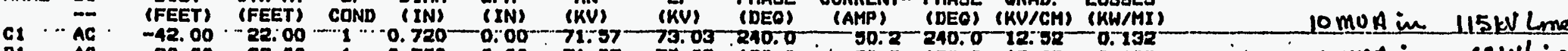

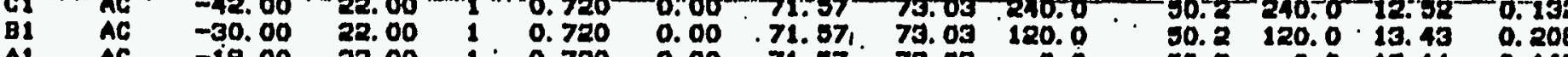

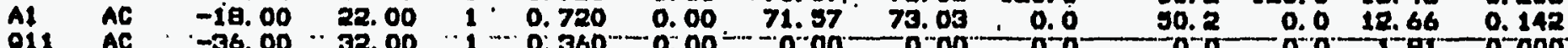

$\begin{array}{llllllllllllll}011 & A C & -36.00 & 32.00 & 1 & 0.360 & 0.00 & 0.00 & 0.00 & 0.0 & . & 0.0 & 0.0 & 1.81 \\ 012 & A C & -24.00 & 32.00 & 1 & 0.360 & 0.00 & 0.00 & 0.00 & 0.0 & 0.0 & 0.0 & 1.50 & 0.000\end{array}$

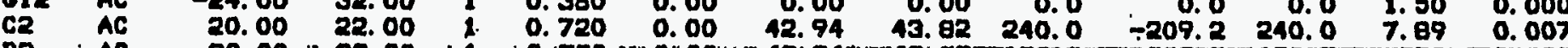

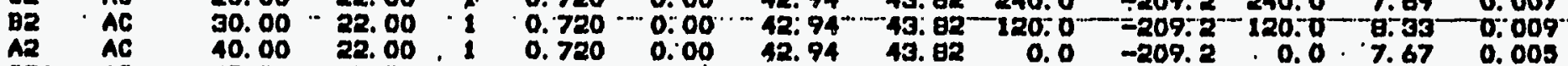

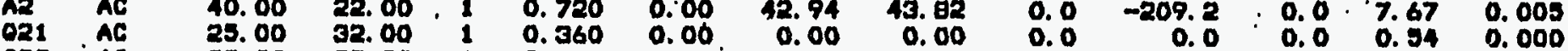

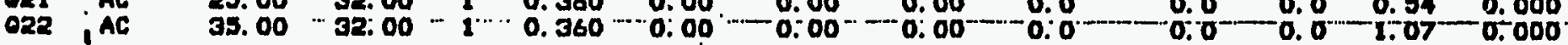

AN MIC. HT $=5.0$ FT ALTITUDE= 7500.0 FT. E-FIELD DET. HT= 3.3 FT WIND VEL. 1.00 MI/HR

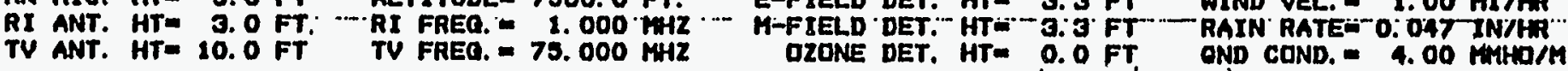

-. LATERAL DIBT-

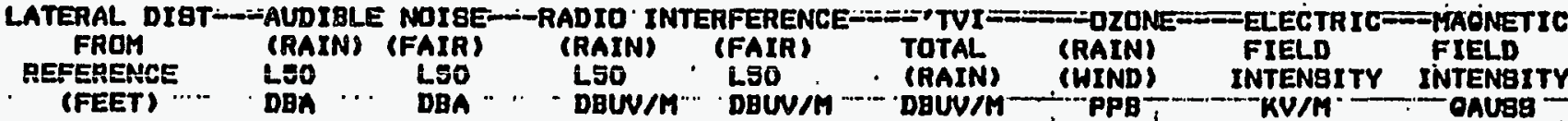

$\begin{array}{rr}-300.0 \\ -290.0 \\ -22.4 & -2.6 \\ -22.6 & -2.4\end{array}$

$22.4-2.621$.

$\begin{array}{lll}-280.0 & 22.8 & -2.2\end{array}$

$-270.0 \quad 2300$

-260.0 ....-23.-2-1.

$\begin{array}{lll}-250.0 & 23.4 & -1.6 \\ -240.0 & 23.7 & -1.3\end{array}$

$23: 9$

$\begin{array}{lll}-220.0 & 24.2 & -0.0\end{array}$

$-210.0-24.4-0.6$

$-200.0-7-24.7-0.3$

$-190.0$

25. $0 \quad 0.0$

0.0
0.3

$=170.0$

$-160.0$

$-150.0$

$25 \% 7-0.7$

1. 0

$-140.0$

-120.0 .

1. 4

20. 4

1. 8

$-110.0$

$-90.0$

$-80.0$

$-70.0$

-60.0
-50.0

$-40.0$

$-40.0$

-20.0
-10.0

27.9

2.8

29.03 .4

4. 0

$29.7 \quad 4.7$

$30.6 \cdots \cdots$

6.6

32. 6

7. 8

$\begin{array}{ll}35.2 & 10.2 \\ 35.7 & 10.7\end{array}$

34. 2 . 9.2

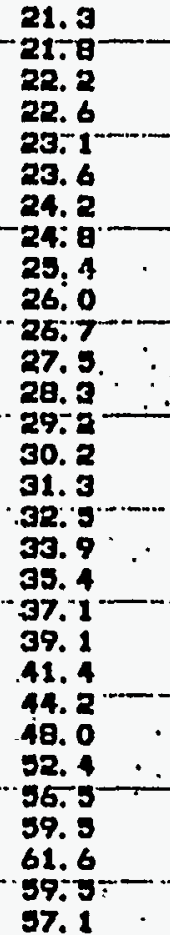

4. 3

$\ddot{7}$

PPP

KV/M

onveg

Wood $H$ freme

anse flow

10 muAin $115 \mathrm{kV}$ Lme

- epporite directiones Exrstrnet Lanes

$4.0-6.10 .000000-0.006-0.00013$

$\begin{array}{llll}5.2 & 0.000000 & 0.008 & 0.00014\end{array}$

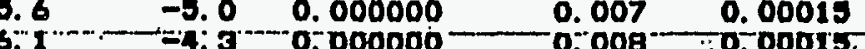

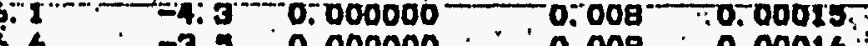

$6.6 \quad-3.9 \quad 0.000000 \cdots 0.009,0.00018$

$7.8-1.7-0.0000000 .00100000017$

8. -1.3 0.000000. 0.01300 .00019

$9.0-1.0 \quad 0.000000$. $\quad-0.015 \quad 0.00019$

9.7 $=0.5 \div 0.000000 \div 0.017 \div 00021$

$10.5 \quad 0.0 \div 0.000000 ;, 0.020: \cdots 0.00020$

$11.3 \quad 0.6$ 0.000000 : $0.024: 0.00024:$

$12.2-1.2-0.000000-0.029-0.00025$

$\begin{array}{lllll}13.2 & 1.9 & 0.000000 & 0.035 & 0.00026\end{array}$

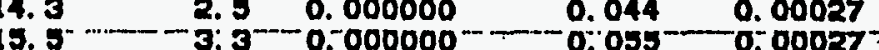

$16.94 .1 .0 .000000,0.071 .0 .00027$,

$\begin{array}{lllllll}18.4 & 5.0 & 0.000000 & 1 & 0.094 & 0.00027\end{array}$

20. $1.0 .000000-0.129-0.00028$

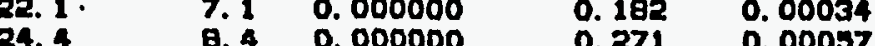

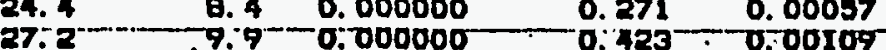

$31.0-11.7 \quad 0.000000 \quad 0.694 \quad 0.00217$

$35.4 \quad 14.00 .000000 \div 1.158 \quad 0.00442$

$39.5-17.3-0.000000-1.705-0.00802$

$\begin{array}{rrrrr}42.3 & 20.3 & 0.000000 & 1.531 & 0.01488 \\ 44.6 & .22 .6 & 0.023312 & .0 .697 . . & 0.01923\end{array}$

42.5-20.3-0.060011-1.358 0.0210

$40.1 \quad 17.9 .0 .075944 \cdot 01.426 \cdot 0.02092:$ 


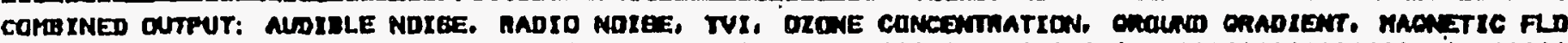

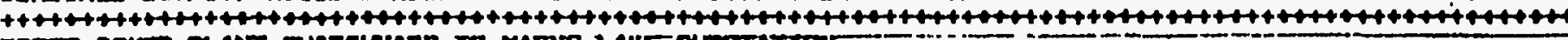

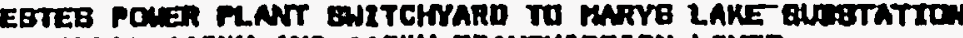
PARALLE BLEV AND ILEKU TRAREMIBSION LINEA

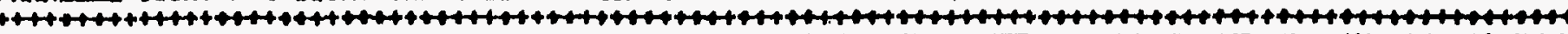

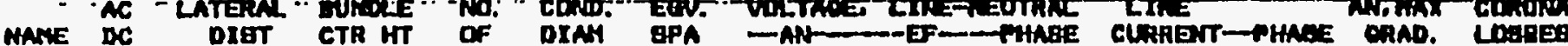

- (FEET) (FEET) CQWD (IN) (IN) (KV) (KV) (DEO) (ANP) (DEO) (KU/CH) (NM/AL)

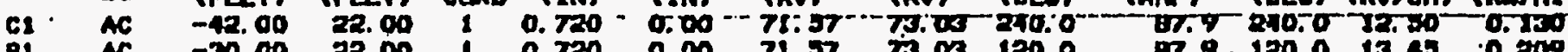

B2 AC -30.0022 .00$

Al AC $-18.00 \quad 22.00$

ora $A C \quad-24.00 \quad 32.00$

Ce AC $18.00 \quad 28.00$

a2 AC 30.00 32:00

$\begin{array}{llll}12 & 1 C & 4200 & 2000 \\ 021 & A C & 24.00 & 30.00\end{array}$

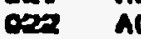

$\begin{array}{ll}24.00 & 32.00 \\ 34.00 & 32.00\end{array}$

0.720

0. 720

- 0. 380

0.360

0.0071 .57 73.03 120.0

97.9.120.0 13. 45

$0.00 .71 .97 \quad 73.03 \quad 0.0$

0. 720

$\begin{array}{llll}0.00 & 0.00 & 0.00 & 0.0\end{array}$

87.9

- $0.012 .75 \circ 0.248$

0. 720

0.00. 78.37

$\begin{array}{rr}0.00 & 0.0 \\ 73.03 & 240.0\end{array}$

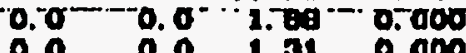

0. 340
0.340

$0.00 \quad 71: 97$

73. $05 \cdot 700: 0$ 97.90 .010 .32

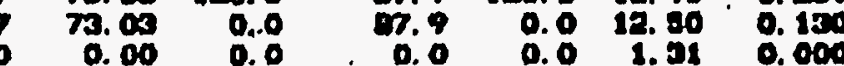
87. 9240.0 12. 75

0. 000

87.90 .019 .90 0.190

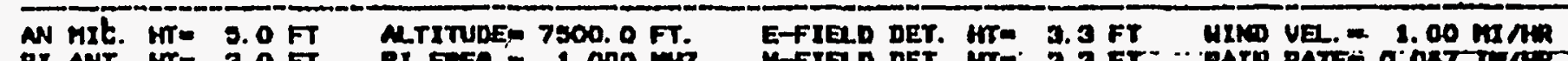
$0.00-\cdots, 00-0.0 \cdot \cdots-6.0$.

0:0

$\frac{1000}{6.000}$

H. Frume

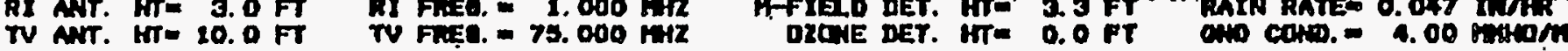

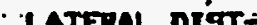

Propacen perallal $115 \mathrm{LV}$

18.5 mUA in ench hine num dirostax-

ANOTIOE Ma18E-

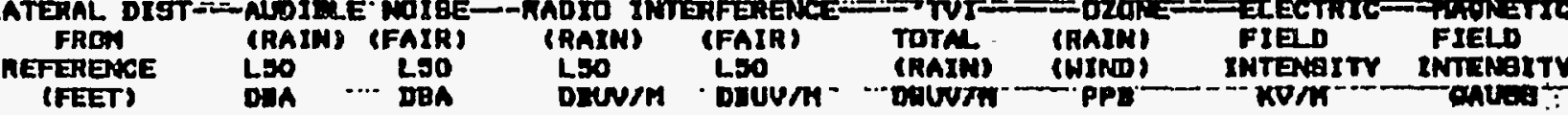

DAN … DEA

Devorm

$-2,90.0$

2

$-2800.0$

$-270.0$

$-260.0$

$-250.0$

$-240.0$

$-200: 0$

$-2 x$

$-210.0$

$-190.0$

$-100.0$

$-170.0$

$-160.0$

$-150.0$

$-140.0$

$-1 \sin 0$
-120.0

$-110.0$

$-100.0$

$-90.0$

$-10.0$

$-7.0$

$-60.0$

$-40.0$

$-\$ 0.0$

$-20.0$

2.2

20. 6

$25.8 \cdot 0$

2t. 0

26.2

$26-5$

26.6

26.9

27.7 2. 7

2a. 0

29. 3

28. 6

29. 0.3 .6

29. 4

90. 4.9

0

31. 5 6.

23

34. 8 9. 1

-35.2.-. - 10.

3b. 2

11.8

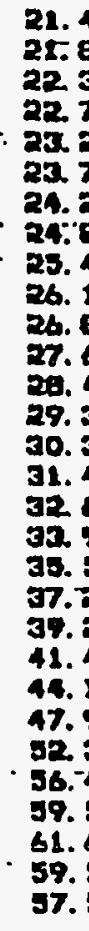

4. 4

-7.0 0. a00000

kom

muses.

Prensing

$c \cdot \rightarrow$ \& $A$

8 - 8

$7 \quad 3.3 \quad-5.7 \quad 0.000000$

$5.7 \quad-5.0 \quad 0.000000$

B.: $2^{-}$

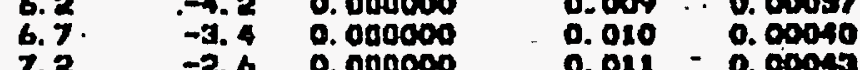

$0 \quad 0.007$

0. 00007

7

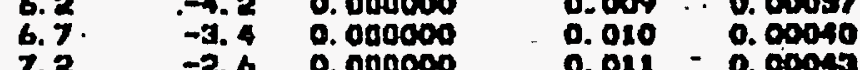

$-4.2-0.000000$

-

0.4 -1. 0.000000 0.084 0.00047

$\begin{array}{llllll}3.1 & 0.1 & -1.4 & 0.000000 & 0.014 & 0.00025 \\ 36.1 & 9.1 & -0.7 & 0.000000 & 0.014 & 0.00054\end{array}$

.......

-0.1-0.000000

10. 8

11. 1 -... 0.7 - 0.000000

o. O16

0.026

0.0.0.7.

12.3 $3.2: 2-0.000000$

0.001

0.000 o.

$\begin{array}{llll}20.3 & 13.3 & 1.7 & 0.000000 \\ 21.4 & 14.4 & 2.6 & 0.000000\end{array}$

26.9

18. 9

3. 0.000000

0.047

i. 0000

0.00125

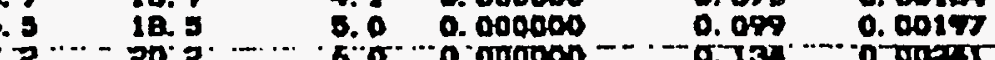

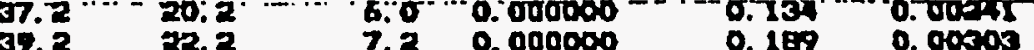

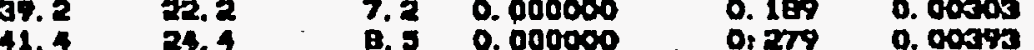

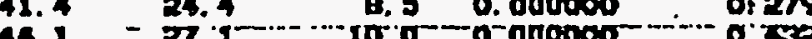

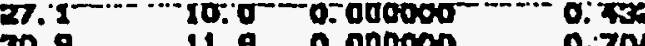

30.9

92. 3 . 35.

36. $-4-\cdots-39: 4 . \cdots-17.0$

3.370 .0000000

0.706
2. 178

42. $20.3 \quad 0.000000$. 1.595

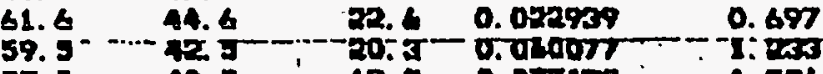

10. ' 18.2 Q.077279

1. 2018

0. $000 \times 1$

o. 0075 : $^{-1}$

0.01121

0 . 02171

$\begin{array}{ll}36: 7 & 7-11.7 \\ 36.3 & 11.3\end{array}$

o.prus 


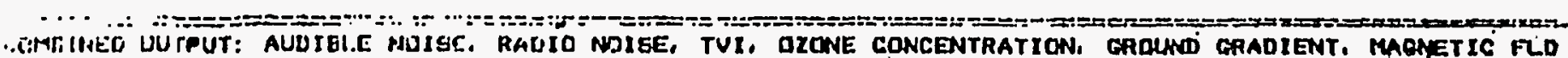

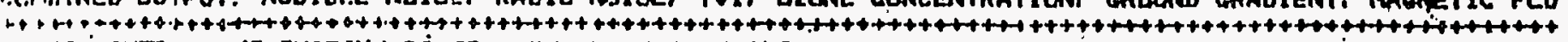

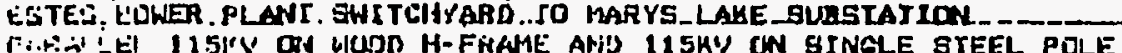

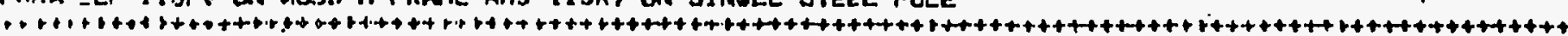

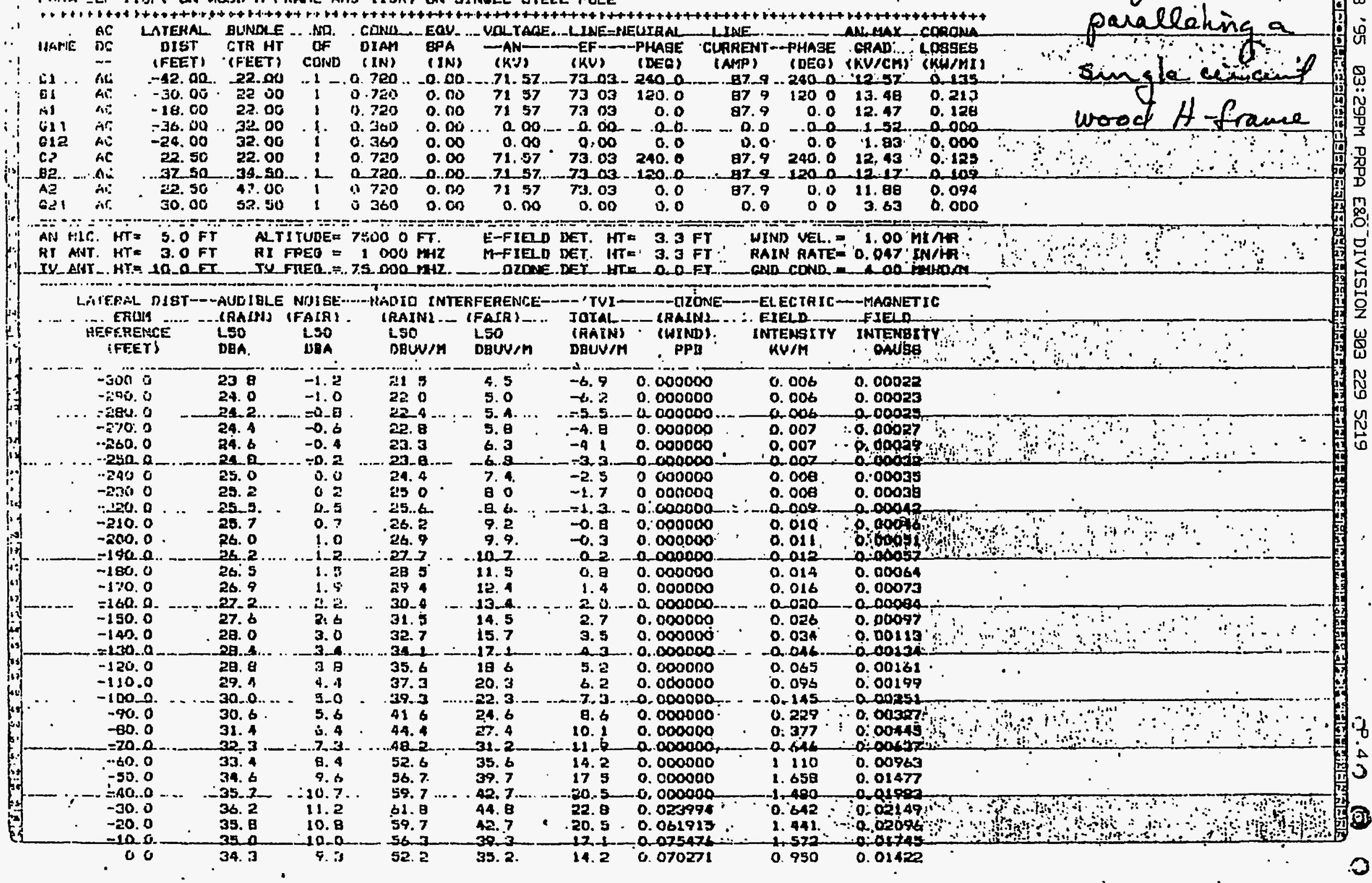




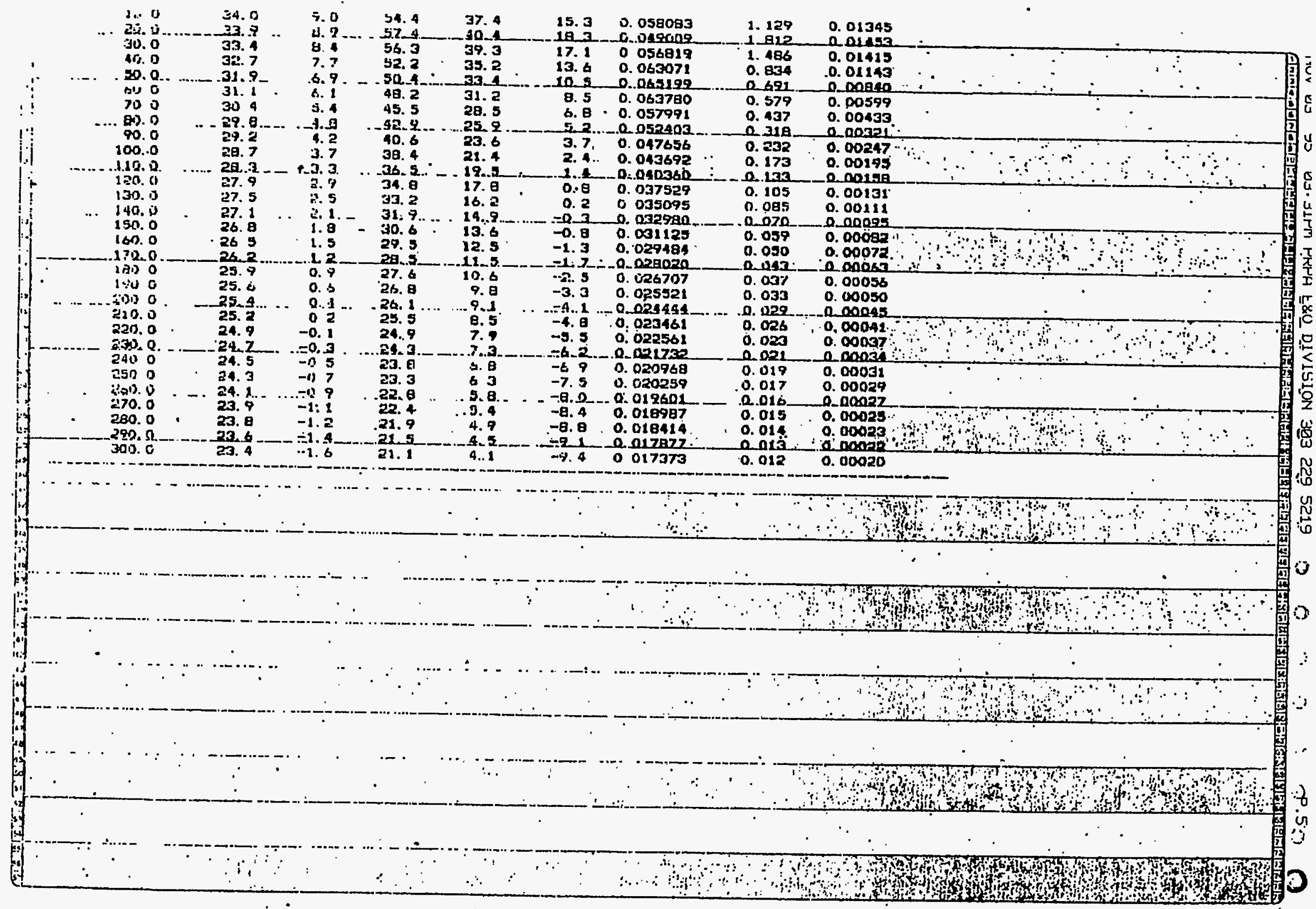




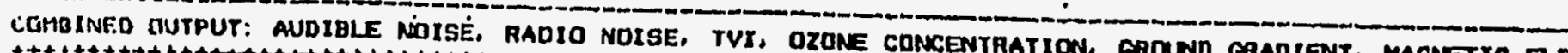
MARGL POLER PLANT EWITCHYARD TO MARYS LAKE

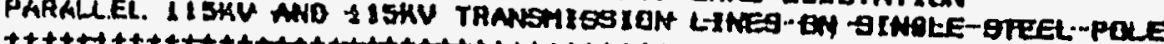

AC LATERA BUNGK

NAME DC CATERA BUNDLE NO. COND. EQU. VOLTAOE. LINE-NEUTRM LENE

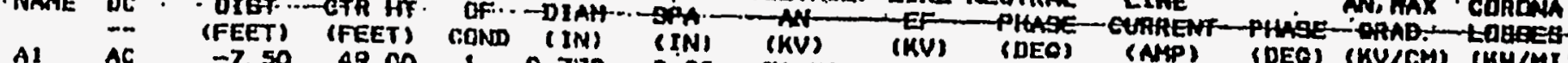

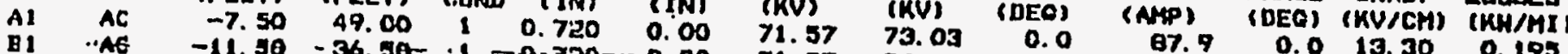

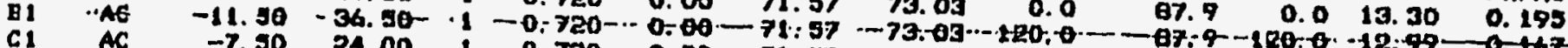

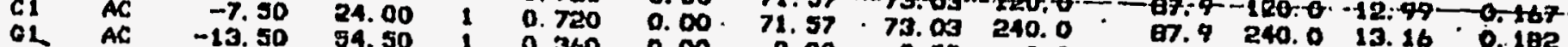

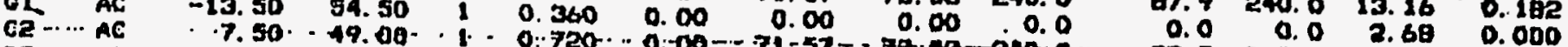

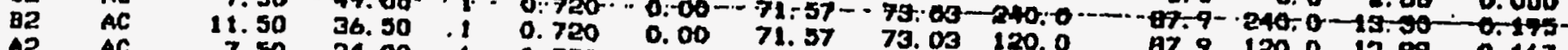

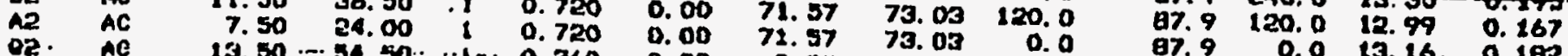

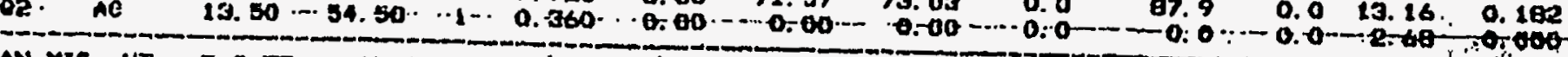

AN MIC. HTE 5. O FT ALTITUDE- $7500.0 \mathrm{FT}$.

TV ANT HT: 10. D FT

E-FIELD DET. HTE 3.3 FT

PHI Cirsingl Ale

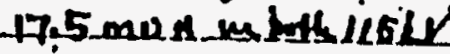

sane drection

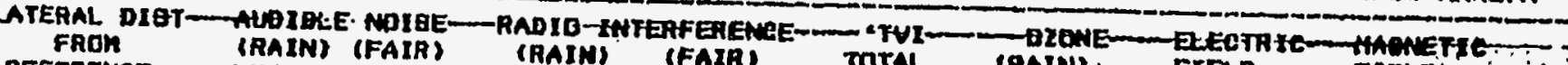

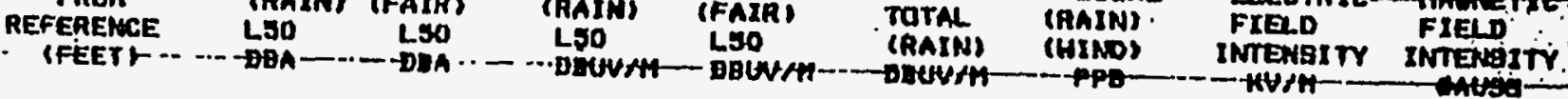

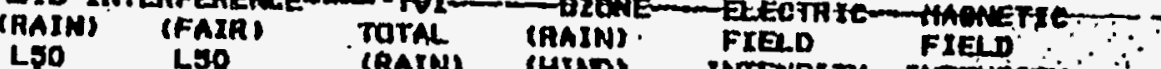

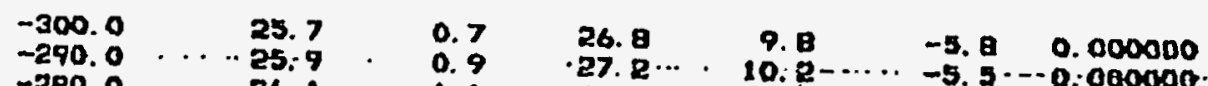

26. 8

26. 3

-250.0 . 25.

$\begin{array}{ll}-250.0 & 26.6 \\ -240.0 & 26.6\end{array}$

$-240.0$

$-250.0$

$-210.0$

$-200.0$

2,3

$-190.0$

3. 0

$-170.0 \cdots-.729 .2$

$-260.0$

$-150.0$

28.

27. 6 10.6 $\quad-3.2 \quad 0.000000$

28.0 11.0

-28.4.-.....14.4-..... -

20. 8 11. 8

29. 3 is 3

-3. 8 0. 000000

horh-chita

30.

30. 8

2. $8-3.5-0.000000$

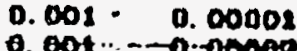

0. 001 0.000002

0.0D1 0.00002

-

$-140,0$

3. $\mathrm{B}$

0.00

$0.002 \quad 0.00002$

0 15. $150-2.2-0.000000$

$\begin{array}{lll}15.6 & -1.3 & 0.000000\end{array}$

$34.3-16.3-\cdots-0.9$

34. 17.

17. 9

$\begin{array}{ll}35.8 & 18.6 \\ 36.7 & 19.7\end{array}$

$-120.0$

29.4... - -4:4

37. 8 20.8

9a:- $\ldots-21.9 . \ldots . .2$

$-100.0$

30-5 - . 5

40. 1

41.4 . 24.

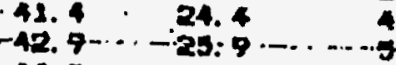

40. 0 ............

70.0 32.5. 7.5

-60.0 33. 2

50.

$-40.0$

39. 0

34.6

44. $5 \quad 27.5$

46. 129.1

47.9 .30 .9

53. 0

32. 9

$-0.3$

$-20.0$

10.6

37.0

10. 0

37. 0

12. 2

56: 9

59. 4

$24 \quad$-7.6 - 0.000000

$0: 002$

o. 000003

37. 0-....12. 0

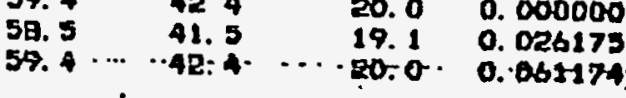

0.002

$0.0000 x$

0. 0iogor

0.0040 .00005

0.0040 .00004

0.000000 ...... 0.005. 0.004

$0.000000_{1}, \quad 0.008$. 0.00000

$0.000000 \quad 0.007$

0.007

00009 "Phereanen."

A. C

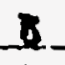

$\longrightarrow$

0.020

. 00015

$\begin{array}{llll}0.000000 & 0.013 & 0.00019\end{array}$

3. 0.000000 0.02R 0.0003e.

a 0.000000 0.000 0.00042

6. . $0.000000 \quad 0.0420 .00057$

\begin{tabular}{llll}
\hline .4 & 0.000000 & 0.0091 & 0.00079
\end{tabular}

10.1--0.000000 ...... $0.091 \quad 0.00114$

$146--1.0 .06171$

. 462 . 0.002s6

$-0.841-0.00 \times 01$

1.090 0.01032

O1194 
Table G1

Preliminary Alternative Route

Impact Evaluation Criteria

\begin{tabular}{|c|c|c|c|c|c|c|c|c|c|c|c|c|c|c|c|c|c|c|c|c|c|}
\hline \multicolumn{2}{|c|}{ Alternative Route } & \multicolumn{4}{|c|}{ Alt. A } & \multicolumn{4}{|c|}{ Alt. B } & \multicolumn{4}{|c|}{ Alt. C } & \multicolumn{3}{|c|}{ Alt. D } & \multicolumn{3}{|c|}{ Alt. $\mathrm{E}$} & \multicolumn{2}{|c|}{ Alt. $F$} \\
\hline Criteria & Links & 1 & 2 & 3 & 4 & 1 & 2 & 5 & 4 & 1 & 6 & 7 & 4 & 1 & 6 & 9 & 8 & 7 & 4 & 8 & 9 \\
\hline
\end{tabular}

\section{Environmental Planning (Natural, Human and Cultural)}

\begin{tabular}{|c|c|c|c|c|c|c|c|c|c|c|c|c|c|c|c|c|c|c|c|c|c|}
\hline \multirow{3}{*}{$\begin{array}{l}\text { Land Use - Number of } \\
\text { existing residentlal } \\
\text { parcels adjacent fo, or } \\
\text { crossed by, right-of-way }\end{array}$} & Occurrences & 0 & 48 & 41 & 0 & 0 & 48 & 7 & 0 & 0 & 65 & 7 & 0 & 0 & 65 & 23 & 49 & 7 & 0 & 49 & 23 \\
\hline & Impact Total & \multicolumn{4}{|c|}{89} & \multicolumn{4}{|c|}{55} & \multicolumn{4}{|c|}{72} & \multicolumn{3}{|c|}{88} & \multicolumn{3}{|c|}{56} & \multicolumn{2}{|c|}{72} \\
\hline & Criteria Ranking & \multicolumn{4}{|c|}{6} & \multicolumn{4}{|c|}{1} & \multicolumn{4}{|c|}{3} & \multicolumn{3}{|c|}{5} & \multicolumn{3}{|c|}{2} & \multicolumn{2}{|c|}{3} \\
\hline \multirow{3}{*}{$\begin{array}{l}\text { Land Use - Number of } \\
\text { new residential parcels } \\
\text { adjacent to, or crossed } \\
\text { by, right-of-way }\end{array}$} & Occurrences & 0 & 3 & 4 & 0 & 0 & 3 & 57 & 0 & 0 & 61 & 8 & 0 & 0 & 61 & 30 & 88 & 8 & 0 & 88 & 30 \\
\hline & Impact Total & \multicolumn{4}{|c|}{7} & \multicolumn{4}{|c|}{60} & \multicolumn{4}{|c|}{69} & \multicolumn{3}{|c|}{91} & \multicolumn{3}{|c|}{96} & \multicolumn{2}{|c|}{118} \\
\hline & Criteria Ranking & \multicolumn{4}{|c|}{1} & \multicolumn{4}{|c|}{2} & \multicolumn{4}{|c|}{3} & \multicolumn{3}{|c|}{4} & \multicolumn{3}{|c|}{5} & \multicolumn{2}{|c|}{6} \\
\hline \multirow{3}{*}{$\begin{array}{l}\text { Land Use - Number of } \\
\text { commercial parcels } \\
\text { adjacent to, or crossed. } \\
\text { by, right-of-way }\end{array}$} & Occurrences & 2 & 2 & 1 & 0 & 2 & 2 & 0 & 0 & 2 & 25 & 1 & 0 & 2 & 25 & 0 & 3 & 1 & 0 & 3 & 0 \\
\hline & Impact Total & \multicolumn{4}{|c|}{5} & \multicolumn{4}{|c|}{4} & \multicolumn{4}{|c|}{28} & \multicolumn{3}{|c|}{27} & & 4 & & & \\
\hline & Criteria Ranking & & & & & & & & & & & & & & 5 & & & 2 & & & \\
\hline Land Use - Number of & Occurrences & 0 & 0 & 0 & 0 & 0 & 0 & 0 & 0 & 0 & 0 & 1 & 0 & 0 & 0 & 1 & 0 & 1 & 0 & 0 & 1 \\
\hline prohibit other & Impact Total & & & & & & & & & & & & & & 1 & & & 1 & & & \\
\hline 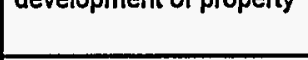 & Criteria Ranking & & & & & & & & & & & & & & 3 & & & 3 & & & \\
\hline Land Use - Number of & Occurrences & 0 & 0 & 0 & 0 & 0 & 0 & 7 & 0 & 0 & 89 & 8 & 0 & 0 & 89 & 23 & 52 & 8 & 0 & 52 & 23 \\
\hline new right-of-way would & Impact Total & & & & & & & & & & & & & & 112 & & & 60 & & & \\
\hline & Criteria Ranking & & & & & & & & & & & & & & 6 & & & 3 & & & \\
\hline
\end{tabular}




\section{Table G1}

\section{Preliminary Alternative Route \\ Impact Evaluation Criteria}

\begin{tabular}{|c|c|c|c|c|c|c|c|c|c|c|c|c|c|c|c|c|c|c|c|c|c|}
\hline \multicolumn{2}{|c|}{ Alternative Route } & \multicolumn{4}{|c|}{ Alt. A } & \multicolumn{4}{|c|}{ Alt. B } & \multicolumn{4}{|c|}{ Alt. C } & \multicolumn{3}{|c|}{ Alt. D } & \multicolumn{3}{|c|}{ Alt. E } & \multicolumn{2}{|c|}{ Alt. F } \\
\hline Criteria & Links & 1 & 2 & 3 & 4 & 1 & 2 & 5 & 4 & 1 & 6 & 7 & 4 & 1 & 6 & 9 & 8 & 7 & 4 & 8 & 9 \\
\hline \multirow{3}{*}{$\begin{array}{l}\text { Recreation - Number of } \\
\text { crossings through a } \\
\text { developed park, } \\
\text { recreation area, or } \\
\text { sensitive, special } \\
\text { recreation management } \\
\text { area }\end{array}$} & Occurrences & 1 & 0 & 0 & 1 & 1 & 0 & 0 & 1 & 1 & 1 & 0 & 1 & 1 & 1 & 0 & 3 & 0 & 1 & 3 & 0 \\
\hline & Impact Total & \multicolumn{4}{|c|}{2} & \multicolumn{4}{|c|}{2} & \multicolumn{4}{|c|}{3} & \multicolumn{3}{|c|}{2} & \multicolumn{3}{|c|}{4} & \multicolumn{2}{|c|}{3} \\
\hline & Criteria Ranking & \multicolumn{4}{|c|}{1} & \multicolumn{4}{|c|}{1} & \multicolumn{4}{|c|}{4} & \multicolumn{3}{|c|}{1} & \multicolumn{3}{|c|}{6} & \multicolumn{2}{|c|}{4} \\
\hline \multirow{3}{*}{$\begin{array}{l}\text { Transportation - Number } \\
\text { of crossings requiring a } \\
\text { significant increase in } \\
\text { construction time, traffic } \\
\text { delays, expense (e.g., } \\
\text { highways, railroads, } \\
\text { streams) }\end{array}$} & Occurrences & 2 & 0 & 1 & 1 & 2 & 0 & 1 & 1 & 2 & $0^{*}$ & 1 & 1 & 2 & 0 * & 3 & $6^{* *}$ & 1 & 1 & 6 * & 3 \\
\hline & Impact Total & \multicolumn{4}{|c|}{4} & \multicolumn{4}{|c|}{4} & \multicolumn{4}{|c|}{4} & \multicolumn{3}{|c|}{5} & \multicolumn{3}{|c|}{8} & \multicolumn{2}{|c|}{9} \\
\hline & Criteria Ranking & \multicolumn{4}{|c|}{1} & \multicolumn{4}{|c|}{1} & \multicolumn{4}{|c|}{1} & & 4 & & & 5 & & & \\
\hline Number of structures & Occurrences & 4 & 1 & 0 & 0 & 4 & 1 & 0 & 0 & 4 & 16 & 1 & 0 & 4 & 16 & 8 & 7 & 1 & 4 & 7 & 8 \\
\hline transportation routes & Impact Total & & & & & & & & & & & & & & 28 & & & 12 & & & \\
\hline & Criteria Ranking & & & & & & & & & & & & & & 6 & & & 3 & & & \\
\hline Number of existing & Occurrences & 7 & 114 & 102 & 7 & 7 & 114 & 18 & 7 & 7 & 117 & 12 & 7 & 7 & 117 & 30 & 70 & 12 & 7 & 70 & 30 \\
\hline the transmission line & Impact Total & & & & & & & & & & & & & & 154 & & & 89 & & & \\
\hline & Criteria Ranking & & & & & & & & & & & & & & 5 & & & 1 & & & \\
\hline Number of new & Occurrences & 0 & 4 & 12 & 0 & 0 & 4 & 57 & 0 & 0 & 61 & 8 & 0 & 0 & 61 & 30 & 88 & 8 & 0 & 8 & 30 \\
\hline the transmission line & Impact Total & & & & & & & & & & & & & & 91 & & & 96 & & & \\
\hline & Criteria Ranking & & & & & & & & & & & & & & 5 & & & 6 & & & \\
\hline
\end{tabular}




\section{Table G1}

Preliminary Alternative Route

- Impact Evaluation Criteria

\begin{tabular}{|c|c|c|c|c|c|c|c|c|c|c|c|c|c|c|c|c|c|c|c|c|c|}
\hline \multicolumn{2}{|c|}{ Alternative Route } & \multicolumn{4}{|c|}{ Alt. A } & \multicolumn{4}{|c|}{ Alt. B } & \multicolumn{4}{|c|}{ Alt. C } & \multicolumn{3}{|c|}{ Alt:D } & \multicolumn{3}{|c|}{ Alt. E } & \multicolumn{2}{|c|}{ Alt. F } \\
\hline Criteria & Links & 1 & 2 & 3 & 4 & 1 & 2 & 5 & 4 & 1 & 6 & 7 & 4 & 1 & 6 & 9 & 8 & 7 & 4 & 8 & 9 \\
\hline \multirow{3}{*}{$\begin{array}{l}\text { Number of Commercial } \\
\text { developments from } \\
\text { which the transmission } \\
\text { line would be visible }\end{array}$} & Occurrences & 8 & 18 & 1 & 1 & 8 & 18 & 0 & 1 & 8 & 48 & 0 & 1 & 8 & 48 & 0 & 6 & 0 & 1 & 6 & 0 \\
\hline & Impact Total & \multicolumn{4}{|c|}{28} & \multicolumn{4}{|c|}{27} & \multicolumn{4}{|c|}{57} & \multicolumn{3}{|c|}{56} & \multicolumn{3}{|c|}{7} & \multicolumn{2}{|c|}{6} \\
\hline & Criteria Ranking & \multicolumn{4}{|c|}{4} & \multicolumn{4}{|c|}{3} & \multicolumn{4}{|c|}{6} & \multicolumn{3}{|c|}{5} & \multicolumn{3}{|c|}{2} & \multicolumn{2}{|c|}{1} \\
\hline \multirow{3}{*}{$\begin{array}{l}\text { Number of structures } \\
\text { visible from recreation } \\
\text { areas }\end{array}$} & Occurrences & 2 & 0 & 2 & 2 & 2 & 0 & 14 & 2 & 2 & 0 & 2 & 2 & 2 & 0 & 2 & 11 & 2 & 2 & 11 & 2 \\
\hline & Impact Total & \multicolumn{4}{|c|}{6} & \multicolumn{4}{|c|}{18} & \multicolumn{4}{|c|}{6} & \multicolumn{3}{|c|}{4} & \multicolumn{3}{|c|}{15} & \multicolumn{2}{|c|}{13} \\
\hline & Criteria Ranking & \multicolumn{4}{|c|}{2} & & & & & & & & & & 1 & & & 5 & & & \\
\hline Number of structures & Occurrences & 2 & 2 & 1 & 0 & 2 & 2 & 6 & 0 & 2 & 2 & 0 & 0 & 2 & 2 & 0 & 8 & 0 & 0 & 8 & 0 \\
\hline & Impact Total & & & & & & & & & & & & & & 4 & & & 8 & & & \\
\hline & Criteria Ranking & & & & & & & & & & & & & & 1 & & & 4 & & & \\
\hline Number of prominent & Occurrences & 0 & 0 & 3 & 0 & 0 & 0 & 2 & 0 & 0 & 6 & 3 & 0 & 0 & $6^{*}$ & 3 & 5 & 3 & 0 & 5 & 3 \\
\hline $\begin{array}{l}\text { alignment } \\
\text { aline the }\end{array}$ & Impact Total & & & & & & & & & & & & & & 9 & & & 8 & & & \\
\hline & Criteria Ranking & & & & & & & & & & & & & & 5 & & & 3 & & & \\
\hline Number of structures & Occurrences & 0 & 0 & 4 & 2 & 0 & 0 & 14 & 2 & 0 & 0 & 8 & 2 & 0 & 0 & 13 & 16 & 8 & 2 & 16 & 13 \\
\hline $\begin{array}{l}\text { landscapes } \\
\text { lack }\end{array}$ & Impact Total & & & & & & & & & & & & & & 13 & & & 26 & & & \\
\hline & Criteria Ranking & & & & & & & & & & & & & & 3 & & & 5 & & & \\
\hline Number of structures in & Occurrences & 0 & 0 & 0 & 0 & 0 & 0 & 6 & 0 & 0 & 0 & 0 & 0 & 0 & 0 & 3 & 0 & 0 & 0 & 0 & 3 \\
\hline$(>50 \%)$ with soils & Impact Total & & & & & & & & & & & & & & 3 & & & 0 & & & \\
\hline slump and creep & Criteria Ranking & & & & & & & & & & & & & & 4 & & & 1 & & & \\
\hline
\end{tabular}




\section{Table G1}

\section{Preliminary Alternative Route Impact Evaluation Criteria}

\begin{tabular}{|c|c|c|c|c|c|c|c|c|c|c|c|c|c|c|c|c|c|c|c|c|c|}
\hline \multicolumn{2}{|c|}{ Alternative Route } & \multicolumn{4}{|c|}{ Alt. A } & \multicolumn{4}{|c|}{ Alt. B } & \multicolumn{4}{|c|}{ Alt. C } & \multicolumn{3}{|c|}{ Alt. D } & \multicolumn{3}{|c|}{ Alt. E } & \multicolumn{2}{|c|}{ Alt. F } \\
\hline Criteria & Links & 1 & 2 & 3 & 4 & 1 & 2 & 5 & 4 & 1 & 6 & 7 & 4 & 1 & 6 & 9 & 8 & -7 & 4 & 8 & 9 \\
\hline \multirow{3}{*}{$\begin{array}{l}\text { Number of structures in } \\
\text { steep soils }(25-50 \%) \\
\text { with slopes susceptible } \\
\text { to erosion, slump and } \\
\text { creep }\end{array}$} & Occurrences & 0 & 0 & 11 & $\mathbf{0}$ & 0 & 0 & 5 & 0 & 0 & 0 & 0 & 0 & 0 & 0 & 0 & 0 & 0 & 0 & 0 & 0 \\
\hline & Impact Total & \multicolumn{4}{|c|}{11} & \multicolumn{4}{|c|}{5} & \multicolumn{4}{|c|}{0} & \multicolumn{3}{|c|}{0} & \multicolumn{3}{|c|}{0} & \multicolumn{2}{|c|}{$\mathbf{0}$} \\
\hline & Criteria Ranking & \multicolumn{4}{|c|}{6} & \multicolumn{4}{|c|}{5} & \multicolumn{4}{|c|}{1} & \multicolumn{3}{|c|}{1} & \multicolumn{3}{|c|}{1} & \multicolumn{2}{|c|}{1} \\
\hline \multirow{3}{*}{$\begin{array}{l}\text { Number of water } \\
\text { crossings }\end{array}$} & Occurrences & 0 & 0 & 0 & 1 & 0 & 0 & 0 & 1 & 0 & 0 & 0 & 1 & 0 & 0 & 0 & 2 & 0 & 1 & 2 & 0 \\
\hline & Impact Total & \multicolumn{4}{|c|}{1} & \multicolumn{4}{|c|}{1} & \multicolumn{4}{|c|}{1} & \multicolumn{3}{|c|}{0} & \multicolumn{3}{|c|}{3} & \multicolumn{2}{|c|}{2} \\
\hline & Criteria Ranking & \multicolumn{4}{|c|}{2} & & & & & & & & & & 1 & & & 6 & & & \\
\hline Number of wells within & Occurrences & 0 & 0 & 1 & 0 & 0 & 0 & 0 & 0 & 0 & 0 & 0 & 0 & 0 & 0 & 0 & $\mathbf{0}$ & 0 & 0 & 0 & 0 \\
\hline & Impact Total & & & & & & & & & & & & & & 0 & & & 0 & & & \\
\hline & Criteria Ranking & & & & & & & & & & & & & & 1 & & & 1 & & & \\
\hline Number of structures in & Occurrences & 0 & 0 & 0 & 0 & 0 & 0 & 0 & 0 & 0 & 0 & 0 & 0 & $\mathbf{0}$ & 0 & .0 & 2 & 0 & 0 & 2 & 0 \\
\hline & Impact Total & & & & & & & & & & & & & & 0 & & & 2 & & & \\
\hline & Criteria Ranking & & & & & & & & & & & & & & 1 & & & 5 & & & \\
\hline Number of acres of & Occurrences & 0 & 0 & 0 & 0 & 0 & 0 & 22 & 0 & 0 & 0.5 & 0 & 0 & 0 & 0.5 & 4 & 0 & 0 & 0 & 0 & 4 \\
\hline & Impact Total & & & & & & & & & & & & & & 4.5 & & & 0 & & & \\
\hline & Criteria Ranking & & & & & & & & & & & & & & 5 & & & 1 & & & \\
\hline Number of structures & Occurrences & 0 & 0 & 2 & 0 & 0 & 0 & 0 & 0 & 0 & 0 & 8 & 0 & 0 & 0 & 4 & 19 & 8 & 0 & 19 & 4 \\
\hline & Impact Total & - & & & & & & & & & & & & & 4 & & & 27 & & & \\
\hline & Criteria Ranking & & & & & & & & & & & & & & 3 & & & 6 & & & \\
\hline
\end{tabular}




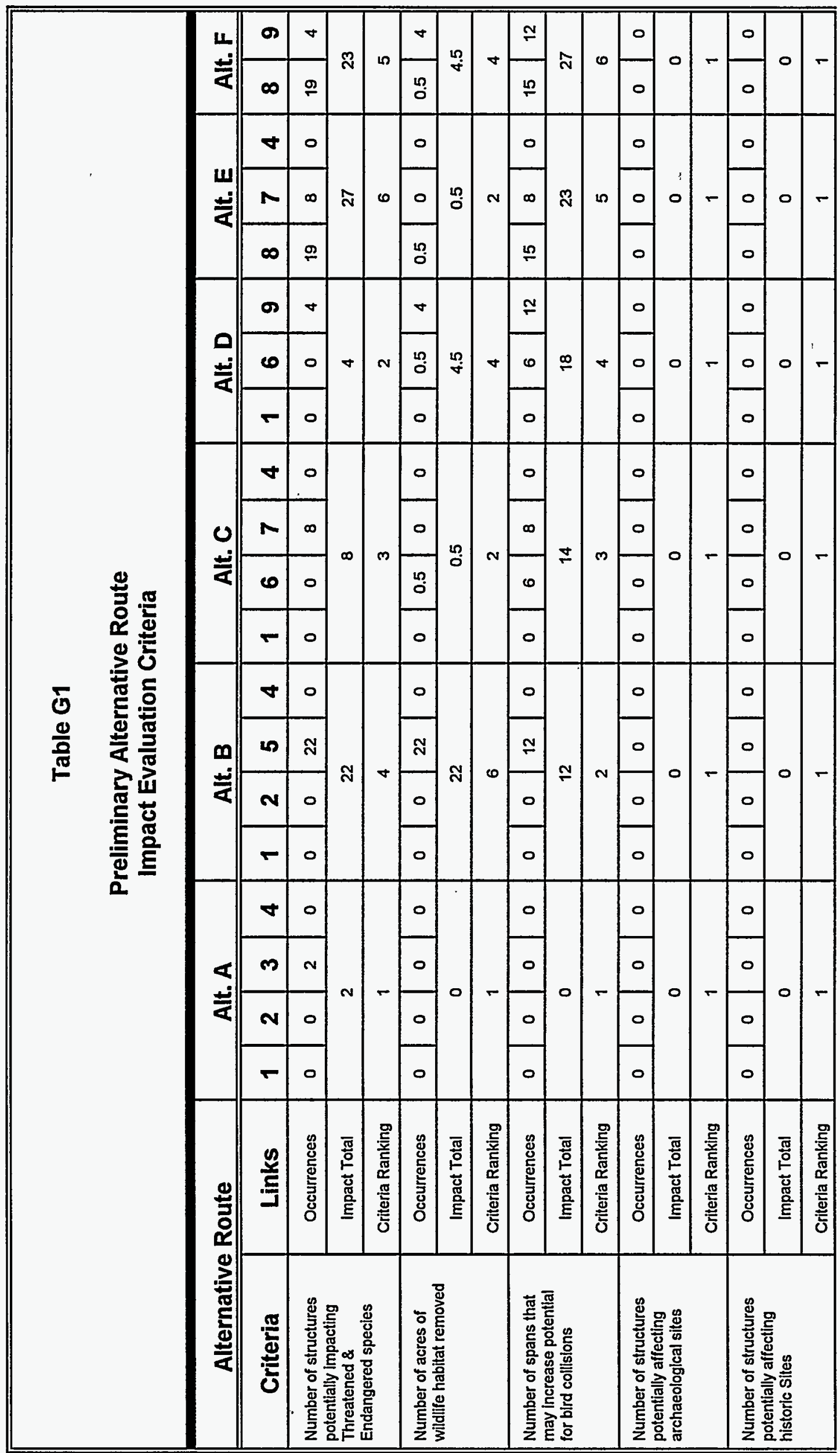




\section{Table G1}

\section{Preliminary Alternative Route Impact Evaluation Criteria}

\begin{tabular}{|c|c|c|c|c|c|c|c|c|c|c|c|c|c|c|c|c|c|c|c|c|c|}
\hline \multicolumn{2}{|c|}{ Alternative Route } & \multicolumn{4}{|c|}{ Alt. A } & \multicolumn{4}{|c|}{ Alt. B } & \multicolumn{4}{|c|}{ Alt. C } & \multicolumn{3}{|c|}{ Alt. D } & \multicolumn{3}{|c|}{ Alt. E } & \multicolumn{2}{|c|}{ Alt. F } \\
\hline Criteria & Links & 1 & 2 & 3 & 4 & 1 & 2 & 5 & 4 & 1 & 6 & 7 & 4 & 1 & 6 & 9 & 8 & 7 & 4 & 8 & 9 \\
\hline
\end{tabular}

\section{Transmission Line and Substation Engineering}

\begin{tabular}{|c|c|c|c|c|c|c|c|c|c|c|c|c|c|c|c|c|c|c|c|c|c|}
\hline \multirow{3}{*}{$\begin{array}{l}\text { Number of instances } \\
\text { requiring construction to } \\
\text { be scheduled to avoid } \\
\text { nesting or breeding } \\
\text { periods critical to } \\
\text { sensitive species }\end{array}$} & Occurrences & 0 & 0 & 1 & 0 & 0 & 0 & 1 & 0 & 0 & 0 & 0 & 0 & 0 & 0 & 1 & 1 & 0 & 0 & 1 & 1 \\
\hline & Impact Total & \multicolumn{4}{|c|}{1} & \multicolumn{4}{|c|}{1} & \multicolumn{4}{|c|}{0} & \multicolumn{3}{|c|}{1} & \multicolumn{3}{|c|}{1} & \multicolumn{2}{|c|}{2} \\
\hline & Criteria Ranking & \multicolumn{4}{|c|}{2} & \multicolumn{4}{|c|}{2} & \multicolumn{4}{|c|}{1} & \multicolumn{3}{|c|}{2} & \multicolumn{3}{|c|}{2} & \multicolumn{2}{|c|}{6} \\
\hline \multirow{3}{*}{$\begin{array}{l}\text { Number of miles of new } \\
\text { right-of-way disturbance }\end{array}$} & Occurrences & 0 & 0 & 0 & 0 & 0 & 0 & 1 & 0 & 0 & 2 & 1 & 0 & 0 & 2 & 2 & 3.5 & 1 & 0 & 3.5 & 2 \\
\hline & Impact Total & \multicolumn{4}{|c|}{0} & \multicolumn{4}{|c|}{1} & \multicolumn{4}{|c|}{3} & \multicolumn{3}{|c|}{4} & \multicolumn{3}{|c|}{4.5} & \multicolumn{2}{|c|}{5.5} \\
\hline & Criteria Ranking & \multicolumn{4}{|c|}{1} & \multicolumn{4}{|c|}{2} & \multicolumn{4}{|c|}{3} & \multicolumn{3}{|c|}{4} & \multicolumn{3}{|c|}{5} & \multicolumn{2}{|c|}{6} \\
\hline \multirow{3}{*}{$\begin{array}{l}\text { Number of miles of } \\
\text { helicopter construction }\end{array}$} & Occurrences & 0 & 0 & 0 & 0 & 0 & 0 & 15 & 0 & 0 & 0 & 0 & 0 & 0 & 0 & 0 & 0 & 0 & 0 & 0 & 0 \\
\hline & Impact Total & \multicolumn{4}{|c|}{0} & \multicolumn{4}{|c|}{15} & \multicolumn{4}{|c|}{0} & \multicolumn{3}{|c|}{0} & & 0 & & & \\
\hline & Criteria Ranking & & & & & & & & & & & & & & 1 & & & 1 & & & \\
\hline Number of structures & Occurrences & 0 & 0 & 0 & 0 & 0 & 0 & 11 & 0 & 0 & 0 & 0 & 0 & 0 & 0 & 4 & 0 & 0 & 0 & 0 & 4 \\
\hline & Impact Total & & & & & & & & & & & & & & 4 & & & 0 & & & \\
\hline & Criteria Ranking & & & & & & & & & & & & & & 4 & & & 1 & & & \\
\hline Number of structures & Occurrences & 0 & 4 & 0 & 0 & 0 & 4 & 0 & 0 & 0 & 0 & 0 & 0 & 0 & 0 & 0 & 0 & 0 & 0 & 0 & 0 \\
\hline conflicts with the & Impact Total & & & & & & & & & & & & & & 0 & & & 0 & & & \\
\hline heliport or landing strip & Criteria Ranking & & & & & & & & & & & & & & 1 & & & 1 & & & \\
\hline
\end{tabular}




\section{Table G1}

\section{Preliminary Alternative Route \\ Impact Evaluation Criteria}

\begin{tabular}{|c|c|c|c|c|c|c|c|c|c|c|c|c|c|c|c|c|c|c|c|c|c|}
\hline \multicolumn{2}{|c|}{ Alternative Route } & \multicolumn{4}{|c|}{ Alt. A } & \multicolumn{4}{|c|}{ Alt. B } & \multicolumn{4}{|c|}{ Alt. C } & \multicolumn{3}{|c|}{ Alt. D } & \multicolumn{3}{|c|}{ Alt. E } & \multicolumn{2}{|c|}{ Alt. F } \\
\hline Criteria & Links & 1 & 2 & 3 & 4 & 1 & 2 & 5 & 4 & 1 & 6 & 7 & 4 & 1 & 6 & 9 & 8 & 7 & 4 & 8 & 9 \\
\hline \multirow{3}{*}{$\begin{array}{l}\text { Number of angles in the } \\
\text { alignment of } 41^{\circ}-90^{\circ}\end{array}$} & Occurrences & 0 & 0 & 1 & 1 & 0 & 0 & 2 & $\cdot 1$ & 0 & 2 & 0 & 1 & 0 & 2 & 2 & 5 & 0 & 1 & 5 & 2 \\
\hline & Impact Total & \multicolumn{4}{|c|}{2} & \multicolumn{4}{|c|}{3} & \multicolumn{4}{|c|}{3} & \multicolumn{3}{|c|}{4} & \multicolumn{3}{|c|}{6} & \multicolumn{2}{|c|}{7} \\
\hline & Criteria Ranking & \multicolumn{4}{|c|}{1} & \multicolumn{4}{|c|}{2} & \multicolumn{4}{|c|}{2} & \multicolumn{3}{|c|}{4} & \multicolumn{3}{|c|}{5} & \multicolumn{2}{|c|}{6} \\
\hline \multirow{3}{*}{$\begin{array}{l}\text { Number of angles in the } \\
\text { alignment of } 2^{\circ}-40^{\circ}\end{array}$} & Occurrences & 1 & 0 & 2 & 0 & 1 & 0 & 1 & 0 & 1 & $6^{*}$ & 3 & 0 & 1 & $6^{*}$ & 0 & 3 & 3 & 0 & 3 & 0 \\
\hline & Impact Total & \multicolumn{4}{|c|}{3} & \multicolumn{4}{|c|}{2} & \multicolumn{4}{|c|}{10} & \multicolumn{3}{|c|}{7} & \multicolumn{3}{|c|}{6} & \multicolumn{2}{|c|}{3} \\
\hline & Criteria Ranking & \multicolumn{4}{|c|}{2} & \multicolumn{4}{|c|}{1} & \multicolumn{4}{|c|}{6} & \multicolumn{3}{|c|}{5} & \multicolumn{3}{|c|}{4} & & \\
\hline & Link Totals & 29 & 196 & 192 & 16 & 29 & 196 & 303 & 16 & 29 & 508 & 88 & 16 & 29 & 508 & 206 & 482 & 88 & 20 & 402 & 206 \\
\hline Alternati & Route Impact Totals & & & & & & & & & & & & & & 743 & & & 590 & & & 8 \\
\hline Alternati & Route Rank Totals & & & & & & & & & & & & & & 108 & & & 110 & & & \\
\hline Alter & ive Route Ranking & & & & & & & & & & & & & & 4 & & & 5 & & & \\
\hline
\end{tabular}




\section{Standard Construction Practices}

1. The contractor shall limit the movement of crews and equipment to the ROW, including access routes. The contractor shall limit movement on the ROW to minimize damage to residential yards, grazing land, crops, orchards, and property, and shall avoid marring the lands. The contractor shall coordinate with the landowners to avoid impacting the normal function of irrigation devices during project construction and operation.

2. When weather and ground conditions permit, the contractor shall obliterate all construction caused deep ruts that are hazardous to farming operations and to movement of equipment. Such ruts shall be leveled, filled and graded, or otherwise eliminated in an approved manner. Ruts, scars, and compacted soils in hay meadows, alfalfa fields, pastures, and cultivated productive lands shall have the soil loosened and leveled by scarifying, harrowing, discing, or other approved methods. Damage to ditches, tile drains, terraces, roads, and other features of the land shall be corrected. At the end of each construction season and before final acceptance of the work in these agricultural areas, all ruts shall be obliterated, and all trails and areas that are hard-packed as a result of construction operations shall be loosened and leveled. The land and facilities shall be restored as nearly as practicable to the original condition.

3. Water turnoff bars or small terraces shall be constructed across all ROW trails on hillsides to prevent water erosion and to facilitate natural revegetation on the trails.

4. The contractor shall comply with all Federal, state, and local environmental laws, orders and regulations. Prior to construction, all supervisory construction personnel will be instructed on the protection of cultural and ecological resources. To assist in this effort, the construction contract will address: a) Federal and state laws regarding antiquities and plants and wildlife, including collection and removal; and b) the importance of these resources and the purpose and necessity of protecting them.

5. The contractor shall exercise care to preserve the natural landscape and shall conduct his construction operations so as to prevent any unnecessary destruction, scarring, or defacing of the natural surroundings in the vicinity of the work. Except where clearing is required for permanent works, approved construction roads, or excavation operations, vegetation shall be preserved and shall be protected from damage by the contractor's construction operations and equipment.

6. On completion of the work, all work areas except access trails shall be scarified or left in a condition that will facilitate natural revegetation, provide for proper drainage, and prevent erosion. All destruction, scarring, damage, or defacing of the landscape resulting from the contractor's operations shall be repaired by the contractor.

7. Construction trails not required for maintenance access shall be restored to the original contour and made impassable to vehicular traffic. The surfaces of such construction trails shall be scarified as needed to provide a condition that will facilitate natural revegetation, provide for proper drainage, and prevent erosion.

8. Construction staging areas shall be located and arranged in a manner to preserve trees and vegetation to the maximum practicable extent. On abandonment, all storage and construction materials and debris shall be removed from the site. The area shall be regraded, as required, so that all surfaces drain naturally, blend with the natural terrain, and are left in a condition that will facilitate natural revegetation, provide for proper drainage, and prevent erosion.

9. Borrow pits shall be so excavated that water will not collect and stand therein. Before being abandoned, the sides of borrow pits shall be brought to stable slopes, with slope intersections shaped to carry the natural contour of adjacent, undisturbed terrain into the pit or borrow area, giving a natural appearance. Waste piles shall be shaped to provide a natural appearance. 


\section{Standard Construction Practices}

10. Construction activities shall be performed by methods that prevent entrance or accidental spillage of solid matter, contaminants, debris, and other objectionable pollutants and wastes into flowing streams or dry water courses, lakes, and underground water sources. Such pollutants and wastes include, but are not restricted to, refuse, garbage, cement, concrete, sanitary waste, industrial waste, radioactive substances, oil and other petroleum products, aggregate processing tailings, mineral salts, and thermal pollution.

11. Dewatering work for structure foundations or earthwork operations adjacent to, or encroaching on, streams or water courses will not be performed without prior approval from appropriate state agencies.

12. Excavated material or other construction materials shall not be stockpiled or deposited near or on stream banks, lake shorelines, or other water course perimeters where they can be washed away by high water or storm runoff or can in any way encroach upon the actual water source itself.

13. Waste waters from construction operations shall not enter streams, water courses, or other surface waters without use of such turbidity control methods as settling ponds, gravel-filter entrapment dikes, approved flocculating processes that are not harmful to fish, recirculation systems for washing of aggregates, or other approved methods. Any such waste waters discharged into surface waters shall be essentially free to settleable material. Settleable material is defined as that material that will settle from the water by gravity during a 1-hour quiescent period.

14. The contractor shall utilize such practicable methods and devices as are reasonably available to control, prevent, and otherwise minimize atmospheric emissions or discharges of air contaminants.

15. Equipment and vehicles that show excessive emissions of exhaust gases due to poor engine adjustments, or other inefficient operating conditions, shall not be operated until corrective repairs or adjustments are made.

16. Burning or burying of waste materials on the ROW or at the construction site will not be allowed. The contractor shall remove all waste materials from the construction area. All materials resulting from the contractor's clearing operations shall be removed from the ROW.

17. The contractor shall make all necessary provisions in conformance with safety requirements for maintaining the flow of public traffic and shall conduct his construction operations so as to offer the least possible obstruction and inconvenience to public traffic.

18. Western will apply necessary mitigation to eliminate problems of induced currents and voltages onto conductive objects sharing a ROW, to the mutual satisfaction of the parties involved. Western will install fence grounds on all fences that cross or are parallel to the proposed line.

19. The contractor will span riparian areas located along the ROW and avoid physical disturbance to riparian vegetation. Equipment and vehicles will not cross riparian areas on the ROW during construction and operation activities. Existing bridges or fords will be used to access the ROW on either side of riparian areas. 


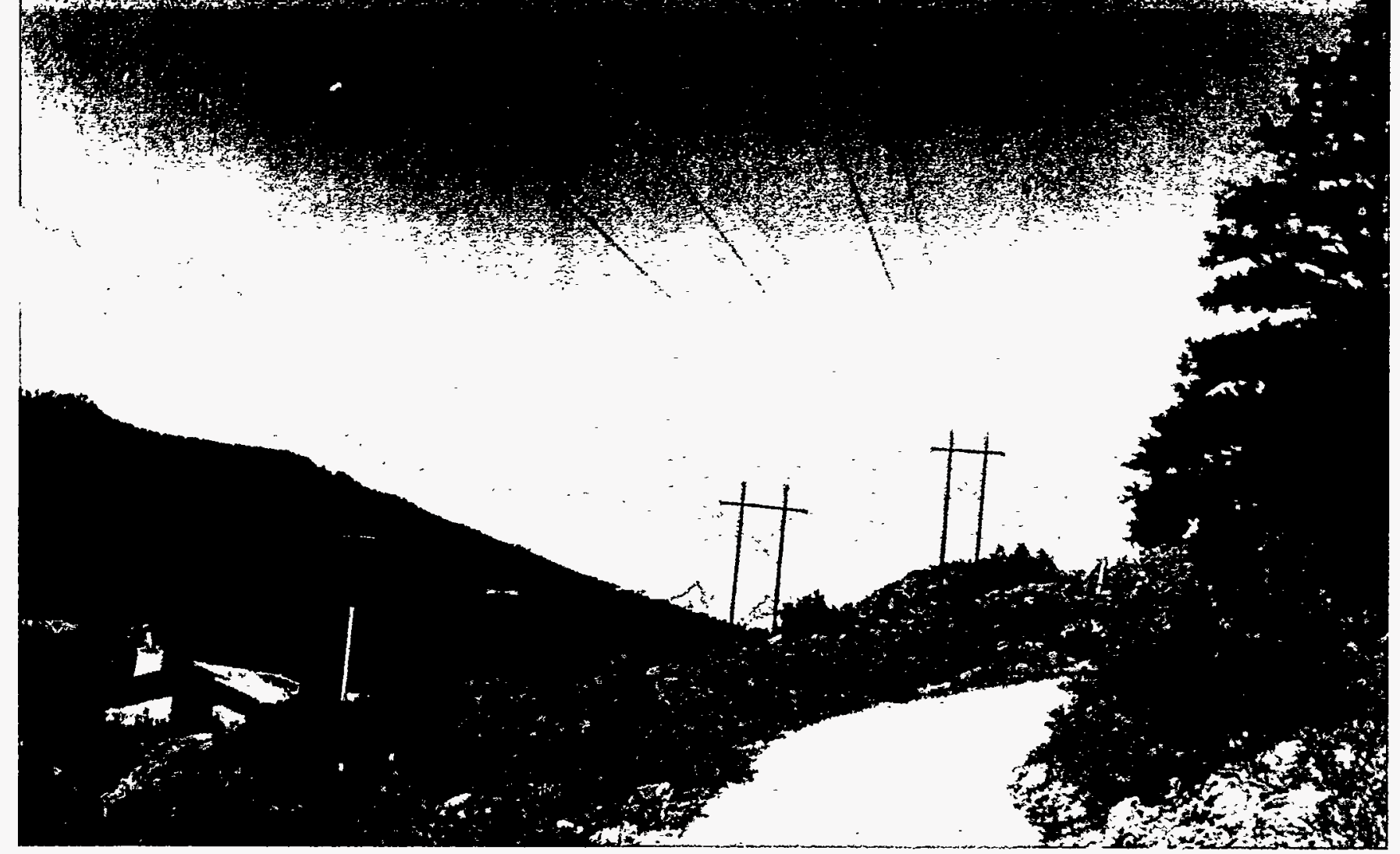

Existing Condition

Illustrating existing 115,000 volt transmissiion line (left) and existing 69,000 volt transmission line (right).

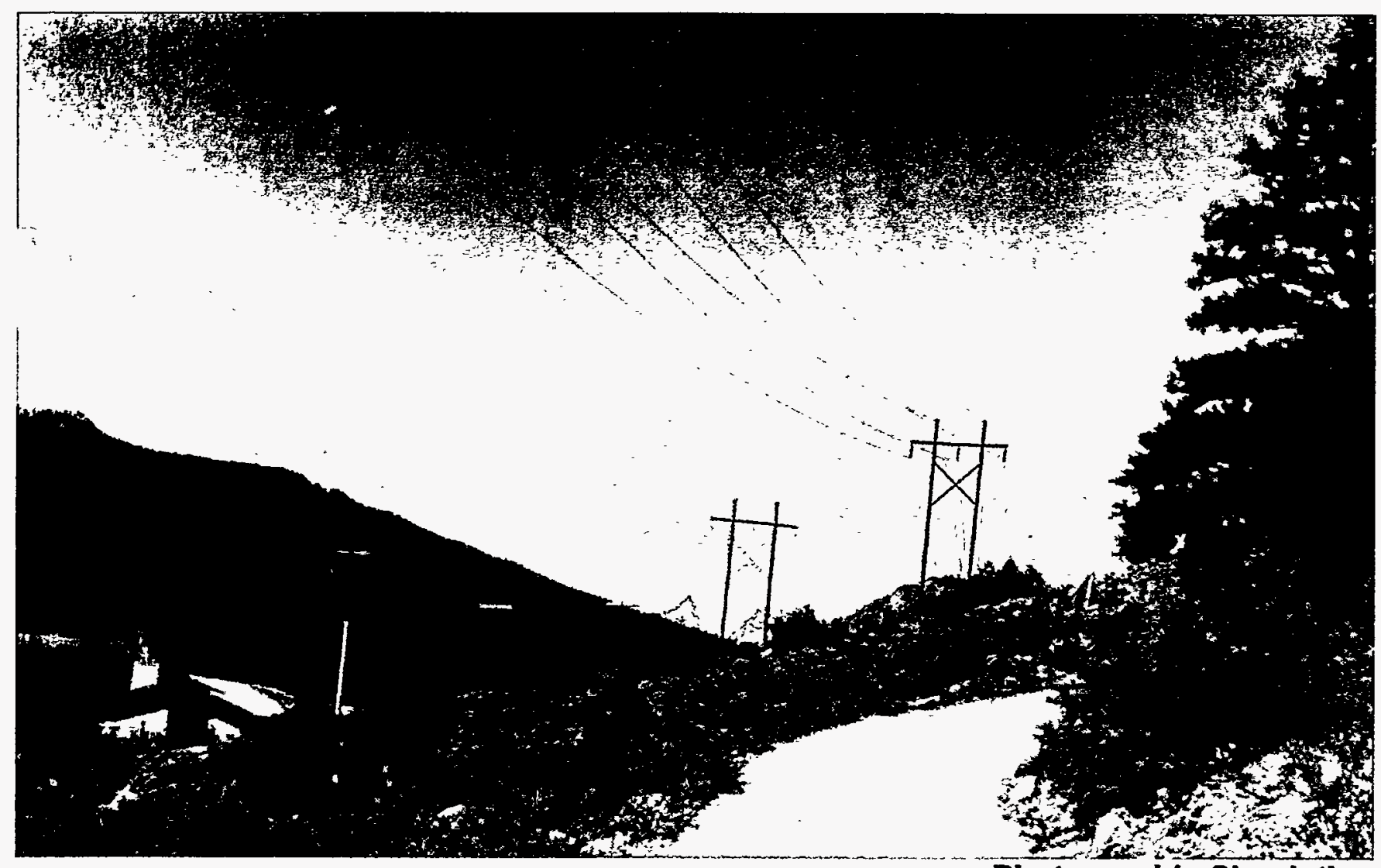

Photographic Simulation

Illustrating upgrade of existing 69,000 volt transmission line to 115,000 volts using wood $\mathrm{H}$-frame structure. Proposed Action, H-Frame Structure Figure I-1 


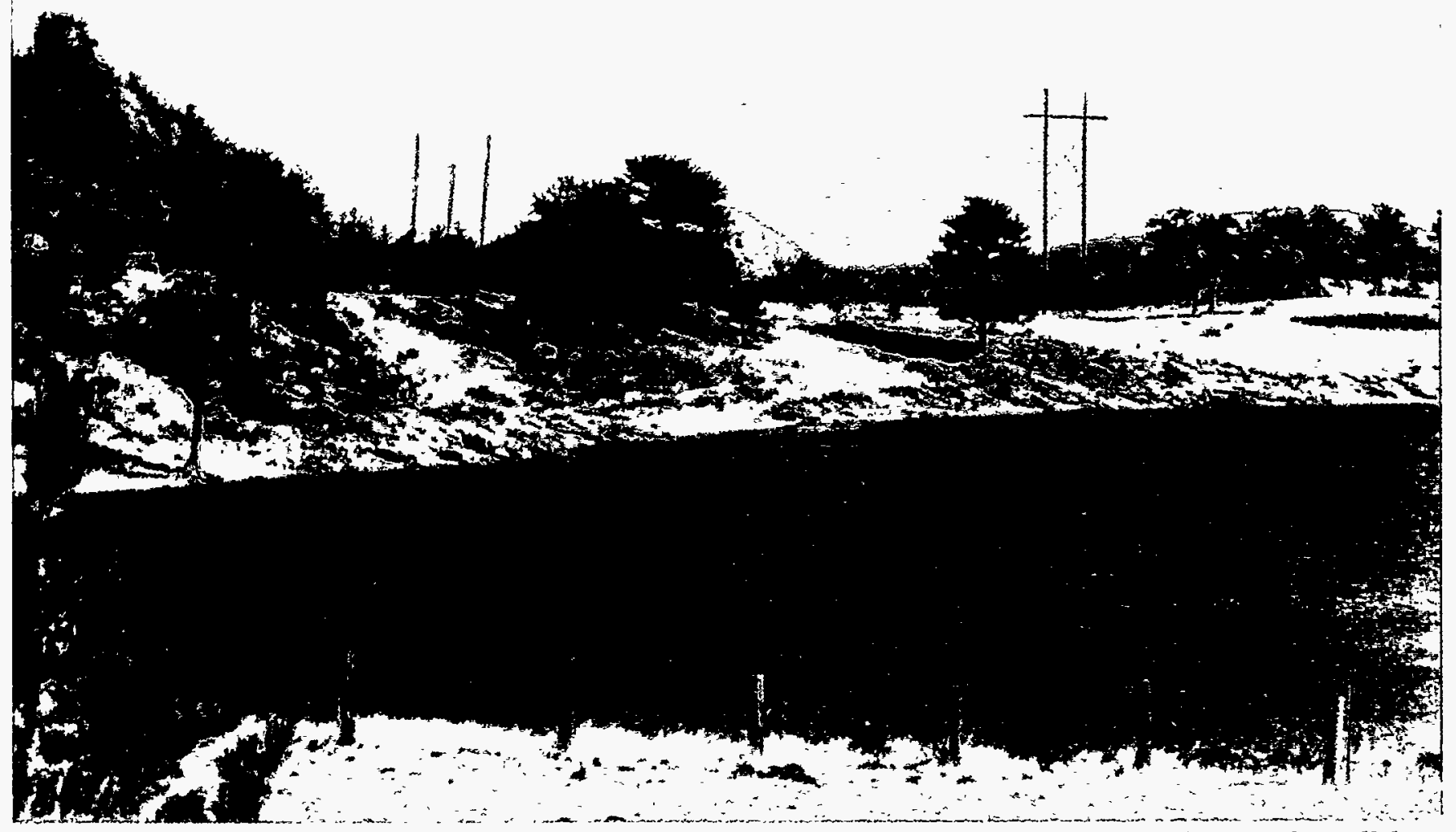

Existing Condition

Illustrating existing 115,000 volt transmission line crossing Marys Lake

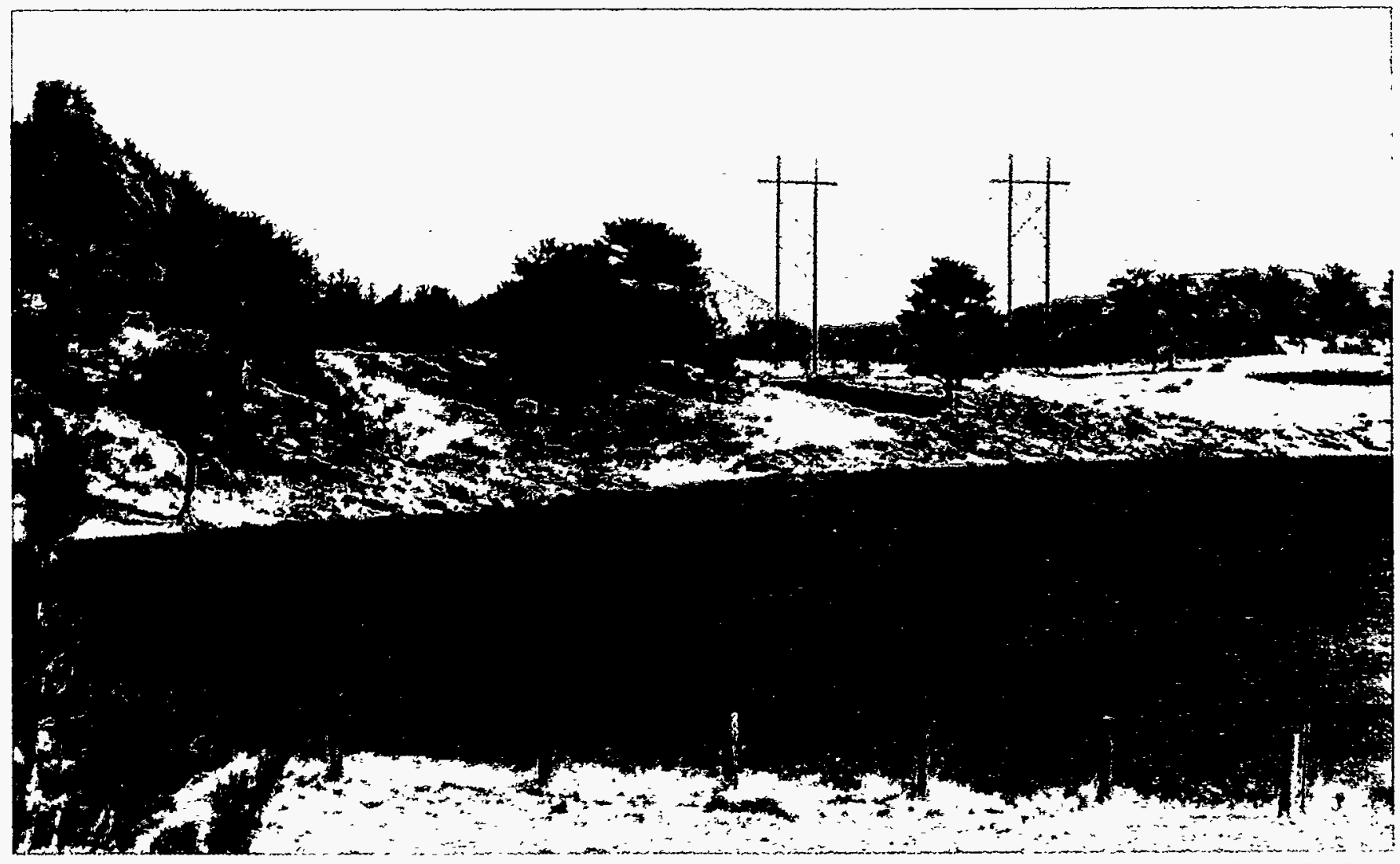

Photographic Simulation Illustrating new 115,000 volt transmission line (left) on wood $\mathrm{H}$-frame structure next to existing 115,000 volt wood $\mathrm{H}$-frame structure.

Proposed Action, H-Frame Structure at Marys Lake Figure I-2 


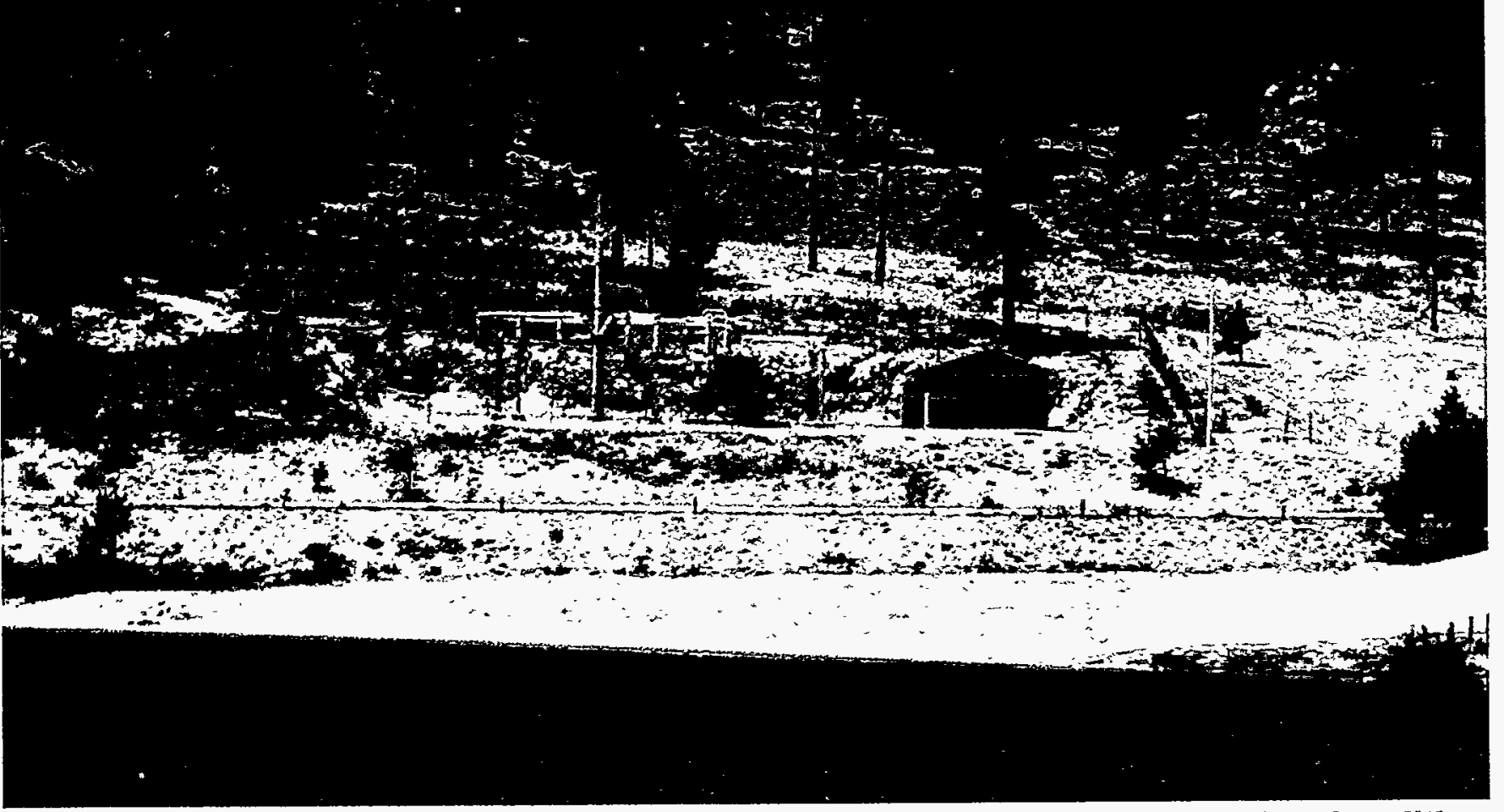

Existing Condition Marys Lake Substation

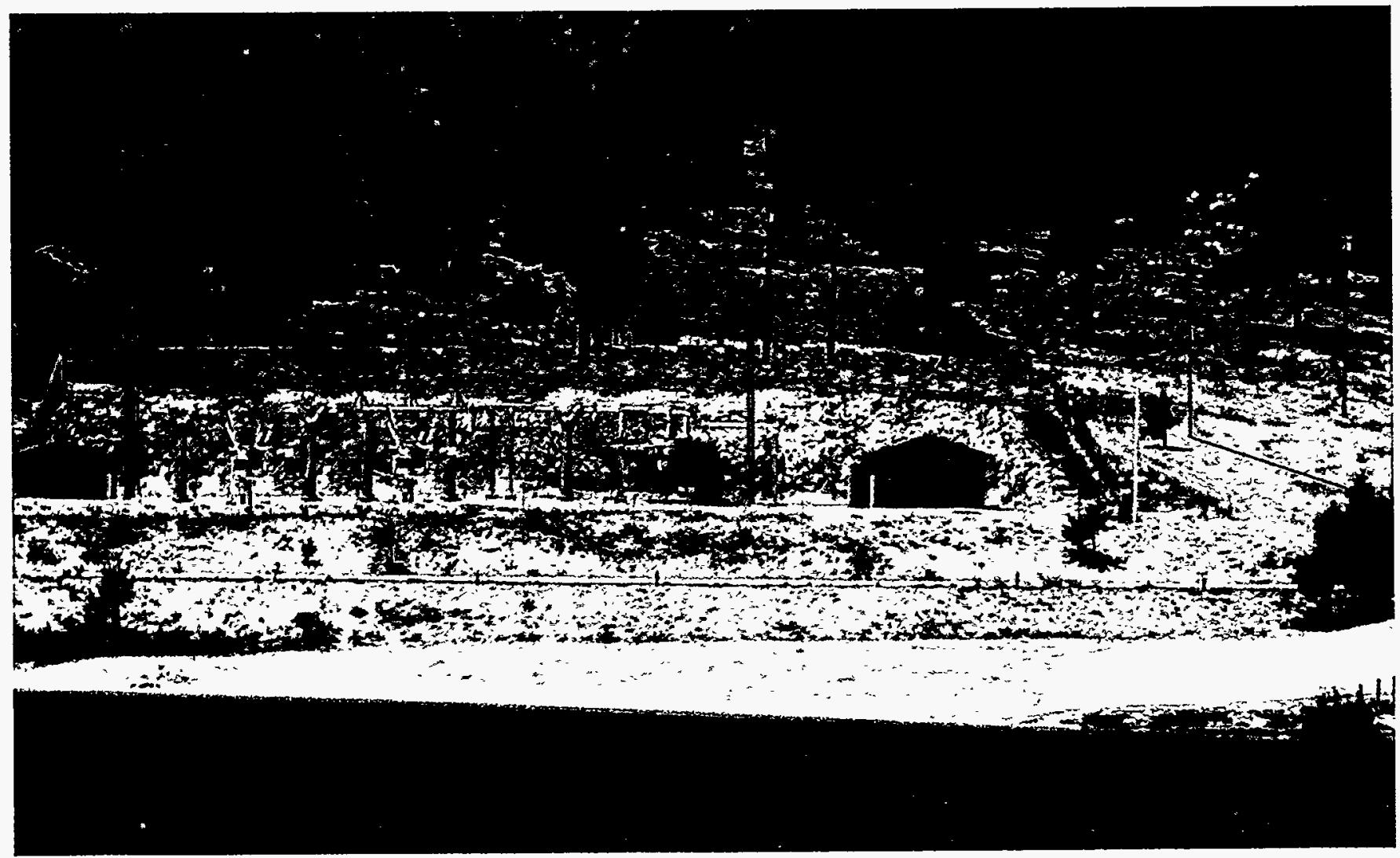

Photographic Simulation Illustrating the Expansion of Marys Lake Substation. Proposed Action, Expansion of Marys Lake Substation Figure I-3 


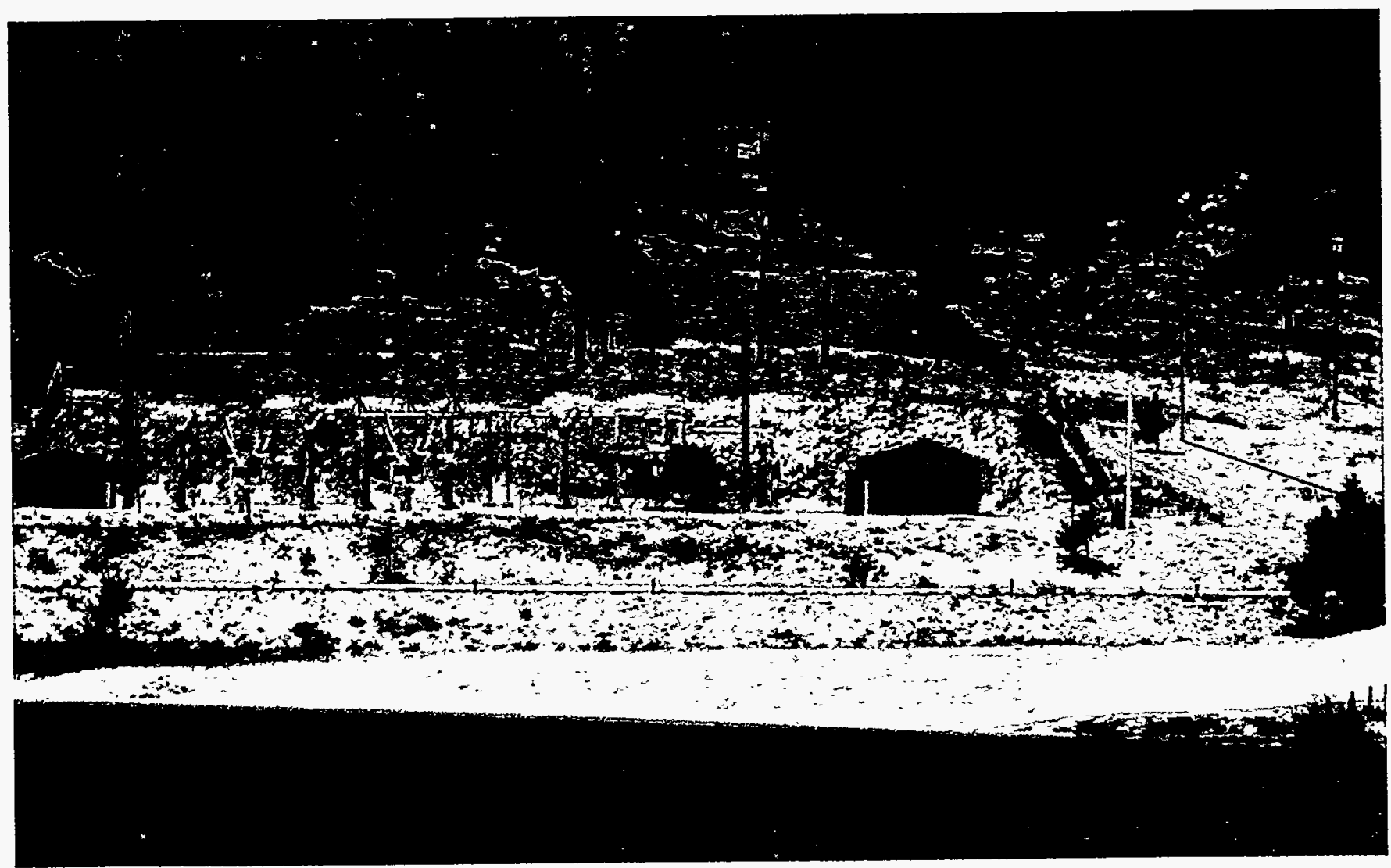

Photographic Simulation Illustrating the Expansion of Marys Lake Substation.

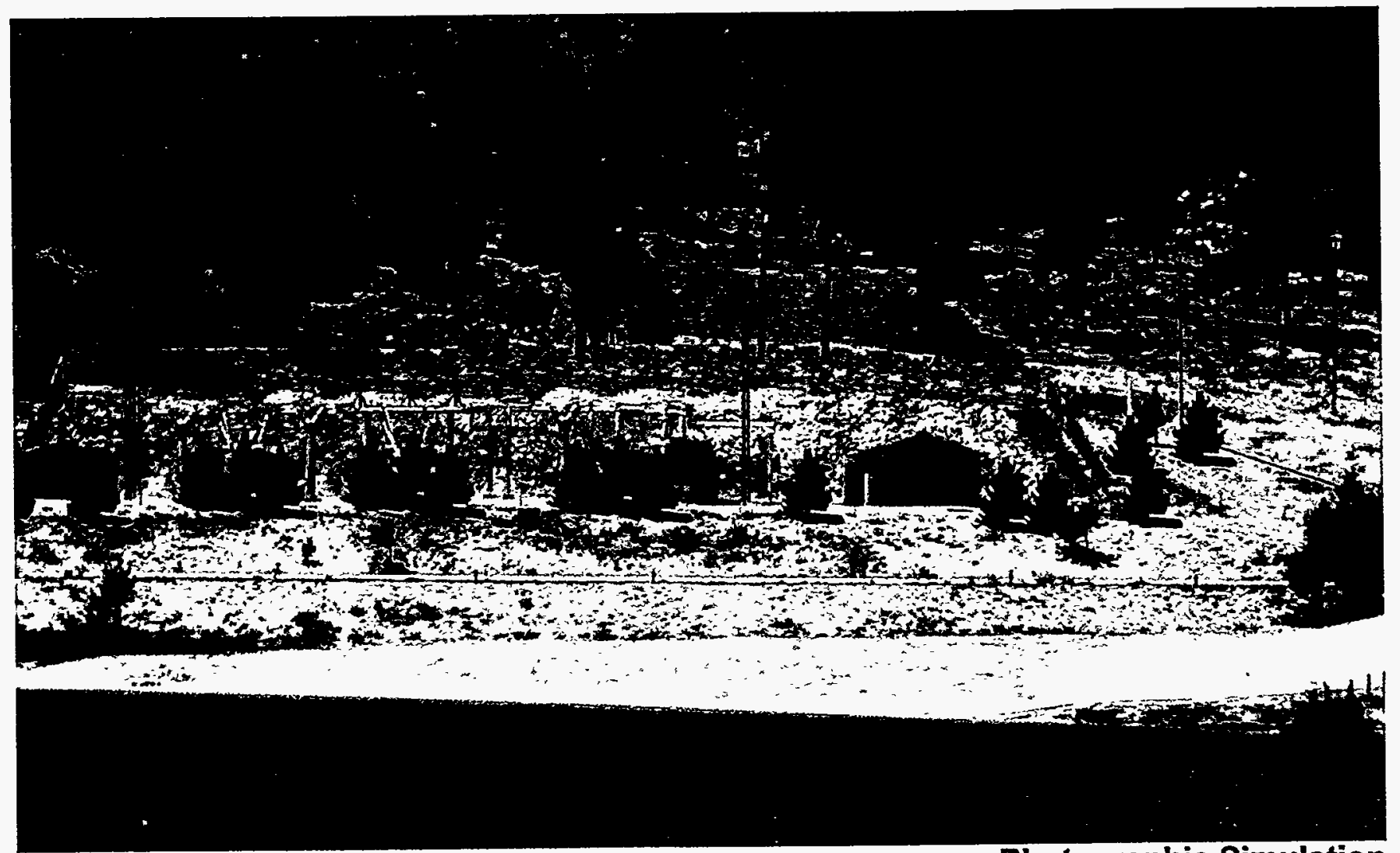

Photographic Simulation Illustrating screening of Marys Lake Substation utilizing $10^{\prime}-15^{\prime}$ trees.

Proposed Action, Screening of Marys Lake Substation Figure I-4 


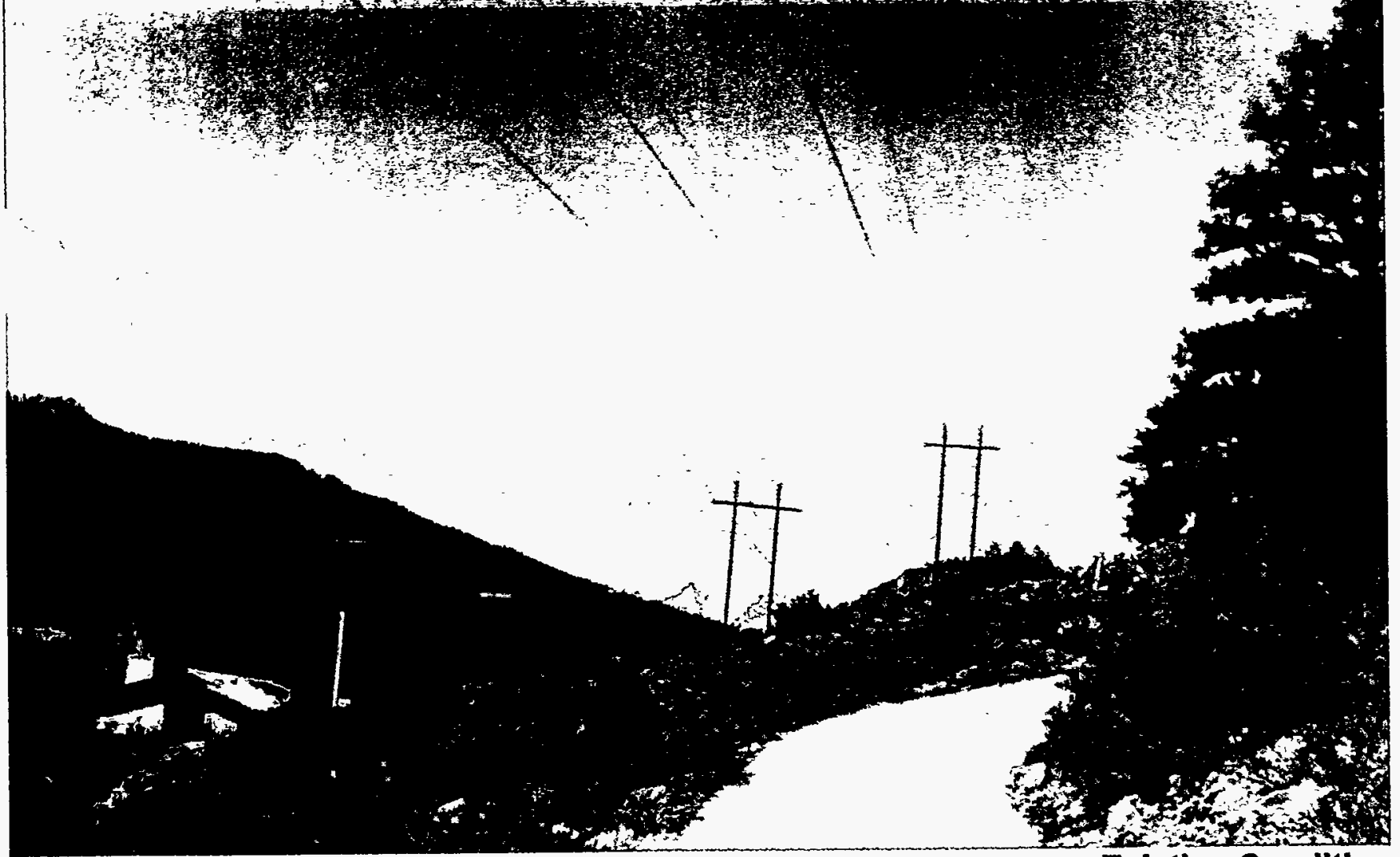

Existing Condition

Illustrating existing 115,000 volt transmission line (left) and existing 69,000 volt transmission line (right).

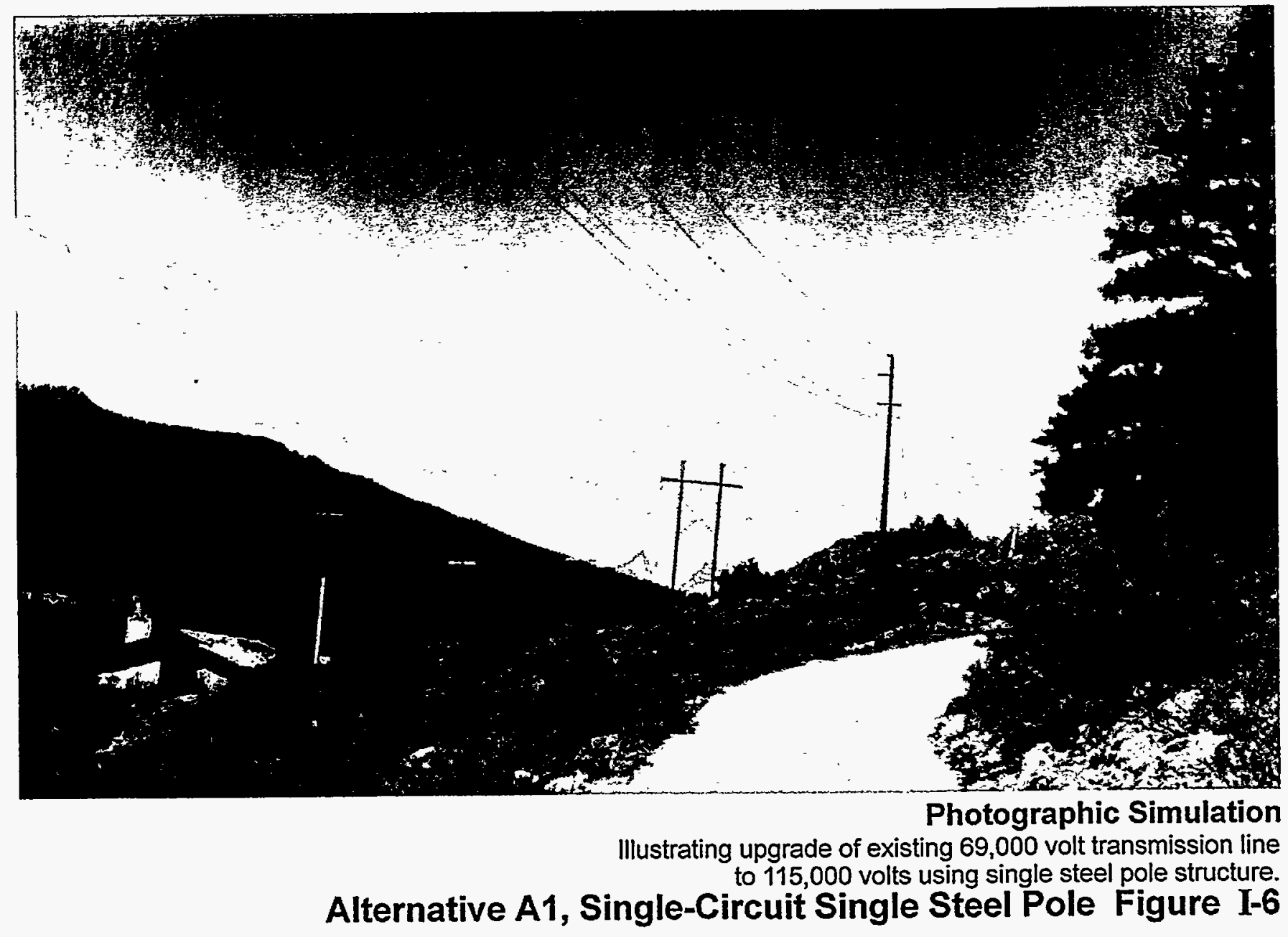




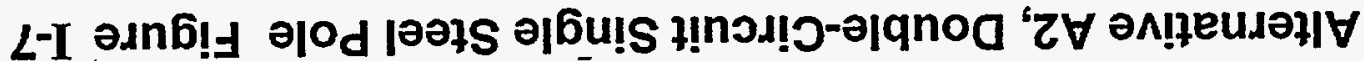

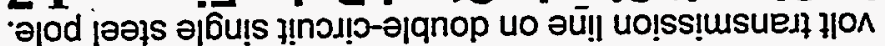

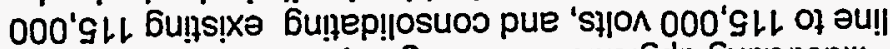

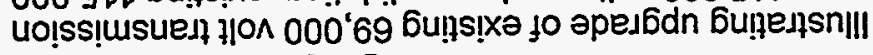

\section{uo!ne|nu!s ग!ydexbozoud}

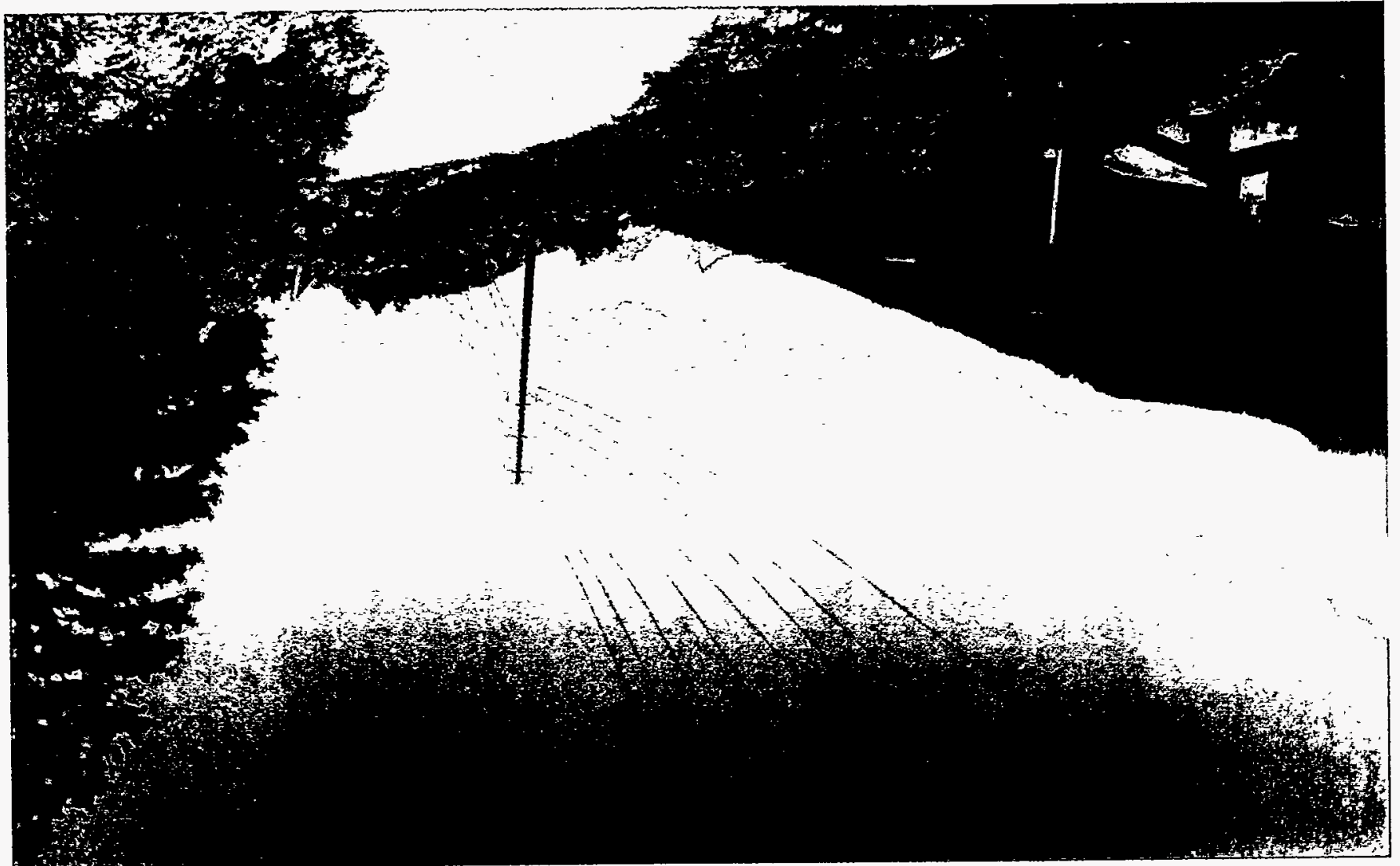

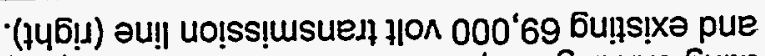

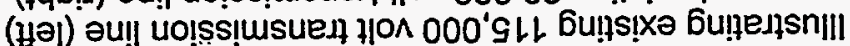

uo!n!puos bu!ns!x

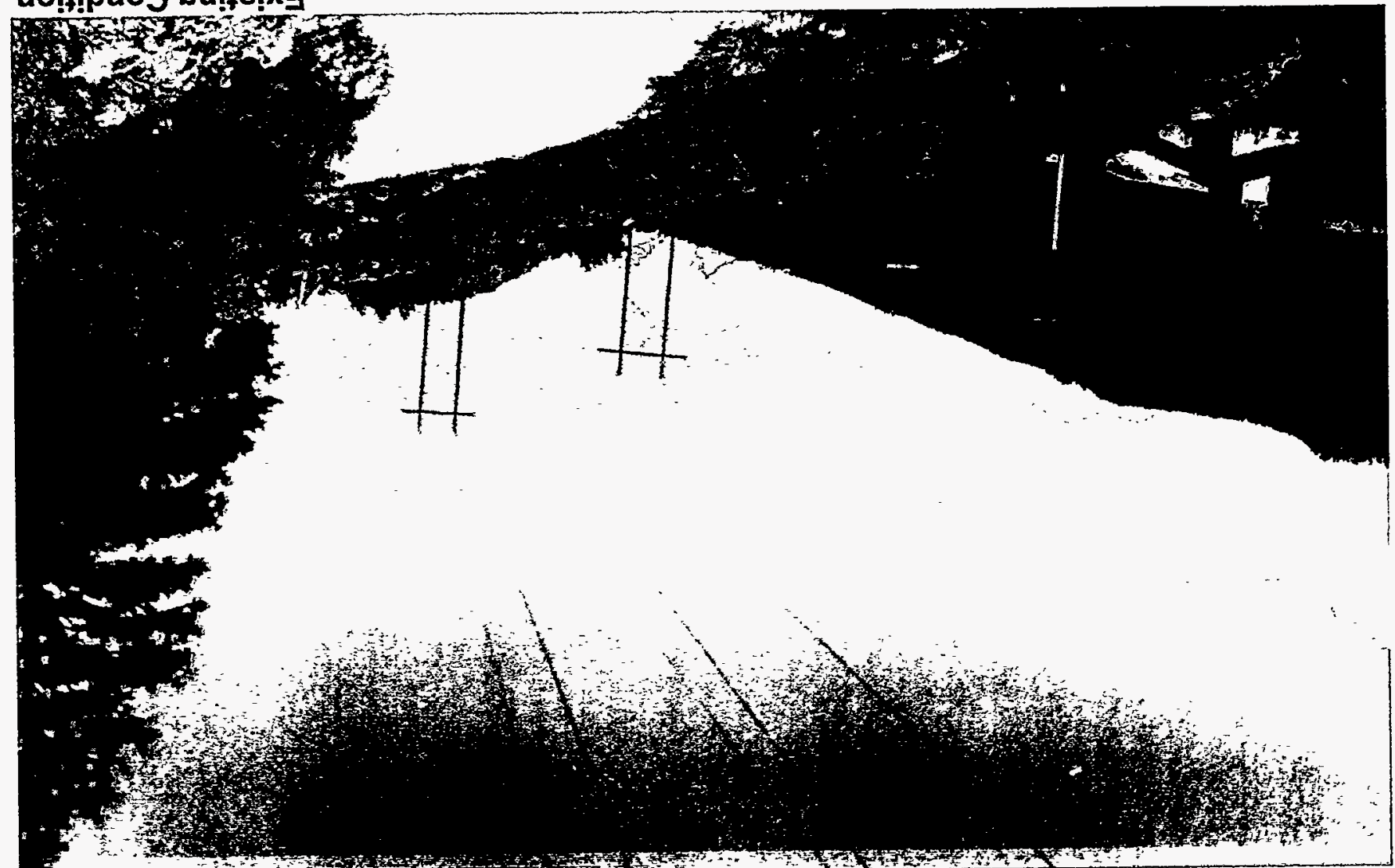


The following discussion outlines Western's construction and restoration guidelines for the Marys Lake transmission line upgrade and substation project. It includes special measures developed for the project as well as routine practices used by Western on all of its construction projects.

1) Prior to construction, Western's Land Division will provide notice to each individual landowner regarding access for construction on their property. Landowners having specific concerns regarding disturbance to vegetation especially to trees, shrubs and other landscape features should notify the Lands Division at this time.

2) Appropriate landowner comments will be incorporated into the construction specifications prepared for the contract. Special requirements including minimizing disturbance to vegetation will be reviewed with the construction contractor during the preconstruction conference held for the project.

3) Western's Environmental Division will consult with the Natural Resources Conservation Service (formerly the SCS) regarding appropriate erosion control and revegetation techniques for this high elevation, southern exposure site. Western will perform both a preconstruction and post construction review with the NRCS. Recommendations provided by NRCS will be incorporated into the construction specifications or any site-specific revegetation plans prepared for individual properties.

4) Western's Environmental Division will visit the site during construction and consult with the onsite inspector regarding compliance with all proposed environmental mitigation measures including those associated with restoration.

5) Culverts, waterbars and diversion ditches will be used as necessary to control runoff and erosion during and after construction.

6) Restoration and erosion control will begin immediately following clean-up. All proposed restoration techniques would be reviewed and approved by the NRCS. Preconstruction drainage patterns will be restored.

7) If new graded access roads are necessary, the top 4-6 inches of seedbank and topsoil would be stripped, stockpiled and later respread following final clean-up. Areas that are not graded but are used for cross county access will be evaluated individually. All disturbed areas, including any ruts, compaction, or erosion rills will be treated, and seeded if necessary to facilitate recovery.

8) Clean straw mulch, tackifier, jute netting, excelsior matting or other appropriate material will be used to mulch and protect cut slopes steeper than 2:1 or areas prone to wind or water erosion.

9) One year following construction and implementation of the erosion control measures, the site will be reviewed with NRCS to assess the revegetation efforts and identify any problem areas. Problem areas are sites where lack of soil stabilization will prevent long-term recovery of the site by native vegetation. Remedial action plans will be developed and implemented as necessary until soil stabilization is achieved.

10) Finally, the Lands Department will be available following construction to settle any damage claims filed by the landowners. 